
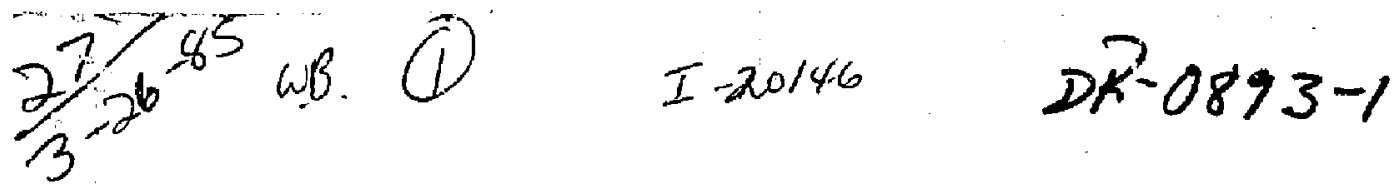

UCID-19975-1

\title{
Fusion Power Demonstrations I and II
}

\author{
Technical Editor: J. N. Doggett
}

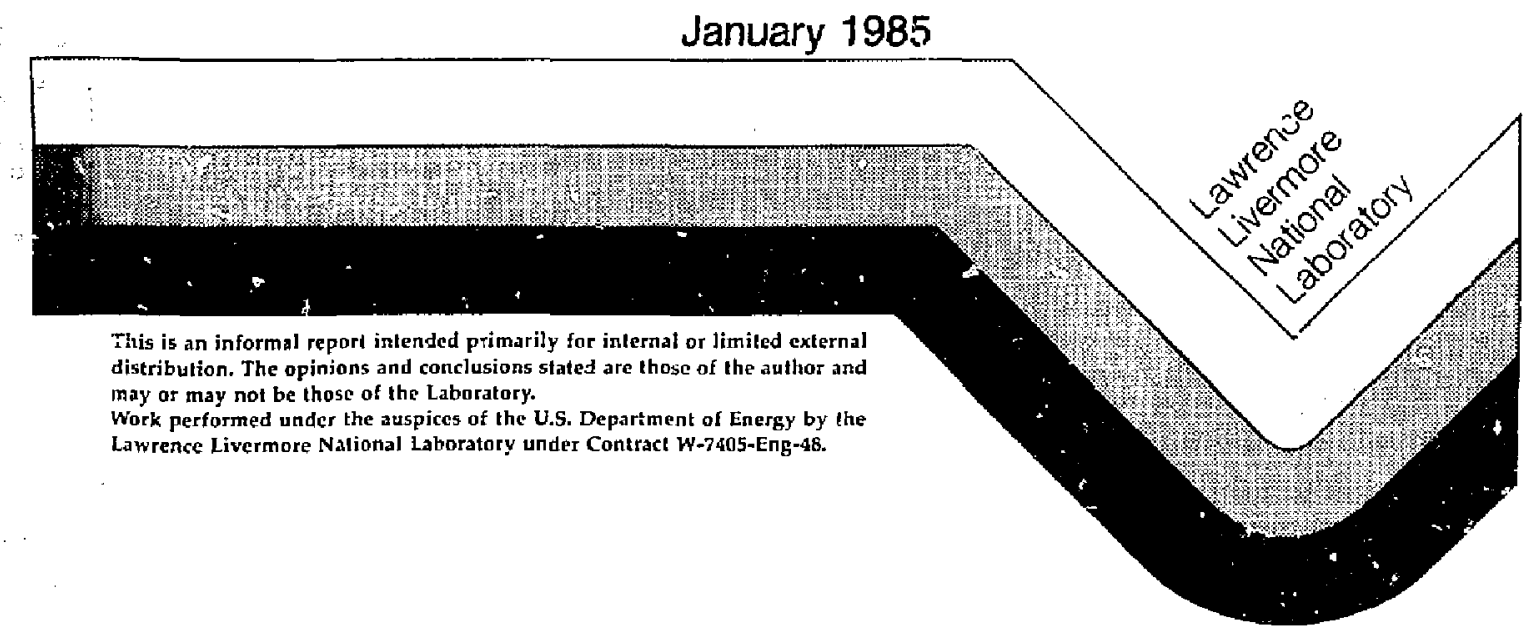

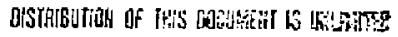




\section{Lawrence Livermore National Laboratory}

L. J. Perkins, R, H. Bulmer, B. G. Logan, J. D. Lee, J. N. Doggett, W. L. Barr, S. R. Devota, W. S. Neef D. W. Dorn, R. C. Maninger

\section{Negion}

J. H. Fink

\section{TR'}

R. B. Campbe11, M. E. Fenstermacher

Grumman Aerospace Corporation

I. Clarkson, T. Luzzi

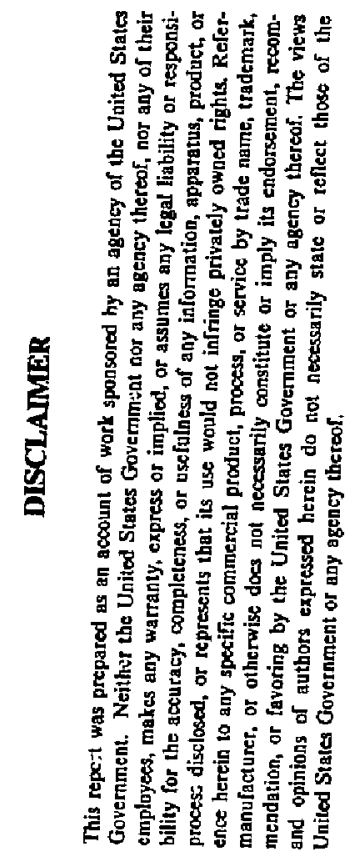

INEL/EG\&G

P. Hsu

General Dynamics/Convair Division

J. Parmer

Oak kidge Nationai Laboratory/Fusion Engineering Design Center

W. D. Nelson, S. S. Kalsi, V. C. Srivistava, S. A. Freije

G. E. Gorker, J. R. Haines, W. R. Hamilton, J. Kirchner,

T. L. Mann, D. H. Metzler, J. A. O'Toole, R. L. Reid,

P. T. Spampinato, F. W. Wiffin

Bechtel

S. Chose

Argonne Nationa1 Laboratory

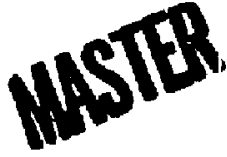

P. A. Fjnn, M. Y. Gohar

i $/ j i$

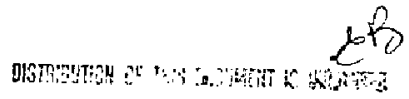


Scope $\ldots \ldots \ldots \ldots \ldots \ldots \ldots \ldots \ldots \ldots \ldots \ldots \ldots \ldots \ldots \ldots \ldots \ldots \ldots \ldots \ldots \ldots \ldots \ldots \ldots \ldots \ldots \ldots$ vi

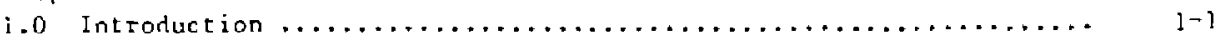

Reference ............................... $1-3$

2. 0 The Engineering Test Reactor Mission ...................... 2-1

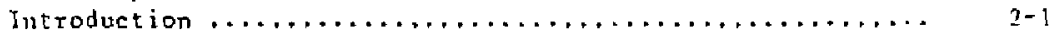

Mission .................................. $2-1$

Generic ETR objectives .................... $2-2$

Tandem Mirror ETR Objectives ................. 2-3

3.0 Plasma Engineering ................................

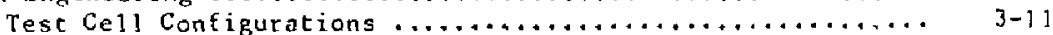

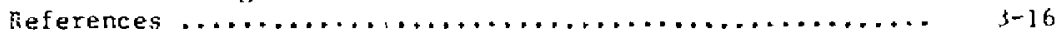

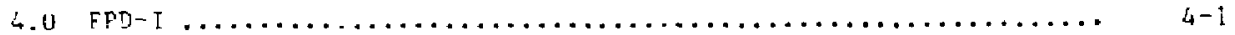

The FPD-I ConEiguratij on Overview .................... $4-1$

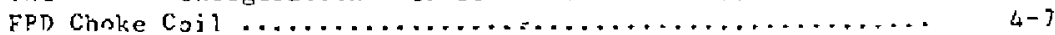

Central Cell z.............................. $4-9$

Central Cell Magnet System .................. $4-9$

Shielding and Vacuum Containment .............. 4-13

support Structure ........................ $4-15$

End Celi Magnets .......................... $4-15$

Plasma Heating Systems ................... $4-21$

Drift Pumping........................... $4-3\}$

Lalo Scraper/Direct Converter ................. $4-4 k$

Fueling Injection systems .................. $4-50$

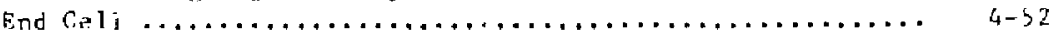

Shielding and varum Containment ............. $4-52$

support structure ........................ 4-53

Neutronics Analysis .......................... $4-53$

Radiation Protection Criteria for the Coils ........ $4-5 h$

Central Cell Analysis ....................... $4-58$

Choke Coil Analysis ....................... $4-62$

End Gell ............................ $4-62$

Materials ................................ $4-n 7$

Electrical systems ........................... $4-71$

AC Power system ........................ $4-71$

Electrical Power Conversion Systems ............. 4-75

Tritium systems ............................ 4.75

Haincenance Requirements and Operating Availability ...... 4-79

Maintenance Requirements .................... 4-79

Operating Availability .................... $4-8 l$

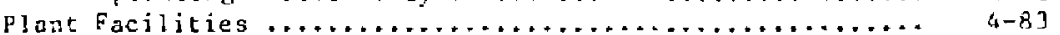

Site Plan ............................. $4-83$

Plant Arrangement ........................ $4-83$

References ............................... $4-90$

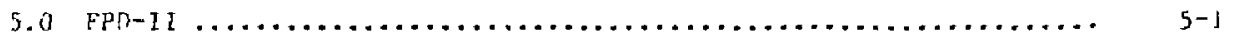

The FPD-II Configurdtion Overview ................ 5-1

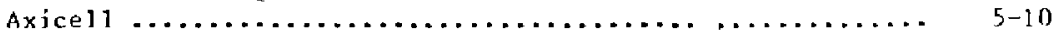

Positive-Ion-Based Neutra1-Ream System ........... $5-10$

DT Axicell Magnets ........................ $5-17$

Shielding and Vacutm Containment ............... $5-24$

Support Structure ........................ $5-28$ 
Central Ce11 .................................

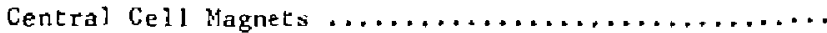

Shielding and Vaculum Containment ..................

Support Structure.$\ldots \ldots \ldots \ldots \ldots \ldots \ldots \ldots \ldots \ldots \ldots \ldots$

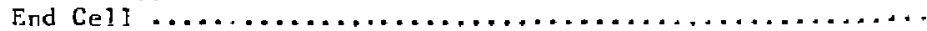

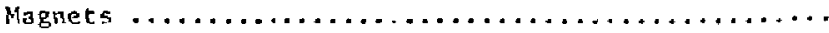

End-Ce11 Plasma Heating Systems $\ldots \ldots \ldots \ldots \ldots \ldots \ldots$

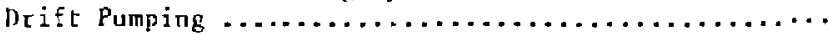

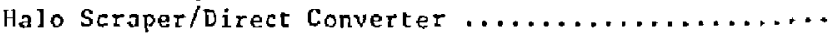

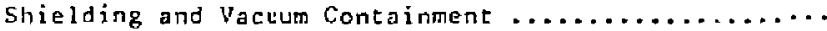

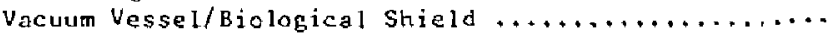

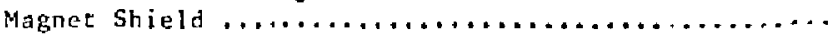

Sufport structure $\ldots \ldots \ldots \ldots \ldots \ldots \ldots \ldots \ldots \ldots \ldots \ldots$

G-Coil Nucleonics: One-Dimensional Estimate $\ldots \ldots \ldots \ldots \ldots$

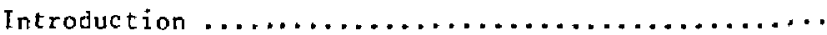

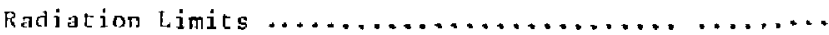
Proposed End-Cell Design and Optimization Procedure..

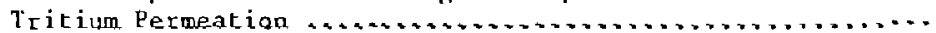

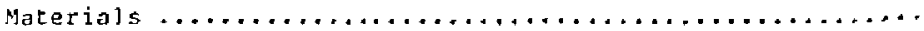

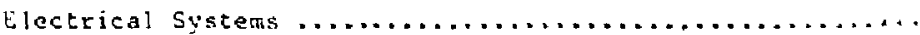

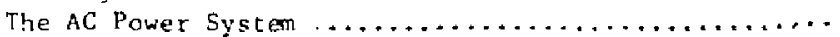

Electrical Power Conversion Systems $\ldots \ldots \ldots \ldots \ldots \ldots$ Instrumentation and Control $\ldots \ldots \ldots \ldots \ldots \ldots \ldots \ldots \ldots$

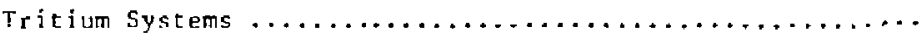
Maintenance Reqrirenents and Operating Availability ........

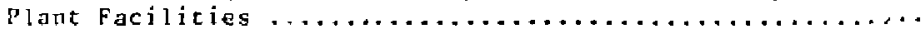

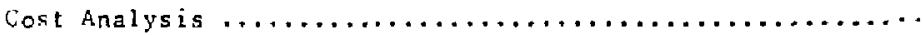

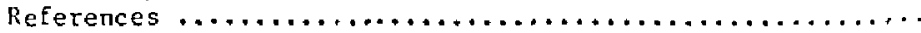

6.0 Studying the Cricicai Technbology Issues $\ldots \ldots \ldots \ldots \ldots \ldots \ldots \ldots$

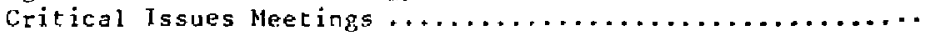

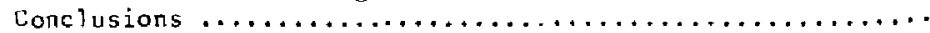

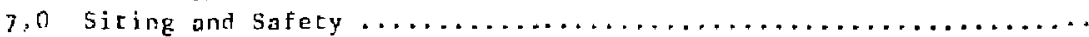

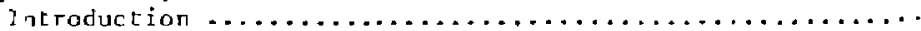

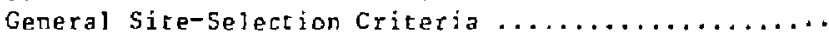

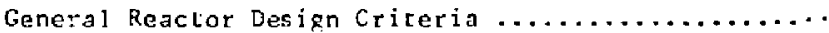

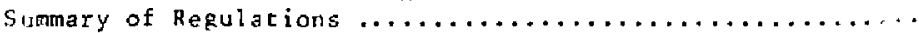

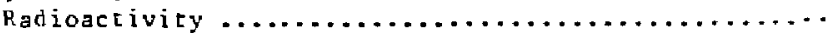

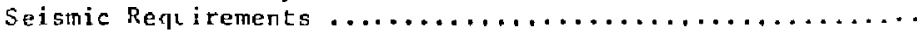

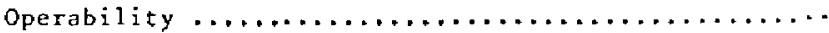

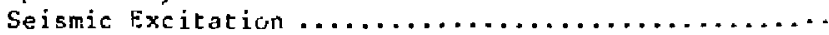

Specific FPD Siting and Safety Considerations ........... Tritium lise ...........................

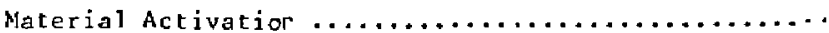

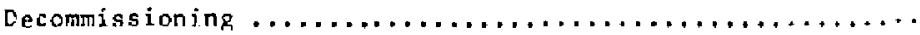

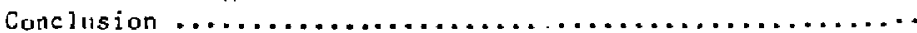

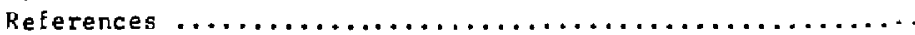

8.0 Tandem Mirror Reactor Systems Code (TMRsC) ................

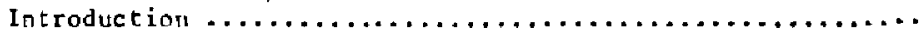

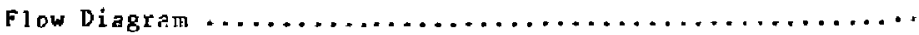

Modulo Descriptions ...........................

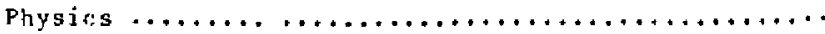
Neutronics 
Blanket Thermal Hydraulics .................. $8-6$

Magnetics ................................. $8-6$

Magnet ................................. $8-7$

Neutron Source (Auxiliary Physics) .............. $8-7$

Direct Converter .......................... $8-7$

Plasma Heating ........................... $8-8$

Vacuum Vessel ........................... $8-8$

AC Power ............................... $8-9$

Magnet Electrical ......................... $8-9$

Instrumentation and Control ( $1 \& c) \ldots \ldots \ldots \ldots \ldots \ldots$

Maintenance Equipment ....................... $8-9$

Facility ............................... $8-10$

Code Status .............................. 8 8 . 10

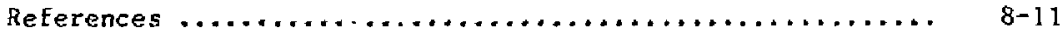

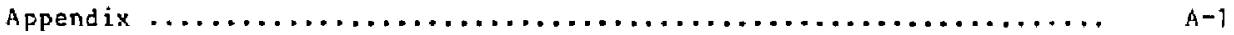

A Mircor Ignition Machine with Octupole End Plugs .......... A-1

Yin-Yang Shielding ............................. A 14

Neutron Fluence Design Limit for Superconducting Magrets .... A-26

Critical Issues ............................... A-31

Siting and safety Criteria ...................... A-52 
In this report we present a summary of the first phase of the fusion Pover Demonstration (FPB) design study. During this first phase, we investigated two configurations, performed detailed studies of major components, and identified and examined critical issues. In addition to these design specific studies, we also assembled a mirror-systems computer code to help optimize future device designs.

The two configurations that we have studied are based on the MArs magnet configuration and are labeled FPD-I and FPD-II. The FPD-I configuration employs the same magnet set used in the FY83 FPD study, whereas the FPD-II magnets are a new, much smaller set chosen to help reduce the capital cost of the system.

As part of the FPD study, we also identified and explored issues critical to the construction of an Engineering Test Reactor (ETR). These issues involve subsystems or components, which because of their cost or state of cechnology can have a significant impact on our ability to meet FPD's mission requirements on the assumed schedule. General Dynamics and Gruman Aerospace studied two of these systems, the high-field choke coil and the halo pump/direct converter, in great detail and their findings are presented in this repott.

Because this is an interim report presenting the results of this work to date, the document has not been extensively edited to eliminate minor inconsistencies and omissions. An additional report will be produced in the early parc of 1985 at the completion of the FPD-III phase of this study. 


\subsection{INTRODUGTION}

The Fusion Power Demonstration (FPD) is an Engineering Test Reactor (ETR) class device. The FPD design includes all systems requirgd in a Demonstration Power Reactor except for a turbine plant. We basen the first two iterations of the FPD design on the physics concepts developed in the MARS study that was completed in September, 1983.1

The plasma engineering configuration of FPD follows the principles employed in MARs ${ }^{l}$ and comprises a low-field (2.5-T) soienoidal-central-cell region, the high-field (24-T) central-cell choke coils, and an end-cell magnet system composed of a double quarirupole archor/plug yin-yang pair.

Central-cell passing particles that trap in the long end-cell transition regions are radially "drift pumped" to the plasma halo and represent a major power loss from the system. To reduce costs, the ignition conditions for FPD-I and FPD-1I were obtained at the minjinum central-cel] length where fusion alpha particle hearing balances the drift purp and other system losses.

The engineering design philosophy for FPD-I and FPD-II reflects the configuration developed in the 1983 Mirror Fusion Test Facility-lipgrade (MFTF-Up:rade) study that minimizes size and emphasizes zase of maintenance.

The FPD-I configuration has a central cell length of $74 \mathrm{~m}$ and proruces $360 \mathrm{MW}$ of fusion power (see Fig. 4-1 in Sec. 4). With a recirculation power of approximately $170 \mathrm{MW}$, this option, with minor revision, could reach engineering breakeven. The most visible difference, between the MaRS and FPD-I concepts, is the application of sheer coils co the central cell in FPD-I, which reduces field ripple and improves performance. A test cell is included in the FPD-I concept; and in this case the test cell will develop a wall loading of $2 \mathrm{MW} / \mathrm{m}^{2}$ of uncollided $14-\mathrm{MeV}$ neutrons.

The FPD-II configuration has a central cell length of $96 \mathrm{~m}$ and produces 480 MW of fusion power (see fig. 5-1 in See. 5). At this power level, this device could produce about 200 MW of net electrical power when using a reasonably efficient turbine plant. A test cell is included in the FPD-Il concept, which produces an uncolitided $14-\mathrm{MeV}$ nelitron flux of $4.91 / \mathrm{m}^{2}$, A revision of the geometry ard a hetter understanding of the physics account for the differences in performance berween this device and FPD-I. 
The FPD-I and FPD-II studies are each bosed on somewhat different physics; and the costs for each were generated with different algorithms. The plyssics changes are an cutcome of our continuing work in modeling mirror systems. The costing revisions are hased on the methods used in costing Tokamuk Fusion Core Experiment (TFCX) during this same period of time. When adjustments are made for the above differences, the results show that we lave made progress ir. reducing the size and mass of the mirror system by using an agricssive approach in designing subsystems, particularly the magnet systems. Capital costs wjl follow this trend, bit at some point the capital cost saving will he overwhelmed hy increased operating costs. 
REFERENCE

I. B. G. Logan, MARS Mirtor Advanced Reactor Study, Lawrence Livermore National Laboratory, Livermore, CA, UCRL-53480 (1984).

$$
1-3 / 1-4
$$




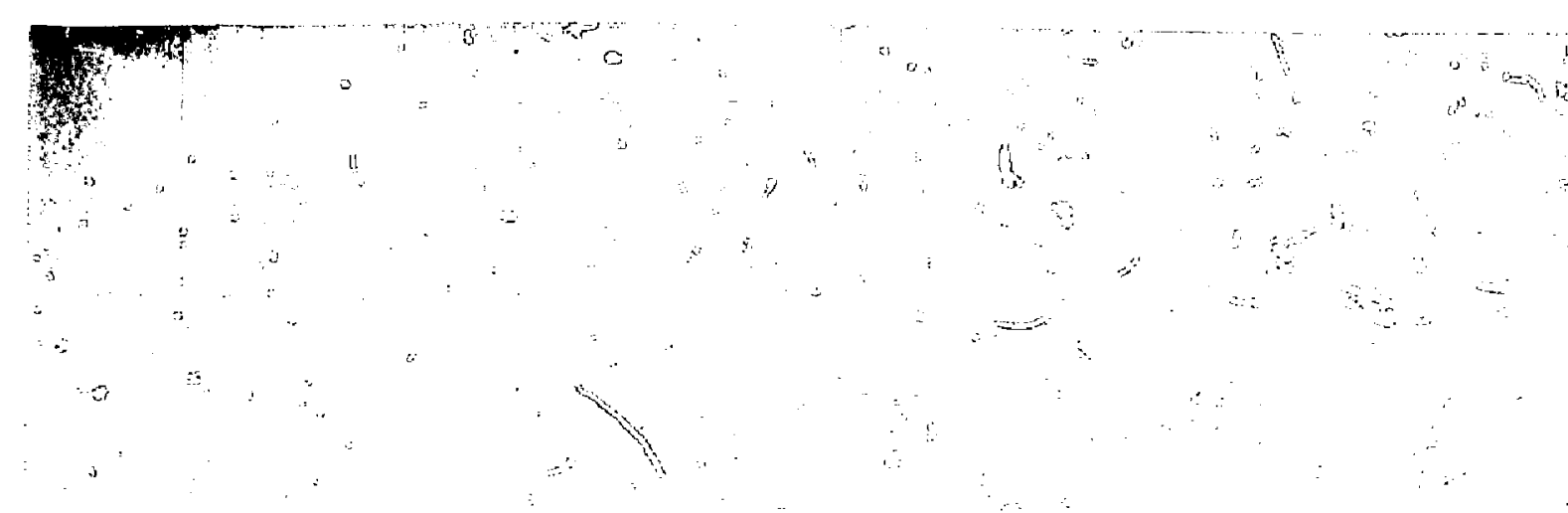

Section 2

THE ENGINEERING TEST REACTOK MISSION

5 


\section{INTRODUCT ION}

The FPD mission statement that follows consists of the tandem mirrcr relevant portions of the dritt generic Engineering Test Reactor (ETR) mission statement generated by Grumman Aerospace Corporation as part of their responsibilities as the Techpical support Services contractor to the Department of Energy (DOE) office of Fusion Energy.

\section{MISSION}

The ETR mission is (') to test critical reactor componeuts in an nnvircment that $c$ an be exirapolated to a commercial fusion power reactor, and (2) :o demonstrate the safe and rejiable operation of a fusion reactor that is representative of a commercial fusiun power reactor.

The ETR is an elemert of the overall national program of development for Hagnetic Fusion Energy as summarited in the Comprehensive Program Managenent Plan (CPMP) of the U.S. Department of Energy, June 1983. The design of the E'lR will be based on the scnfinement concept selected during the Product Definition Phase (tokamak and tandem mitror concepts are the current leading candidates) and on the initiai plasma optimization efforts of the Product Develoment Phase. The ETR will concentrate on the demonstration of technologiesi in support of and leading to a Fusiun Demonstration Powerplant (DFMO). The D:Ho will address the econnmics of froducing electrical por $2 \mathbf{r}$ from fusion energ;. Goals and objectives of doth the E'Tn and nENo are expanded it the following peragraphs.

This mission statement is writcen to provide guidanse for current Reactor Design Studies in preparation for future ETR definitinn/desizn activities. The ETh gorls and objectives are based on the assumftion that the E[R will be the next m jor machine to be built. If additional reactors such as Tokamak. Fusion Core Experiment (TFCX), Burning Core Experiment (BC $x$ ), or upgrades to Mirror Fusion Test Facility (MFF-B) are incorporated into the CPMP, severa] of the E'TR objectives may be reassigned to these machines and other. may be redefined accordingly. 
GENERIC ETR OBJECTIVES

The following objectives are applicable to botil cokamak and tandem míror concepts.

- Demonstrate startup, fractional powet, and shutdown operations in a reactor rejevant regime.

- Demonstrate full fuel-cycle operation including fuel injection, tritium recovery from a breeder blanket, tritium handling throughout the system, and the potential for seif-sufficiency of fuel. (The demonstration of self-sufficiency of fuel is an objective of the DEMO mission.)

- Demonstrate neutrnn thermalization and thermal energy transfer to a blanket coolant at high enough temperatures to be of engineering significance. (The demonstration of electricity proaiuction may be included, but is not a primary objective of the ETR nisoion.)

- Demonstrate the remote handling operations required to attain the desired maintainability for a commercial power reactor. (The demonstration of commercially acceptable availability is an objective of the DEMO mission.)

- Demonstrate shielding effectiveness to prove that the radiation environment of a commercial reacior can be reduced to levels that are acceptable for the operation of radiation sensitive components and to permit the use of projected maintenance scenarios to meet maintainability goals .

- Demonstrate acceptable behavior of critical components when exposed co radiation intensities and dosages that might be expected during a commercial reactor's 1 ifeline. (Although the ETR components will generally not experience such intensities and dosages, loweffectiveness shielding may be used in areas of the dcvice to allow exposure of selected components to integrated dosages representative of a commercial reactor radiation environment,)

- Provide sufficient testing capability to permit comparative demonstr-tions of competing alternative configurations for subsystems or components, when such evaluation cannot be effectively performed in a complenentary program. 
TANDEM MIRROR ETR OBJEC'TIVES

- Demonstrate ignited operation with $\mathrm{M}$ as defined below applying to the central cell unly:

$$
M=\text { ignition margin }=\frac{\text { al pha heating power }}{\text { total plasma power losses }} .
$$

- Demonstrate negative-ion-based neutral-beam heating systems.

- Demonstrate impurizy removal and vacuum pumping by plasma halas (dense boundary layers).

$$
2-3 / 2-4
$$





\subsection{PLASMA ENGINEERING}

The plasma engineering effort for FPD-I and FPD-II was conducted to meet the following three main design goals

1. The central cell should be ignited, i.e., the power deposited by the fusion alpha particles in the central-cell plasma volume should balence the cotal power loss (energetic particles and radiation) from this volume.

2. The central-cell Jength should be the minimum requirec to achieve ignition.

3. The device should be capable of making net electrical power, i.e., the engineering $Q$ (gross electric power divided by recirculating electric power) should be greater or equal to unity.

Both FPD-I and FPD-II employ end cell magnets based on the Mirror Advanced Reactor Study (MARS) configuration, l namely a double quadrupole set with separate anchor and piug regions. The FPD-I magnet set is identical to that used in the FY83 FPD study, ${ }^{2}$ and represents an initial attempt to design a self-consistent tandem-mirror Engineering Test Reactor (ETR). The FPD-II magnet set is a result of system optimization studies performed during FY84 and represents the most compact end-cell magnet set for a minimum cost ignition machine based on the MARS configuration. Figure 3-la,b compares the magnetic configurations of FPD-I and FPD-II, whereas Table 3-1 compares the corresponding baseline plasma parameters.

The major advances in FPD plasma engineering in FY 84 to date are sumnariand in Table 3-2. The principal task of the FPD plasma engineering effort this year has been the optimization of the system design through extensive paramerric analysis consistent with the above design goals. To achieve system optimization, we have searched for minimum length ignition cases by characterizing the close coupling between the major plasma parameters and the magnetic configuration. In particular, as described in more detail below, we were able to demonstrate the strong dependence of the central-cell 


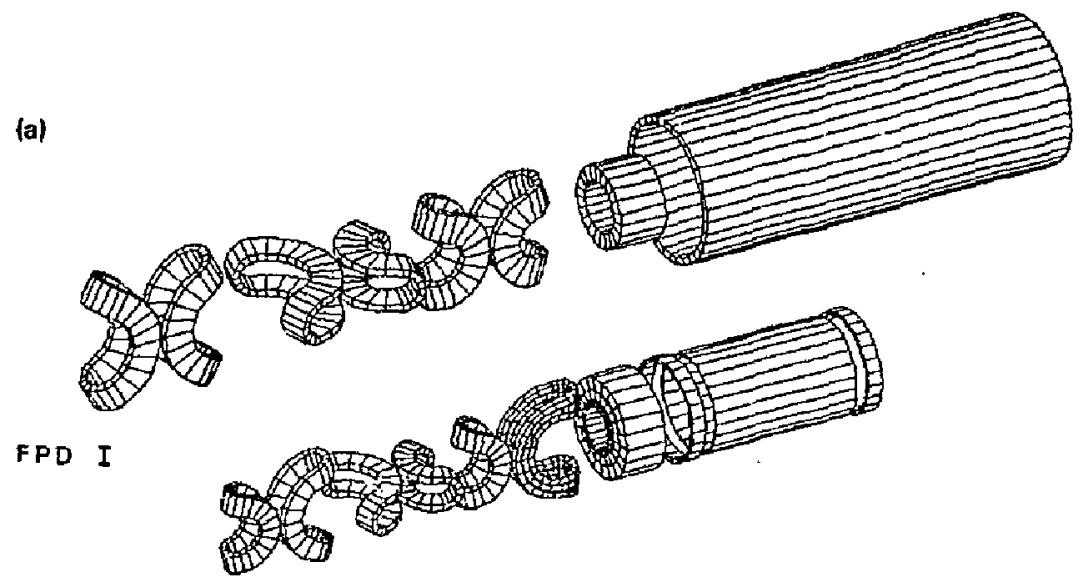

FPD II

(b)
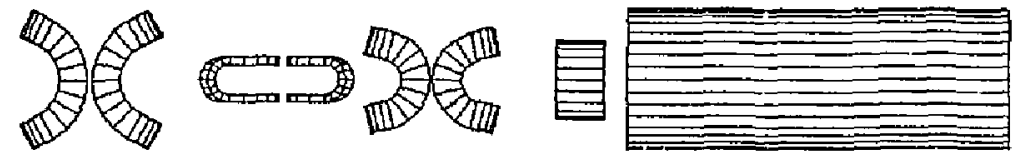

FPD I

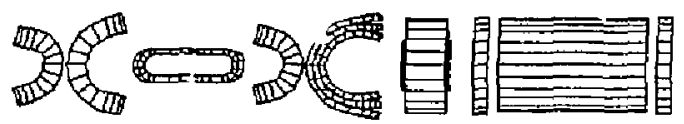

FPD II

Figure 3-1. Two views ( $a$ and $b$ ) comparing the magnetic configurations for FPD-I and FPD-II. For FPD-I, a short section of a representative, continuous solenoid is shown for the central cell magrets. For FPD-1I, one of the centrol cell sheet solenoids with accompanying trim coils is shown. 
Table 3-1. Principal plasma parametses for FPD-I and FPD-II.

\begin{tabular}{|c|c|c|}
\hline Parameter & FPD-I & FPD-1I \\
\hline \multicolumn{3}{|l|}{ General } \\
\hline Fusion power (Mb) & 828 & 479 \\
\hline$Q$ & 28.4 & 36.7 \\
\hline Neucron wall loading $\left(\mathrm{MW} / \mathrm{m}^{2}\right)$ & 3.44 & 1.00 \\
\hline Cold fueling current (kA) & 0.660 & 0.249 \\
\hline End cell magnet confjguration & MARS-mode & MARS-mode \\
\hline End cell trapping length ${ }^{a}(\mathrm{~m})$ & 317.2 & 213.6 \\
\hline \multicolumn{3}{|l|}{ Central Cell } \\
\hline$L_{c}(m)$ & 90 & 90 \\
\hline$r_{c}(m)$ & 0.60 & 0.458 \\
\hline First wall radius (m) & 0.81 & 0.674 \\
\hline$B_{c}(T)$ & 2.5 & 2.5 \\
\hline$\left\langle B_{e}\right\rangle$ & 0.6 & 0.6 \\
\hline $\mathrm{T}_{\mathrm{i}}(\mathrm{keV})$ & 36.7 & 40 \\
\hline $\mathrm{T}_{\mathrm{e}}(\mathrm{keV})$ & 25.7 & 27.7 \\
\hline$n_{c}\left(\mathrm{~cm}^{-3}\right)$ & $1.69 \times 10^{14}$ & $1.65 \times 10^{14}$ \\
\hline
\end{tabular}

Choke Region

$\begin{array}{lll}r_{\text {plasma }}(\mathrm{m}) & 0.154 & 0.118 \\ \text { rcoil (m) }_{\text {coin }} & 0.277 & 0.14 \\ \text { B(T) } & 24 & 24\end{array}$

Anchor

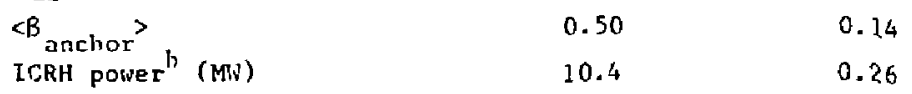


Table 3-1. (continued.)

\begin{tabular}{llll}
\hline Parameter & & FPD-I & FPD-II \\
\hline
\end{tabular}

Plug

$\begin{array}{lll}\left\langle\beta{ }_{p 1}\right\rangle & 0.367 & 0.30 \\ \text { ECRH power, }{ }^{\prime} \text { A (MW) } & 1.15 & 0.345 \\ \text { ECRH power, }{ }^{\text {B }(M W)} & 16.7 & 11.09 \\ \text { Sloshing ion beam power }{ }^{b}(M W) & 0.89 & 1.37\end{array}$

\section{Drift Pump P $\Rightarrow$ rameters}

Transition Coil:

$\begin{array}{lll}\text { Central frequency (MHz) } & 0.064 & 0.107 \\ \text { Frequency spread } & 0.4 & 0.37 \\ \text { Antennt flux required (Wb) } & 0.072 & 0.0054\end{array}$

Plug Coil:

$\begin{array}{lll}\text { Central frequency (MHz) } & 1.1 & 0.83,1.33^{\mathrm{C}} \\ \text { Frequency spread } & 0.66 & 0.10,0.10^{\mathrm{C}} \\ \text { Antenna flux required (Wb) } & 0.0065 & 0.0035\end{array}$

${ }^{a}$ Distance between 24-T peak and plug electrostatic potential peak. ${ }^{b}$ Trapped power, both ends.

cseparate frequencies for cold ions and sloshing ions. 
Table 3-2. Major advances in FPD plasma engineering in FY84.

General

- Parameterized physics and magnetics scaling of ignition condicions in optimized (i.e., minimum length) ETR configuratioñ.

- Characterized the dependence of the minimum central-cell length for ignition on the end-cell magnet configuration and central-cell alpha physics.

- Improved modeling of ion trapping rates in the end cell including multispecies ( $D, T$, alpha) dependence.

- Revised TMRBAR power balance code extensively to improve running time, flexibility, and "user-friendliness". Code is now able ta solve fo: minimum length for ignition, with or without fixed fusion power.

Alpha and Halo Physics

- Characterized central-cell alpha-particle confinement due to nonadiabaticity.

- Modeled alpha-particle energy loss to the halo for cases where the alpha larmor diameter is an appreciable fraction of the central-cell plasma radius.

- Improved modeling of halo physics including power flow, fueling, shielding requirements, and end-dump heat loads.

Magnetics

- Replaced discrete (MARS-type) central cell magnets with lower-cast, lower-ripple, sheet solervids.

- Optimized central-cell trim solenaids to yield minimum rms field curvature and maximum beta.

- Investigated central-cell ripple reduction using field-shaping iron inserts.

- Increased central-cell volume-averaged betas from $49 \%$ to $60 \%$.

- Shortened end-cell transition lengths by developing a new transition coil design.

- Reconfigured the TMG magnetics design code to allow for different magnetic mirror ratios in the plug and anchor regions.

- Implemented a new version of the TEBASCO magnetohyorodynamic (MHD) stability code permitting lower anchor and plug betas for a given central cell beta. 
ignition length on both the end-cell magnetic configuration and certral-cell alpha-particle energy deposition. As a major consequence of these studies, we determined that an optimized mirror ETR based on the MARS magnet configuration requires a minimum central cell length for ignition of about $90 \mathrm{~m}$. At this length, the physics Q (plasma power gain, i.e., plasma fusion power divided by absorbed plasma heating power) is 237 ; whereas $Q_{\text {eng }}$ (engineering power gain, i.e., gross electric power divided by recirculating electric power) is w2. In fact, because of this long-mininum ignition length, the optimized machine will always exhibit an engineering power gain greater than unity.

Although the magnet set for FPD-I is identical to that employed in last year's study, ${ }^{2}$ the updated physics parameters in Table 3-1 show some narked differences. These differences are due to two main changes: (1) Irproved central-cell magnet design has resulted in smaller and lower magnetic-ripple solenoids (see Fig. 3-1), which permit higher beta operation of the central cell plasma ( $60 \%$ vol averaged--compa:-ed wich $49 \%$ in last year's study). (2) Refined Fokker-Planck calculations of end-cell particle-trapping rates, including multispecies effects for $D, T$ and alpha particles; these calculations have unfortunately resulted in longer ignition-length requirements for the central cell of FPD-II ( $90 \mathrm{~m}$ compared with $67.5 \mathrm{~m}$ in FPD I). Ali'ough requiring a longer ignition length, FPD-II does exhibit a higher neutron wall loading than the FY83 baseline $\left(1.44 \mathrm{MW} / \mathrm{m}^{2}\right.$ compared $\omega \dot{5}$ th $\left.0.85 \mathrm{MW} / \mathrm{m}^{2}\right)$. The large overall size of FPD-I and the resulting high capical cost led us, in FPD-II, to seek a more optimized ignition test machine through the performance of parametric analyses.

For a given central-cell magnetic-field, the central-cell ignition length in FPD-II is minimized for a certain central-cell plasma radius $c$. Values of $r_{c}$ larger than the optimum require larger (and more expensive) end cell magnets, which lead to larger end-cell ion-trapping currents and, therefore, longer central cell lengths $L_{c}$. Valuss of $r_{c}$ smaller than the optimum also result in longer values of $L_{c}$ due to the reduced efficiency of fusion alpha-particle-energy deposition in the central cell plasma volume.

We investigated $L_{c}$ vs $r_{c}$ scaling for FPD-II by generating four distinct magnetis configurations, A through $D$, differing in the characteristic volume of the end-cell magnet system. Figure 3-2 compares the end cell magnet configurations for three of these sets, namely $A, B$ and $D$. Table 3-3 summarizes the results of this parametric trade study for all four magnetic configurations. 

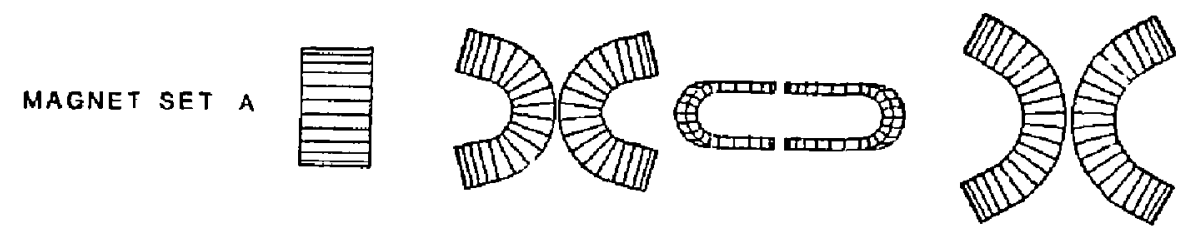

MAGNET SET $B$

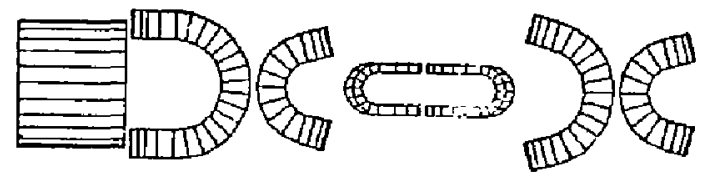

MAGNET SET D
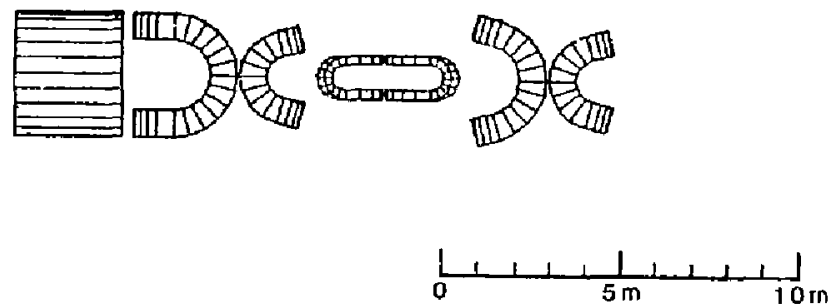

Figure 3-2, Cenparison of the end cel? magnet dimensions for magnet sets $A, B$, and $D$ employed in the comparative trade study. 
ignition length on both the end-cell magnetic configuration and central-cell alpha-particle energy deposition. As a major consequence of these studies, we determined that an optimized mirror ETR based on the MARS magnet configuration requires a minimum central cell length for ignition of about $90 \mathrm{~m}$. At this length, the physics Q (plasma power gain, i.e., plasma fusion power divided by absorbed plasma heating power) is 237 ; whereas $Q_{\text {eng }}$ (engineering power gain, i.e., gross electric power divided by recirculating electric power) is 22. In fact, because of this longminimum ignition length, the optimized machine wili always exhibit an engineering power gain greater than unity.

Although the magnet set for EPD-I is identical to that employed in last year's study, ${ }^{2}$ the updated physics parameters in table $3-$ i show some marked differences. These differences are due to two main changes: (1) Improved central-cell magnet design has resulted in smaller and lower magnetir--ripple solenoids (see Fig. 3-1), which permit higher beta operation of the central cell plasma ( $60 \%$ vol averaged--comparet with $49 \%$ in last year's study). (2) Refined Fokker-Planck calculations of end-cell particle-trapping rates, including multispecies effects for $D, T$ and alpha particles; these calisulations have unfortunately resulted in longer ignition-length requirements for the central cell of FPD-II (90 m compared with $67.5 \mathrm{~m}$ in FPD I). Alr'ough requiring a longer ignition length, FPD-II does exhibit a higher neutron wall loading than the FY83 baseline $\left(1.44 \mathrm{MW} / \mathrm{m}^{2}\right.$ compared with $\left.0.85 \mathrm{MW} / \mathrm{m}^{2}\right)$. The large overall size of FPD-I and the resulting high capical cost led us, in FPD-II, to seek a more optimized ignition test machine through the performance of parametric analyses.

For a given cencral-cell magnetic-field, the central-cell ignition length in FPD-II is minimized for a certain central-cell plasma radius $r_{c}$, Values of $r_{c}$ larger than the optimum require larger (and more expensive) end cell magnets, which lead to larger end-celi ion-trapping currents and, therefore, longer central cell lengths $L_{c}$. Values of $r_{c}$ smaller than the optimum also result in longer values of $L_{c}$ due to the reduced efficiency of fusion alpha-particle-energy deposition in the central cell plasma volume.

We investigated $L_{c}$ vs $r_{c}$ scaling for FPD- $I I$ by generating four distinct magnetic configurations, A through $D$, differing in the characteristic volume of the end-cell magnet system. Figure 3-2 compares the end cell magnet configurar tions for three of these sets, namely $A, B$ and $D$. Table 3-3 sumarizes the results of this parametric trade study for all four magnetic configurarions. 

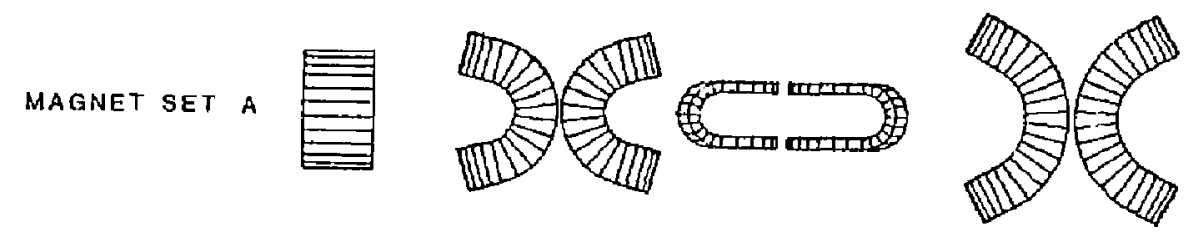

MAGNET SET B

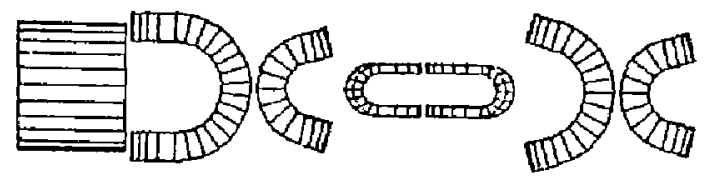

MAGNET SET D
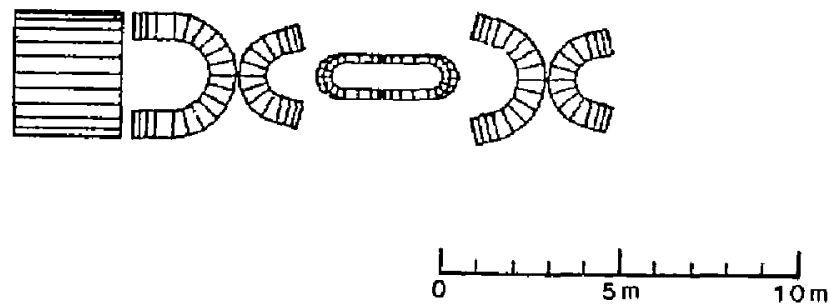

Figure 3-2. Comparison of the end cell magnet dimensions for magnet $\operatorname{sets} A, B$, and $D$ employed in the comparative trade study. 
Table 3-3. Selected features of parametric trade studies for FPD-II. a

\begin{tabular}{|c|c|c|c|c|c|c|c|c|}
\hline $\begin{array}{c}\text { Magnet } \\
\text { set }\end{array}$ & $\begin{array}{l}\text { Central- } \\
\text { celi } \\
\text { plasina } \\
\text { radius, } x_{c} \\
(\mathrm{~m})\end{array}$ & $\begin{array}{c}\text { End-cel1 } \\
\text { erapping } \\
\text { length } \\
(\mathrm{m})\end{array}$ & $\begin{array}{c}\text { Choke } \\
\text { coil } \\
\text { radius } \\
(m)\end{array}$ & $\begin{array}{c}\text { Fusion } \\
\text { poirr } \\
(M H)\end{array}$ & $\begin{array}{l}\text { Neutron } \\
\text { wall } \\
\text { loading } \\
\left(\mathrm{MH} / \mathrm{m}^{2}\right)\end{array}$ & $Q$ & $Q_{\text {eng }}$ & $\begin{array}{c}\text { Minimum } \\
\text { central- } \\
\text { cell } \\
\text { ignition } \\
\text { length, Lc } \\
\text { (m) }\end{array}$ \\
\hline A & 35.7 & 12.7 & 0.114 & 440 & 0.78 & 40.6 & 2.1 & 125 \\
\hline B & 45.8 & 13.8 & 0.140 & 492 & 1.08 & 29.6 & 21.9 & 86 \\
\hline $\mathrm{c}$ & 50.7 & 10.0 & 0.153 & 591 & 1.24 & 25.4 & $q] .9$ & 84 \\
\hline $\mathrm{v}$ & 64.5 & 18.6 & 0.188 & 943 & 1.66 & 31.0 & 2.2 .7 & 84 \\
\hline
\end{tabular}

a Parametric trades for optimum central-cell field formed a separate, parallel study and resulted in $B_{C}=2.5 \mathrm{~T}$.

For a constant central cell ficld $B_{c}$ (a value of 2.5 T was employed here, which is a result of a separate, paralle] optimization study), a large: end-cell magnet volume implies a larger attainable central-cell $n^{\prime}$ asma radius $I_{c}$ because we must conserve magnetic flux mapping

$$
\phi=\pi r_{c}^{2} B_{C}\left(1-B_{c}>\right)^{1 / 2}=A(z) B(z)\left(1-<B_{z}>\right)^{1 / 2},
$$

through the system. As si:own in Table 3-3, the smallest magnet set (set A) can support a maximum central-cell plasma radius of $35.7 \mathrm{~cm}$; the largesc (set D) can support a radius of $64.5 \mathrm{~cm}$. Note that as $\mathrm{r}_{c}$ is increased from $35.7 \mathrm{~cm}$ to $64.5 \mathrm{~cm}$ (i.e., magnet sets $A$ through $D$ ), the minimum central cell length for ignition $L_{c}$ decreases from $125 \mathrm{~m}$ to $84 \mathrm{~m}$. A further increase in end-cell magnet size above that of set $D$ in Table 3-3 would result in a value of $L_{c}$ larget than $84 \mathrm{~m}$.

The apparent ininimum $i$ in the ignition length for magnet sets can be explained as follows: larger end-cell magnet sets result in longer end-cel! trapping lengths ( $i, e$, the distance between the choke-coil mirror peak and 
the end-cell potential peak). This, in turn, :esults in correspondirs.y larger end-cell trapping rates. Because central cell ignition requir ss that alpha heating essentially supports the radial losses incurred by trapping in, and pumping ou: af the pild cell ragion, central cell lengths determined oni: by end-cell trapping would minimize for very smai: central cell redii. Unfortunately, our relatively low $B_{c}$ of $2.5 \mathrm{~T}$ and high $\left\langle\mathrm{B}_{c}\right\rangle$ of $60_{\%}^{\%}$ imply large alpha particle larmor orbits. Hence, a decreasing central cell radius results in a greater fraction of the fusion alpha energy escaping the pasma and being deposited in the halo. Figure 3-3 illustrates this effect where the fraction of the central-cell alpha power deposited in the halo outside the plasma is plotted as a function $n f$ a parameter $p$, which incorpnrates the dependence of $r_{c}, B_{c}$, and $<\beta_{c}>$ as shown. It is interesting to note that with the optimum values of $B_{c}$ and $r_{c}$ at $2.5 \mathrm{~T}$ and $0.45 \mathrm{~m}$, respectively, our $\mathrm{E}$ [R attains iss "optinized" ignition length by discarding $2.20 \%$ of its cenc-al-cell alpha hearing power to the halo! Hence, our minimum length is a compromise between end-cell lengths/volumes and central-cell alpha-energy deposicion.

Mote that magnet set 0 yields an ignition length that is orily $2 \mathrm{~m} \mathrm{less}$ than that of set $B$, although the former exhibits both larger plasma-heating power requirements ( $Q$ times the fusion power) and larger end cell magnets, and consequently, larger capital ast. In this rispect, a design of FPD-tI based on magret set $B$ with $r_{c}=45.8 \mathrm{~cm}$, represents the most desirable option. the final parameters for FPD-II given previously in Table 3-1 show slight:y different values from those for set $B$ in Table 3-3 because of further s1ight refinements in both the magnetic configuration and the physics models. The final baseline exhibits a respectable wall loading of $1 \mathrm{MW} / \mathrm{m}^{2}$ a: a fusion power of $479 \mathrm{~mW}$ and a minimum ignition length of $90 \mathrm{~m}$. Because $r$ f this long ignition length, the physics $Q$ (fusion power divided by absorbed hearing power) is high at 36.7 and yields a system engineering power gain (gross electric autput power divided by recirculating electric power) of 22 .

Tables 3-1 and 3-3 both indicate that an ignition machine with end plugs based on the MARS configuration will be a rather long and celatively expensive device. In the current phase of the FPD roject (i.e., FPD-III), these factors have led us to consijer a much moie compact and cheaper ignition machine based on an octopole end-cell magnetic configuration. Further details on this are given in MFE/RTCD/84-2740a:0127a in the Appendix. 


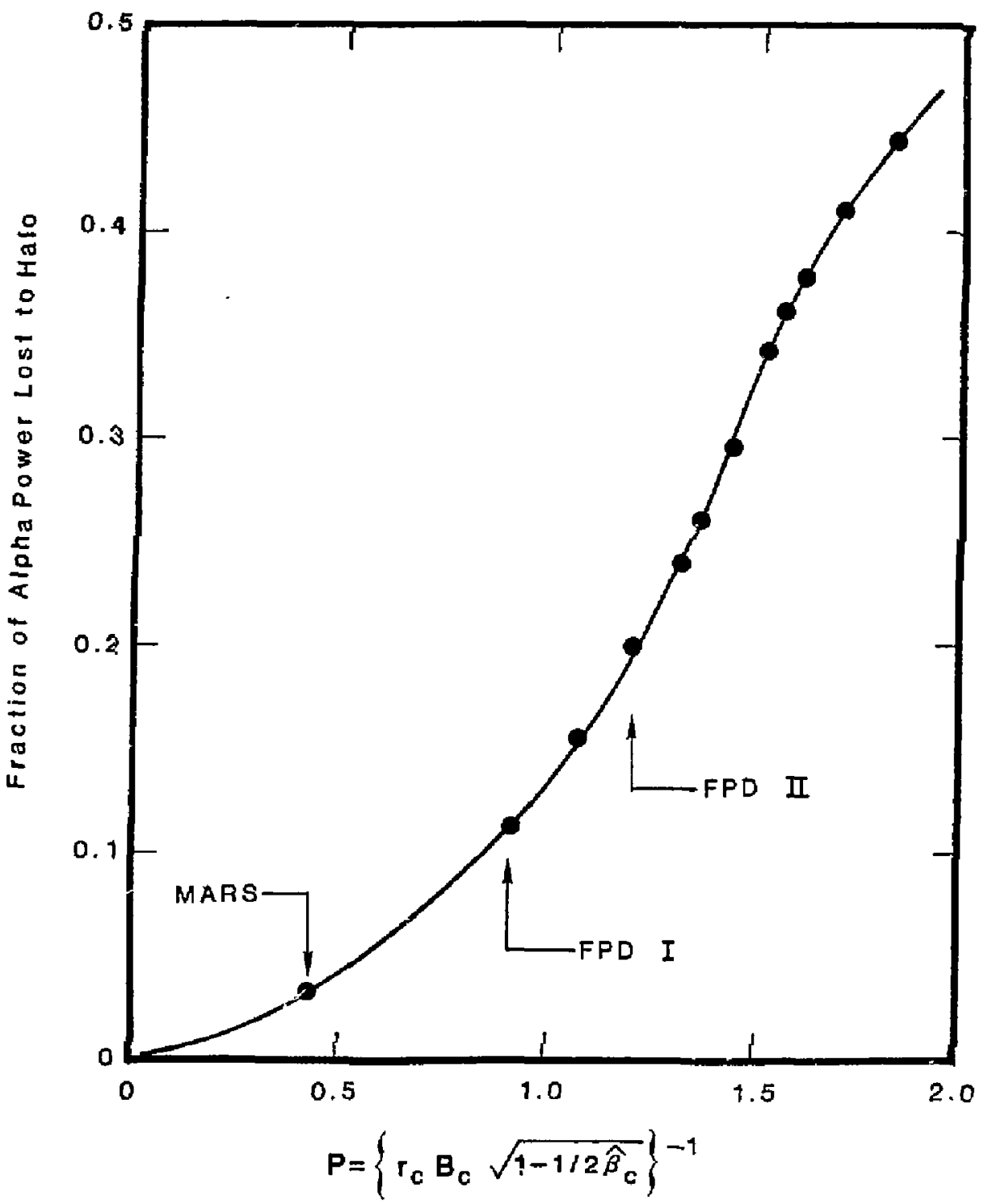

Figure 3-3. Fraction of the central cell fusion alpha power deposited in the halo, expressed in terms of a system parameter $P . P$ is a fuiction of the central cell plasma radius ( $\left.r_{c}\right)$, the central cell $B$-field $\left(\hat{B}_{c}\right)$, and the central cell peak beta $\left(\beta_{c}\right)$. 
This section will focus on an option for FPD-II in which the first half of its rull power operating lifetime would be dedicated to high-Q ignition operation and the second half would concentrate on integrated componert testing of reactor-like blanket modules at high neutron wall loading. To sccomplish the latter goal, one or, more of the central cell magnet/blanket modules would be replaced by an axisymmetric, high-field test-cell insert driven by mixed DT neutral beam injection. In this configuration, called FPD-II+T, high wall loading in the test cell would be obtained by reducing the ion confinement of the device through modification of the axial potential profile and by injecting sufficient current into the test cell to establish a density that is more than a factor of 2 greater than that in the central cell of FPD-II.

We performed scoping studies of FPD-II+T configurations using an expanded version of the TMRBAR tandem mirror physics code, ${ }^{3}$ subject to the following general constraints. First, the requirements on the end cell systems (drift pumping, ECRH, ICRH, sloshing-ion neutral beams, and related systems) have been held to near the FPD-II values or below to avoid costly changes to the end cells. Second, optimized seif-consistent operating parameters have been sought that produce the highest test-cell wall loading for the lowest injection neutral besm power.

Two test-cell configurations have been examined--one accamodating two blanke test modules and the other accommodating four. The short test cell would replace a single $8.7-m^{-1}$ ong FPD-II central cell magnet/blanket module. The long test cell would replace three central cell modules, and would require additional central-cell-like modules of appropriate length to fill in on either side of the test cell.

Examples of the parametrics that have been performed for both configurations are given in Eigs, 3-4 and 3-5. From these studies a partialiy optimized parameter list for the short test cell has been obtained (see Table 3-4) in which the test-cell wall loading is $\Gamma_{t c}=3.0 \mathrm{~mW} / \mathrm{m}^{2}$ with neutral beam power $P_{n b, t c}=26 \mathrm{MW}$ at the MHD beta limits set by stability considerations, For the longer test celi, the comparable case at $\Gamma_{t c}=3.0 \mathrm{MW} / \mathrm{m}^{2}$ requires lese neutral 


\section{Exemple Trode-aff for FPD-I1+T Short Test Cell Configurelion}

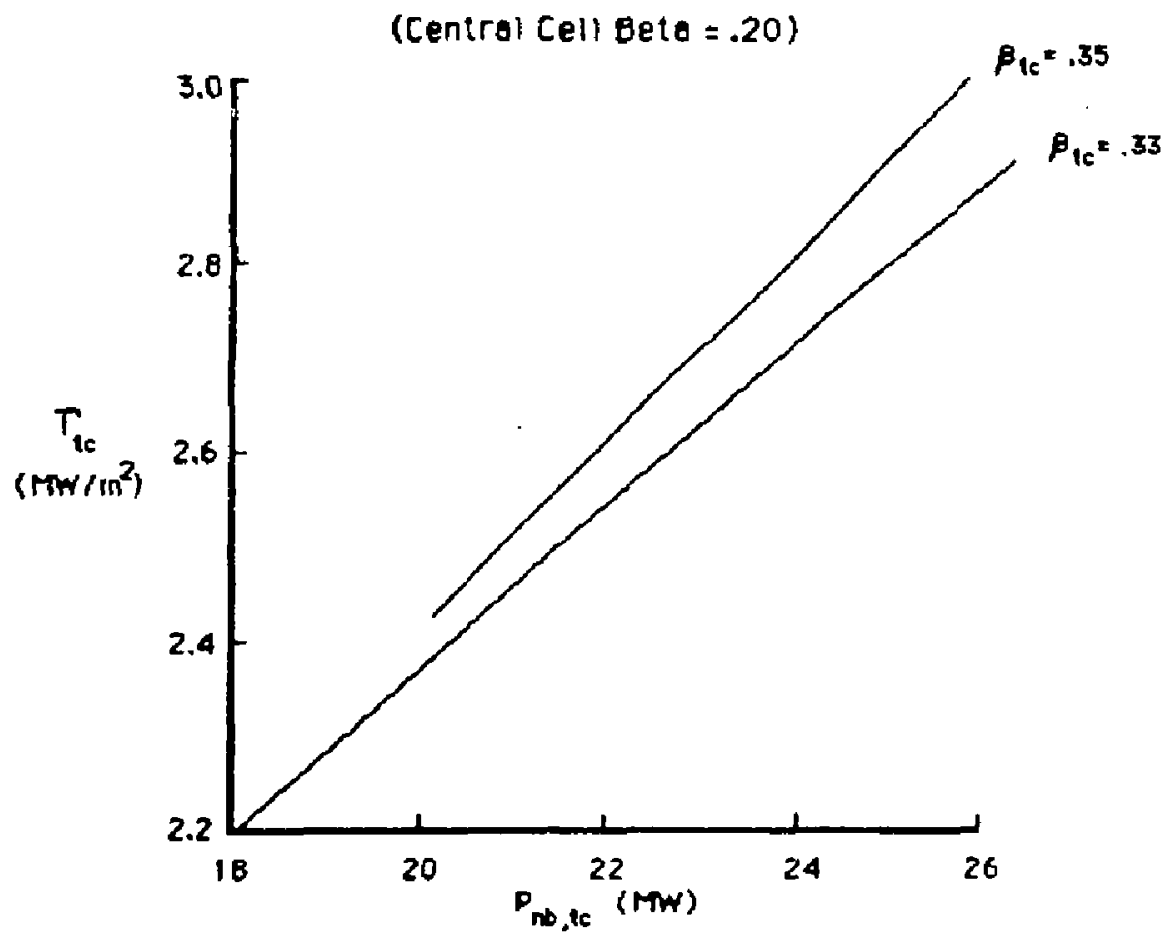

Fijure 3-4. Neutron wall loading as a function of neutra: beam power for the short test-cell configuration (central cell beta $=0.20$ ). 


\section{Example Trade-off for FPD- $11+T$ Long Test Cell Contigurstion}

(Centrol Cell Beto $=.36$ )

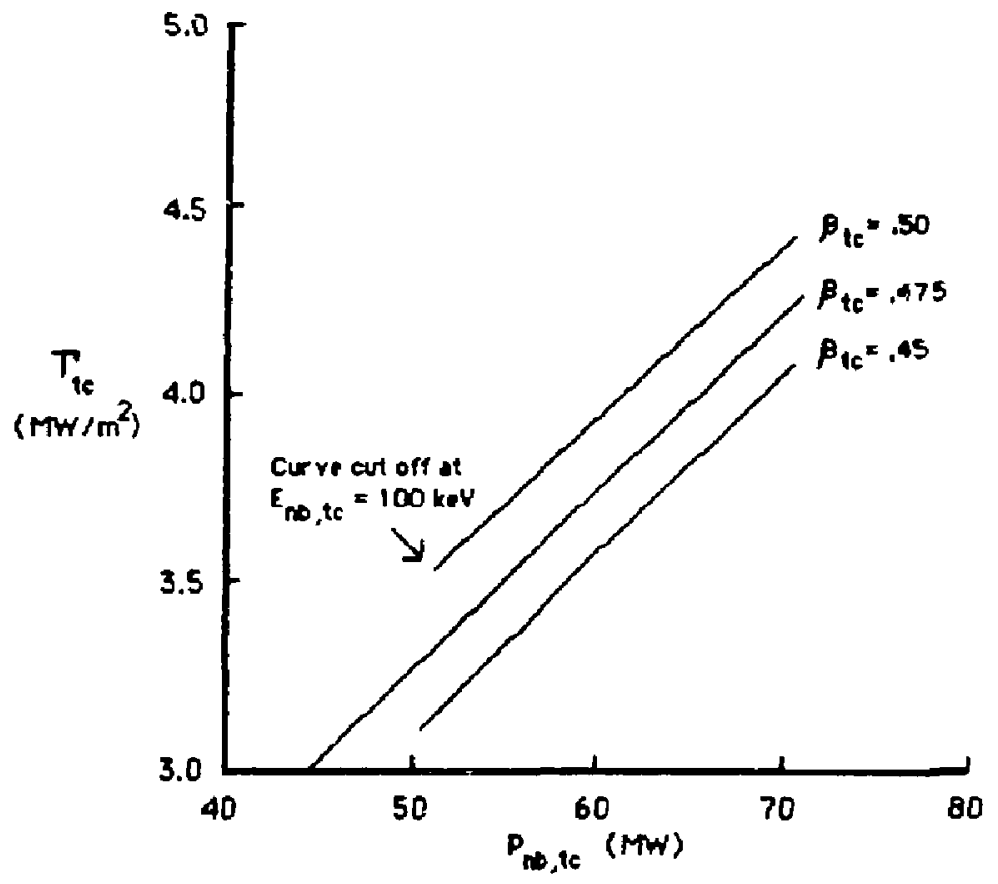

Figure 3-5. Neutron wall losding as a Function of neutral beam power for the long test-cell configuration (central cell beta $=0.36$ ). 
Table 3-4. Optimized FPD-II+T operation parameters.

\begin{tabular}{|c|c|c|}
\hline \multirow[b]{2}{*}{ Parameter } & \multicolumn{2}{|c|}{ Test-ce11 size } \\
\hline & Short & Long \\
\hline Test-cell wall loading, $\tau_{t c}\left(M w / m^{2}\right)$ & 3.0 & 3.0 \\
\hline Central cell ion density, $n_{i, c}\left(\mathrm{~cm}^{-3}\right)$ & $1.1 \times 10^{14}$ & $1.2 \times 10^{14}$ \\
\hline Central cell ism temperature, $T_{i, c}$ (kev) & 16.0 & 24.9 \\
\hline Test-cell ion energy, $\mathrm{E}_{\text {hot }}(\mathrm{keV})$ & 46.7 & 63.7 \\
\hline Central cell peak beta, $B_{c}$ & 0.20 & 0.36 \\
\hline Test-cell peak tata, $\beta_{\text {te }}$ & 0.35 & 0.475 \\
\hline ECRH power at a, $P_{\text {ecrh,a }}(M W)$ & $0.17^{a}$ & $0.11^{3}$ \\
\hline ECRH power at $b, P_{\text {eerh, }}(\mathrm{MH})$ & $10.4^{a}$ & $11 . \mathrm{c}^{\mathrm{a}}$ \\
\hline Anchor ICRH power, $\mathrm{P}_{\text {icrh }}(\mathrm{MW})$ & $3.63^{a}$ & $0.76^{\mathrm{a}}$ \\
\hline Neutral beam power at $a^{\prime}, P_{n b, a^{\prime}}^{\prime}(M W)$ & $0.15^{\mathrm{a}}$ & $0.15^{a}$ \\
\hline Neutral beam energy at $a^{\prime}, E_{n b, a^{\prime}}^{\prime}(k e V)$ & 250 & 280 \\
\hline Test-cell neutral beam power, $P_{n b, t c}(M W)$ & $25.7^{b}$ & $44.4^{b}$ \\
\hline Test-cell neutral beam energy, $E_{n b, t c}(\mathrm{keV})$ & 69.3 & 100.4 \\
\hline$T_{\text {est-cell neutral beam current, }} I_{n b, t c}$ (A) & $371^{\mathrm{b}}$ & $443^{b}$ \\
\hline Central cell fueling current, $I_{\text {Euel, }}$ (A) & 5.0 & 0.0 \\
\hline Transition trapping current, I'trap (A) & 199 & 92 \\
\hline $\begin{array}{l}\text { Direct-converter inner collector heat Elux, } \\
\mathrm{P}_{\mathrm{dc}, \mathrm{ic}}\left(\mathrm{MW} / \mathrm{m}^{2}\right)\end{array}$ & 2.1 & 4.4 \\
\hline
\end{tabular}


beam power per unit test-eell effective length because of the higher beta values achievable at the longer length. Finally, although the value of $3 \mathrm{MW} / \mathrm{m}^{2}$ may be near the maximum achievable wal: loading in the short test cell (without significantly exceeding the capabilities of the FPD-II end cell systems), operation of the long test cell on the stability boundary, subject to the same constraints, can produce a wall loading in excess of $5 \mathrm{MW} / \mathrm{m}^{2}$.

This study has not considered further optimization that might be achieved by modifying the shape of the magnetic field profile in the test-cell refion. Careful design of the field shape could lead to higher beta timits from MHD stability calculations (if the bad curvature drive could be reduced) and better confinement (if the effective mircor ratio could be increased). Both of these effects improve test-cell performance. 
REFERENCES

1. B. G. Logan, et a1, Mirror Advanced Reactor Study (MARS): Final Design Report, Lawrence Livermore National Laboratory, Livermore, CA, UCRL-53480 (1984).

2. C. 0. Henning, et a1, Fusion Power Demonstration: Baseline Report, Lawrence Livermore National Laboratory, Livermore, CA, UCID-19975 (1984).

3. R. B. Campbe11, TMRBAR - A Code to Galculate Plasma Parameters for Tandem Miuror Reactors Operating in the MARS Mode, Lawrence Livermore National Laboratory, Livermore, CA, UCID-19875 (1983). 
The first option of the Fusion Power Demonstration (FPD) that we studied is FPD-I (Fig. 4-1). This configuration has a central cell length of $74 \mathrm{~m}$, measured from tha center of one choke coil to the other, and produces 360 MW of fusion power. With a recirculating power of approximately $175 \mathrm{~kW}$ and a power generetion capability of $170 \mathrm{MW}$, this option can be expected, with minor revision, to reach its goal of breakeven. With the addition of a test cell, which can be configured in a manner similar to the Mirror Fusion Test Facility $\alpha+T$ (MFTE- $\alpha+T)^{1}$ concept, FPD-I will be able to provide a neutron wall loading of $2.0 \mathrm{NW} / \mathrm{m}^{2}$ to a surface approximately $3 \mathrm{~m}^{2}$. An evaluation of the configuration shows that a $50 \%$ availability goal can be met, thus allowing an accumulation of 10 full power years over an operating 1 ifetime of 20 years.

The central cell is configured in a modular fashion using jo-m-jong central cell modules (Fig. 4-1). Each module is made up of a pair of liquid lead, lithium-cooled blanket modules that can be inserted from opposite ends; thus each blanket module will be $5 \mathrm{~m}$ long (Fig. 4-2). We chose this length to limit the magnetohydrodynamic (MHD) effects on the b]anket, while at the same - ime meeting restrictions on the gentetry and total module weight.

We selected a geometry where the central cell is divided into six 10-m modules and two 5-m modules. The 5-m modules are paired with the choke coils (Fiz, 4-3) so that the high axial force acting on the portion of the central cell solenoid coil closest to the choke coil can be carried by permanent structure. Study of the axial magnetic loading on the solenoid shows that the forces resulting from the choke cojl are contained moscly within the first $5 \mathrm{~m}$ of the solenoid. We also selected the 10-m length so that a complete module will weigh less than 5000 tons, which we judge a reasonable upper limit far hand 1 ing and positioning by an overhead bridge crane.

The remainder of the module is composed of a surrounding nuclear shield supported in a circumscribing vacuum vessel by a truss so that the shield can be extracted from the end of the 10-m-long cylindrical vessel. Between the 


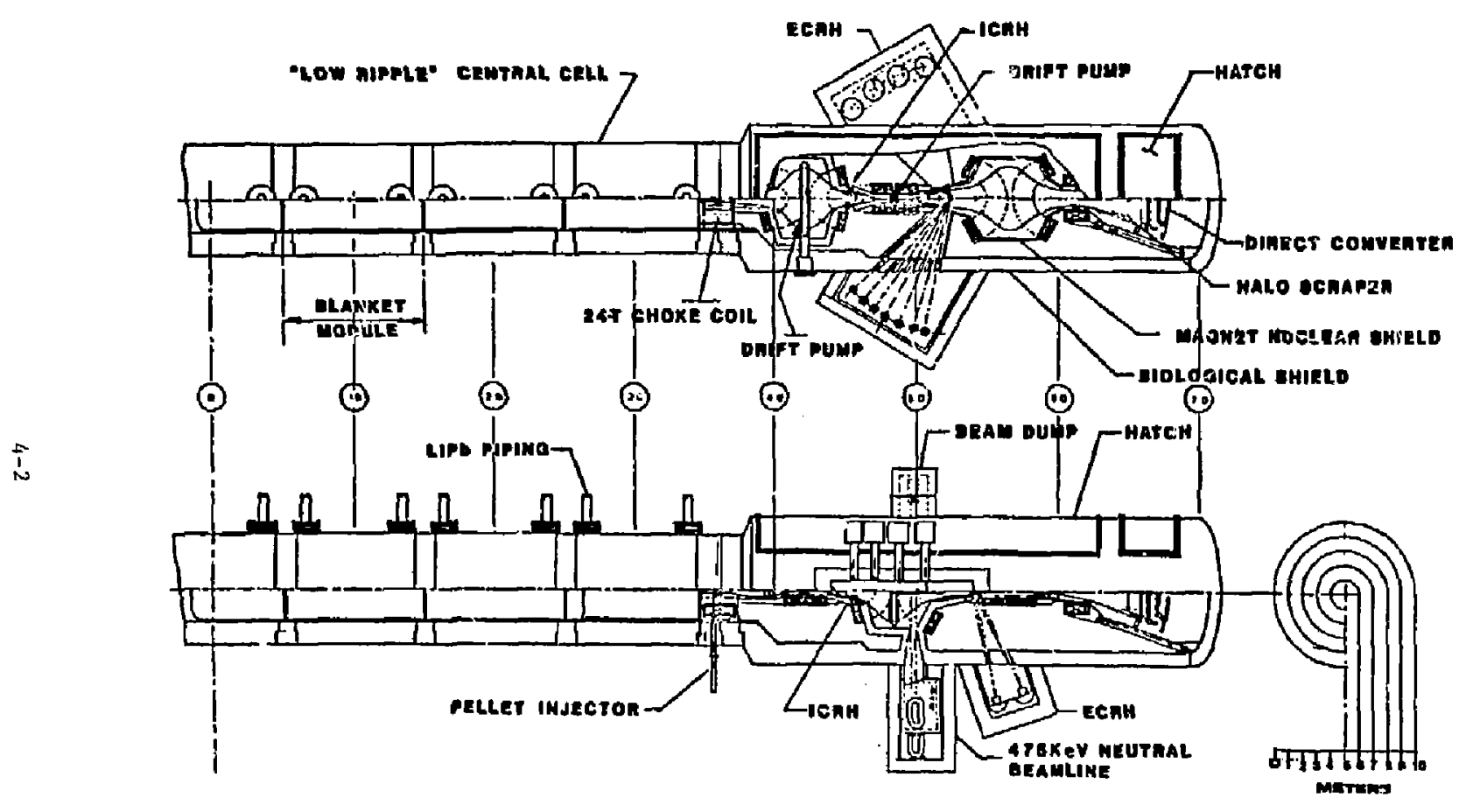

Figure 4-1. The first configuration Eor FPD (2/9/84). 


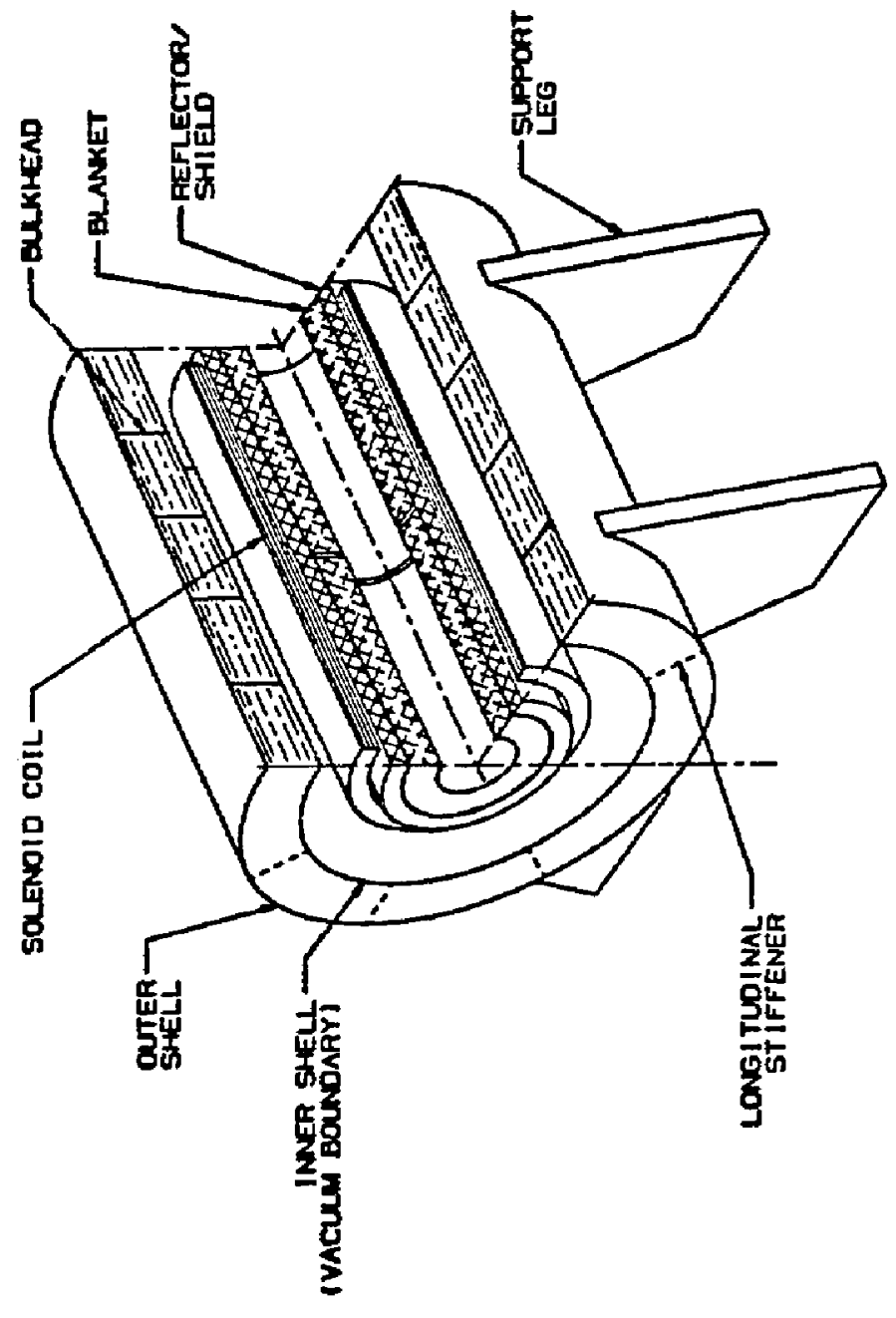

告 


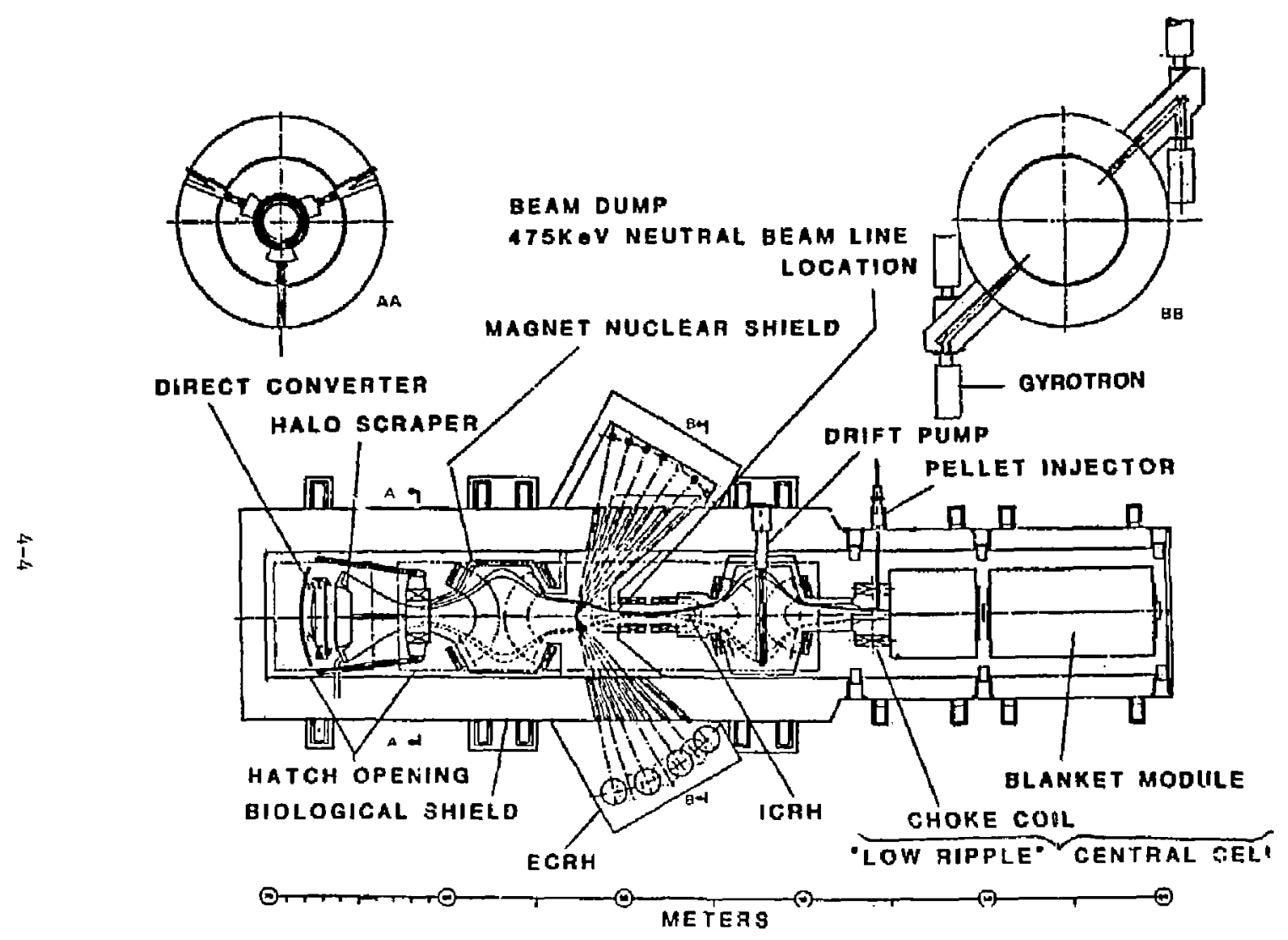

Figure 4-3. The conf'quration of FPD $(2 / 22 / 84)$. 
vessel and the nuclear shield lies a $9.25-m-l o n g$ superconducting solenoid coil, which provides the $2.5 \mathrm{~T}$ central field. The solenoid coils are also supported for removal with the nuclear shield. Thermal isolation is provided by a system of struts to the main supporting truss frame. This configuration, which uses a long, thin solenoid, was developed to satisfy the nced for ninimum magnetic field ripple, a condition necessary to achieve high central cell beta. The vessel is of a double-walled construction that is filled with water. The water acting with a layer of $B_{4} C$ and lead serves as a biological nuclear shield to reduce the radiation level to acceptable levels. A dose rate of $0.5 \mathrm{mrem} / \mathrm{hou}$, twenty-fcur hours after shutdown, was established as a goal based on the as Iow as reasonafy achievable 'ALARA' guideline.

The choks coils create peak field on axis of $24 \mathrm{~T}$. Each is constructed using a normal conducting insert coil together wilh a superconducting background coil. The choke coils are mated to their companion solenoid coils in a modular fashion. The module could be moved to provide access for replacement of the insert coil, which is not envisioned to be a lifetime component. The pancakes of the coils are slightly separated to make provision for the radial injection of fueling pellets from a rail gun (Fig. 4-3).

Each of the end cells are configured ta permit easy assembly of the machine and co permit relatively easy replacement of all of the internal components, including the Iarge $c$ coils that are considered to be lifetiwe components. The concept employed is based on the design developed for the MFTF- $\alpha+T$ study. ${ }^{l}$ The double-walled end-cell vessel contains a large hatch (Fjg- 4-1), which is also of a double-walled construction. The double wall is used to contain the water that forms a part of the biological nuciear shield. It also provides an excellent structural support to the vacuum loadiag. The six C-shaped and ong recircularizing solenoid superconducting coils are placed on cojd tables, which are supported by a set of truss struts tied to the lower trough structure of the vessel. The coils are tied cogether by a set of axial struts that carry the axiol magnetic loading to the end of the vessel. This apprach has the advantage that, should it prove necessary to replace a coil, the reolacement can be accomplished with inimal impact on the other coils and components that are operating satisfactorily. 
Nuclear snielding is provided within the end cell coils to reduce the refrigeration load. This shielding reduces the fluence to the magnets, allowing them to become lifetime components.

The end cell heating subsystems consist of ion-cyclotron resonant heating (ICRH), electron-cyclotron resonant heating (ECRH), drift pumping, and negative-ion-based beam systems (Figs. 4-1 and 4-3).

The ICRH is applied to the transition region using a set of four loop antennae, which we selected because the coil winding configuration does not provide sufficient space for a rigid waveguide.

The ECRH is applier at two positions along the axis of the machine in each of the two end cells. The point "a" ECRH system requizes one gyrotron to provide the basic power needed; a secand one is placed to serve as an on-line spare. Access for these two systems, which employ a quasi-optical transport and launching system, is relatively straightforward. The point "b" ECRH subsystem is somewhat more difficulr, primarily, because if requires 12 aclive and 2 spare gyrotrons. The quasi-optical trallsport and launching system was selected to make it possible to apply the required power through the relatively small space available. The launchers are atrayed axialiy so that the beams may pass through the major radius of the anchot one coil. The gyrotrons are mounted on a wing-like vacuum hox with gate valves so that the gyrotrons can be replaced without bringing the whole vacuum system up to air.

Drift pumping coils are provided in pairs at two lacations. These cojls are arranged in a module together with a nuclear shield plug so that they may be withdrawn radially for replacement. Ti, is concept was conceived during the MARS effort and further developed for the MFTF-a+T study. 1

Lastly, the 475-keV negative-ion-based neutral beamline subsystem is positioned to produce the required sloshing ion distribution in the anchor region. The integration of this system ptoved the most ifficult of all tasks. The target point is located with respect to the $\mathrm{C}$ coils such that axial fanning of the beams from each of the three required snurces is not possible. It is necessary that the three beams, two active and one on-line spare, be arranged itr a circumferential fan as shown in Fig. 4-3. This arrangement, which allows marginal nuclear shielding in the throat of the adjacent $\mathrm{C}$ coils, has two major disadvantages. One disadvantage is the 
possibility that a detailed evaluation would show that the nuclear shielding within the throat of the $C$ coils must be increased in thickness, resulting in an increase in the coil size and therefore in the : se of all of the coils. A second disadvantage is that access to two of the beam sources is more difficult.

The halo scraper and direct converter are considered 1 ifetime components. These components can be removed, should this prove necessary, by lifting them vertically throush their dedicated hatch (Fig. 4-1) in the vessel. This vertical lifting arrangement minimizes the length of the vault while being compatible with the vertical access philosophy of the rest of the components.

End cell configuration is, with the exception of the quasi-optical ECRH and circumferentially arrayed sloshing beamline, based on the earlier MFTF- $\alpha+T$ study. 1

The configuration study for FPD-I broke new ground with the first look at the semi-continuous central cell solenoid design. We developed an attractive, modular approach (from both a commercial-reactor and an experimestal-machine point of view). Further discussion of this concept is contained later in this report.

FPD CHOKE COIL

There are two choke coils in the FPD machine. Their present locations (C83 version) are at $z= \pm 48.00 \mathrm{~m}$, just outside of each end of the centra? cell. The choke coils are solenoids that produce a central axial field of 24 ' (this includes the background field of ahout $1.0 \mathrm{~T}$ ) produced by adjacent coils. These coils are physically constrained to consist of a elear inner bore of $0.3 \mathrm{~m}$ and a winding width of no more than $2.0 \mathrm{~m}$. At this time any additional constraints due to coil supports, service line access, or adjacent coil structure are not defined.

The choke coil is a hybrid design in that it utilizes a resistive insert coil and a superconducting backing coil. This design is necessary because today's $;$.perconductor technology does not permit design of an allsuperconducting coil in which the superconductor has to operate at fields larger than $16 \mathrm{~T}$. 
The FPD resistive insert design was derived from the Mirror Advanced Reactor Study (MARs) ${ }^{2}$ choke coil design. This approach utilizes a spirallymachined disc of high-strength AMZIRC copper to create the coil.

A resistive insert producing 8 ' $T$ on axis is our baseline. This coil has 26 pancakes, each $2.2 \mathrm{~cm}$ wide with $0.1-\mathrm{cm}$ insulation between them. Two pancakes form a basic unit of the coil; they are joined by rivets and dowels at the center. Each pancake has three conductors, and each is machined to carry a soldered-in-place stainless ateel coolant tube (stainless tubing is used to allow high coolant velocities). The tubing spizals down one pancake, crosses over to the other one at the hub, and then spirals out.

The coolant water is routed individualy to each conductor of each first pancake and is then taken away individually from each conductor of the second pancake. This is repeated for all 13 double pancakes. The feasibility of manifolding the coolant lines will be investigated. Three current lead pairs are required. All three conductors are electrically common at the hub. The outer arms of the coil are joined by shear pins so that the tangential load of one conductor arm is reacted by that of its counterpart in the second pancake.

The outer radius of the resistive coil (not counting cooling lines, etc.) is $0.5 \mathrm{~m}$ and its width is $0.6 \mathrm{~m}$. The curzent in each conductor is $33600 \mathrm{~A}$, and the power consumed is $21.6 \mathrm{MW}$. We envision a resistive coil supported by struts from the superconducting backing coil.

Insulating the resistive coil is a problem because of neutron radiation. Organic insulators breakdown under radiation and suitable ceramic insulators are extremely brittle and expensive. The use of anodized metallic strips for electrical insulation is currently under investigation and early test results are encouraging.

Machining of the pancakes is a feasible operation. This fessibility is demonstrated by experience with two tes: pancakes. The electrical dischirge machining (EDM) process was used to cut the spirals and an end mill was used to cut the coolant tube groove. The AMZIRC copper for the test coil was rolled and heat treated to an average yield stress of $57,000 \mathrm{psi}$. There was no evidence of distortion after machining.

The geometry of the resistive insert, including provision for the coolant tubes and any necessary radiation shielding, will define the inner radius of 
the encircling superconducting coil. For an B-T resistive insert, the inner radius of the supercondusting coil is approximateiy $0.85 \mathrm{~m}$. A peak field of approximately $16 \mathrm{~T}+$ can be expected at the inner radius of the superconducting backing coil.

Preliminary calculations indicate that this coil should be cooled with He II and that the superconductor should be $\mathrm{Nb}_{3} \mathrm{Sn}: \mathrm{Ti}$. The conductor should be steel reinforced to withstand the high hoop stresses developed, but its current density will be 1 imited by cryostabitity considerations. The conductor would be graded as the field drops off with radius so that the superconductor could be changed to $\mathrm{Nb}_{3} \mathrm{Sn}$ and then to NbTi.

For economical reasons, we expect that the superconducting coil will be a single unit rathet than having two coils with separate cases. Figure 4-4 shows the $0.42 \mathrm{~m}^{3}$ resistive insert coil and the $16.7 \mathrm{~m}^{3}$ superconducting backing coil.

CENTRAL CELL

CENTRAL CELL MAGNET SYSTEM

The central cell magnet system consists of seven full-size modules. Each module has correction coils to reduce the ripple in the plasma region to an acceptable level.

\section{System Function Summary}

The central cell magnets confine the plasma over its entire length. The length of the central cell is determined by plasma requirements, such as sufficient particle-confinement time to ensure ignition.

\section{Requirement Summary}

The length of the central cell is $70 \mathrm{~m}$. The field required on the plasma axis is $2.5 \mathrm{~T}$, and the magnetic field ripple must be less than 1 . The central cell magnet system must be built from practical length modules. Axial 


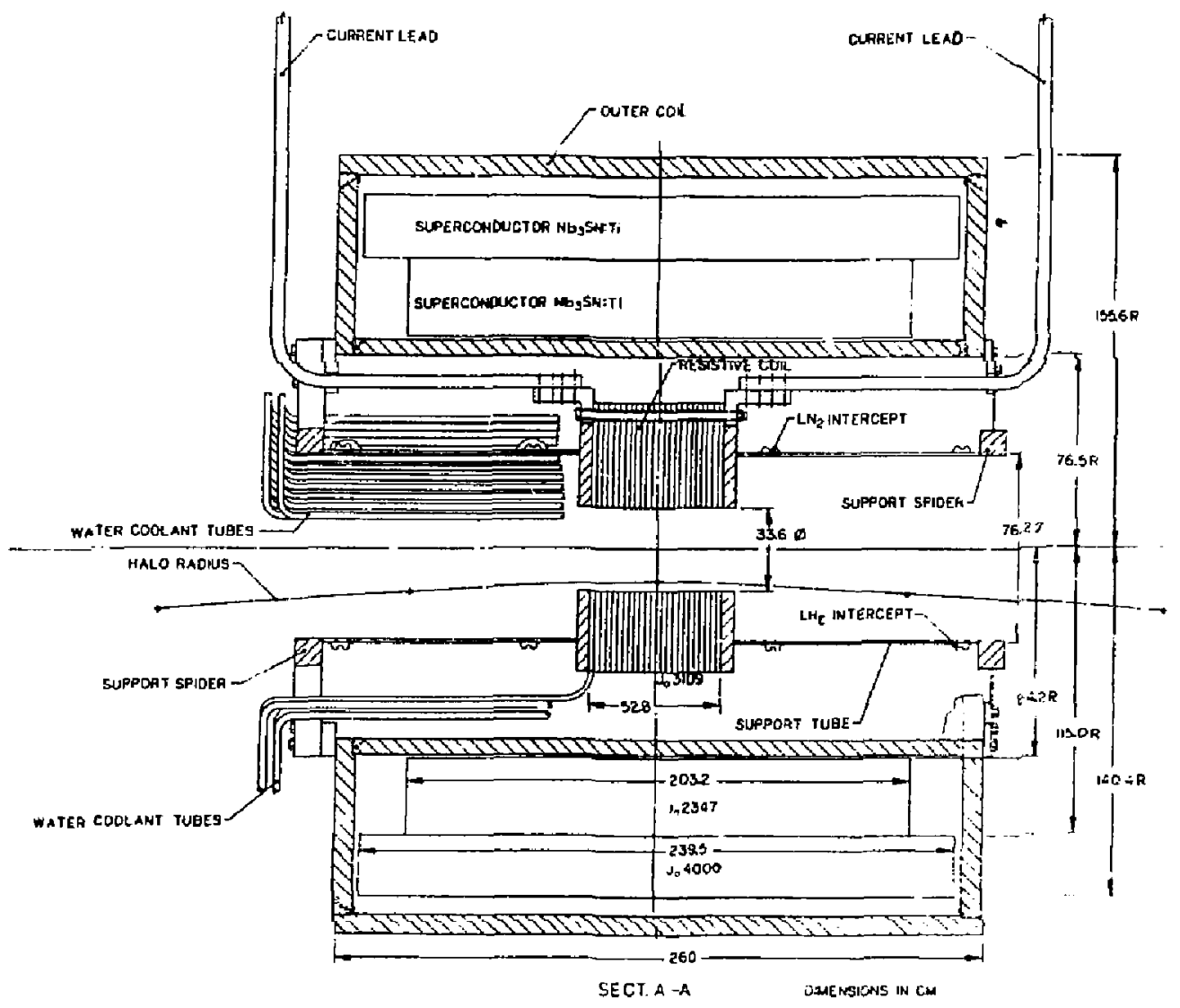

Figure 4-4. The FPD choke coil. 
space must be provided between the adjacent modules to accommodate coolant feed for the nuclear shielding and blanket systems located within the solenoid module. The magnet structure must be adequate to withstand mechanical loads such as magnetic loads, dead weight, 1-g seismic load (externaly and vertically), and operating pressure differentials.

The FPD is required to operate tor is years. During this period, the magners will be energized and de-energized 12,000 times and warmed up 120 times. The magnet structure must be designed to withstand these events.

\section{Magnet Layout}

The central cell magnet wire bundie is shown in Fig. 4-5 along with the key design parameters. Layout of a solenoid module is also shown. The solenoid module is designed to achieve the desired current density of $6000 \mathrm{~A} / \mathrm{cm}^{2}$ at $3 \mathrm{~T}$. The winding design is based on a $\mathrm{Nb}_{3} \mathrm{Sn}$ cable-in-conduit conductar and is cooled with torced-flow helium at $5.7 \mathrm{~K}$. The solenoid winding is a single layer of the force-cooled conductor. An additional layer (40-cm axial length) is introduced at each. end of the solenoid moduje to correct for ripple. The conductor conduit thickness is $6.6 \mathrm{~cm}$, which is four times thicker than the Westinghouse LCP conductor conduit. The thicker conduit is needed to carry the hoop load. It is impractical to fabricate 6.6-cm-wall conduit, but it may be possible to build up the desired wall thickness from 3 to 4 concentric layers. Alternatively, it may be possible to utilize the W-LCP conductor in an "as is" form. In this case, the conductor is cowound with a stainless steel strip for carrying the hoop load. The average heat load in each conductor is $0.12 \mathrm{~mW} / \mathrm{cm}^{3}$. This heat load can be removed by $5 \mathrm{~g} / \mathrm{s}$ of helium flowing through a 10-turn cooling loop. The coil can be safely discharged with $800 \mathrm{~V}$ (peak) without exceeding the hot spat temperature of $280 \mathrm{~K}$.

An alternative design was developed using NbTi conductor in the Mirror Fusion Test Facility-B (MFTF-B) central cell coils. This conductor is cooled with pool-boiling helium. The winding current density achieved with this approach is $3000 \mathrm{~A} / \mathrm{cm}^{2}$ and the winding pack has 11 layers. Stress analysis was performed with STANSOL computer code. It is difficult to control stresses in the conductor unless a stainless steel strip is cowound with the conductor. 

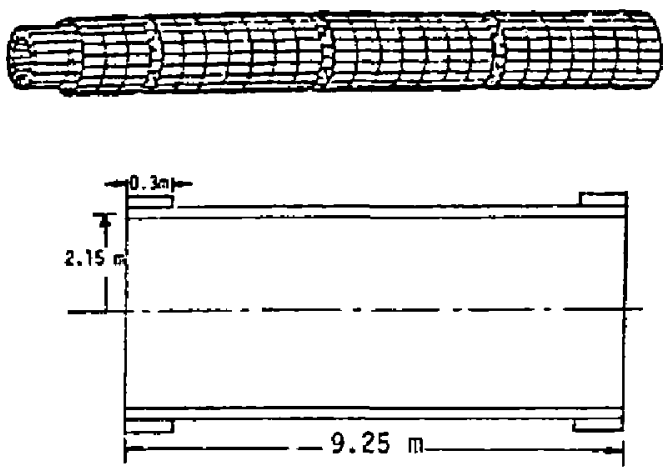

Cenrral cell magnet dimension

Mean magnet radius $(m)$

Axia] length (m)

Module dimensions

Module length $(\mathrm{m})$

Radial build ( $\mathrm{m}$ )

0.06

Axial length of end-compensation zones (m)

0.3

Ampere-turns/module (MA-turns)

18.5

Current densiry, goal $\left(\mathrm{A} / \mathrm{cm}^{2}\right)$

6000

Field on $L$ ía $(T)$

Field at wiuding peak ( $T$ )

2.5

Nuclear heati: peak ( $\mathrm{mW} / \mathrm{cm}^{3}$ )

3.5

Operating current (kA)

1

Energy stored in each module (MJ)

60

Weight $\times 10^{3}(\mathrm{~kg})$

300

40

Figure 4-5. Central cell magnet parameters. 


\section{Conclusions}

We concluded from feasibility studies of two alternative coil designs that a successful coil design can be developed with pool-boiling or forcedElow helium cooling approaches.

SHIELDING AND YACUUM CONTAINMENT

The overall ptoportions of the cylindrical centrat cell are shown in Fig. 4-6. The tocal length is approximately $74 \mathrm{~m}$, and the outside diameter is $9.4 \mathrm{~m}$. The shielding and vacuum containment consist of two basic components: the wit shield to protect the coil from nuclear heating and the biblogical shieli for human protection, which is integral with the vaculm vessel.

The central cell is divided into eight modules. The six A modules are $10 \mathrm{~mm}$ in length. The two $B$ modules, one at each extreme end of the central cell, are slightly aver $5 \mathrm{~mm}$ in length. A typical radial composition of a module is shown in Fig. 4-2. Starting at the outside and moving inward, the first cylindrical layer is the integral vacuum ressel ald biological shield. Next is the solenoid magnet, then the magnet shield, and finally the blanket/ reflector region.

\section{Tacuum Vessel/hiological Shield}

The integral vacuum vessel/viological shield consists of twu "oncentric stainless stee:, cylindrical shells. The outer diameter is $9.4 \mathrm{~m}$ arid the innor shel" diameter is 7.0 m. The double-walled siracture is ctif "ened with Eour bulkherds and eight langitudinal wabs. The region betwecn che shells is Eilled with water. The inner shell actually serves as the vacuum boundary.

To complete the shield, a $5-\mathrm{cm}$ layer of $\mathrm{B}_{4} \mathrm{C}$ with an additional $\mathrm{cm}$ of lead, is attached to the outside of the outer vessel well. The $B_{4} C \mathrm{i}$; packaged in stainless steel cuntainers, and the shield $F$ : irmance is based on the composition of the rilled container ( $40 \%$ stainless ster. and $60 \% \mathrm{~B}_{4} \mathrm{C}$ at 70\% density). 


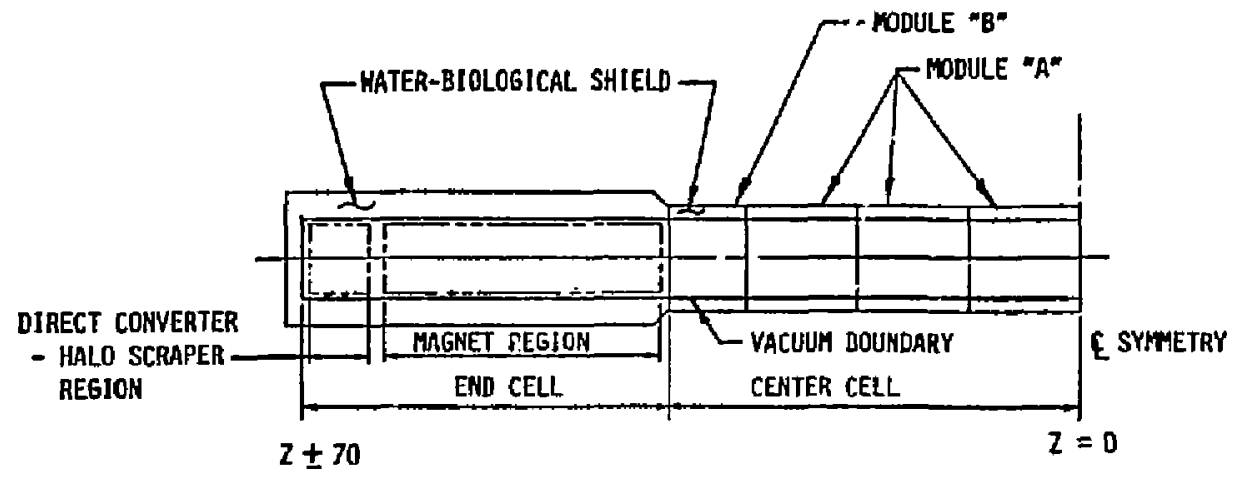

IN igure 4-6. 'The FPD-I vacuum vessel and shield' regions. 
Figure 4-7 illustrates the manner in which the biological shield/vacuum vessel is integrated with some of the other module components. Because the blanket is divided into two pares, a $\mathrm{Li}_{17} \mathrm{~Pb}_{83}$ ( $\mathrm{LiPb}$ ) inlet and outlet manifold are located near each end of the module. The Lipb enters the module at the top and flows out the bottom. Because the point at which the LiPb enters the blanket is at the extreme end, a potential neutron streaming path exists at the end of each module. This path is blocked in the assembly of the modules by removable water-shield plugs and an inner, steel/water shield plug, covering $180^{\circ}$ of the gap between modules.

\section{Magnet Shield}

The solenoidal sheath magnet is protected from nuclear heating by an inner cylindrical steel/water shield (see Fig. 4-7). This shield is $75-\mathrm{cm}$ thick and consists of $80 \%$ utainless steel and $20 \%$ water. In addition, a 5-m-thick layer of $\mathrm{B}_{4} \mathrm{C}$ is placed at the other periphery of the steel/water shield.

The magnet shield serves also as a structural member to which the blanket segments are attached and is the support fo. the magnet itself. The support struts are illustrated in Fig. 4-8.

SUPPORT STRUCTURF.

Each central cell module is supported by a set of four legs (Fig. 4-2) attached to the outer shell of the vacuum vessel/biological shield. The legs, which are in line witw bulkheads that connect the inner and outer shells, (Fig. 4-2) transmit all loads ro reinforced concrete piers (Fig. 4-9).

\section{END CELL MAGNETS}

The end cell magnet system consists of two transition ( $T$ ), two plug (P), and two anchor (A) type coils. A $r$ treularizing coil is also needed as shown in the FPD-Il configuration ( $i$ ig. 5-22 in Sec. 5). Ail c coils in the end cell region are similar in size and ampere-turn requirements. A summary of various coil dimensions and their ampere-turns is given in Table 4-l. 


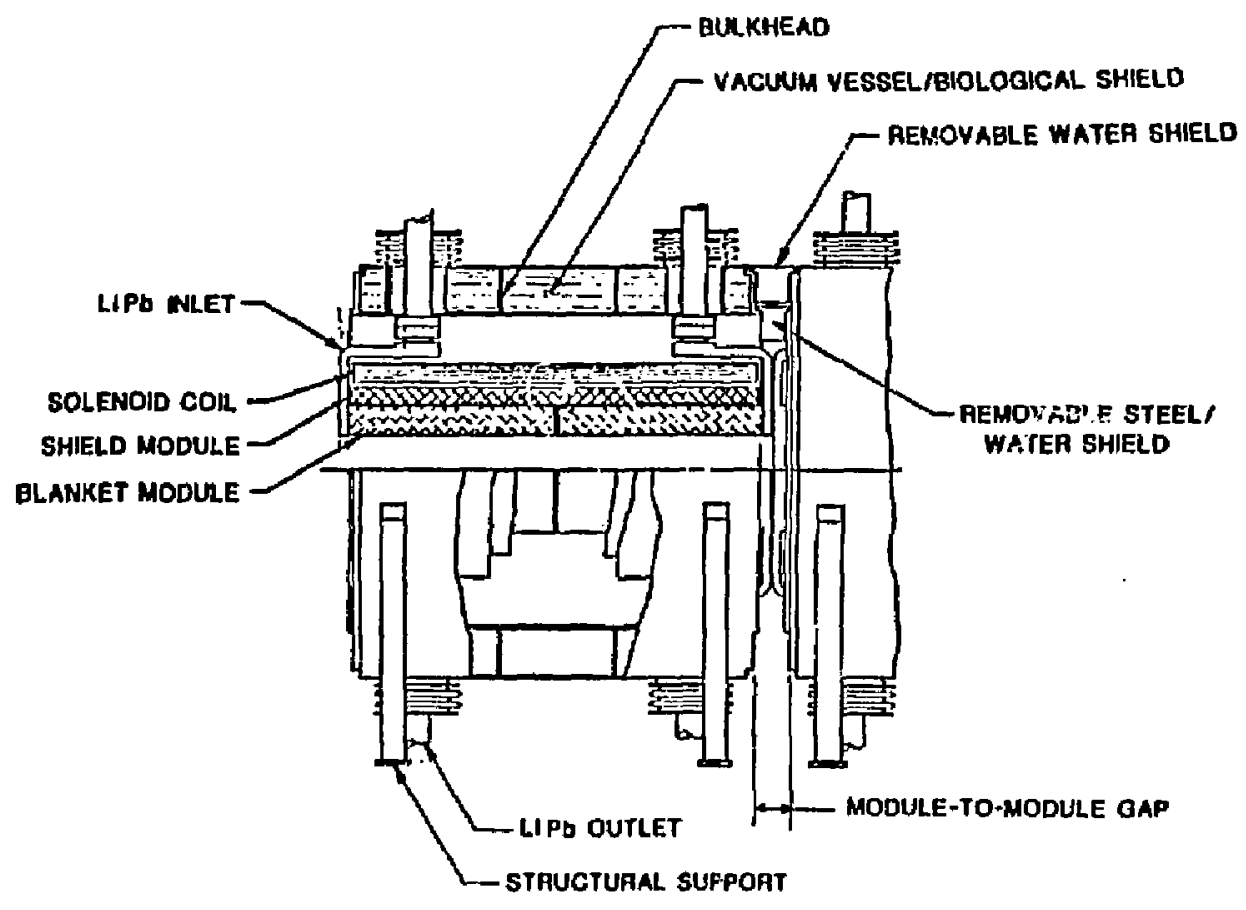

Figure 4.7. The FPD-I central cell module. 


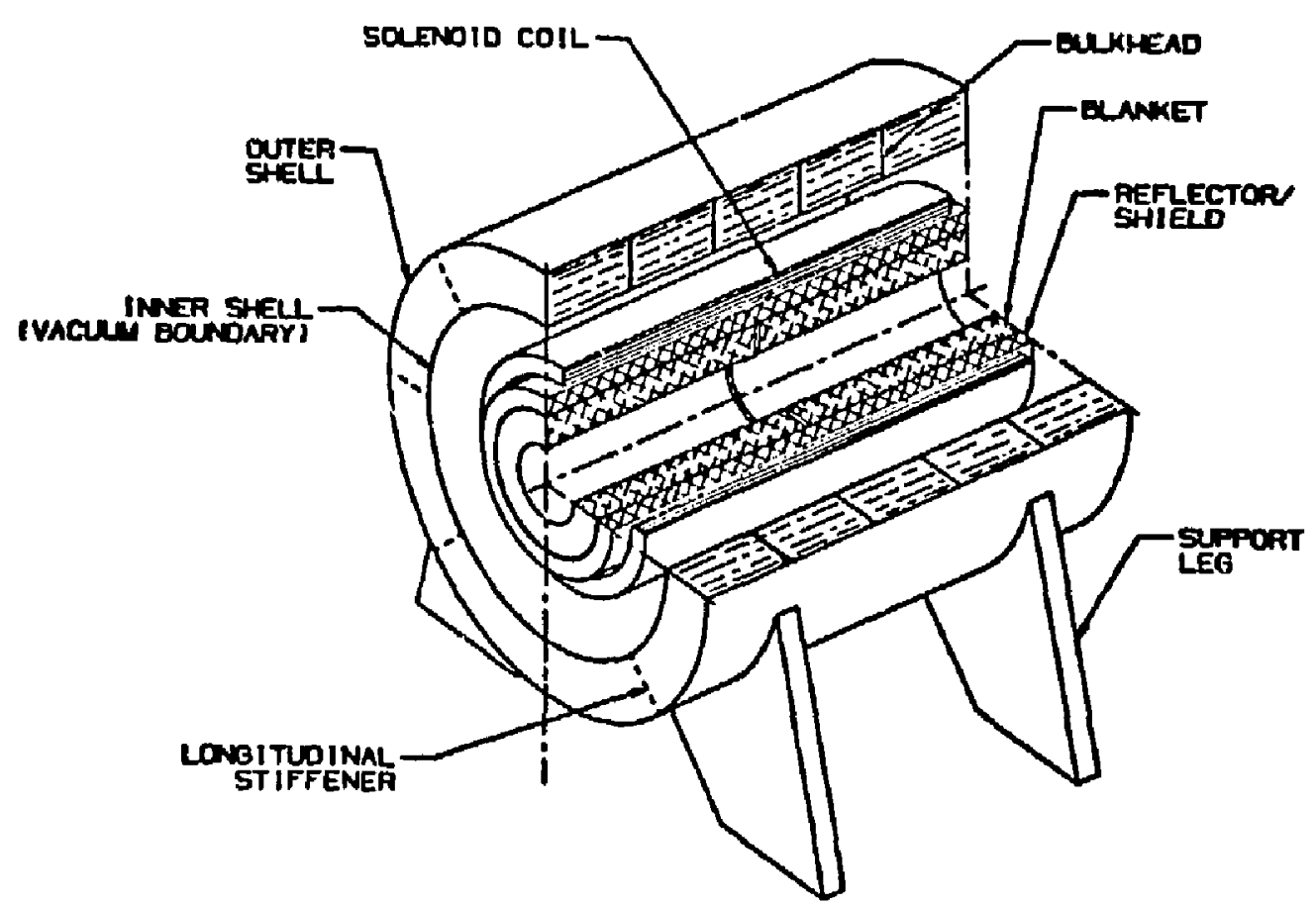

Figure 4-8. Typical FPD-I central cell moduie. 


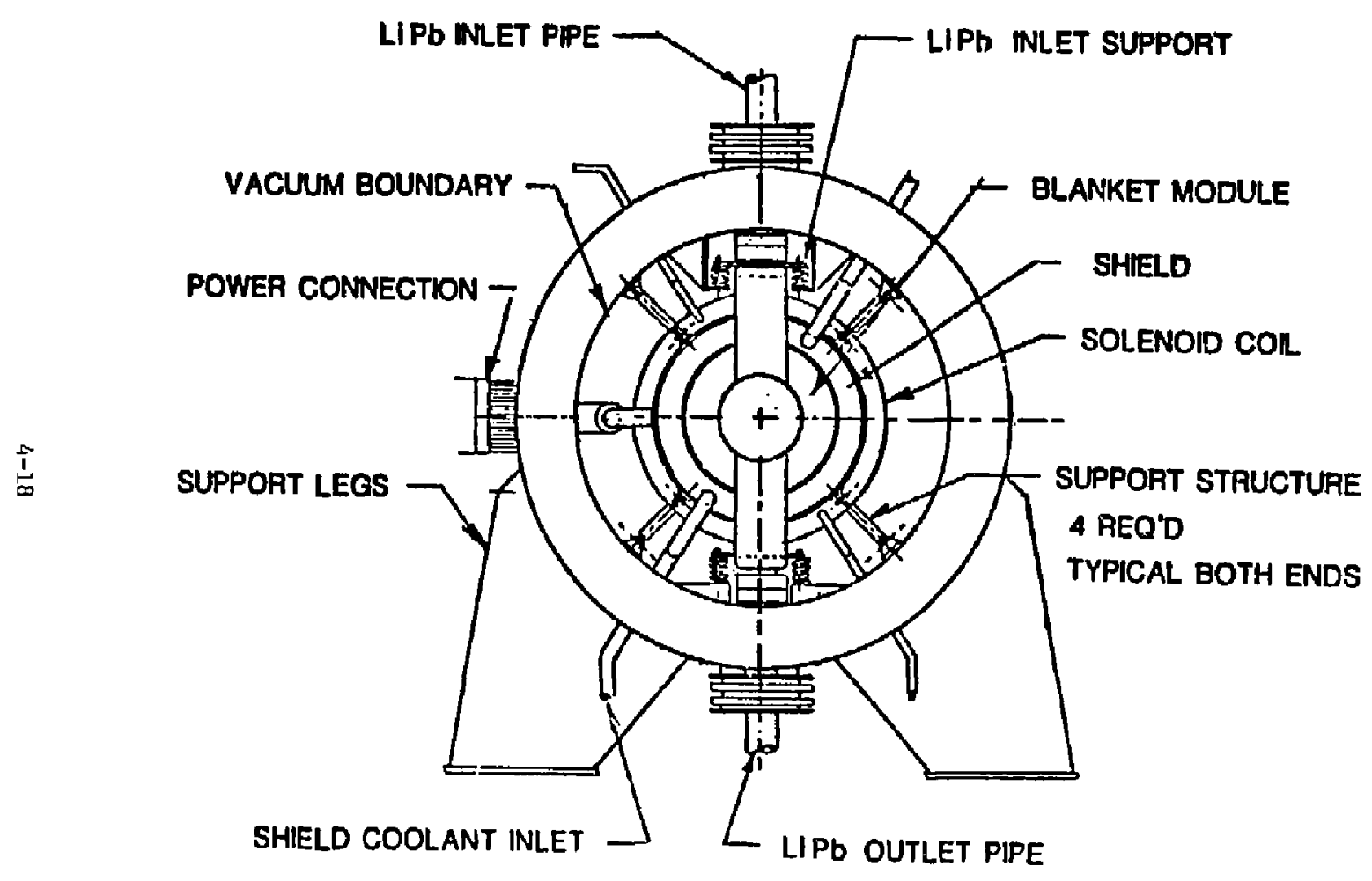

Figure: -4 . End view of the FPD-1 central cell module. 
Table 4-1. Main parameters of end-cell coils for FPD.

\begin{tabular}{|c|c|c|c|c|}
\hline Coils/parameters & $\mathrm{TI}$ & $A 2 / A 1$ & P2/P1 & $\mathrm{T} 2$ \\
\hline Axial location $(m)$ & 40.0 & $46.2 / 44.3$ & $53.6 / 51.4$ & 59.5 \\
\hline Mojor/minor radii (m) & $1.5 / 0.8$ & $1.5 / 0.8$ & $2.25 / 0.8$ & $2.25 / 0.8$ \\
\hline Sweep angle (deg) & 75 & 75 & $61.5 / 75$ & 61.5 \\
\hline Winding dimensions $\mathrm{s} 1 / \mathrm{S} 2$ (m) & $1.2 / 0.3$ & $1.2 / 0.3$ & $1.2 / 0.3$ & $1.2 / 0.3$ \\
\hline Coil current (MAT) & 33.37 & 11.37 & 13.78 & 13.78 \\
\hline Winding current density $\left(\mathrm{A} / \mathrm{cm}^{2}\right)$ & 3158 & 3158 & 3828 & 3828 \\
\hline Peak fjicld on the axis (T) & 6.0 & 6.3 & 7.5 & 7.5 \\
\hline Peak field at the coils (T) & 8.2 & 8.2 & 9.7 & 9.5 \\
\hline
\end{tabular}

In general, the generic end-cell C coil and recircularizing coil requirements for FPD-I and FPD-II are similar, The coils employ the same type of conductor winding and structural supports, Even the fabrication/ manufacturing problems are similar.

The FPD-IT and-cell magnet set with slightly higher fields ard current densities, but smaller winding pack, represents an evolution of the FPD-I design. C-coil design concepts are discussed below.

\section{System Function Summery.}

The magnet system is sized and arranged to provide the on-axis magnetic field required for plasma performance. In addition, the end cells plug the machine and provide MHD stability.

\section{Requirement Summary}

On-Axis Field. The axial fietd profile in the end-cell region is shown in Fig. 4-10. The maximum center-line field in the end cell is $7.50 \mathrm{~T}$ at $\pm 56 \mathrm{~m}$. The minimum center-1ine field in the end cell is approximately $1.9 \mathrm{~T}$ at $\pm 52.5 \mathrm{~m}$. 
0.00
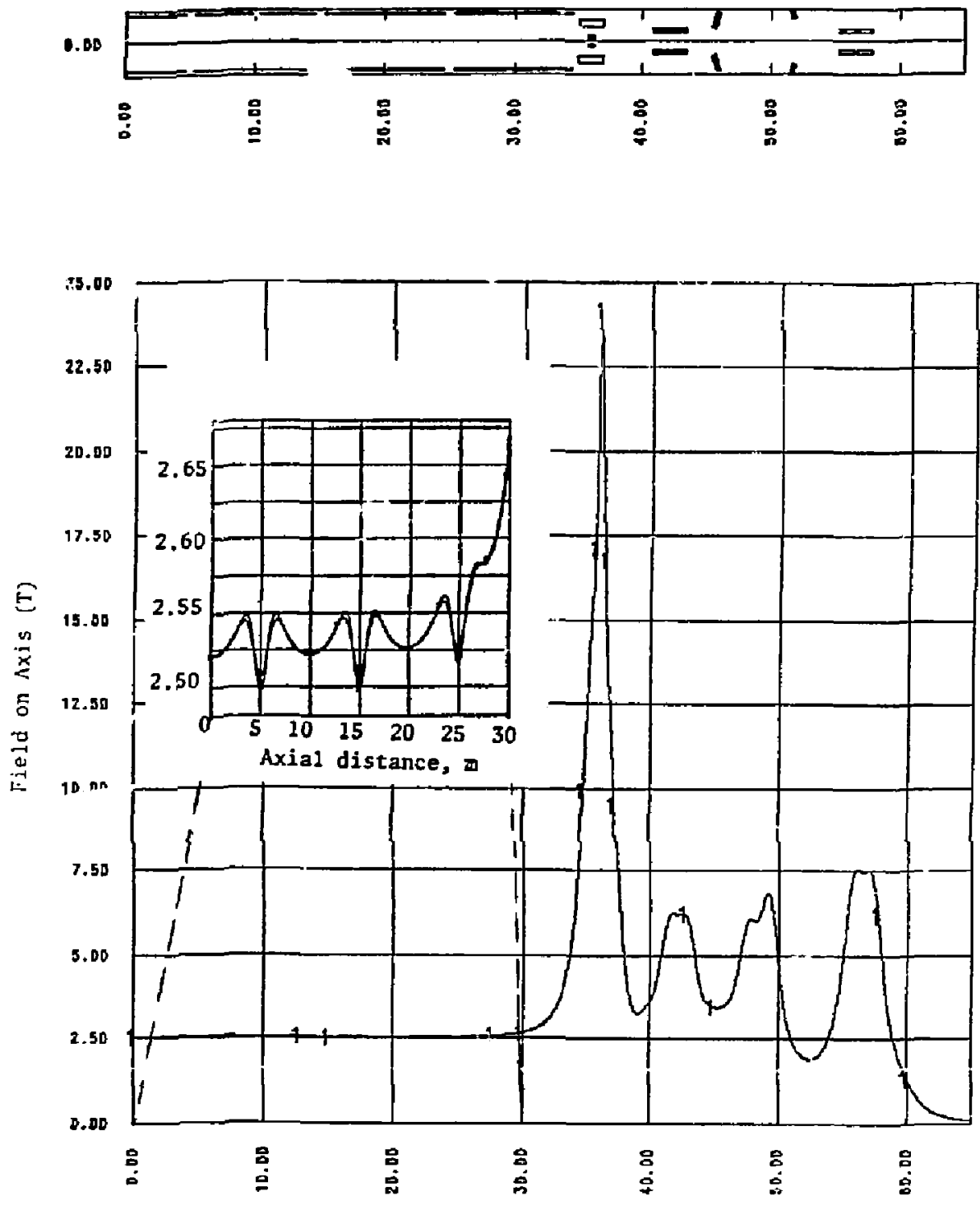

Figure 4-10. Field profi?" "1 ng z-axis. 


\section{Magnet Configuration and Design}

The configuration for the FPD-I end cell is shown in Fig. 4-11. Locations, dimensions, currents, current densities, and fields associated with this configuration are shown in Table 4-1. This conceptual coil set meets the requirements summarized above. Specifics of conductor, structure, winding approach, and fabrication as noted above are basically the same for FPD-I and FPD-II c coils. These items are discussed in Sec. 5.

\section{PLASMA HEATING SYSTEHS}

The FPD I design is of the MARS tandem mirror configuration; consequently, the required end cell heating systems are similar to those for the MARS reactor, ${ }^{2}$ and the subsequent MFTF- $\alpha+T$ device. ${ }^{1}$ The ICRH is used to maintain high beta in the anchor cell, ensuring overall device stability. In the plug, a high energy negative-ion-based neutral beam (NINB) creates the sloshing ion distribution that provides microstability and contributes to the existence of the central-cell ion-confining potential peak. Also in the plug are two electron cyclotron resonant heating (ECRH) systems: one produces the thermal barrier that isolates central cell electrons from those in the potential peak region and the other system enhances the magnitude of the potential peak. Table 4-2 sumarizes the heating systems' requirements. The sloshing beam trapping fraction is calculated in the tandem mirror reactor physics code (TMRBAR), whereas the remaining trapping fractions are educated guesses.

\section{ECRH Systems}

Two ECRH systems operate in the piug region. The thermal barrier system at point $b$ is the highest power heating system and has the largest impact on the overa11 plug configuration. At $19 \mathrm{MW}$, an ECRH system based on current $>200-k w$ gyrotrons and low efficiency transmission systems would be awkward and expensive. Hence as in MARS, ${ }^{2}$ but on a more conservative note, I MW gyrotrons in the $30-$ to $60-\mathrm{GHz}$ frequency range are assumed to be available in the FPD time frame. Because no beam recovery is expected in the conventional 

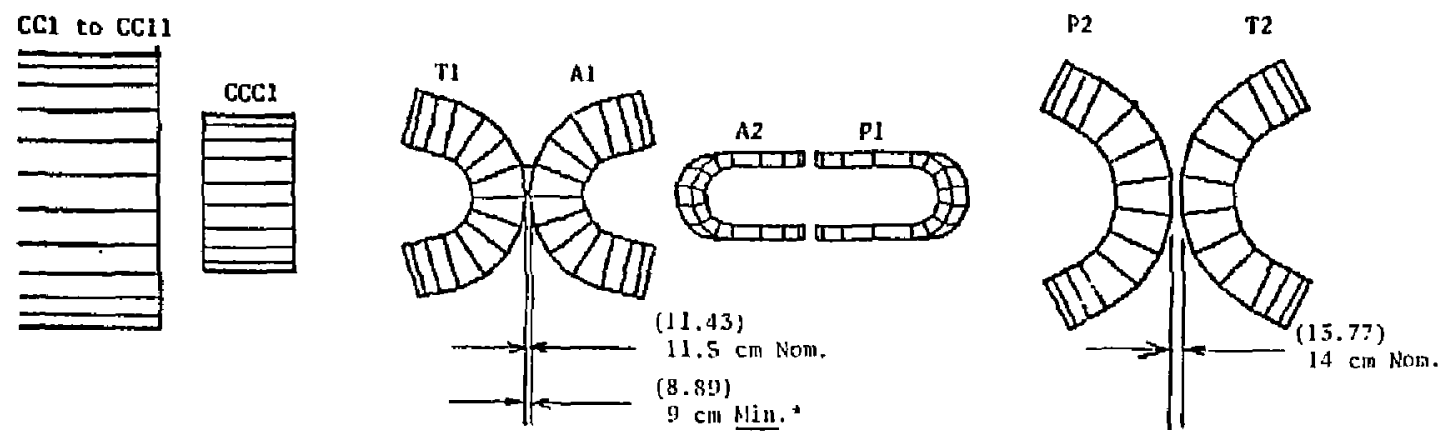

1. Case thicknesses based on

plate bending only (no burking

defiection or stress concentrations

included)

2. Assunes cases touch or are combeted

\section{CCl to CC11}
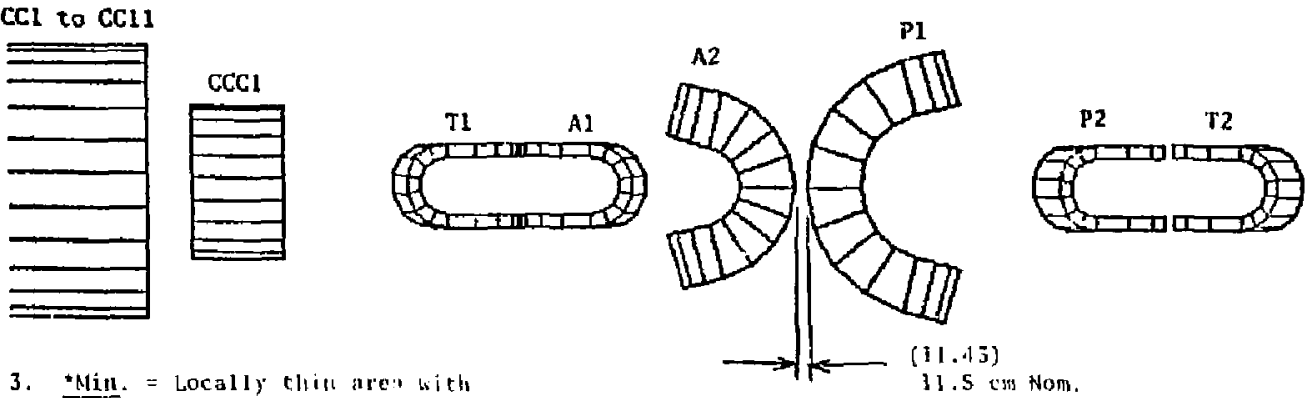

3. Min. = Locally thin anes with additional stiffoling betweis coils

Figure 4-11. The FPD-I end-cell configuratfon. 
Table 4-2. The FPD-I heating system requirements,

\begin{tabular}{|c|c|c|c|c|}
\hline & $\begin{array}{l}\text { Anchor } \\
\text { ICRH }\end{array}$ & $\begin{array}{l}\text { Sloshing } \\
\text { NINB }\end{array}$ & $\begin{array}{l}\text { Potential } \\
\text { peak } \\
\text { ECRH }\end{array}$ & $\begin{array}{c}\text { Thermal } \\
\text { barrier } \\
\text { ECrH }\end{array}$ \\
\hline Seating point & -- & $a^{\prime}$ & $\mathbf{a}$ & b \\
\hline Location, $z(m)$ & $\begin{array}{l} \pm 43.65 \\
\pm 46.90\end{array}$ & \pm 50.0 & \pm 53.9 & \pm 52.55 \\
\hline Absorbed power (MW) & 2.0 & 0.44 & 0.83 & 16.2 \\
\hline Trapping fraction & 0.60 & 0.27 & 0.85 & 0.85 \\
\hline Delivered powet (MW) & 3.5 & 1.64 & 1.0 & 19.0 \\
\hline Vacuum frequency $(\mathrm{Hz})$ & $71.0 \times 10^{6}$ & -- & $72.8 \times 10^{9}$ & $56.0 \times 10^{9}$ \\
\hline Heating frequency $(\mathrm{Hz})$ & $54.0 \times 10^{6}$ & -- & $56.0 \times 10^{9}$ & $35.0 \times 10^{9}$ \\
\hline Delivered current ( $A$ ) & -- & 3.5 & -- & -- \\
\hline Beam energy (keV) & +- & 475 & -- & 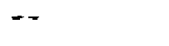 \\
\hline $\begin{array}{l}\text { Injection angle } \\
(1 \text { to z-axis })\end{array}$ & $\rightarrow$ & $30^{\circ}$ & -- & -- \\
\hline
\end{tabular}

closed-cavity gyrotron, we assume gyrotron efficiencies between 45 and $50 \%$. To scope the transmission system and its efficiency, we also assume a $\left[E_{02}\right.$ output mode. These assumptions are justified based on current developmental program results and trends. The thermal barrier system, therefore, utilizes I-MW tubes, whereas the potential peak system needs only $678-\mathrm{kW}$ sources.

Technically, l-MW power levels are achievable in 2-1/2-in. waveguides, but only at high pressures of sulfur hexafluoride. Windows then become an issue, especially in a fusion neutron envirument. To eliminate windows and increase efficiencies, a vacuum quasi-optical transmission system has been utilized. Table 4-3 summarizes che ECRH systems configuration and key parameters.

At $35 \mathrm{GHz}$, the divergence angle of a quasi-optical beam is significant; to 1 imit the beam size through the magnet region and at the plasma, an of fset dual mode horn with paraboli: reflector is used (see Fig. 4-12). The apex of 
Tab]e 4-3, The ECRH system summary.

- ECRH configuration

One ECRH transport systen at each end for the point "a" ECRH system; two beam launchers per system (one operating/one redundant)

Two iCRH transport systems at each end for the point "b" ECRH system; seven beam launchers to system (6 operatingl) tedundant?

- The ac/de converzion is accomplished by two 30-MW ac/dc converter/transformers with one at each end of the device

Efficiency: $\quad 98 \%$

- The l-MW gyrotrons have a regulated (modulator/regulator tube) cathode voltage of $80 \mathrm{kV}$

Efficiency of modulator/regulator: $96 \%$

Gyrotion rf-to-beam conversion efficiency: $45 \%$

- The gyrotron-launcher interface is an evacuaced circular waveguide section with mode converters to properly prepare the wave mode for the launcher

Effjeiency: $\quad 76.8 \%$

- Offset dual mode conical horn/parabolic reflector beam launcher

Efficiency: $96 \%$ (includes beam scrapeaff loss)

- Total system parameters

Efficiency: $\quad 32.5 \%$

LHe requitements (for gyrotrons): $26 \mathrm{~h} / \mathrm{hr}$

$\mathrm{LN}_{2}$ requirements (for byzotrons): $13 \mathrm{l} / \mathrm{hr}$

Cooling water requirements: 12,500 gpm 


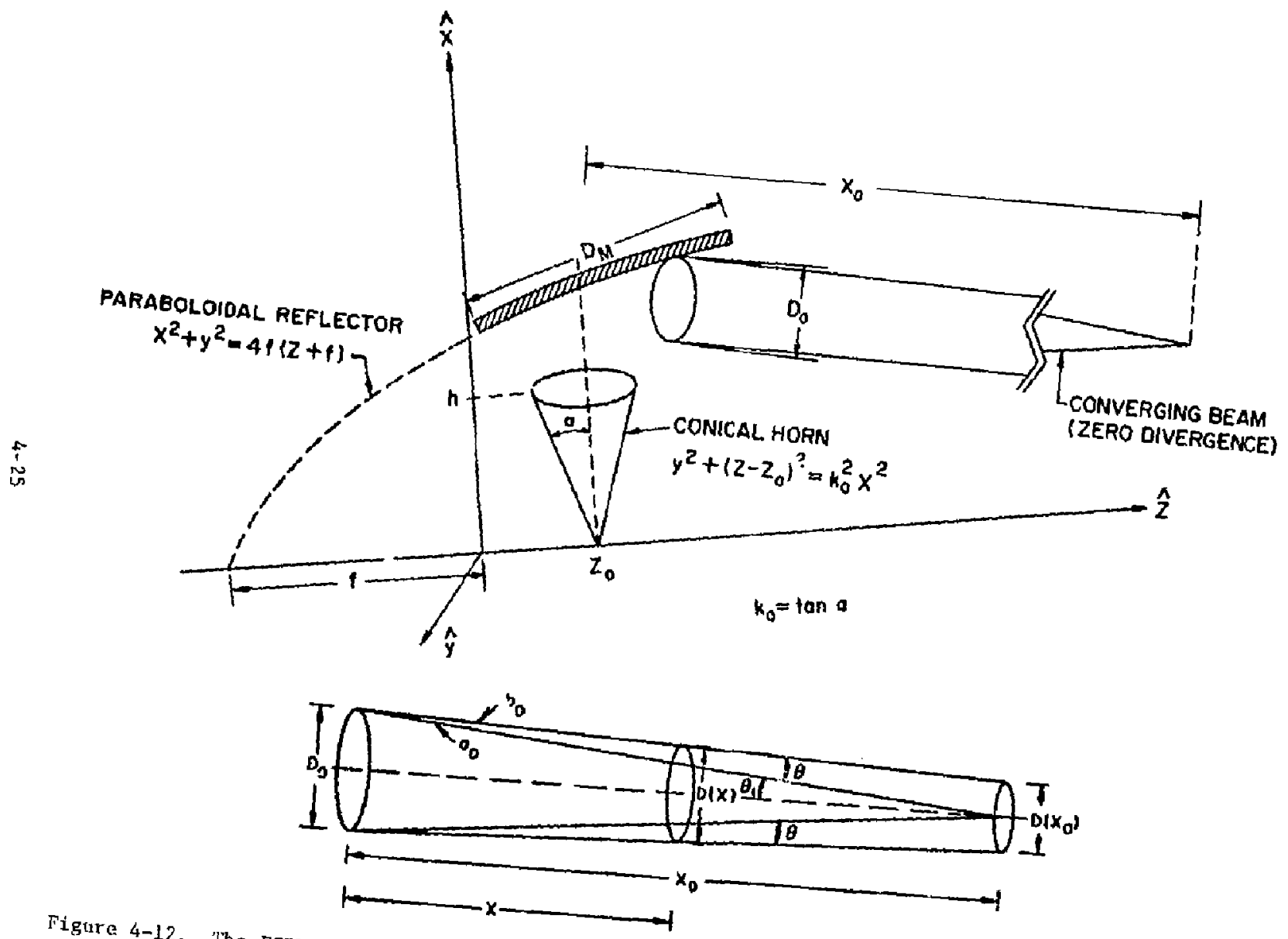

Figure 4-12, The ECHH beam Iauncher geonetry. 
tris horn does not lie at the tocal point of the reflector; the bean is thus focused. The launcher parameters for both ECRH systems are listed in Tabje : -4 and a block diagram of the waveguide section, an interface hetween the gyrotron and launcher, is shown in Fig. 4-13.

The integration of the ECRH systems into the plug is depicted in

Fig. 4-14 and the overall power flow is shown in Fig. 4-15.

Table 4-4. The ECRH launcher characteristics.

At "a"
$\begin{aligned} & \text { Hofset } \\ & \text { conical parabolic "b" }\end{aligned}$

Conical angle, $\alpha$ (deg)

Cone height, $\mathrm{h}(\mathrm{cm})$

Faraboloid focal length, $f(\mathrm{~cm})$

Mirror diameter, $\mathrm{D}_{\mathrm{m}}(\mathrm{cm})$

Initial beam diameter, $D_{0}(\mathrm{~cm})$

Distance from beam focal point, $x_{0}(\mathrm{~cm})$

Distance to magnets, $x(\mathrm{~m})$

Maximum beam diameter in magnet

$$
\text { region, } D(X)(\mathrm{cm})
$$

Eeam diameter at plasma (cm)

Number of ECRH launchers/end

Number of beam launchers/ECR! launcher

Launcher transmission efficiency

(includes $2 \%$ scrapeoff loss) ( $\%$ )
17

54.7

68.2

35.5

43.73

70.0

85.0

49.3

62.4

9.5

27.5

24.0

27.0

14

17

]

2

2

7

96

96 


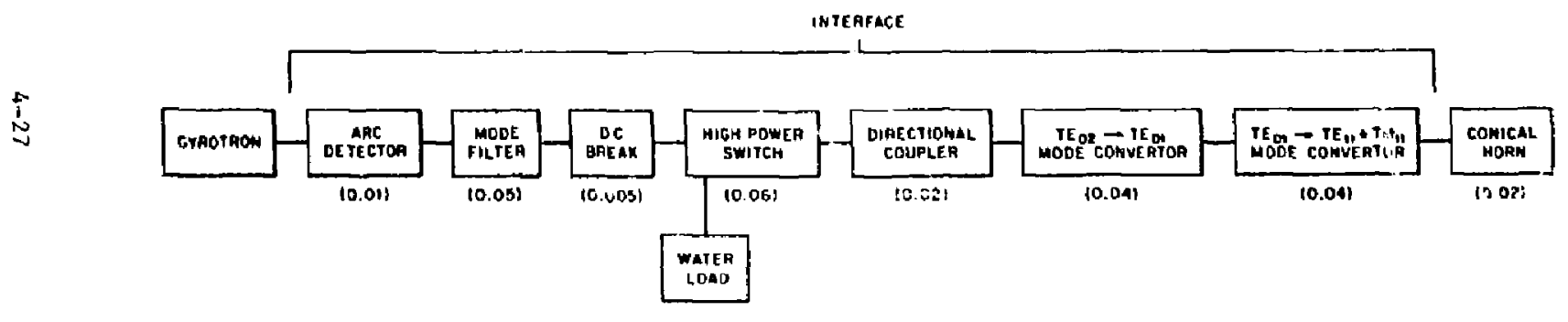

Figure 4-13. The ECRH gyrotron quast-optical launcher interface, The values in parenthesis denote fractlonal power loss. 


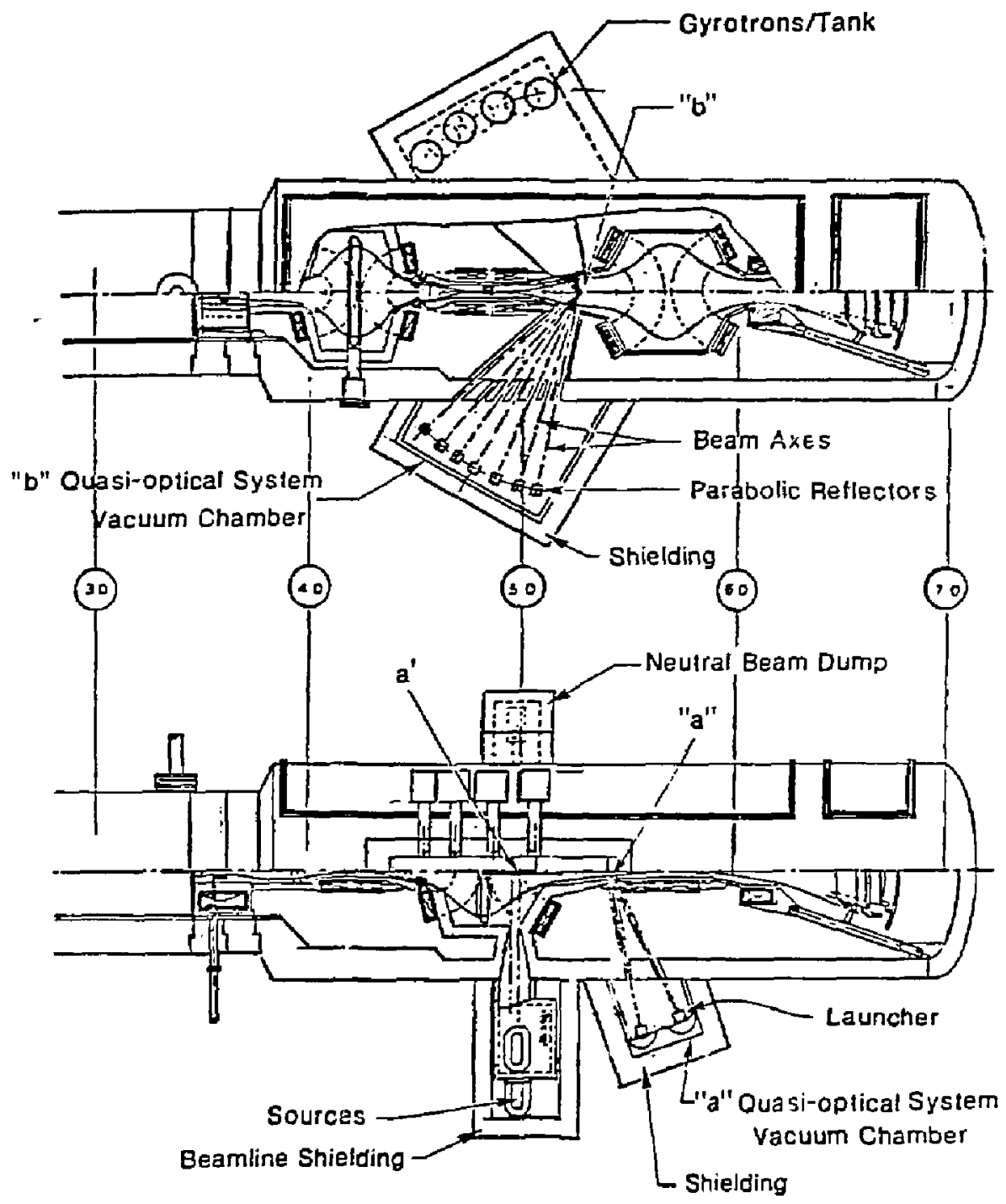

S:

Figure 4-14. The ECRH transport system configurations in the plug region. 


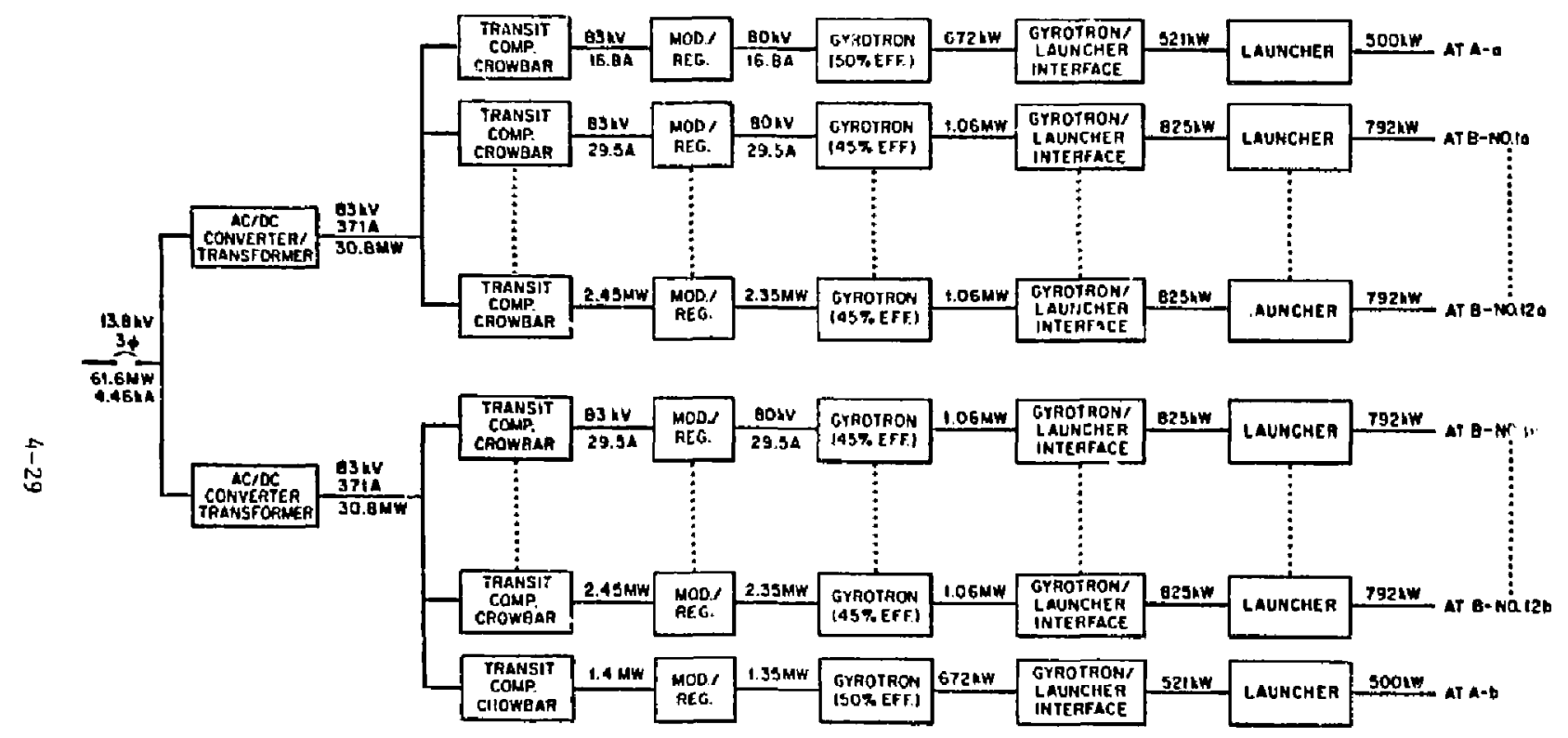

Figure $:-15$. The FPD-I ECRH system power flow. 
The anchor ICRH system must deliver $1.75 \mathrm{MW}$ to each end cell at $54 \mathrm{MHz}$. with the exception of waveguide vs loop antenna selection for the launcher, the FPD I anchor ICRH system is considered conventional for plasma heating. applications. At $54 \mathrm{MHz}$, the width of a ridged-waveguide that is expected to couple well to the plasma is slightly greater than $1.6 \mathrm{~m}$; the plasma boundary changes drastically in the anchor yin-yang magnet pair uver this length. To align the waveguite mouth parallel to the plasma surface within the geometry constraints of the region, one of a number of waveguide distortions are required (e.g., bends or oblique cuts of the face of the guide). Heating at higher harmonics decreases the waveguide size, but fourth or fifth harmonics are required oefore the contortions can be eliminated or become tolerable. At the high ion temperature, this scenario may be plausible, but much analysis will be required before a decision of this sort can be made. We have thus opted for a loop antenna.

The description and expected performance of the system are summarized in Fig- 4-16 and the following:

- Configuration:

Four 1iunchers per anchor ( 2 operating/ 2 redundant)

- Launcher: Center-fed.loop antenna with Faraday shield Antenna power: $875 \mathrm{~kW}$

Efficiency: $95 \%$

- Transmission System:

Mainiy 6-1/8-in. $50 \Omega$ coax, taper down to 3-in. before entering minor radius gap

3-stub turning system

Efficiency: $84.7 \%$

Coolant loops:

No. 1: tauncher and back to stub tuner

20 gpm while operat ${ }^{\circ} \mathrm{g}$

$7 \mathrm{gpm}$ while not operating

No. 2: Remainder--8.5 gpm 
ABSORBED POWER: 2 MW

TRAPPING FRACTION: 0.6

DELIVERED POWER: $3.5 \mathrm{MW}$

$B_{R, V A C}: 4.65 \mathrm{~T}$

$B_{R}: 3.56 T$

HEATING FREQUENCY: $54 \mathrm{MHZ}$

LAUNCHER: LOOP ANTENNAS 2/2 PER END

Transmission Line: $\quad 61 / 8^{n}-50 \Omega$ CoAx 心

Transmitter: Multi-stage chains EFFiciency: $53.5 \%$

Figure 4-16. Ion-cyclotron resonant heating (ICRH) system summary description.

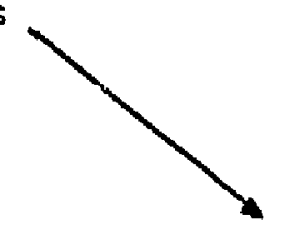

$1 / 8^{\prime \prime}-31 / \mathrm{B}^{\prime \prime}$ Taper
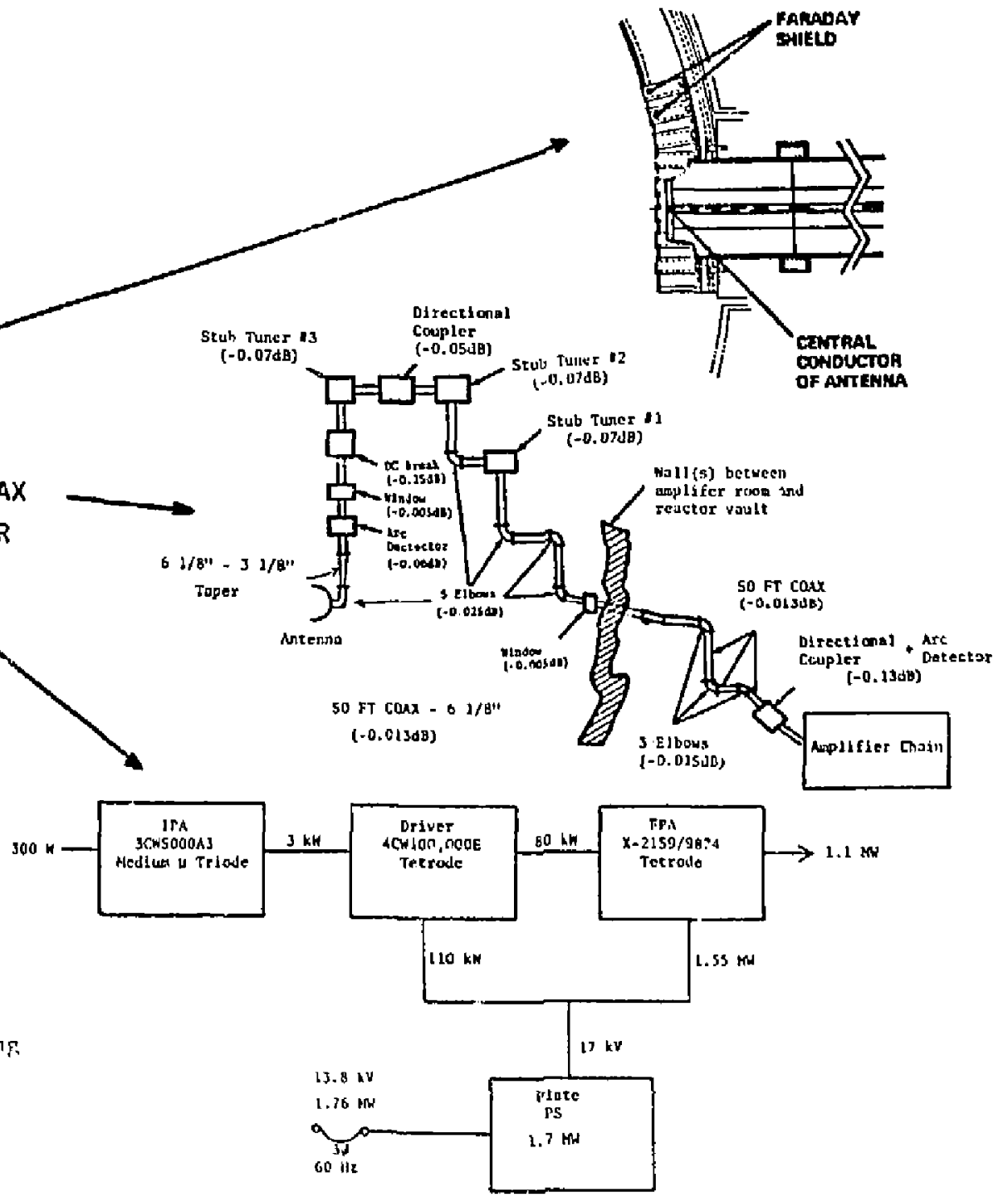


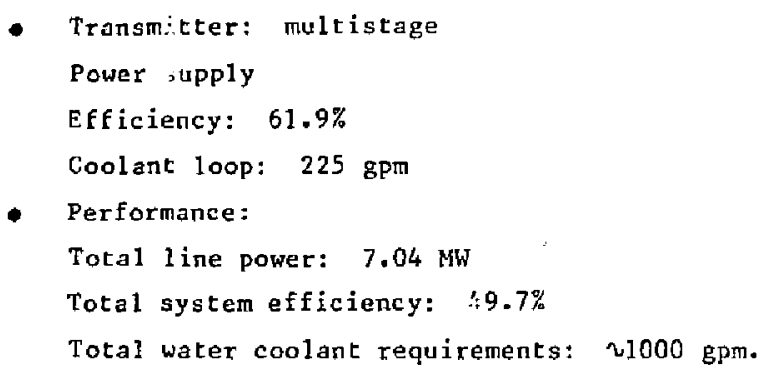

Note that the power lyandling capability of the antenna corresponds to current experimental levels and is below that which could be expected in the FPD time frame. This result was not a result of conservatism, but arose because the 1.75-MW line requires a more complex and less efficient amplifier chain and consequencly was a more costly system than one with two 875-kW 1 ines.

\section{Sloshing Negative-Ion Neutral-Beam (NINB) System}

Each plug has one beamline that delivers $1.75 \mathrm{~A}$ at $\$ 75 \mathrm{keV}$ of deuterium. The technology assessment and development required for this system have been well documented elsewhere and will not be repeated here. 3 The basic system consists of a self-extraction source with an 80-kV pre-accelerator, a transverse field focusing (TFF) transport and high voltage accelerator system, a gas neutralizer, and an ion-bending magnet and dumps, all contained in a vacuum vessel surrounded by magnetic shielding. The soutces are similar to the current Lawrence Berkeley Laboratory (LBL) sources except for an if plasma generator (vs filaments) and forced cesium diffusion from the back of the converiot plate (rather than a CS jet) to enable steady-state operation. The current level per meter is below both present source capability and future expected levels. The TFF concept is currently under development at LBI with a proof-of-principle experiment expected later this year. Since FPD is more near term tian a MARS scale device, ${ }^{2}$ a more conservative; i.e., lower power, laser gystem was assumed available than for MARs, resulting in roughly the same 60\% neutralization efficiency as for a gas neutralizer. Because of the low delivered current (power) requirement, similar neutralization efficiencies, 
and because the laser costs are greater than those associated with the increased gas load of a gas neutralizer, the gas neutralizer was chosen.

Figure 4-17 shows the beamline in context to the end plug configuration, whereas Table 4-5 and Figs. 4-18 and 4-19 describe the system to the next level of detail. Figure $4-20$ is a power flow diagram for a beamline. The beamline power and current efficiencies are $43 \%$ and $41.9 \%$, respectively; the fact that most of the current is lost at low energy is partially offset by the lower polver supply efficiencies at the higher voltages.

DRIFT PUIMPING

Requirements

There are two points in the t... zel] where drift pumping is required: the transition and plug cells. Drift pumping is accomplished ly perturbing the geodesic curvature of the end cell's magnetic field. This eninances the radial drift. Table 4-6 shows the detailed requirements of this perturbation field for the transition and plug cell. The frequency is the center of the frequency spectrum, whereas $\Delta f$ is the spectral widtn either in percent of center frequency or in $\mathrm{kHz}$. The modulation doe not have ta be discrete tones (12 or 110$)$, but tones are probably the easiest to implement because of the broad specrum required. Pinally, there is the specification of the perturbation flux in webers. If a coil configuratirn is assumed, in this case a MARS-like coil, then the circulating power requixed to create this illux can be calculated. Because the coil operates in close proximity to the shield surfaces, eddy currents are expected. These were calculated on the MFTF- $\alpha+T$ project and are determined here by scaling.

\section{Configuration}

Arrangements of power amplifier chains with each chain passing one or more frequencies, are planned. These channels feed a pair of drift pump coils (one on each side of the plasma), which are connected in series. The output 


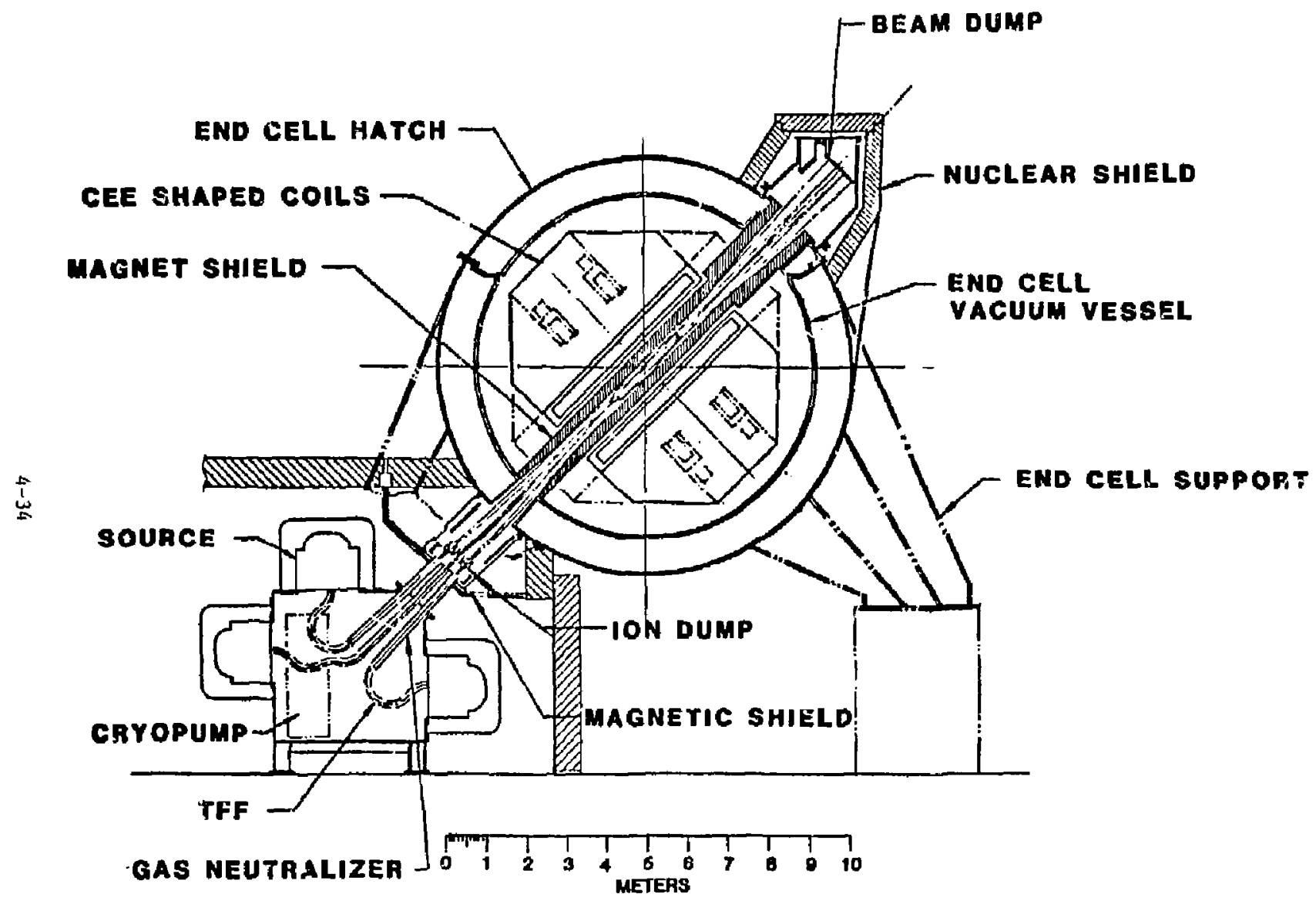

Figure 4-17. The 475-keV NINB configuration (sloshing beam). 
Table 4-5. The NINB system summary description.

- Configuration:

One beamline" per plug;

Three sources per beamline ( 2 operating/1 redundant).

u 2.1-A. LBL-type self-extraction source at $-475 \mathrm{kV}, 2 \times 50 \mathrm{~cm}^{2}$ ribbon beam:

RF plasma generator in magnetic multipole bucket containment;

Forced cesium diffusion chrough converter plate;

Sma1 transverse magnetic fields to divert electrons;

- Standatd 80-kv single-slot preaccelerator;

Gas efficiency: $12 \%+$ gas flow: $3.1 \mathrm{~T} \% / \mathrm{s}$.

o The TFF cransport and high voltage accelerator:

80-kV CFF transport section (LEBT) at $-395 \mathrm{kV}$ with multistage

differential pumping $+7.5 \mathrm{~m}^{2}$ cryopumps;

Four stage TFF high voltage accelerator $(-305 \mathrm{kV},-220 \mathrm{kV},-135 \mathrm{kV}$,

$-50 \mathrm{keV})$;

Ifigh energy beam transport section . IEBT;;

TFF focusing voltages range from $\pm 25 \mathrm{kV}$ to $\pm 50 \mathrm{kV}$;

$\therefore$

Divergence: $0.45^{\circ} \times 1^{\circ}$;

Fressure $1 \times 10^{-5}$ Torr.

- Gas neutralizer:

$\therefore \quad$ Optimum gas thickness: $6.5 \times 10^{15} \mathrm{~cm}^{-2}$;

Average gas pressure $\langle p\rangle=7.5 \times 10^{-4}$ Torr;

Approximate dimensions: $\mathrm{H} \times \mathrm{W} \times \mathrm{L}=15 \mathrm{~cm} \times 55 \mathrm{~cm} \times 130 \mathrm{~cm}$;

Gas load: $5.72 \mathrm{~T} \mathrm{~g} / \mathrm{s}$.

- Ion magnet/dump region:

Pressure $1 \times 10^{-5}$ Torr;

$3.6 \mathrm{~m}^{2}$ cryopumps. 

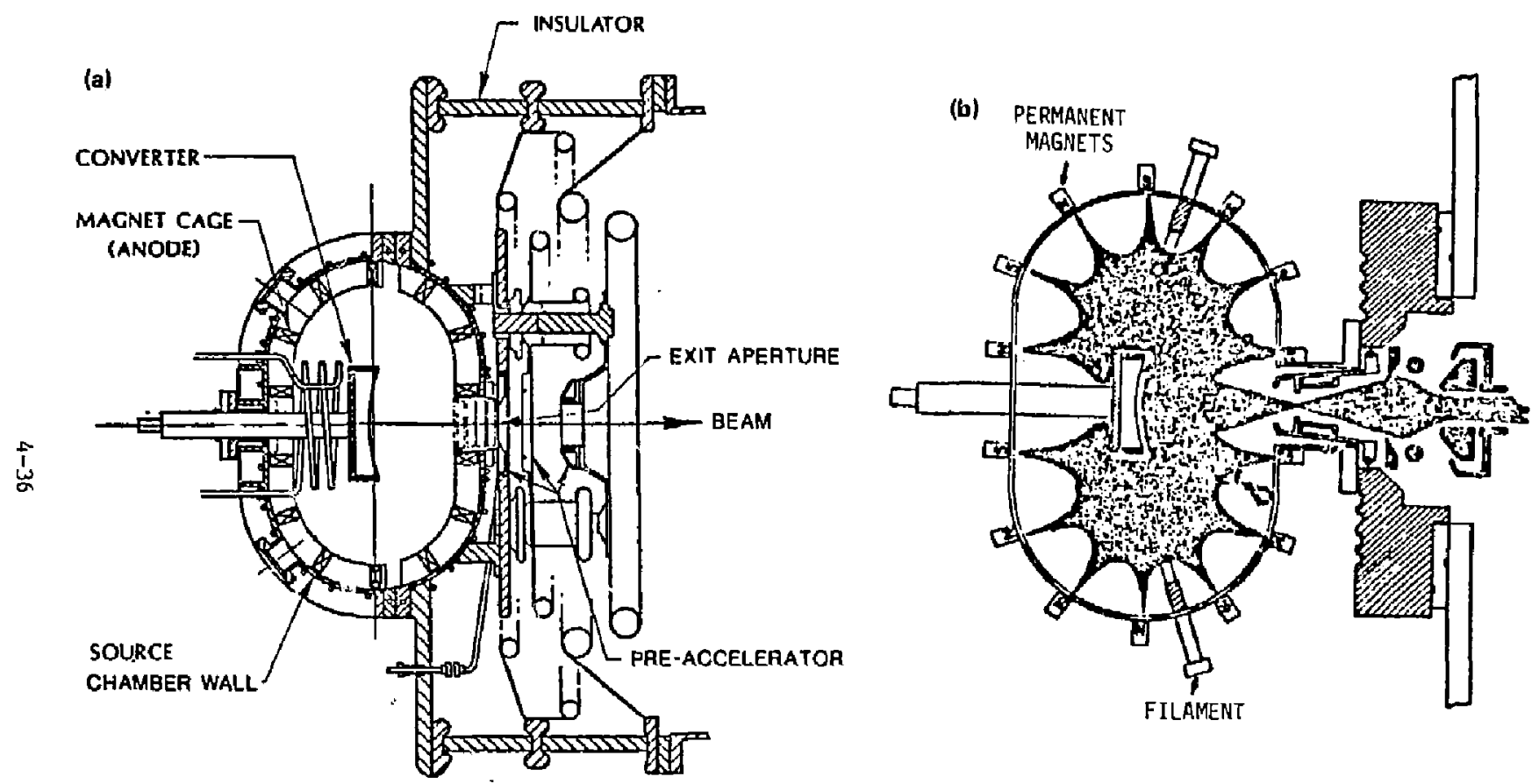

Figure 4-18. Negative ion source: (a) Self-extractfon source with an ri plasma generator; (b) LBL Monte Carlo simulation of rsent filament driven source. 


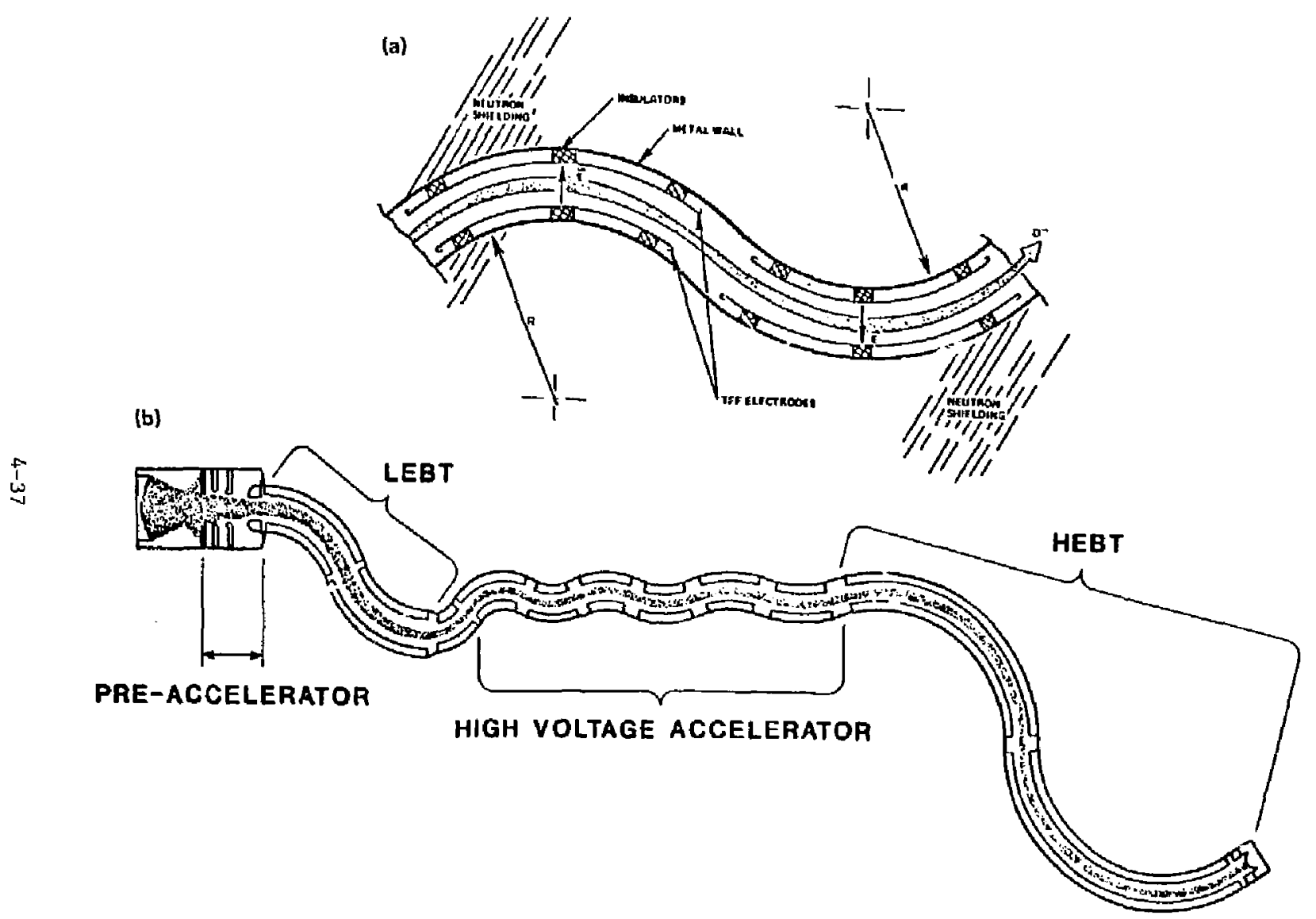

Figure 4-19. The TFF accelerator and transport system: (a) LBL Monte Carlo simulation of source and transport system; (b) section of TFF system. 


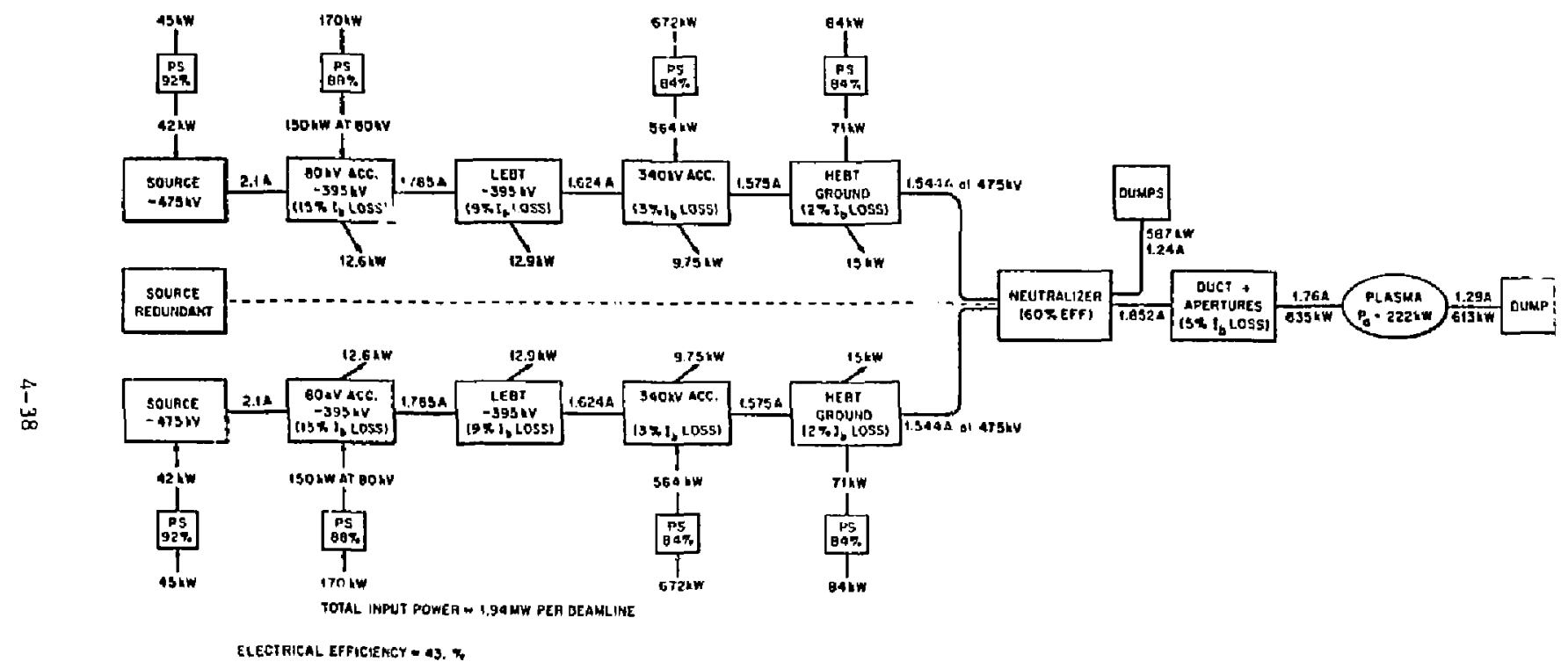

Figure 4-20. Beamline current and power fluw. 
Table 4-6. Drift pumping requirements. ${ }^{a}$

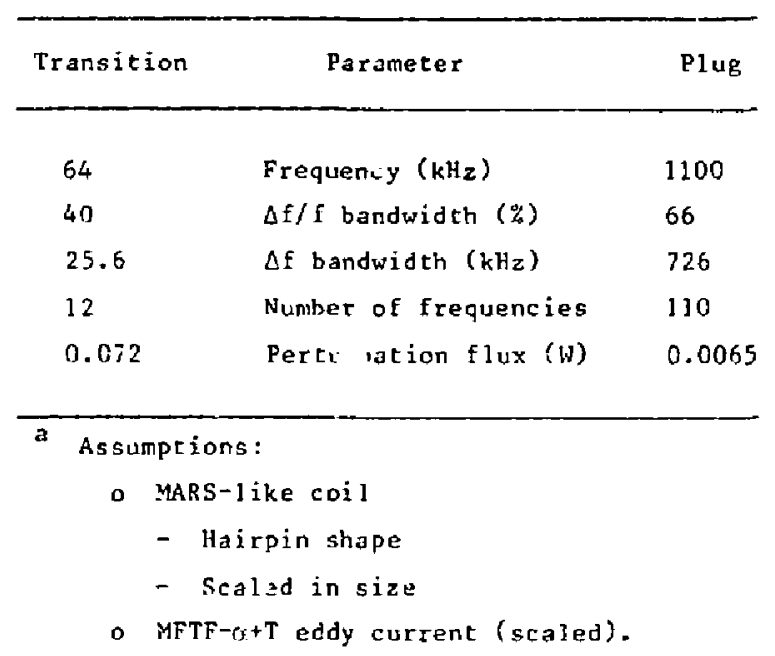

of each channel is matched to the coil pair througl a nartow-band resonating circuit, which ineludes the drift pump coil. This configuration was first Aeveloped on the MFTF- $\alpha+T$ study. ' Figures 4-21 and 4-22 portray this configuration. For the transition, there are only 12 channels required; each ccrrying a single tone. The plug cell is satisfied by a simildrarrangement; however, 110 channels are required. This large number of channels is not desirable and can be reduced if each channel's bandwidth handles two or more tones. This point is addrersed in the following section. The power of each channel is the Luide fower multiplied by the ratio of tones per channel to total number of tones.

\section{Performance}

This performance analysis follows the one developed for the MFTF- $\alpha+T .{ }^{1}$ The total coil current $I$ is given by solving

$$
B=\frac{\Phi}{A}=\frac{I L}{N A}
$$




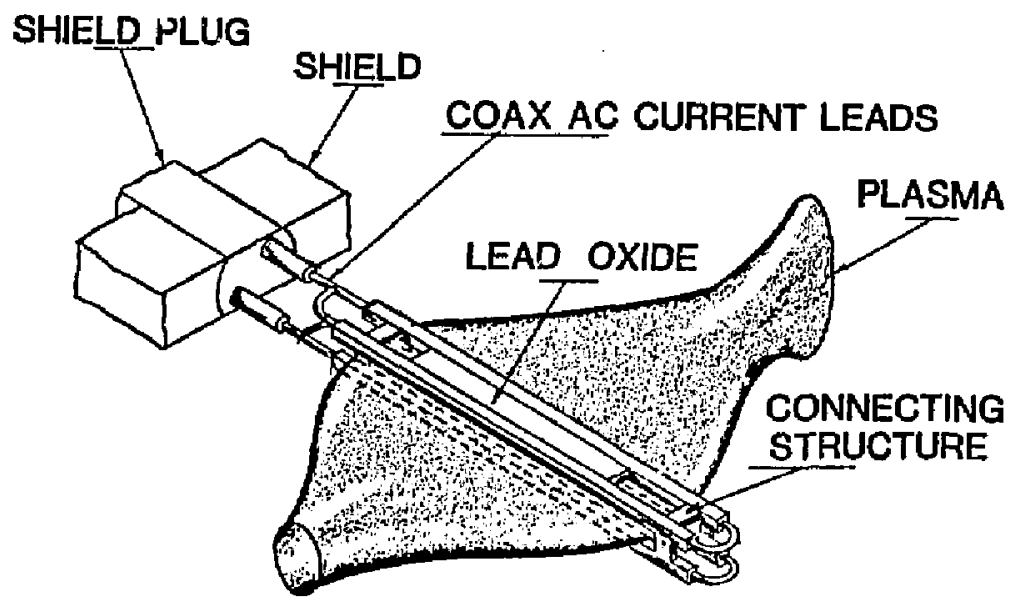

Finure 4-21. Drift-pump antenna arrangement.

$\epsilon$ 


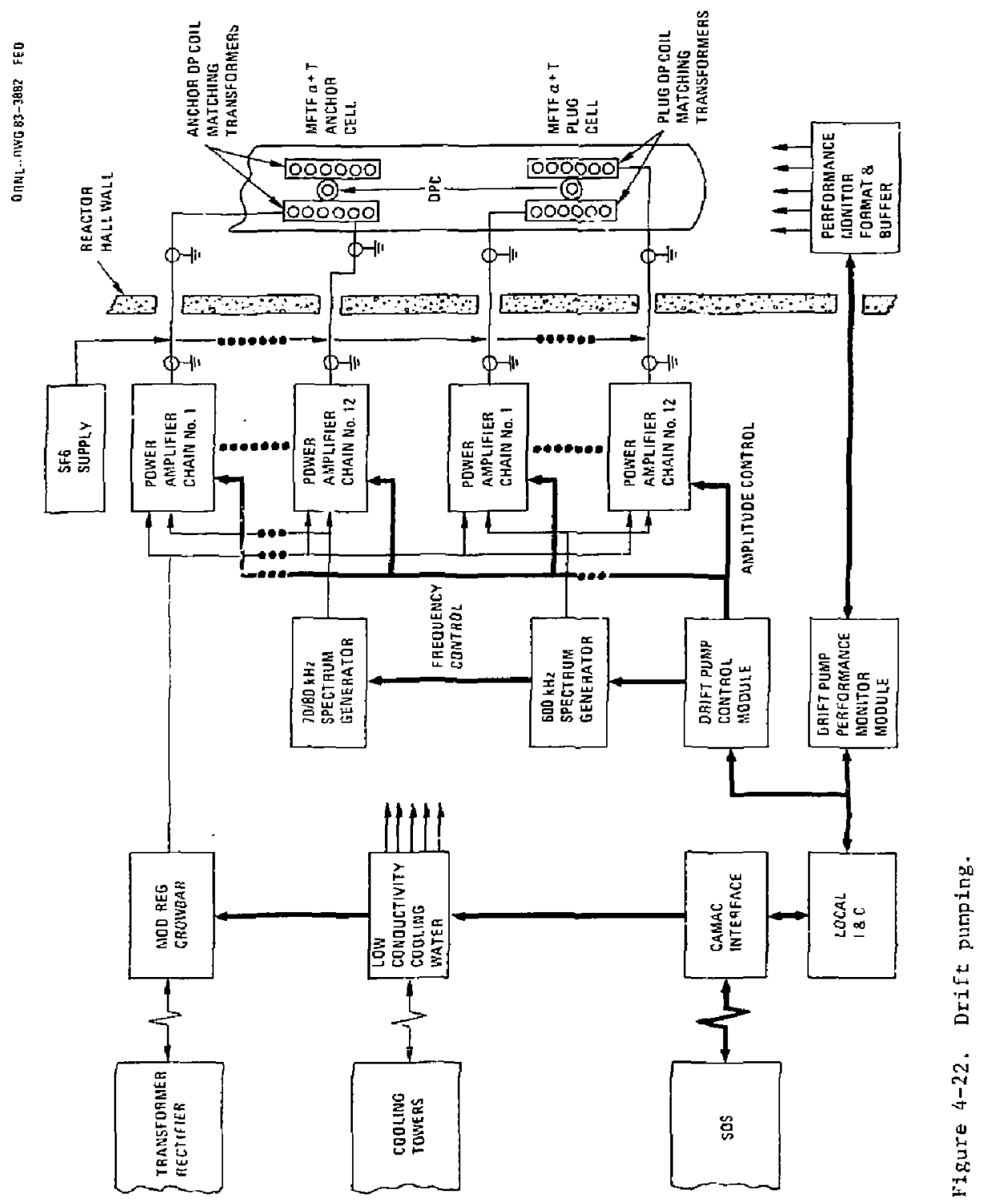


where the parameters have their usual meanings. Hence

$$
\begin{aligned}
\mathbf{I} & =\frac{\Phi \mathrm{N}}{\mathrm{L}} \\
& =18 \mathrm{kA} \text { transition } \\
& =1.625 \mathrm{kA} \text { piug. }
\end{aligned}
$$

Table 4-7 summarizes scaled down MARS drift-pump coil parameters at the FPD-I frequencies. From this point, the delineation of performance will cover the transition cell first followed by the plug cell.

The toral real power supplied to each coil is

$$
P=I^{2} R_{L}=I^{2}\left(R_{E C}+R_{C}\right)=2.53 \mathrm{NW},
$$

where $R_{E C}$ and $R_{C}$, are the equivalent resistances for the eddy current loss and the coil. The power and curcent supplied by each channel are

$$
P=211 \mathrm{~kW},
$$

and

$$
\mathrm{I}=5.2 \mathrm{kA} \text {. }
$$

Figure 4-23 shows a sketch of these channels. Following the analysis from MFrF- $\alpha+\tau$, the component values are as iollows:

$$
\begin{aligned}
& C_{1}=5.98 \times 10^{-1}, \\
& L_{1}=2.77, \\
& C_{2}=3.05 \times 10^{-4}, \\
& L_{2}=21,100, \\
& C_{3}=2.07 \times 10^{-2}, \\
& L_{3}=362.8, \\
& C_{4}=5.2 \times 10^{-3}, \\
& L_{4}=1741.2,
\end{aligned}
$$

where capacitance is in nicrofarad and inductance is in micrahenries. One tube capable of $20.75 \mathrm{MW}$ is the EIML 2170 . 


\begin{tabular}{|c|c|c|}
\hline Transition & Parameter & Plug \\
\hline & Coil: & \\
\hline 4 & Inductance (uH) & 4 \\
\hline 6.4 & Resistance $(m \Omega)$ & 26.5 \\
\hline 246 & $Q$ & 981 \\
\hline 1.4 & Load $(\pi \Omega)$ & 5.9 \\
\hline 202 & Q loaded & 801 \\
\hline 454 & Eddy loss (kW) & 15.6 \\
\hline 2073 & Coil loss $(k \mathrm{k})$ & 70.0 \\
\hline \multirow[t]{2}{*}{18} & Current $(k A)$ & 1.625 \\
\hline & Transmitter: & \\
\hline 714 & Power/chanuel (kt) & 2.6 \\
\hline 377 & $\Delta \mathrm{f} /$ channe $(\mathrm{Hz})$ & 2989 \\
\hline 32 & \#/drift pump coil pair & 110 \\
\hline 1156 & Prime power per channel $(\mathrm{kH})$ & 4.3 \\
\hline 13,870 & Prime power per drift-pump coil pair (kW) & 466 \\
\hline
\end{tabular}




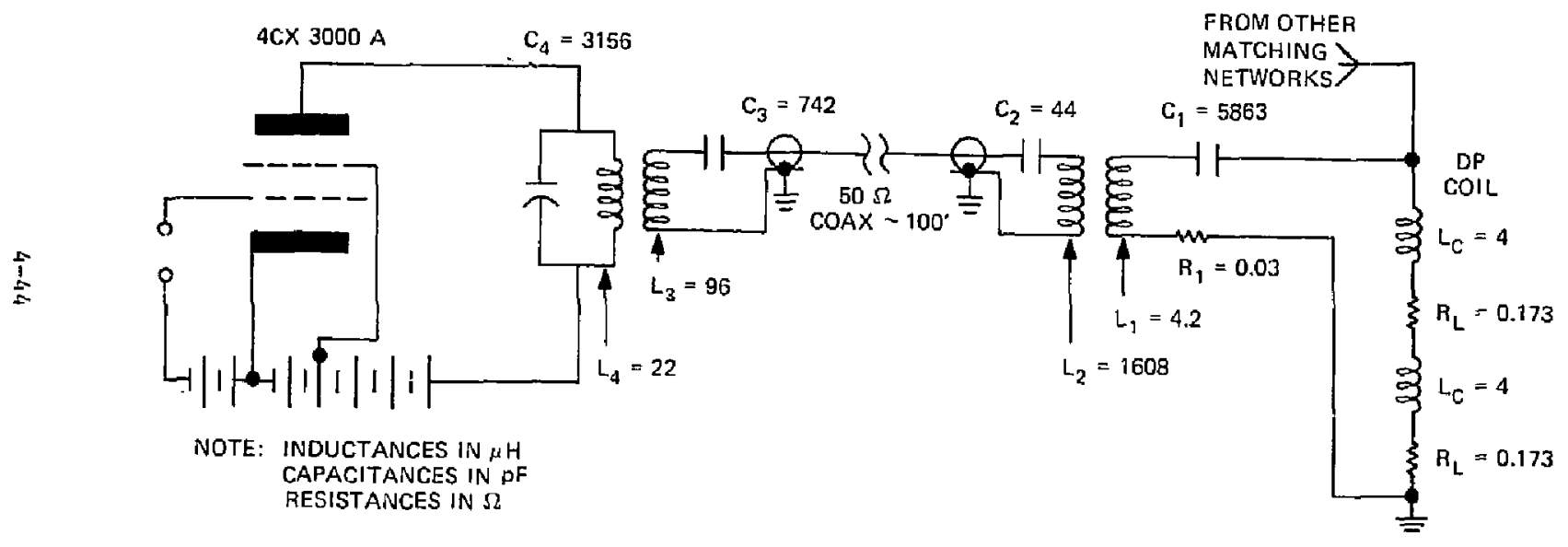

Figure 4-2j. Transmitter channel diagram. 
The plug cell requirements are very difficult to meet hecause of the large bandwidth along with the high $Q$ of the dift pumping cojl. Assuming only the load of eddy currents in the shield on the coil, results in a $Q$ of $\because$ out 800 . If actuality, this $Q$ is somewhat smaller because of connection resistance and plasma loading. If the required bandwidth of $66 \%$ is divided into 110 channels, each channel would have $0.6 \%$ bandwidth resulting in o ? about 160 . With those 110 channels, there would be continuous coverage across the $726 \mathrm{klz}$ band. Any modulation technique (noise, cw sweep, or discrete tones) could be used. However, the power dissipated rises by $800 / 160$, a factor of 5. The extra power dissipated would be $340 \mathrm{kH}$. This is an undesirable solution because 110 channels, operating with less than $10 \%$ efficiency, are required. For operations with only discrete tone modulation, the $Q$ and efficiency could be higher and only limiced by the plasma loading and circuit connections. Table 4-7 summarizes a design of this type in whith the $Q$ is about 370. Referring to Fig. 4-22, the values for these channels are as follows: $\quad C_{1}=1.97 \times 10^{-3}, 41=4, C_{2}=8.4 \times 10^{-6}, \mathrm{~L}_{2}=2820$, $\mathrm{C} 3=2.15 \times 10^{-3}, \mathrm{~L} 3=16.3, \mathrm{C} 4=1.83 \times 10^{-4}$ and $\mathrm{L} 4=129.4 \mathrm{CC}$ in microfarads, t in microhenries). A tube in the 4 CX3000A class wald suffice.

\section{Future Work}

In FPD-Il, the plug-cell drift-pump spectrum is defined in more detail, There are two distinct bands: ane for the cold ions and another for the sloshing ions. This relieved the design complexity somewhat, but 45 channels are still required to interface with each drift-punp coil pair. A similar investigation of FPD-l should be carriad out. The eddy current loading model requires more work as does the technique for flux routing around the irift-pump coil. Finolly, some kind oi recovery system in the matching network needs to be developed, which will allow wideband (1ow ") operation with good efficiency (see MFTF- $\alpha+T$ report ${ }^{1}$ ).

Since the FPD-I effort was completed, new Fokker-Planck calculations for IPD-II have shown a decrease in the electron energy coupling from the plugs to the central cell. In retrospect, for FPD-1 to remain ignited, 35 MW oz power would have :o be absorbed by the plasma; in this case, ICRH was chosen. The partitioning of ansorbed powet among the ions, electrons, and alphas does not matter, hence the trapping frazion is assumed to he quite high 285 to $90 \%$. 
The central cell vacuum field is $2.5 \mathrm{~T}$ carresponding to $38 \mathrm{MHz}$ for the second harmonic of deuterium, but the equilibrium beta is quite high with a peak value of $90 \%$. 'l'o simplify the ICRH design and analysis, we have assumed that as beta increases, the frequency is held constant and the heating region is allowed to move up the slope of the choke field. At full plasma parameters, $38 \mathrm{MHz}$ will heat the suriace associated with a $33.5-\mathrm{T}$ vacuum field at the ends of the central cell.

The system comprises twelve Faraday shielded center-feed loop antennas divided between the two ends of the central cell; each antenna is supplied by a high power transmission system with? three-stub matching network and a multistage amplifiet chain. Each antenna covers nearly one-half the plasma circumference and is less than a quarter of a wavelength in length; a power density 1 imitation of $1 \mathrm{kw} / \mathrm{cm}^{2}$ defines an antenna width of $n 20 \mathrm{~cm}$. The antenna, feedthrough, and Faraday shield are assumed to consume $28 \%$ of the power; the transmission system is similar to that described for the anchor ICRH system and is approximately $85 \%$ efficient. The transmitter is multistage with a very high power hybrid combiner and two higl power hybrid combiners funneling $1.17 \mathrm{MW}$ from four $X-2159 / 9874$ tetrodes into the 9-3/16-in. coaxial transmission system. The transmiter efficiercy is $259 \%$. Two converter/ transformers supply the dc power; each is rated at $45 \mathrm{MW}$ at $25 \mathrm{kV}$. The line requirement for the system is $8 \% \mathrm{MW}$, and the ICRI system efficiency is $45.4 \%$.

\section{IAALO SCKAPER/DIRECH CONVEHTER}

The following discussion is a brief summary of the design, supporting analyses, and calctlations performet for the direct converter for FPD-I. The basis for the direct converter design and femote maintenance considerations for FPD-I is the A-18 magnet set. We assume that the distribution of power in the direct converter is sinilar to that in MARS. 2 
The electron collectors and the halo scrapers provide a collection system for the charged particles that exit the cencral celi. The escaping particles contain a significant amount of power ( $20 \%$ of the fusion power plus the injected power), which results in very bigh thermal power densities on the surface on which they are collected.

Design Assumptions

We made some assumptions in this study to arrive at a design for costing purposes, they are:

- Use circular plasma cross sectional shape at the direct converter plates.

- Use siape simplification to ease manufacturing--make all cooled elements flat.

- Limit the size of the direct converter so that it can be contained in a 7.0-m diameter vacuum vessel.

- Use $53.5 \mathrm{MW}$ of charged particular energy, er end distributed in the same proportion as with MARS ${ }^{2}$ (see Table 4-8).

Table 4-8. Power distrihution

(MW per end).

\begin{tabular}{ccc} 
& MARS & FPD-1 \\
\hline nuter halo & 10.0 & 2.0 \\
Inner halo & 50.0 & 9.0 \\
Outer end & & \\
Thermal & 11.0 & 2.0 \\
Electrical & 12.5 & 2.5 \\
Inner end & & 13.0 \\
Thernol & 69.5 & 25.0 \\
\hline
\end{tabular}




\section{Design Options}

There are several design options availabie depending on the goals chosen for a direct converter on FPD:

- Use a high temperature coolani to permit recovery of the thermal energy at $300^{\circ} \mathrm{C}$. This option requires high technology fabrication techniques for refactory metal (TZM) collectors.

- Use low temperature collection of the thermal energy with no energy recovery. This option permits simple fabrication of copper collectors and low pressure water coolant.

- Use low temperature coilection of the thermal energy with a high temperature module to demonstrate feasibility.

o Discard electrical energy.

- Use electrical energy at collector potential.

- Invert collected electrical energy and feed grid.

\section{Design "escription}

We considered designs for both the high-temperature recovered-heat and the low temperature discarded-heat options; and performed a costing exercise for both. The mechanical designs for both options are very similar (see Fig. 4-24) with the major difference being the collector and halo materials. A preliminary assessment ố the vacuum fumping reçuiremerts was made. This assessment resulted in an estimated open duct pumping speed of $4.0 \times 10^{5}$ $1 \mathrm{iter} / \mathrm{s}$ that could be achieved by using 80 TMPs at $5000 \mathrm{liter} / \mathrm{s}$ capacity or $5.6 \mathrm{~m}^{2}$ or cryo parels backed by a roots b]cwer.

\section{Costs}

Table 4-9 summarizes the costs of the two options considered for FPD-I with a comparison to MARE. 


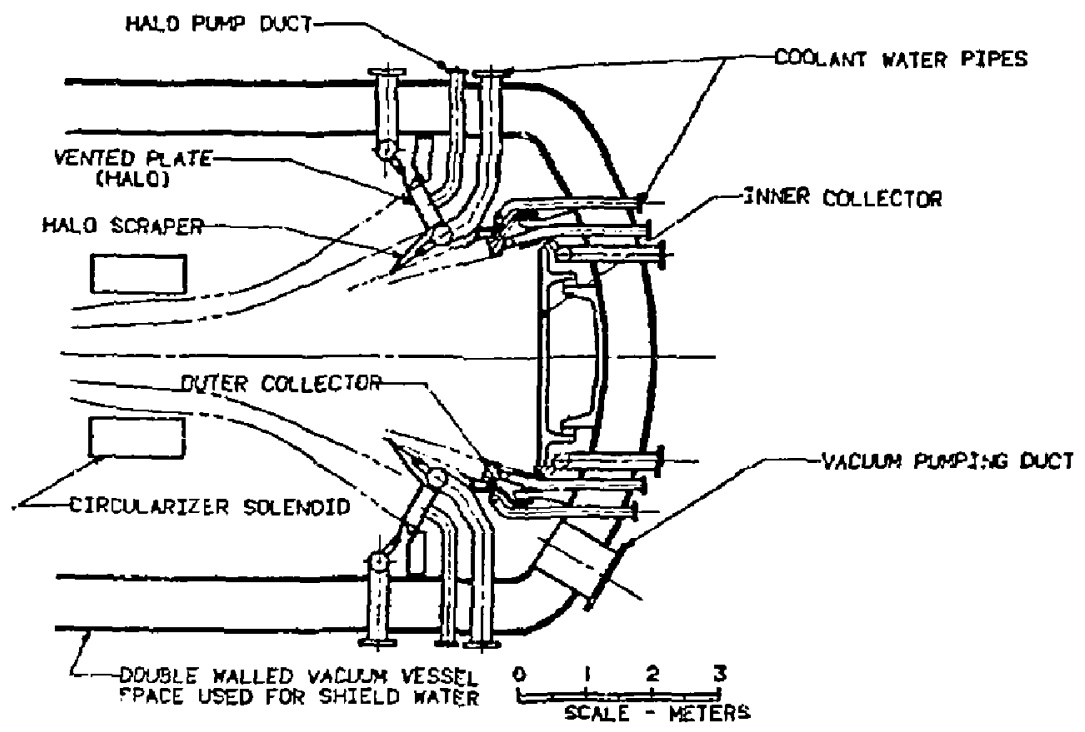

Figure 4-24. The FPD-I direct converter. 
Table 4-9. Costs in 1984 dollars including materials, fabrication, and installation.

\begin{tabular}{lcccc}
\hline & $\frac{\text { MARS FPD-I }}{\text { TZM }}$ & & \multicolumn{2}{c}{ FPD-I } \\
\hline & & & TZM \\
$(\mathrm{m})$ & & $\begin{array}{c}\text { Copper } \\
(\mathrm{m})\end{array}$ \\
\hline Piping and supports & 1.63 & 0.94 & 0.28 \\
Halo & 4.13 & 1.71 & 0.34 \\
Collector & 4.00 & 0.77 & 0.15 \\
& 9.76 & 3.42 & 0.77 \\
\hline
\end{tabular}

FUELING INJECTION SYSTEMS

The FPD macluine has two independent gas-puffing injec:ion systems for initial loading and startup. Either gas-injection system can perform these operations with one system maintained while the other is in operation. The gas-injection systems can supply either hydrogen or deuterium gas, but not tritium. Therefore, the gas injection system developed for other machines can be procured without having to upgrade to meet tritium safety requirements. The maximum gas injection rate is $300 \mathrm{~g} / \mathrm{h}$. Both pulsed and analog modes of operating are available.

Two independent fiel pollet injectors are provided, with one at each end of FPD. Either injector can provide all the deep-fueling needs of the machine. The pellet injectors cam inject $2.75 \mathrm{trm}$ pellets with velocities up to $12,000 \mathrm{~m} / \mathrm{s}$, corresponding to a pellet penetration of about $50 \%$ of the radius near the throat of the choke coil. Table 4-10 contains the characteristic oesign data for two-stage pellet injectors consisting of is pneumatic-gun first-stage preinjector and an electromagnetic-rail-gun secondstage accelerator.

The fuel pellet can be controlled within a range from 0 to 10 per second to cover the large uncertainty in the plasma confinement time and effectiver $s$ of the pellet fueling. The fuel pellet formers can make DT pellets ith atomic mix ratios between 0.5 and 1.5 . The pellets can 
Table 4-10. Fuel pellet injector data.

No. of pellet injectors

Pneumatic gun data:

$\begin{array}{ll}\text { Pellet diameter and length (mm) } & 2.75 \\ \text { Pellet rate }\left(\mathrm{s}^{-1}\right) & 0.10 \\ \text { Pellet velocity }(\mathrm{m} / \mathrm{s}) & 500\end{array}$

Peljet composition:

Deuterium

$>95 \%$

Tritium

$>95 \%$

Atomic mix ratio

0.5 to 1.5

Propellent gas

D2

Supply pressure (PSIA)

150

Barrel length (m)

0.8

Electromagnetic rail-gun accelerator data:

Pellet entry velority $(\mathrm{m} / \mathrm{s})$ 500

Maximum pellet exit velocity $(\mathrm{m} / \mathrm{s})$

12,000

Maximum theoretical rail-gun

10.5

current (kA)

Rail-gun barrel length $(m)$

16.6

Rail-gun energy supply (kJ)

15.0

Fueling supply rate data:

DT fuel injection rate $(g / h)$

'rritium fueling supply rate $(g / h)$

39

Deuterium fueling supply rate $(\mathrm{g} / \mathrm{h})$

26

Other fuel system operating, data:

Vacuum pumping requirement (LPM)

Liquid nitrogen supply zate $(g / h)$

Liquid heljum supply rate $(g / h)$

Electric power consumption ( $k W$ ) 
bt injected in the reduced section of the central cell plasma near the inboard side of the water-cooled choke coils. Isolation valves will be provided at the rail gun exit to permit operation with one injector out of service. Replacement of the pellet laurcher and rail gun accelerator will be possible without entering the vault.

Although rail guns were developed to inject non-metallic pellets up to $11 \mathrm{~km} / \mathrm{s}$, no one has ever built one to accelerate frozen fuel pellets. Considerable development work is needed to determine the feasibility of using an electronagnetic sail gun for injecting high velocity fuel pellets.

END CELL

\section{SI! TELDING AAD VACUUY: CONTA INMEN'T}

Shielding analyses for FPD-I have identified a need for two types of shield for the end cell. These two, shown in Fig. 4-5, are (1) magnet and (2) biological shields. The magnet shield is located between the plaptia and the coils in the end cell. The biological shield is an integral part of the vacuum vessel.

\section{Magnet Shields}

The magnet shields tailored in shape and location to the individual coils in the end cell are shown in Fig. 4-24: therefore, they vary throughout the length of the end cell. The choke coil requires thicker shielding than tre recircularizing coil. All of the $\mathrm{c}$ colls have $35-\mathrm{cm}$ thick slields. This shield consists of $30-\mathrm{cm}$ steel shieldins and $5 \mathrm{~cm}$ of boron shielding. The steel shield compositiuil is $80 \%$ steel and $20 \% \mathrm{H}_{2} \mathrm{O}$; the boron shielding composition is $40 \%$ stee 1 and $60 \% \mathrm{~B}_{4} \mathrm{C}$. ( $\mathrm{B}_{4} \mathrm{C}$ has a sisity factor of 0.7. )

\section{Vacuum Vessel/Biological Shield}

The function of the biological shield is integrated with the function of vacuum containment in a double-walled vessel. The wall spacing of $2.4 \mathrm{~m}$ is set by the biological shutdown dose rate. In addition, a 5-cm-thick boron shield and a 5 -cm-thick lead shield are attached to the outside of the 
integral vessel. These three shield Iayers limit the shutdown dose rate co $0.5 \mathrm{mrem} / \mathrm{hour}, 24$ hours after shutdown.

The end cell has the following physical dimensions:

- Lengeh = approximately $33 \mathrm{~m}$.

- Inside diameter $=7.0 \mathrm{~m}$.

- Outside diameter $=11.8 \mathrm{~m}$.

The end cell vacuum vessel consists of an inter and ytes sinell separated by six bulkheads, as shown in Fig. 4-25. Figure 4-26 sho. the magnet cold structure integrated into the cylindrical vacuum vessel. ha renovable top hatch is framed by a beam structure. Both the hatch and the vacuum vessel have longitudinal stiffeners on $45^{\circ}$ spacing. Each end cell has two hatches. The large hatch is for coil removal, and the smaller one is for the direct converter/halo scraper removal. The hatches are sealed with a single-convolution welded hellows.

SUPPORT STRUCTURE

The end cell is supported by three sets of legs, as shown i Fig. 4-25. These are situated on top of reinforcer concrete piers. The suf, it legs sit on a roller tyre support, which al)ows axial movement (z-directi) fer thermal expansion. All lateral or vertical movement is constrined. Fach sel of legs is in line wit, a vacuurn-vessal bulkhead.

\section{NEUTRONICS ANALYSIS}

Neutronics analyses for the FPD-I design were performed for 1 . central cell, choke area, and the end cell. The central cell analysis: wes 1 blanicet optimization to Ieduce the capital cost, a shield desigr. the protection of the central cell coils, and a biological shield de ign for the ieactor room access one day atter shutdown. The shoke area anal. 's was carried out to define nuclear responses, $n$ the copper insert coil and the superconductor portion of the coil. Rigorous analysis was performe. for the end cell because the capital cost of the end cell amounts to $260 \%$ of the total capital cost. An elaborate three-dimensional ( $D$ ) radiation transport analysis for the complete reactor systent, including the eding blanket, the 


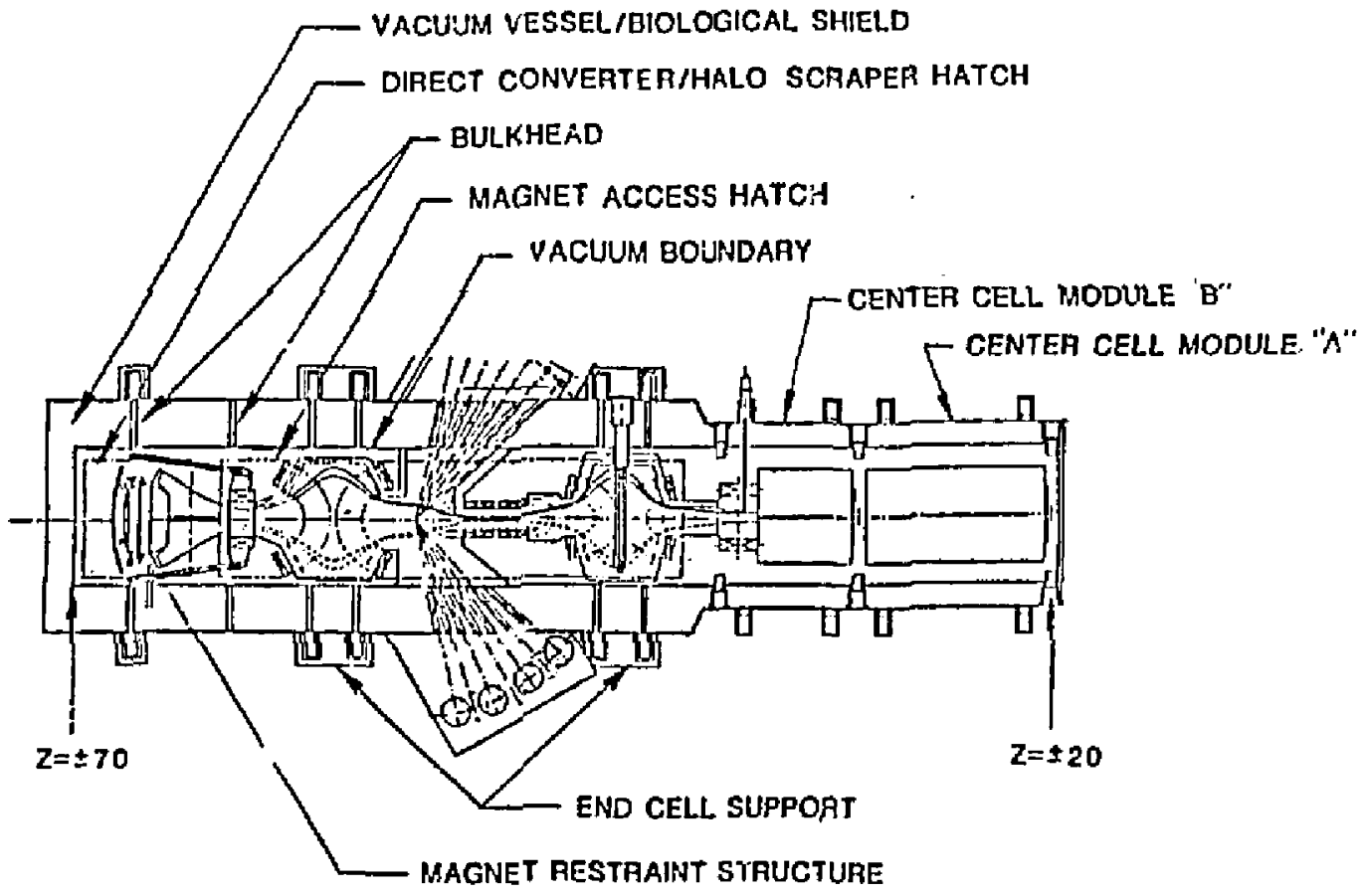

Figure 4-25. The FPD-I end-ce11 plan vi.w. 


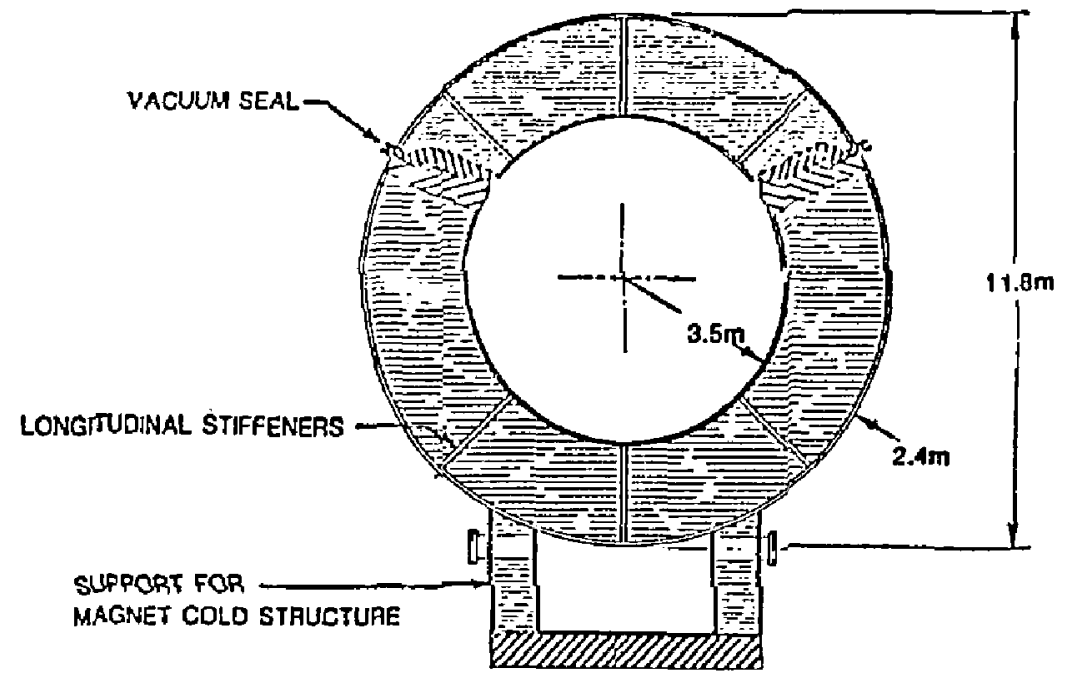

Figure 4-26. Section rhrough the FPD-I end-cell vacuum vessel. 
bulk shield, the central cell coils, the choke coils, the coils, and the biological shield, was carried out. The general purpose Monte Carlo compiter code, MCNP, was used for the calculations with a continuous energy representation for the nuclear cross sections based on ENDF/B- $V$ uuclear tata files. The energy spectrum and spatial distribution of the neutron source from the DT plasma in the central cell and the end cell were modeled explicity in the calculations. The geometry of the $C$ coils wiso muinled explicitly without approximation in the calculation model. Resules from tho 3D analysis include the net tritium breeding ratio, energy deposition in each :omponent of the reactor, radiation damage parameters in each roil, neutron leakage from the cer'ral call to the end cell, and the detaried sitielu design for the end cell.

RADIATION PROTECTION CRITERIA FOR THE COILS

In general. Te effect of radiation on coil componenis tends :o lower their performances. For superconductor materials, neutron irradiation reduces che critical density ( $J_{c}$ ) and the critical temperature ( $T_{f}$ ). For NbTi superconductors, $J_{e}$ is decreased by $w 0 \%$ at $4 \times 10^{18} \mathrm{n} / \mathrm{cm}^{2}$ ( $\mathrm{E}>0.1 \mathrm{MeV}$ ) fluence, whereas $T_{c}$ is unchanged. ${ }^{4,5}$ Irradiation experiments at R'TNS-II ${ }^{6}$ on NbTi supercanductors show consistent results with previous work. On the other hand, $J_{c}$ of $\mathrm{Nb}_{3} \mathrm{Sn}$ generally increases, reaching 7 maximum and then decreases as the neutror. flutence increases. 7 Irradiation experiments at $61 \mathrm{~K}$ (Refs. 4,j) with a maximum neutron fJuence of $4 \times 10^{18} \mathrm{n} / \mathrm{cm}^{2}$ show that the maximum value and ihe increased rate of $J_{c}$ increases with the magnetic field. At a magnetic field of $5 \mathrm{~T}$, the $61 \mathrm{~K}$ irradiation resulted in a $16 \%$ increase in $I_{c}$ after $2 \times 10^{8} \mathrm{n} / \mathrm{em}^{2}$ without reaching a peak. Irradiation experiments at higher teriperatures $(2350 \mathrm{k})$ shaw the same hehavior for J $c^{*}$ However, the $J_{c}$ peak was lower than the corresponding value at lower temperature for tine same magnetic field. For example, the $350 \mathrm{~K}$ irradiation gave an $\mathrm{B} \%$ increase corresponding to the $16 \%$ mentioned before at $6 \%$. Other irradiation experiments at $400 \mathrm{~K}$ and a $10 \mathrm{~T}$ field ${ }^{8}$ resulted in a $40 \%$ increase for $\mathrm{J} \mathrm{c}$ at $44 \times 10^{18} \mathrm{n} / \mathrm{cm}^{2}$ and dropped to the original value of $J_{c}$ at $10^{19} \mathrm{n} / \mathrm{cm}^{2}$. Based on thesp experimental results, ${ }^{4,7,8}$ the compatison bet een the room temporatire and the $6 \mathrm{~K}$ irradiation results, and the maximuin field of $11 \%$, a neutron fluence above $10^{\prime 7} \mathrm{n} / \mathrm{cm}^{2}$ can be acinieved in $\mathrm{Nb}_{3} \mathrm{Sn}$ wit. ut a derzear = in the critisal current density. 
The stabilizer material carries the current in the event that the superconductor temporarily becomes resistive. The coil is designed to remove the generared teat $\left(I^{2} R\right)$ so that the normal region does not propagate. The re.istance (R) of the stabilizer is the most important consideration for this process. Coppet and aluminum are the two choices for the stabilizer material. However, copper is the prepared macerial because it has the lowest resistivity in the fusion environment. 9,10 The total resistivity of the copper stabilizer can be described as the sum of three components: the initial resistivity $\rho_{0}$, the magneto-resistivity $\rho_{u}$, and the irradiation induced resistivity $\rho_{i r r^{*}}$ Magneto-resistance is a function of $\rho_{O}, \rho_{i f r}$, and the magnetic field which complicates the evaluation of p. Few experimental studies ${ }^{5,9-13}$ have been done on the change of copper resistivity as a function of field, neutron fluence, and numer of cycles of alcernate neutron irradiation ( $4 \mathrm{~K}$ ) and anneding $(300 \mathrm{~K})$. The change in the copper resistivity can be accommodated by using more copper stabilizers, which increase the thickress of the coils, can be partially annealed out by warming the coils, or can be avoided by improving the shielding performance (increase shielding thiikness or use better materials). The FPD cesign limits the irradiation-induced resistivity to $25 \times 10^{-8} \mathrm{~cm}$ in the copper stabilizar at the end of 1 ife to avoid any impact on the coil design.

The most sensitive component in the coils is the insulator material because the irreversible irradiation damage 'imits the operating life of the coils. The properties of interest for the coil designs are the electrical resistivity, dielectric strength, mechanical strength, and thermal insulation. Experimental results form neutron irradiation at $5 \mathrm{~K}$ suggests that polyimides can withstand a radiation of $10^{10}$ rads and retain high resistivicy and mechnical strength. Glass-cloth reinforcad epoxy type GlD-CR or G11-CR shows a serious degradation at $2 \times 10^{9}$ rads. The FPD design assumes a $10^{10}$ rads maximum tolerable dose in the insulator naterial at the end or life. 
The nuclear energy deposiced in the coils impacts the refrigeration power required since alour $500 \mathrm{H}$ of electrical power is consume to remove one watt from the coil at $4 K$. This low removal efficiency calls for minimizing the nuclear energy deposited in the coils. Thus, limiting the maximum nuclear seating to a few $\mathrm{mW}^{\mathrm{c}} \mathrm{cm}^{3}$ is required to avoid a large cryogenic system.

\section{CENTREL CELL ANALYSIS}

The central cell analysis cors:s the following three sections: (1) the tritium breeding blanket, (2) the shielding design to protect the central cell coils, and ( 3 ) the biological shields. In the design process for these three sections, the emphasis us on reduciug the capital cost and the total weight of the central c 11 . The blanket is designed to convert the kinetic energy of the DT neutrons to recoveraole heat and produce adequate tritium breeding to supply tha tritium fuel requirement during the whole reactor lifetime; the blanket is designed as well to generate a surplus of tritium to compensate for operating with nonbreeding blanket sections or to start another reactor within a reasonable period of time. Economic and shielding considarations require the blanket design to maximizo the recoverable neat produced, which is defined as the energy deposited in the first wall, breeding zone, and reflector per fusion neutron. A neutronics analysis was performed to study the performance of the self-tcooled naturai lithium-lead $\left[\mathrm{Li}{ }_{17} \mathrm{~Pb}_{83}(\mathrm{Ti} \mathrm{Pb})\right]$ b]anket concept. The impact of the breeding zone thickness, reflector material selection, refiector composition, and reflector zone thickness are analyzed to determine the maill blanket parameters. In the analyses, five key parameters are considered to define the blanket for FPo. These parameters are the capital cost, the total weight, the tritium breedina ratio, the energy deposition in the blanket per fusion neutron, and the energy loss to the shielding system. For the Lipb blanket concept, the tritium inventory is less than $1.0 \mathrm{~kg}$, which requires 1.0 l net tritium breeding ratio to achieve about one year doubling time. However, the neutronics analysis was performed with a wide range for each key parameter. As an example of the results, Fig. 4-27 shows the tritium breeding ratio as a function of the breeding zone thickness $(10$ to $50 \mathrm{~m}$ ), for different reflector zone thicknesses $(20,30$, and $40 \mathrm{~cm})$. Table 4-11 gives the cencral cell parameters that resulted from the analysis for the FPD design. 


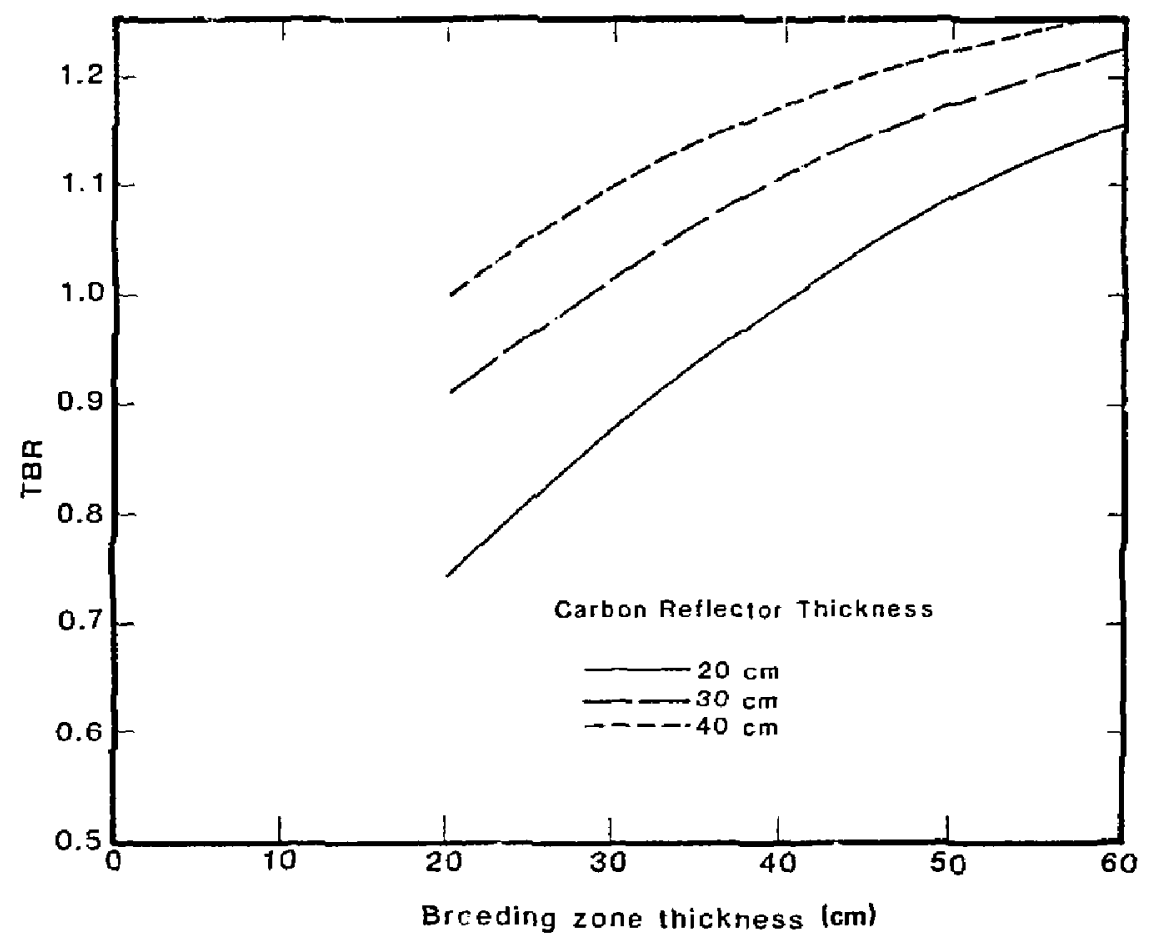

Figure 4-27. Tritium breeding as a function of the ratural LiPb breeding zone tiickness for difficent earbon reflector zone thicknesses. 
Table 4-11. The FPD-I central cell and choke coil parameters.

\section{Central Cell Blanket Parameters}

\section{Materials :}

Natural LiPb breeder

Carbon reflector

Ferritic steel structural

Dimensions and composition in the neutronics model:

$\begin{array}{ll}\text { Eirst wall thickness }(50 \% \text { fezritic, } 50 \% \mathrm{LiPb})(\mathrm{cm}) & 1 \\ \text { Breeder zone thickness }(7.5 \% \text { ferritic, } 92.5 \% \mathrm{LiPb})(\mathrm{cm}) & 49 \\ \text { Reflector zone thickness }(10 \% \text { ferritic, } 10 \% \mathrm{LiPb}, & 70 \\ \quad 80 \% \mathrm{c})(\mathrm{cm}) & 1.95 \\ \text { Breeding blanket length }\left(\mathrm{m}^{2}\right) & \\ \left.\text { Neutron wall loading (MS } / \mathrm{m}^{2}\right) & \end{array}$

Performance parameters:

Tritium hreeding ratio

1.11

Lithium-6 enrichment

Natural

Planket energy multiplication factor

1.30

Total energy matipication factor

1.37

Energy fraction deposited in the shield

$4.83 \times 10^{-2}$

\section{Central Cell Slield}

Materials:

Steel balls, water, $B_{4} C$ (powder), lead

Dimension and composition under the coils:

Steel shield $\left(60 \%\right.$ Fel 422 steel alloy, $\left.40 \% \mathrm{H}_{2} \mathrm{O}\right) \quad 45 \mathrm{~cm}$

Boron shield $\left(42 \% \mathrm{~B}_{4} \mathrm{C}, 20 \%\right.$ Fel422 steel alloy, $\left.20 \% \mathrm{H}_{2} \mathrm{O}\right) \quad 5 \mathrm{~cm}$ 
Nuclear rasponses in the central cell coils:

Maximum tuclear heating in the coil case $\left(\mathrm{mW} / \mathrm{cm}^{3}\right)$

0.16

Maximum nuclear heating in the winding naterial $\left(\mathrm{mb} / \mathrm{cm}^{3}\right)$

0.03

Maximum dose in the thermal insulator ( $\left.\mathrm{rads} / \mathrm{MW} \cdot \mathrm{y} / \mathrm{m}^{2}\right)$

$7.79 \times 10^{7}$

Maximum dose in the electrical insulator (rads, $M \cdot \cdot \cdot \mathrm{y} / \mathrm{m}^{2}$ )

$2.70 \times 10^{7}$

Maximum dpa in the copper stabilizer (dpa/MW-y/m ${ }^{2}$ )

$2.11 \times 10^{-6}$

Fast neutron fiuence in the winding material

(neutrons $\mathrm{cm}^{2} / \mathrm{NH} \cdot \mathrm{y} / \mathrm{m}^{2}$ )

$8.85 \times 10^{10}$

\section{FPD-1 Choke Coil}

Copper insert:

Neutron wall loading $\left(\mathrm{MW} / \mathrm{m}^{2}\right.$ )

0.6

Maximum nuclear heating in the coil case ( $W / \mathrm{cm}^{3}$ )

7.0

Maxim!m nuclear heating in the copper coi? $\left(\mathrm{W} / \mathrm{cm}^{3}\right)$

5.3

Maximum nuclear heating in the ceramic insulator

$\left(\mathrm{rads} / \mathrm{Mw} \cdot \mathrm{y} / \mathrm{m}^{2}\right)$

$6.1 \times 10^{12}$

Maximum atomic displacement in the coproer (dpa/MW.y/m ${ }^{2}$ )

6.8

\section{Superconductor :}

Neutron wail loading $\left(M W / m^{2}\right)$

0.80

"iximum shielding thickness (cm)

70.0

Maximum nuclear heating in the coil case $\left(\mathrm{mb} / \mathrm{cm}^{3}\right)$

0.52

Maximum nuclear heating in the winding materials (mW/ $\mathrm{cm}^{3}$ )

0.22

Maximum dose in the insulator ( $\mathrm{rads} / \mathrm{Kh} \cdot \mathrm{y} / \mathrm{m}^{2}$ )

$7.00 \times 10^{8}$

Moximum dose in the electrical insulator (rads, MW.y/m ${ }^{2}$ )

$2.92 \times 10^{8}$

Fast neutron fluence in the winding material

( $E>0.1 \mathrm{MeV}),\left(\mathrm{n} / \mathrm{cm}^{2} / \mathrm{Mw} \cdot \mathrm{y} / \mathrm{m}^{2}\right)$

$1.81 \times 10^{17}$

Maximum atomic displacement in the coppar stabilizer

$\left(\mathrm{dpa} / \mathrm{MW} \cdot \mathrm{y} / \mathrm{m}^{2}\right)$

$1.23 \times 10^{-4}$ 
The shieldiug thickness for the central cell is defined to achiev. $0.1 \mathrm{miv} / \mathrm{cm}^{3}$ maximum nuclear heating in the coil case, At this nuclear heating rate, th. capital cost for the central cell is at minimum based on the MFTF- $\alpha+T$ design analysis. 1 The design criterion based on the nuclear heating and the tive years operating time (100\% availability) produce low nu:lear responses in the superconductor coils as shown in Table 4-11. The de-ign criteria for superconductor coil protection against radiation is about two orders of magnitede higher than the values in Table 4-11.

IHOKE COIL ANAT,YSIS

The choke coil analysis was performed to define the nuclear responses in both sections of the choke coil: the normal copper insert and the supercciductor section. The maximum neutron wall loading for eacin section is shown in Tabie 4-12. Based on the nuclear responses given in Table 4-11, the copper insert can operate for 1.7 years $\left(100 \%\right.$ availability) to reach $10^{13}$ rads in the ceraric insulator which corresponds to 3 vol\% swellint in the $\mathrm{MgAl}_{2} \mathrm{O}_{4}$. The superconductor section has an adequate margin to operate for five years (100\% avajlability) lithout teacining any radiation desibn limit.

END CFLI.

An accurate 30 analysis was performed for the whole reactor to provide the following information: (1) the neutron wall loading in the end cell, (2) the energy deposition in each component, (3) the net tritium breeding ratio, (4) the neutron leakage from the central cell to the and cell, and (5) the hot spot points in the C coils. The 3D geometrical model tor the calculations is shown in Fig. 4-28. The key results from this analysis orf summarized in this section. The neutron wall loading in the end cell has a $0.15 \mathrm{~mW} / \mathrm{m}^{2}$ peak value at $z=46.1 \mathrm{~m}$. The neutron wall loading distribution shows that the C cojls' shield thickness can be tapered to less than the 35 im starting from $z=54 \mathrm{~m}$. Tabje 4-12 gives the energy deposition in each component pet fusion neutron and the statistical errot within one standard deviation. The energy deposition in the $\mathrm{C}$ coils and the end cell biological shield is 90.4 and $35.6 \mathrm{~kW}$, respectively. The shield thickress for the C coils 
Table 4-12. Nuciear heating and power distribution.

\begin{tabular}{|c|c|c|c|}
\hline & \multicolumn{3}{|c|}{$(\mathrm{MeV} / \mathrm{DTn})$} \\
\hline & Neutron & Gamma & Total \\
\hline \multicolumn{4}{|l|}{ Blanket } \\
\hline First wall & $0.3288 \pm 0.51 \%$ & $0.5991 \pm 1.09 \%$ & 0.9279 \\
\hline Breeding zone & $4.8433 \pm 0.63 \%$ & $5.8394 \pm 0.60 \%$ & 10.6827 \\
\hline Ref1ector & $2.9348 \pm 0.69 \%$ & $2.4177 \pm 0.94$ & 5.3525 \\
\hline Total & 8.1069 & 8.8562 & 16.9631 \\
\hline \multicolumn{4}{|c|}{ Central cell coil shield } \\
\hline Steel shield & $1.4112-2 \pm 3.86 \%$ & $1.0859 \pm 11.52 \%$ & 1.1000 \\
\hline $\mathrm{B}_{4} \mathrm{C}$ shield & $6.2042-6 \pm 10.58 \%$ & $8.6578-6 \pm 11.52 \%$ & $1.4862-5$ \\
\hline Total & $1.4118-2$ & 1.0859 & 1.1000 \\
\hline \multicolumn{4}{|l|}{ Central cell coil } \\
\hline Coil case & $2.2878-7 \pm 17.12 \%$ & $7.0058-6 \pm 14.94 \%$ & $7.2346-6$ \\
\hline Coil winding & $7.1454-1 \pm 14.67 \%$ & $3.0479-5 \pm 23.06 \%$ & $1.1194-5$ \\
\hline Total & $9.4332-7$ & $1.7485-5$ & $1.8428-5$ \\
\hline
\end{tabular}

Central cell biological shields

$\begin{array}{lllll}\mathrm{B}_{4} \mathrm{C} \text { shield } & & 8.6626-9 \pm 13.7 \% & 5.4116-8 \pm 15.0 \% & 1.4074-7 \\ \mathrm{~Pb} \text { shield } & & 62.417-9 \pm 23.9 \% & 4.5354-8 \pm 18.1 \% & 4.5978-8 \\ & \text { Total } & 8.7250-8 & 9.9470-8 & 1.8672-7\end{array}$

Choke coil shield

Steel shield

$7.3229-2 \pm 2.26 \%$

$4.5173-1+2.29 \%$

5.2496-1

$\mathrm{B}_{4} \mathrm{C}$ shield

$1.2498-7 \pm 29.3 \%$

$1.3163-7 \pm 34.6 \%$

$2.5661-7$

Pb shield

$2.4027-9 \pm 80.1 \%$

$6.3297-8 \pm 29.6 \%$

6.5700-8

Total

$7.3229-2$

$4.5173-8$

$5.2496-1$

Copper choke coil

$\begin{array}{lllll}\text { Coil case } & & 1.1434-3 \pm 6.28 \% & 4.5239-3 \pm 6.13 \% & 5.6673-3 \\ \text { Coil winding } & 2.0223-3 \pm 5.05 \% & 2.0665-3 \pm 9.06 \% & 4.0888-3 \\ & \text { Total } & 3.1657-3 & 6.5904 & 9.7561-3\end{array}$


Table 4-12. (Continued.)

\begin{tabular}{|c|c|c|c|}
\hline & \multicolumn{3}{|c|}{$(\mathrm{MeV} / \mathrm{DT} \mathrm{n})$} \\
\hline & Neutron & Gamma & Total \\
\hline \multicolumn{4}{|c|}{ Superconductor cluoke coil } \\
\hline Coil case & $2.20 € 0-6 \pm 30.1 \%$ & $8.7658-5 \pm 27.8 \%$ & $8.9864-5$ \\
\hline Coil winding & $1.5796-6 \pm 26.1 \%$ & $2.7122-5 \pm 20.0 \%$ & $2.8702-5$ \\
\hline Total & $3.7856-6$ & $1.1478-4$ & $1.1857-4$ \\
\hline \multicolumn{4}{|l|}{ C coils shield } \\
\hline Steel shield & $3.9440-2 \pm 2.26 \%$ & $1.6293-1 \pm 2.58 \%$ & $2.0237-1$ \\
\hline$B_{4}, \mathrm{C}$ shield & $1.7490-3 \pm 4.36 \%$ & $1.6874-3 \pm 11.2 \%$ & $3.436-3$ \\
\hline Total & $4.1189-2$ & $1.6462-1$ & $2.0580-1$ \\
\hline \multicolumn{4}{|l|}{ C coils } \\
\hline Coil cases & $2.3006-5 \pm 7.87 \%$ & $4.9066-4 \pm 3.92 \%$ & $5.1366^{-4}$ \\
\hline Coil winding & $1.7444-4 \pm 5.78 \%$ & $1.6501-3 \pm 4.91 \%$ & $1.8245-3$ \\
\hline T'otal & $1.9745-4$ & $2+1408-3$ & $2.3382-3$ \\
\hline \multicolumn{4}{|c|}{ End cell biological shield } \\
\hline Water shiejd & $9.1126-4 \pm 7.33 \%$ & $1.1430-5 \pm 33.5 \%$ & $9.2269-i$ \\
\hline$B_{4} C$ shield & $2.4537-10 \pm 38.6 \%$ & $1.1064-6 \pm 78.4 \%$ & $1.0166-6$ \\
\hline Ply shield & $3.1575-12 \pm 58.5 \%$ & $4.0372-7 \pm 55.6 \%$ & $4.0372-7$ \\
\hline Total & $9.1126-4$ & $1.2850-5$ & $9.2411-4$ \\
\hline
\end{tabular}

Power Parameters

Total DT neutron power (MW)

542.55

Di neutron power in the end cel] (MW)

5.54

Neutron wall loading at first wall ( $\mathrm{MW} / \mathrm{m}^{2}$ )

1.95

Neutron leakage from central cell (n/DTn)

$6.50 \times 10^{-4}$ 
Table 4-12. (Continued.)

Power Distribution

\begin{tabular}{lcc} 
& MeV/DTn & $M W$ \\
\hline Blanket & 16.96 & 654.86 \\
Central cell coil shield & 1.10 & 42.47 \\
Central cell coil & $1.84-5$ & $7.10-4$ \\
Central cell biological shield & $1.87-7$ & $7.22-6$ \\
& & \\
Choke coil shield & $5-25-1$ & 20.27 \\
Copper chake coil & $9.76-3$ & $3.76-1$ \\
Superconductor choke coil & $1.18-4$ & $4.56-3$ \\
& & 7.95 \\
C coits shield & $2.06-1$ & $9.04-2$ \\
C coils & $2.34-3$ & $3.56-?$ \\
End cell biological shield & $9.24-4$ & \\
\hline
\end{tabular}




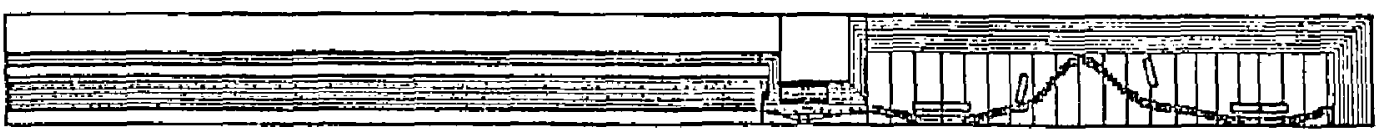

$x-Z$ PLANE

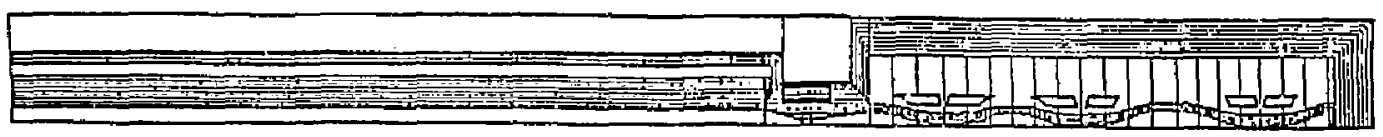

$X=Y-Z$ PLANE

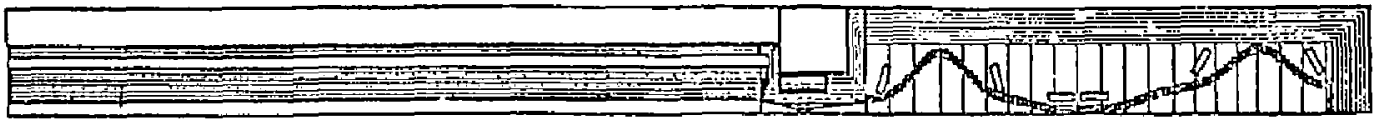

$Y-Z$ PLAME

Figure 4-28. Three-dimensional model. 
in the 3D analysis is $35 \mathrm{~cm}$. Figure 4-29 gives the emergy deposition in the $C$ coils as a function of the shield thickness for tulgsten and steel type shield based on a one-dimensional cylindrical model.

This one-dimensional model assumes that the radiation leakage is completely deposited in the coils. For the $35 \mathrm{~cm}$ of steel shields, the onedimensional model estimates $133 \mathrm{~kW}$ deposited in the $\mathrm{C}$ coils compared with the 90.4-kW estimate from the 3D analysis. These results give a coverage ratio of $90.4 / 133=0.68$, Usirg this coverage ratio, Toble $4-13$ gives the energy deposited in the coils as a function of the shield thicktiess for both types of shield. For the FPD-I design, it is possible to use $45 \mathrm{~cm}$ of shield instead of $35 \mathrm{~cm}$ except where a few spots reduce the energy deposition in the c coils to about $26.4 \mathrm{~kW}$. The point wich minimum space for shielding has a $7.7 \mathrm{~mW} / \mathrm{cm}^{3}$ maxinum nuclear heating rate in the coil case (a 2 -cm coil case thiskness was used in the $3 D$ analysis), which is an allowable lovel for the $C$ coil design.

\section{MATERTALS}

The projected operating Iifetime of FPD is 2.5 effective full power ycars, with a first wall neutron loading near $1 \mathrm{Mw} / \mathrm{m}^{2}$. This exposure of $2.5 \mathrm{mw} / \mathrm{y} / \mathrm{m}^{2}$ or less raises questions about the potential life-limiting effects of radiation on component material. Although no complete analysis of component liferime has been conducted, a few of the issues of potential cancern are outlined here.

Because FPD must breed tritium, and a MARS-like blanket ${ }^{2}$ has been assumed, the operating conditions for the first wall and blanket structural material are reactor relevant. The use of the hiph breeding blanket will requice temperatures in the range of 300 to $400^{\circ} \mathrm{c}$, even though the thermal energy will only be rejected to a heat dump system. The neutron flux at the first wall will result in approximately $25 \mathrm{dpa}$ at end of $1 \mathrm{ife}$ and the generation of 250 to 400 at.ppm lle in steels. 


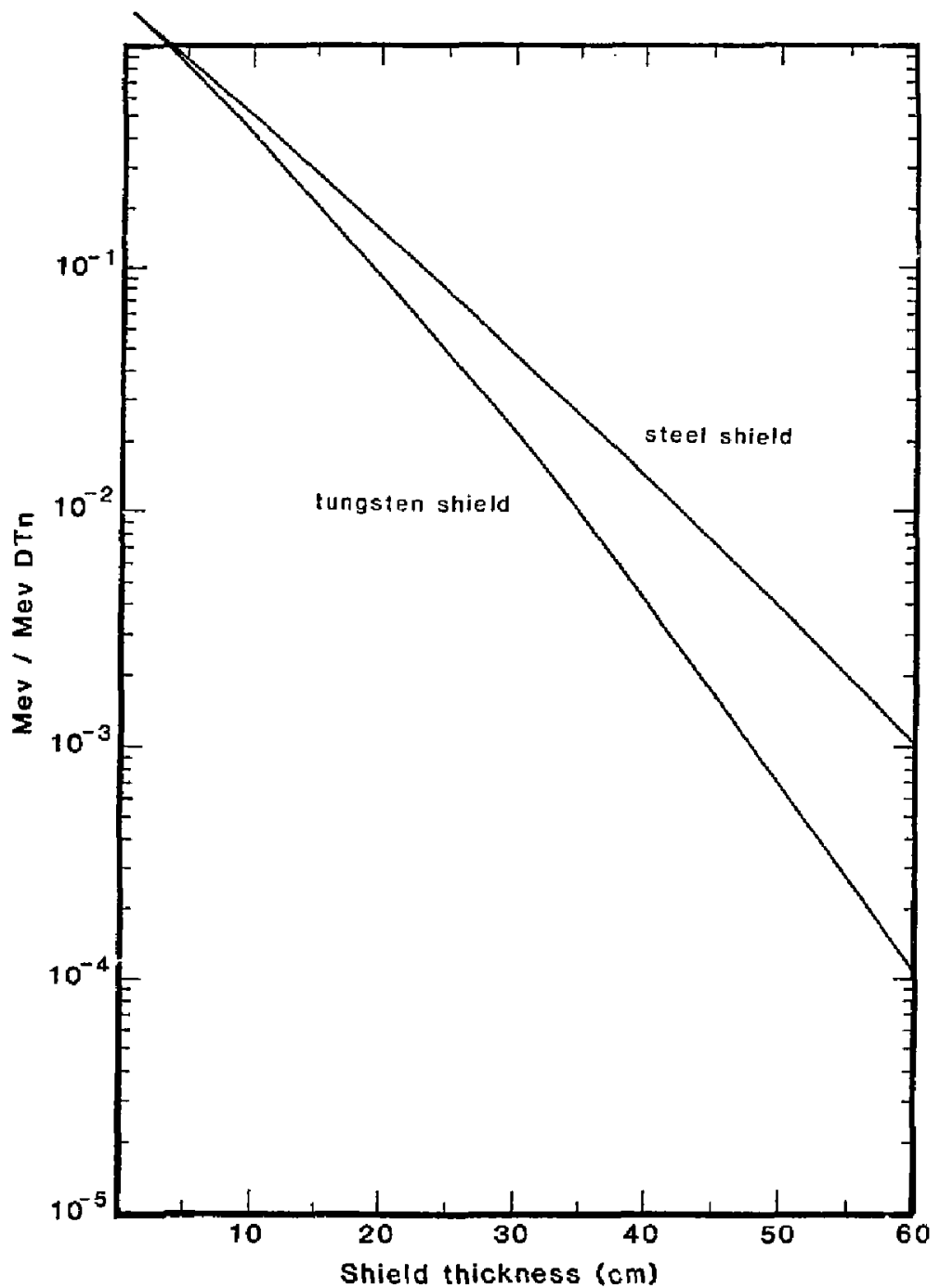

Figure 4-29. Energy deposited in the coils as a function of the shield thickness. 
Table 4-13. Energy deposited in the $C$ coils as a function of shield thickness for steel and turgsten type shields.

\begin{tabular}{ccc}
\hline $\begin{array}{c}\text { Shield thickness } \\
(\mathrm{cm})\end{array}$ & $\frac{\text { Power deposited in the } \mathrm{C} \text { coils }(\mathrm{kW})}{\text { Steel shield }}$ \\
\hline 35 & 90.4 & 33.9 \\
40 & 49.0 & 14.3 \\
45 & 26.4 & 6.0 \\
50 & 14.3 & 2.6 \\
55 & 7.6 & 1.0 \\
\hline
\end{tabular}

The structural material specified for the MARS blanket is the ferritic/martensitic steel HT-9. The compatibiity, strength, ductility and fatricability of this alloy should be adequate for the FPD application. For the lifetime of $2.5 \mathrm{MW}-\mathrm{y} / \mathrm{m}^{2}$, the alloy is not expected to swell, and tensile properties and irradiation creep rate will not limit the reactor performance. A shift in the ductile-to-brittle transition temperature (DBTT) will result from the irradiation of a ferritic/martensitic steel. Data on HT-9 show that the DBTT could be shifted above $100^{\circ} \mathrm{C}$ by FPD conditions. The available experimental results suggest that the $9 \mathrm{cr}-1$ Mo steel under study for fusion reactor application would be a better choice than HT-9 due to the lower post-irradiation DBTT. Continuing efforts of the materials program can be expected to qualify one of the steels, or a modified steel in the-Cr-Mo family, for service at FPD conditions. Progress of these efforts should be monitored, so that the best candidate steel is selected for FPD.

An austenitic stainless steel such as type 316 or an advanced developmental grude is also viable fot the Mars-like first wall and blanket of FPD. The data base for irradiation effects on austenitic steel is much larger than on ferritic/martensitic steels, and the DBTT embritt]ement does not occur in these steels. The austenitic steels would also offer some simplification in fabrication, but somewhat poorer thermal properties, relative to HT-9. The 
compatibility limits of the austenitic stainless steels with liquid LiPb ate inferior to the ferritic/martensitic steels, but would be adequate for a reduced temperature, Mars-1ike blanket.

The U.S. Fusion Reactor Mater:als Program has work in progress to develop low activation steels. The goal is to produce both austenitic and ferriticl martensitic grades with new compositions that wi 1 allow simplified disposal of spent reactor components under the Class $C$ catagory of lOcFR61. There are ewo families of steels under study: austenitic steels with Mn replacing hi and with low levels of Mo, $N$, Nb and $C_{u}$, and fertitic/martensitic steels with $W$ and/or $V$ replacing Mo and with low levels of $\mathrm{Ni}, \mathrm{N}, \mathrm{Nb}$, and $\mathrm{Cu}$. Because this program was not initiated until late 1983, it is not expected to deliver qualified steels in time for the FPO project. The use of these developmental steels without an adequate data base would not seem to be a justifjable risk.

Another class of critical components in FPD is the magnet materials. For the central cell superconducting magrets, the organic insulation is the critical component, and the shield must be designed to provide adequate protection of this insulation. The radiation limits on the iosulation is poorly established, and is probably below $10^{9}$ rar for epoxy-glass insulation and below $10^{10}$ rad for polyimide-glass irsulation. Ongoing research will refine these limits in the next few years, and allow greater confidence in designing a s'ield to give adequate protection. The insert northal magnet in the choke coil is exposed to the unshielded neutron flux and will be a rife-liniting reactor component that must be designed for simple replacemert. Analysis of the 1 ifetime of this magnet is provided in the MARs study. ${ }^{2}$ Areas of uncertainty in these estimates lie in the effects of radiation on the ceramic insulator anc on the copper alhog conductor. Active research on both materials will allow refined lifetime fluence estimates and may provide superior candidate materials in time for the FPD project.

Ceramic reactor components in addition to the choke coil insulation are susceptible to radiation damage. These materials may be used in the auxiliary lieating systems, beamlines, direct converters, and other subsystems. The potential effects on these components have yet to be examined in detail. 
Several other classes of materials will need to be investigated: candidate selection must be verified and service performance predicted. These materials may include the following: shield materials to provide superior performance to the steel-water shields (perhaps $T i t l$ ), better thermal barriers in load support columns (perhaps using composite-metal combinations), tritiun barrier materials, and a whole host of other component systems, each with its own specific set of material property requirements.

\section{ELEC'RICAL, SYSTEMS}

The electrical systems include the electric plant equipment of the ac power system, the power conversion for the confinement magnets, and the power conversion for the microwave and NBI systems. These electrid systems also include the instrumentation and control systems.

AC POWER SYSTEM

The ac power system includes all the switch gear, transformers, and distribution feeders of FPD. In addition to the distribution of power to the electrical loads identified in Table 4-14, the ac power system includes the bussing and fault protection for the turbine generator and direct converters, and the javerters for the direct conversion system. Referring to Table 4-14, the total recycle power neaded by FPD-1 is $280.1 \mathrm{~W}$. The total electrical power output is $40 \mathrm{MW}$ from direct converters and $135 \mathrm{MW}$ from the turbine generator. Engineering $Q_{e}$, defined as power generated divided by power consumed by the plant, is 1.0 .

Figure 4-30 is a one-line diagram of the FPD-1 power distribution system. Mnemonics used in the diagram are identified in Table 4-15. Medium voltage power is provided at both $13.8 \mathrm{kV}$ and $2.4 \mathrm{kV}$ level. The direct converter and turbine generator provide power to the $13.8 \mathrm{kV}$ bus through $1200 \mathrm{~A}$ and $3000 \mathrm{~A}$ circuit breakers, respectively. There is no net power delivered to the $230 \mathrm{kV}$ utility line; neither is there any separate facility power substation. The two main transformers supply all the FPD-I power from one utility line. 
Table 4-14. Estimate of FPD-I electrical pDwer generation and loads.

\begin{tabular}{|c|c|c|}
\hline \multirow[b]{2}{*}{ Power generation or load description } & \multicolumn{2}{|c|}{ Electrical power (MH) } \\
\hline & Input & Output \\
\hline Central cell neutral beam injectors & 0 & \\
\hline Central cell ICRH power & 95 & \\
\hline Plug cell neutral beam injectors & 5 & \\
\hline Amchor cell IGRH & 7 & \\
\hline Anchor and plug cell drift pumps & 28 & \\
\hline Plug cell ECRH & 60 & \\
\hline Resistive coil power & 40 & \\
\hline Cryogenic system power & 25 & \\
\hline Cooling system and vacuum system pover & 12 & \\
\hline Superconducting coil power systems & 1. & \\
\hline Fuel processing and tritium cleanup & 7 & \\
\hline Direct converters & & 40 \\
\hline Turbine-generator & & 195 \\
\hline Total (with axicell) & 280 & 175 \\
\hline
\end{tabular}




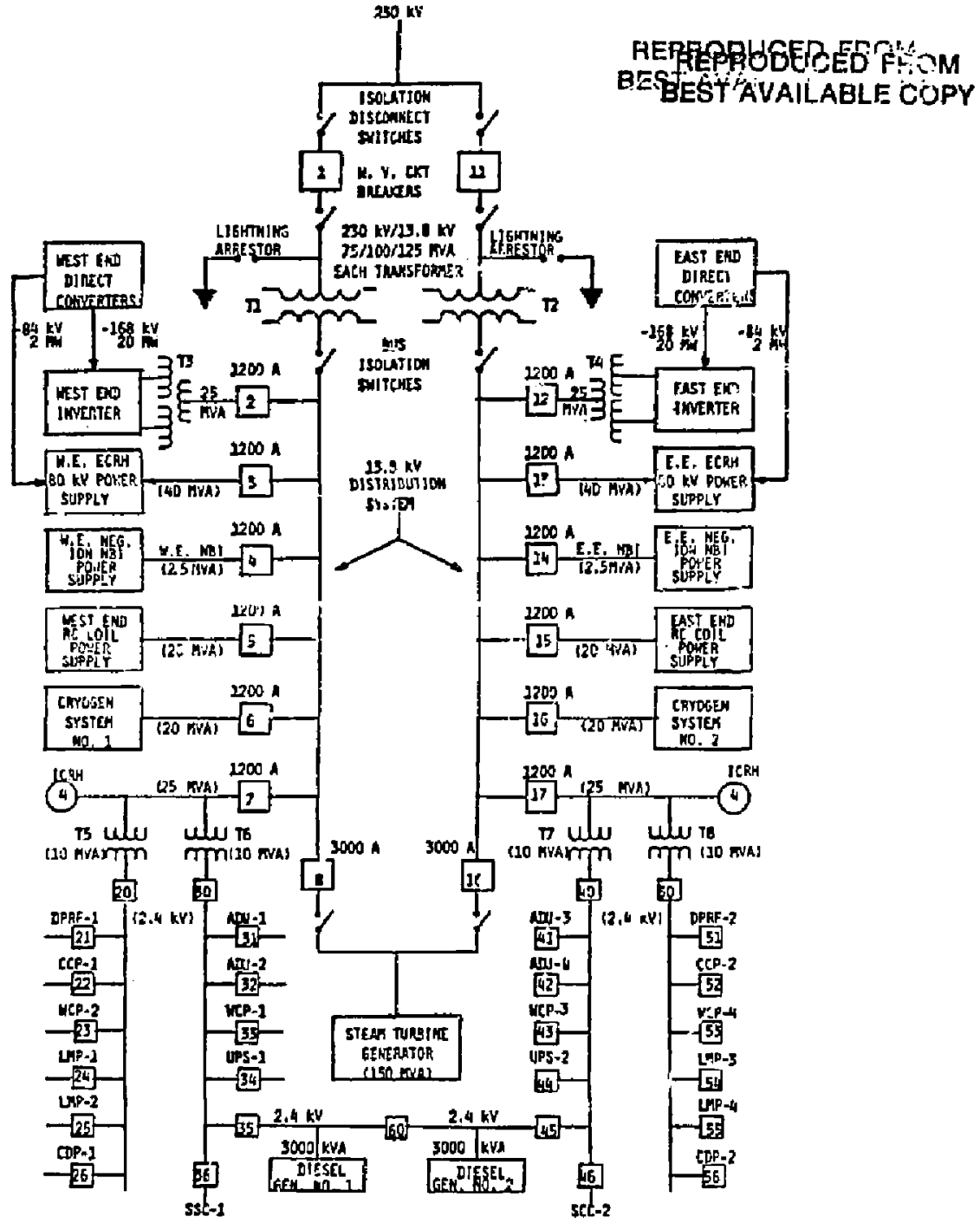

Figure 4-30. One-line diagram of the power distribution system fo. Fip-t, 
T ble 4-15. Mnemonic definitions.

\begin{tabular}{|c|c|}
\hline Mnemonic : & Description \\
\hline DPRF & Drift pump rf fower \\
\hline$A D U$ & Atmcsplaric detritiation unit power \\
\hline WCP & Water cooling pump power \\
\hline LMP & Liquid mecal pump power \\
\hline Ups & Uninterruptible power supply \\
\hline CFP & Condensate feed pump power \\
\hline $\mathrm{CCr}$ & Condenser cooling pump prwer \\
\hline $\operatorname{scc}$ & Sularconducting coil power \\
\hline NPS & Number of power supplies \\
\hline PSVOLT & Power supply voltage \\
\hline PSKA & Pcwer supply current (kA) \\
\hline BUSLM & Bus length $(m)$ \\
\hline NEKRS & Number of dc circuit breakers \\
\hline NDR & Number of dump resistors \\
\hline EDHMJ & Maximum energy dissipated in a dump resiscor (MJ) \\
\hline PDRMW & Marimum power to a dump resistor (MW) \\
\hline
\end{tabular}


Facility power and the diesel Renerator backup power are provided at the $2.4 \mathrm{kV}$ level. There is a trend towards using only two medium voltages taday, namely, $4.16 \mathrm{kV}$ and $13.8 \mathrm{kV}$. It may be desirable to change from $2.4 \mathrm{kV}$ to $4.16 \mathrm{kV}$, as proposed for FPD-II.

ELECTRICAL. POWER CONVERSION SYSTEMS

The electrical power conversion system includes all the power supplies for the magnets and power injection systems for the plasma, coil protection equipment, and the cables and bussing. Table 4-16 contains key magnet power conversion system data for FPD $I$. The magnet design was not well enough established during the early study to determine the coil currents. Coil currents were based on rypical currents used in the MARs magnets. ${ }^{2}$ These MARS currents are much lower than the magnet design currents established later for FPD-II. As a result, the bussing and coil protection cost far FPD-I are substentially less than for FPD-II. Egergy requirements were calculated for the central cell and axicell coils. For end cell magnets, the energy requirements were extrapolated from similar data for MARS.

\section{TRITIUM SYSTEMS}

The features of a fusion reactor like EPD-I that are important for the design of the tritium systems are: (1) the amount of fusion power and the fractional burn; (2) the use of neutral beams or pellet fuelers for fueling;

(3) the presence of a blanket module with or without a power train; and

(4) the size of fuel storage requirements.

The size of the fuel processing and storage system depends on the fusion power, the fractional burn, and the length of the burn. These input parameters and the tritium and deuterium mass flow rates that result are shown in Table 4-17 for two different fueting options--positive neutral beams anc pellets. The overall efficiency of positive neutral beams ranges from 0.2 to 0.3 ; therefore, the total tritium input ranges from 22 to $33 \mathrm{~g} /$ hour or 7 to $10 \mathrm{~kg}$ during a burn cycle of 300 hours. The fueling rate for pellet fuelers may range from 3 to 10 pellets $/ \mathrm{s}$ with $2100 \%$ waste at each of these rates. 
Table 4-16. The FPD-II magnet power conversion data.

\begin{tabular}{lcccccccc}
\hline \multicolumn{1}{c}{ Magnet group } & NPS & PSVOLT & PSKA & BUSLM & NBKRS & NDR & EDRMJ & PORMH \\
\hline Central cel1-7 & 1 & 30 & 6 & 150 & 5 & 16 & 175 & 2.2 \\
Choke insert-2 & 1 & 1 & \pm 220 & 100 & 0 & 0 & 0 & 0 \\
Choke bkgrd-2 & 2 & 30 & 9 & 100 & 4 & 8 & 500 & 3.0 \\
Transition 1-2 & 2 & 12 & 6.5 & 100 & 4 & 8 & 100 & 1.6 \\
Anchor cel1-4 & 2 & 12 & 6.5 & 120 & 4 & 8 & 100 & 1.6 \\
Plug cell-4 & 2 & 12 & 6.5 & 140 & 4 & 8 & 120 & 2.0 \\
Transition 2-2 & 2 & 12 & 7.0 & 160 & 4 & 8 & 75 & 1.8 \\
Recircularize-2 & 2 & 12 & 7.0 & 180 & 4 & 8 & 75 & 1.8 \\
\hline
\end{tabular}

"For mnemonic definitions see Table 4-i5.

The total tritium input ranges from 13 to 38 g/hour; the minimum rate corresponds to a supply rate of $4 \mathrm{~kg} / \mathrm{cycle}$. At the lower throughput, the pellet fueler has an advantage over neutral beams for the following reason. First, since two hours of tritium fuel is stored to ensure constant fueling during operation, higher fueling rates result in higher inventories. Second; processing units will contain higher tritiun inventories at the higher rates. Using the throughput rates in Table 4-17, tritium inventories in the test cell and other processing areas are determined. These are shown in Table 4-18. A system with an inventory of $200 \mathrm{~g}$ could be used so handle both options.

The units supplied in the processing area include uranium storage beds, a fuel cleanup unit, a cryogenic distillation unit, a waste gas recovery system, a solid waste disposal system plus all controls, monitors, analytical equipment and necessaxy secondary confinement, and processing systems needed to support the system. The units are sized based on Tritium Systems Test Assembly (TSTA) reference units; they are located in a tritium processing builoing. 
Table 4-17, Tritium and deuterium mass flow rates for FPD-I.

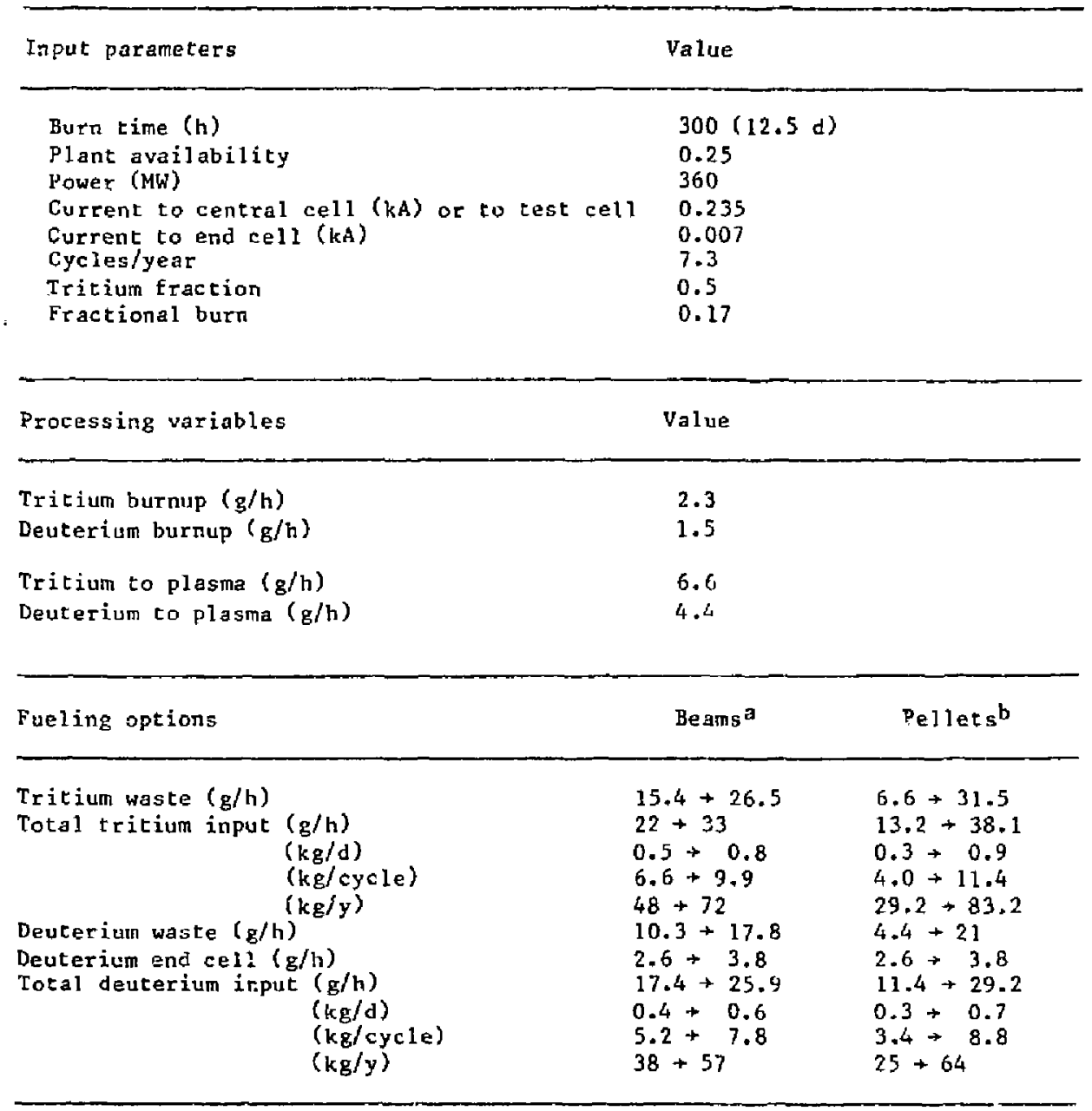

a Beam efficiencies (+) 20-30\%, (-) 7-10\%.

b Waste will range from $100 \%$ to $300 \%$. The maximum assumes a rate of 10 pellets/s rather than 3 pellets/s (base case). 
Table 4-18. Tritium inventories $(g)$ in FPD-I.

\begin{tabular}{|c|c|c|}
\hline Option & Beams & Pellet \\
\hline \multicolumn{3}{|l|}{ Location } \\
\hline Structure ${ }^{a}$ & $<30$ & $<30$ \\
\hline Beam pump ${ }^{b}$ & $2.5+4.2$ & -- \\
\hline Surge tank & $2.5+4.2$ & -- \\
\hline Pellet fueler & -- & 10 \\
\hline B lanket & 1 & 3 \\
\hline Blanket recovery & 3 & 1 \\
\hline Total test cell & $39+42$ & 44 \\
\hline Storage & $44+66$ & $26+76$ \\
\hline Pellet preparation & -- & $13 \rightarrow 38$ \\
\hline Fuel cleanup & $45+48$ & $43+50$ \\
\hline Cryogenic distillation & $55+58$ & $53-59$ \\
\hline Total processing & $144+172$ & $135+223$ \\
\hline Total & $183+214$ & $179 \rightarrow 267$ \\
\hline
\end{tabular}

The blanket system is assumed to supply all tritium burned ( $25 \mathrm{~kg} /$ year) and all tricium lost to decay, released or lost to waste in processing. The amount lost to decay $(<20 \mathrm{~g} /$ year $)$ depends on the plant inventory. The amount lost to waste depends on the efficiencies of the multiple processing systems. The assumptions made ar. that losses will be $\leq 0.1 \%$ of the amount processed or $\leq 85 \mathrm{~g} / \mathrm{year}$. The required breeding ratio is then 1.03 .

The processing system to remove tritium from the $\mathrm{LiPb}$ blanket includes $a$ tritium removal system, a tritium purification system to remove gamma impurities, a tritium control system for the power train coupled to the blanket, an impurity removal system for the Lipb plus auxiliary equipment, dump tanks, etc. This equipment is located in the hot cell. 
Four different atmospheric tritium recovery (ATR) systems are provided for the four tritium areas--test cell, hot cell, tritium building, and heat exch-nger building. The units are sized for the air volumes processed and the processing time selected ( 5 days). The areas have minimum iriternal volumes of $25 \times 10^{4} \mathrm{~m}^{3}, 22 \times 10^{4} \mathrm{~m}^{3}, 21.6 \times 10^{4} \mathrm{~m}^{3}$, and $23.2 \times 10^{4} \mathrm{~m}^{3}$. A throughput rate of $0.5 \mathrm{vol} \% / \mathrm{min}$ j.s needed to achieve cleanup in 5 days. This corresponds to $250 \mathrm{~m}^{3} / \mathrm{min}, 100 \mathrm{~m}^{3} / \mathrm{min}, 80 \mathrm{~m}^{3} / \mathrm{min}$, and $160 \mathrm{~m}^{3} / \mathrm{min}$, respectively.

A tritiated water recovery unit is provided. It serves to remove tritium from any water system that becomes contaninated, and it is also used to concentrate the tritiated water callected by the different ATR systems. Water systems that may become contaminated are those that serve beam dumps, halo plates, direct converter units, etc. The unit has the potential for reducing tritium waste from water systems by a factor of $10^{4}$.

MAINTENANCE REQUIREMENTS AND OPERATING AVALLABILITY

MAINTENANCE PF.QUUIREMEN'S

The maintenance requirements for FPD-I are based on the earlier work done ror the Technology Demonstration Facility (TDF) ${ }^{14}$ and the MFTF- $\alpha^{+}$T facility. ${ }^{15}$ These requirements were used to guide the development of the FPD-I configuration in the arsas of shield design, component location, and access. The primary thrust of these requirements is that contact operations are permitted on the device, 24 hours after shutdown, provided the plasma chamber is unopened and all shielding is in place. The biological shield is designed to limit activation to $0.5 \mathrm{mrem} /$ hour one day after shutdown. This is in accordance with DOE Order 5480.1 , Chatser XI, "Reyuirements for Radiation Pratection," which stipulates that a design objective of one-fifth the maximum permissible dose to radiation workers will meet the ALARA requirement of 1 rem/year. Under these conditions, workers may spend up to 2000 hours/year (40 hours/week) near the device. This enables personnel to rou' inely perform hands-on inspection, disassembly of connections, maintenance equipment setup, and supervision of maintenance activities in the reactor cell prior to any device disassembly.

Maintenance operations that require opening the plasma chamber must be performed remotely because of the high gamma radiation within the shield 
boundary. These operations use proven remote-equipment technolozy in the areas of manipulator handling and vieting.

Component installations are modularized and arranged so that independent: disassembly and removal may be accomplished wherever practical using overhead lifting. In addition, reasonable access on the device and within the reactor cell is provided to accommodate lifting fixtures and remote equipment. An example of this access is the overhead access into the end cell to vertically remove $\mathrm{C}$ coils or the choke coil set as independent modules. The end cell access cover is estimated to weight 85 tonnes (without water) the c coils weigh $<85$ tonnes, and the choke coil set weighs 130 tonnes (without shielding). Fach of these components weighs less than the main crane capacity of 250 tonnes. Table 4-19 is a listing of ma for component weights.

Table 4-19. Major component weights for FPD.

\begin{tabular}{lc}
\hline \multicolumn{1}{c}{ Component } & $\begin{array}{c}\text { Weigint } \\
\text { (tonres) }\end{array}$ \\
\hline Central cell module A & 155 \\
Central cell module B & 110 \\
End cell access cover & $235^{a}$ \\
Central cell solenoids & 419 \\
Holo scraper/direct converter & 10 \\
Transition coil (T1) & 78 \\
Transition coil (T2) & 56 \\
Recircularizing coil & 15 \\
Choke coil set (without shield) & 129 \\
Anchor coil (Al, A2) & 56 \\
Plug coil (P], P2) & 66 \\
\hline appD I; the cover for FPo II weighs \\
\hline 85 tonnes.
\end{tabular}


In-vesse 1 inspection will precede operations that require opening the plasma chamber. The numerous locations along the length of FPD (approximately every 10 meters) with air-lock interfaces will allow full viewing of the components internal to the plasma chamber, without the requirement of venting. A more detailed discussion can be found in Ref. 15 .

Several other maintenance requirements are noteworthy, even though they do not impact the configuration design: (1) personnel and maintenance equipment are not permitced in the reactor cell during device operation. (2) Prior to, and during maintenance operations, power supplies are shutdow and coils are de-energized. (3) Superconducting coils may be kept at cryogenic temperatures for maintenance operations that do not require venting the plasma chamber.

OPERATING AVAILABILITY

Tir nperating life for EPD is ten years with an availability objective of 25\%, defined as a perconcage of total calenuar time. If the operations plan used for MFTF- $\alpha+T^{1}$ is assuned for FPD, the annual allocation of time is as shown in Table 4-20.

Table 4-20. Time allocation for FPD.

\begin{tabular}{lcc}
\hline Allocation & \% of Total & Hours \\
\hline Average operating time of the device & 25 & 2190 \\
$\begin{array}{l}\text { Scheduled downtime; } 2 \text { weeks/month, } \\
5 \text { days/week, } 2 \text { shifts/day }\end{array}$ & 23 & 1920 \\
$\begin{array}{l}\text { Potentially available but not operating } \\
\text { (PABNo); all remaining calendar time }\end{array}$ & 52 & $4530^{\circ}$ \\
\hline
\end{tabular}

aThis time is available for device operation or maintenance.

We assume that the operating time for the device occurs within a 5-ton-6-day week with also two working shifts similar to that of scheduled downtime. We also assume that the scheduled downtime averages two weeks per month but may occur at irregular intervals, depending upon the mean tine between failure 
(MTBF) and mean time to replacement (MTTR) of components. All remaining time (PABNO) consists of the third daily shift and weekends and is approximately one-iralf of the calendar yeat. The PABNO time can be considered the reserve for unscheduled maintenance operations, thermal cycling of the superconducting coils and plasma chamber reconditioning, and additional device operation beyond the availability objective.

\section{Component Replacements}

Several major components have been identified as requiring scheduled replacements. These components are listed in Table 4-21 along with estimates of their $\mathrm{MTBF}^{15}$ and the total number of replacements required, assuming 2190 hours/year of device operations. All others are considered to be lifetime components, but with varying degrees of risk. OnIy those replacements

Table 4-21. Replacement scheme for components.

\begin{tabular}{lcc}
\hline Component & $\begin{array}{c}\mathrm{MTBF}^{a} \\
\text { (hour) }\end{array}$ & $\begin{array}{c}\text { No. of } \\
\text { replacements }\end{array}$ \\
\hline Choke coils & 2200 & $8-10$ \\
Ion sources & 900 & $20-24$ \\
Lon dumps & 1800 & $10-12$ \\
Cryopanels & 4400 & 5 \\
Windows & 1600 & $12-14$ \\
\hline
\end{tabular}

Mean time between failures.

in the neutral beam system, and possibly the replacement of diagnostics, do not require venting the plasma chamber. Therafore, all other operazions are assumed to require thermal cycling of the superconducting coils.

The coils are designed to accommodate 120 warmup/cooldown cycles over the ten year life of the device, and Batzer et al, estimates that each cycle requires six weeks of downtime. ${ }^{15}$ clearly, it is not possible ta accommedate 120 cycles duriub the device lifetime. An estimate of the number 
of cycles can be made by assuming that the scheduled downtime plus the PABNu Lim: is available for cyrling if some maintenance activities can be accomplished in parallel. In addition, we assume that plasma chamber detritiation and reconditioning also occur simultaneausly; therefore, 6470 hours are potentially available for an upper limit of six thermal eycles per year.

\section{PLANT FACILI'TIES}

The plant for FPD-I includes. features common to any experimental fusion facility as well as features unique to mirror fusion. The various elements of the plant are designed and arranged to achieve a smoothly functioning and economic arrangement. Much of the conceptual design effort is focused on high cost facilities, whereas a less detailed definition is given for the remaining facilities. This effort has resulted in an estimate of the approximate sizes and $a n$ identification of the general characteristics of the major facilities. Although all elements of the facilities, are accounted for in the cost estimate, only the principal elements are summarized in the following paragraphs.

\section{STTE PLAN}

A representative location for FPD-type devices is identified within the Lawrence Livermore Nationa] Laboratory (LLNL) complex at Livernore, California, shown in Fig. 4-31. This figure shows the relative location of FPD with respect to other LLNL facilities. Good access, ease of construction, and ucilization of lud facilities to the maximm practical extent were considered in identifying the TPD locatirn.

\section{PLANT ARRANGEMEN'T}

The relative location of all najor buildings and facilities are shown in Fig. 4-32. This layout represents a compact arrangement to minimize buildings and systems costs, which are affected by the ehoice of layout. Common building walls and floor mat, short piping and ducting, and common use of support systems are examples of cost-reducing measures used in the plant arrangement. An additional feature used is the separation of nuclear grade 


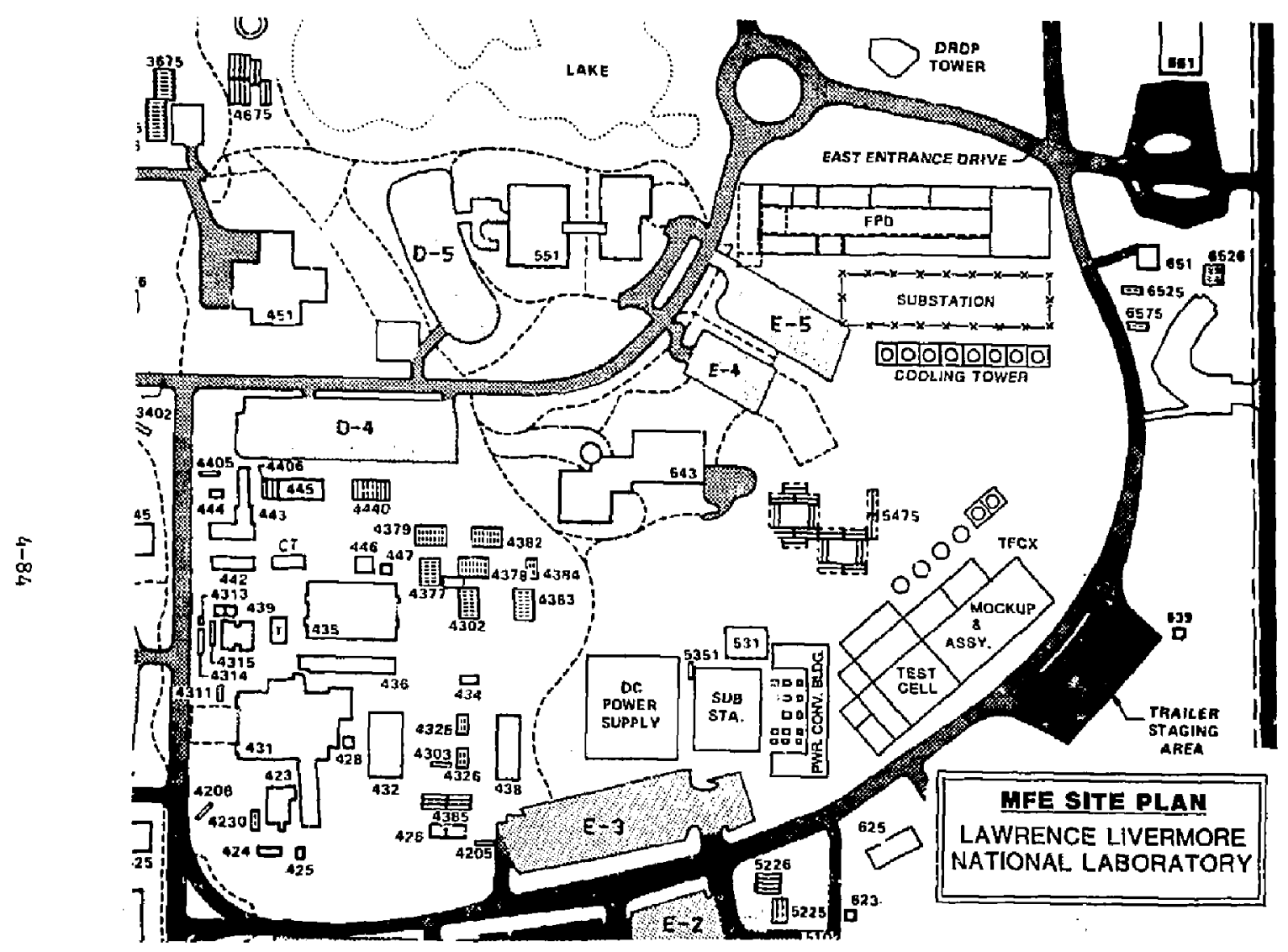

Figure 4-31. The Magnetic Fusion Energy (MFE) site plan at Lawrence Lfvermore National Laboratory. 


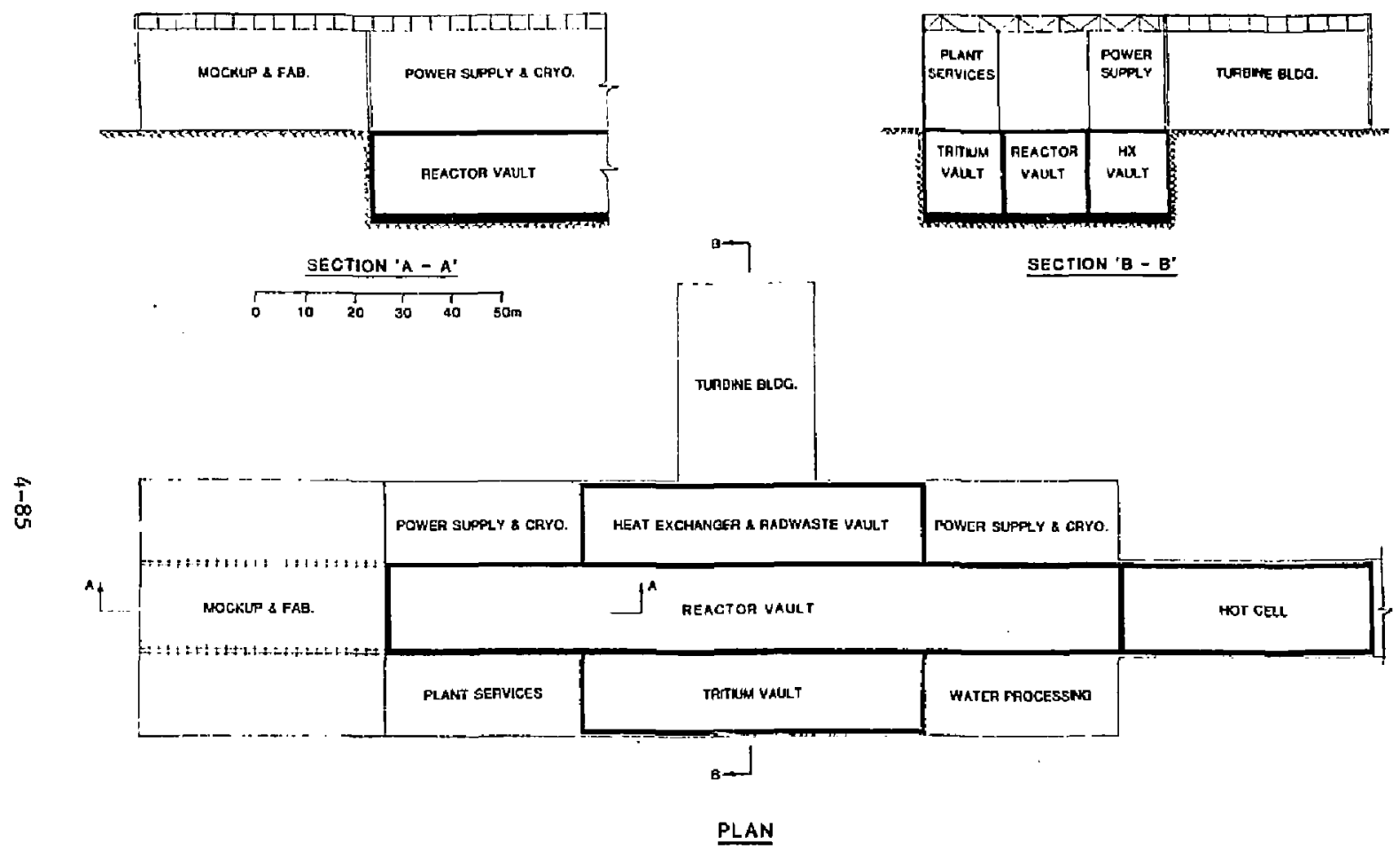

Figure 4-32. The FPD-I building arrangement. 
and non-nuclear grade systems and structures so that the non-nuclear grade system and structures may be constructed at a much lower cost. If these two grades are not separated, the entire plant needs to be nuclear grade, as are the present fission plants; thus, the nuclear grade facilities of FPD are clustered cogether to provide the desired separation.

Snme of the supporting structures are not shown in Figs. 4-30 and 4-31 because corresponding existing LLNL Facilities are adequate for these purposes (e.g., control building).

All plant buildings, structures, and systems are designed to meet Department of Energy (DOE) and other appropriate safety and environmental requirements.

Reactor Vault

Because the reactor vault is the most important and expensive of all the buildings, a design concept trade off involving this building was conducted with attention paid to: (1) underground vs above ground comstruction, and (2) horizontal vs vertical methods of reactor module replacement, affecting the width and height of the building. Based on economic and tecinical considerations, we selected an underground reactor building using the vertical method of module replacement ( $E$ ig. 4-31).

A unique feature of the reactor building shown in Fig. 4-33 is the overliead transporter corcept. In this concept, the main crane (500 tonne) is located in the transporter, which is external to the reactor building. The external transporter leaves the reactor building much shorcer chan if the crane were located inside the building. To remove a reactor nodule duriug a maintenance operation, the transporter is placed directly over the module. A smaller crane (75 tonne) inside the transporter removes the $T$-shaprd roof beams to allow tine lifting of the reactor module with the help of the Irger crane. After the module is lifted, the roof beams are replaced and the module is transported to the hot cell. In this cell, a similar procedure is used to lower the module.

A safety concern in this concept is the leakage of tritium from the reactor vaut into the transporter and then to the space outsire the transporter. To mitigate this concern, the space directly above the reactor 


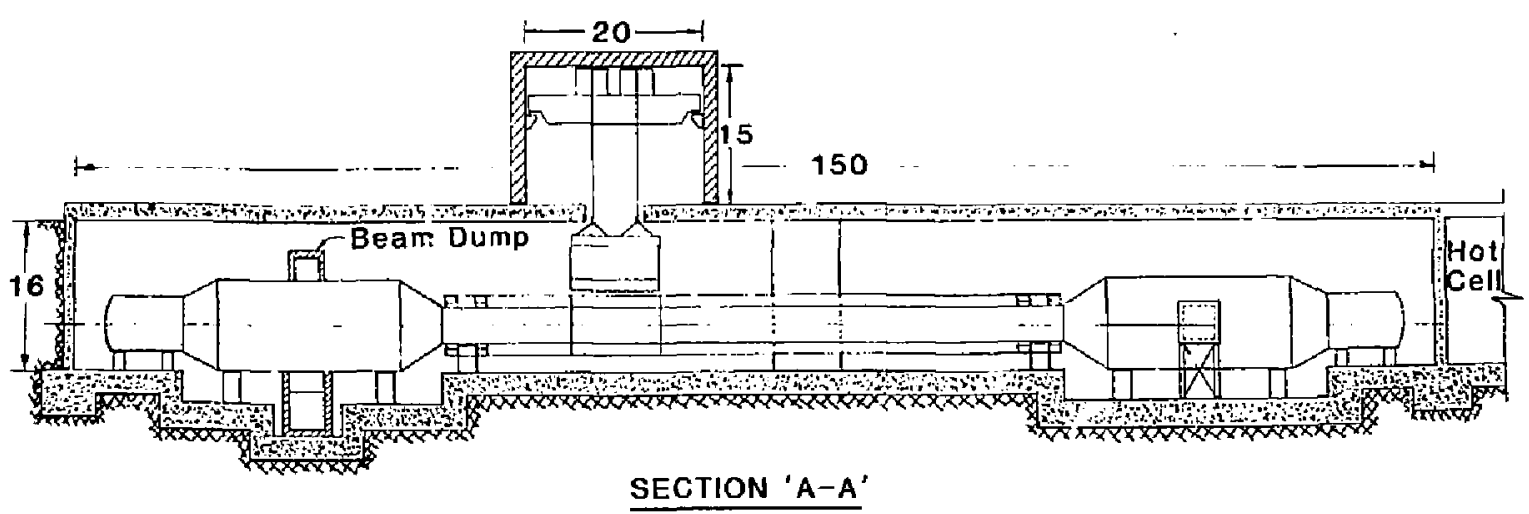

$\underset{1}{\mathfrak{d}}$

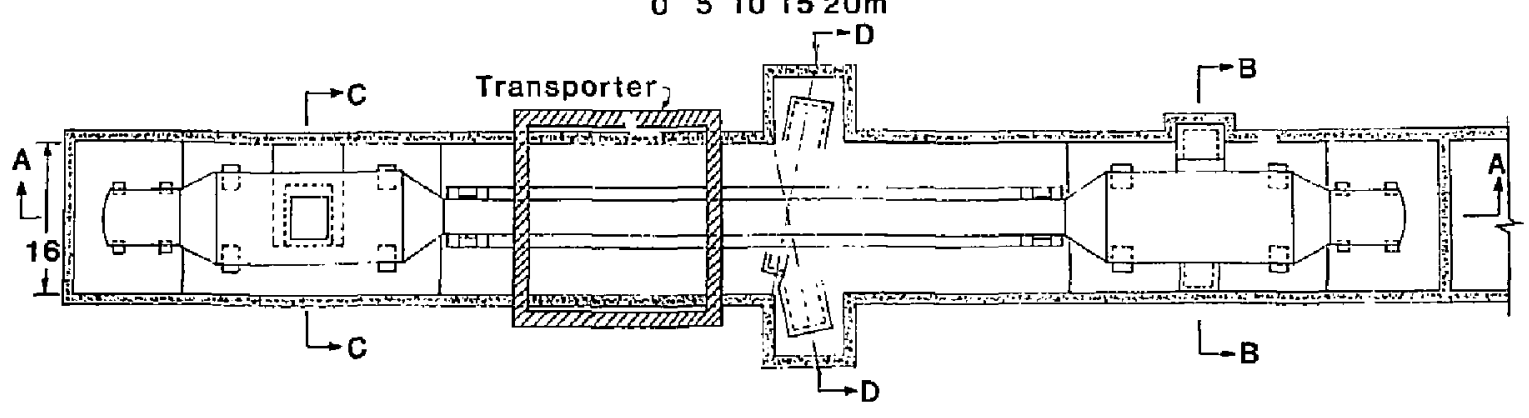

\section{PLAN}

Figure 4-33. The FPD-I reactor building-trench styls. 
vault (i.e., the tranporter fassageway) is made gas-right to reduce the leakage of critium into the environment. Moreover, a sutatmospheric pre sure will be maintained in this space.

\section{Dcher Major Builitigs}

Other major buildings and structures that are provided for FPD-I plant include: hot rell, tritium vault, heat exchanger and radwaste vault, power supply and ceyogenics building; fabrication, assembly anc mockup building; plant services building; water processing building; control building; curbine building; cooling tower; and miscellaneous structures.

\section{Mechanical Systems}

The heat transpor: system for FPD-I transports heat fron the reacfor (blanket, reflector, direct converter, halo scraper) to the steam generator. Total thermal power is $422 \mathrm{MW}$. A steam turbine power conversion system generates $164 \mathrm{MW}$ gross electric power. The heat rejection system rejects $258 \mathrm{MW}$ through a mechanical draft wet cooling tower (Fig. 4-34). An additional $80 \mathrm{MW}$ is rejected from the auxiliary cooling systems.

In addition to the major suatem described soove, a large number of ut ler mechanical systems are needed to suppart the operation of FPD-I. Some $::$ these systems are:

- Auxiliary cooling system,

- Emergeney cooling system,

- Radwaste handling system,

- Liquid metal ( $L i P b$ ) processing system,

- Water supply systems,

- Air supply systems,

- Gas systems,

- Heating, ventilation, and air cenditioning systems,

- Radiation moritoring systen,

- Fire protection syscem,

- Plant sucurity system. 


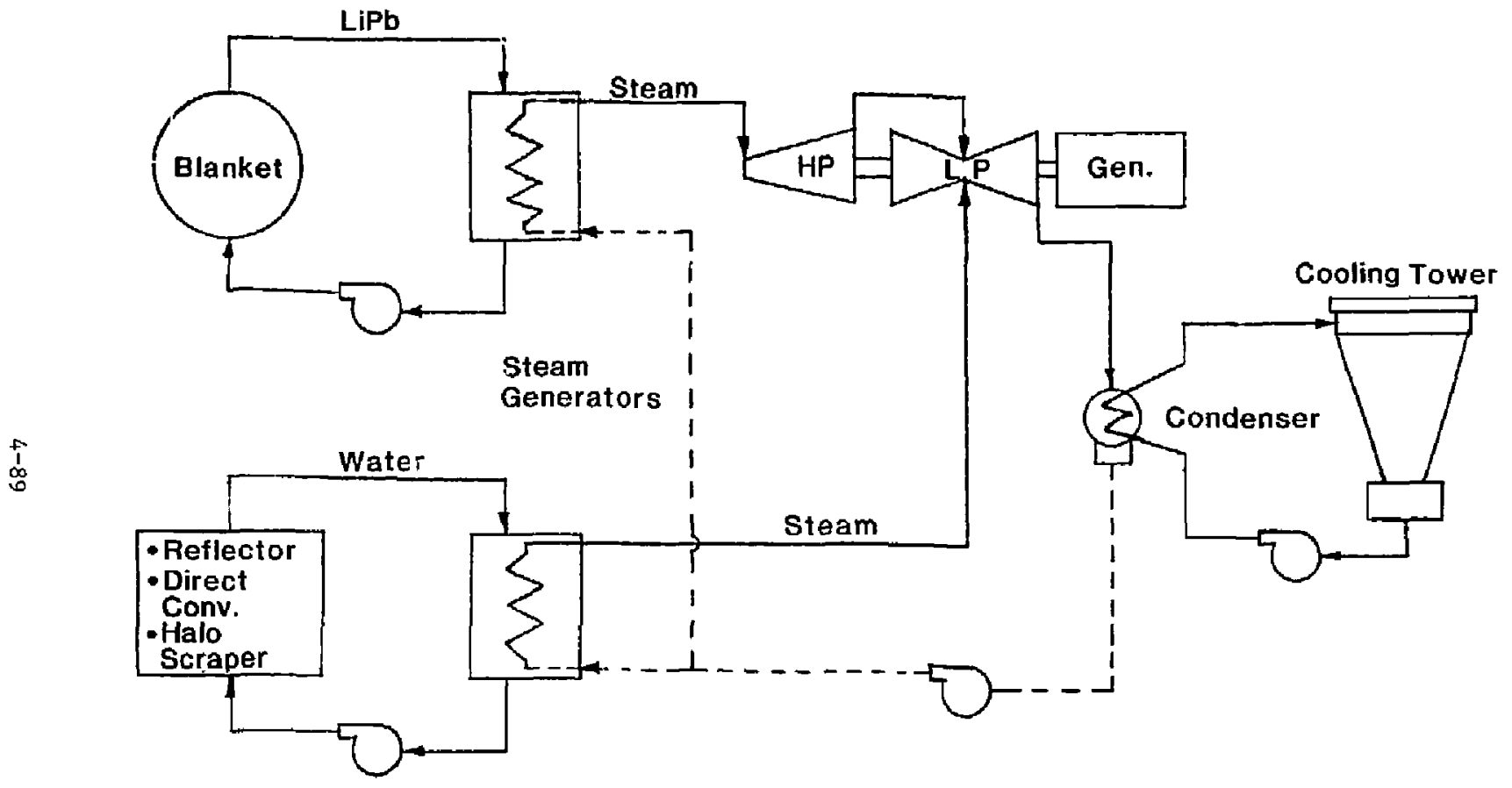

Figure 4-34. The FPD-I heat transport and power conversion system. 
1. W. D. Nelson et al., MFTE-a+T Progress Report, Oak Ridge National laboratory, Oak Ridge, TN, ORNL/FEDC-83/9 (to be published).

2. B. G. Logan et al., Mirror Advanced Reactor Study (MARS), Einal Report, Lawrence Livermore National Laboratory, Livermore, CA, UCRL-53480 (1984).

3. W. S. Cooper and R. V. Pyle, The National Negative-Ion-Based Neutral Beam Development Plan, Lawrence Berkeley Laboratory, Berkeley, CA, PUB-464 (1983).

4. B. S. Brown, "Radiation Effects in Superconducting Fusion Magnet Materials," J. Nuc. Mater. 97, I (1981).

5. M. Soel1, "Influence of Radiation Damage on Maximum Attainable Magnetic Field Eor Toroidal Fusion Magnet Systems," 1. Nuc. Mater. 72, 168 (1978).

6. R. A. Vankonyuenburg, et al., "Fusion Neutron Damage in Superconductors and Magnet Stabilizers," J. Nuc. Mater. $103 \& 104,739$ (1981).

7. B. S. Brown and T. H. Blewite, "Critical Current Density Changes in Irtadiated $\mathrm{Nb}_{3} \mathrm{Sn}, " \mathrm{~J}$. Nuc. Mater. 80, 18 (1979).

8. C. L. Snead, et al., "High-energy-treutron Damage in $\mathrm{Nb}_{3} \mathrm{Sn}$ : Changes in Critical Properties, and Damage-energy Analysis," J. Nuc. Mater. $103 \&$ 104, $749(1981)$.

9. C. E. Klaburde, et a1., "The Effects of Irradiation on the Normal Metal of Composite Superconductor: A Comparison of Copper and Aluminum," J. Nuc. Mater. 85 \& 86, 185 (1979).

10. J. M. Williams et al., "The Effects of Irradiation on the Copper Normal Metal of a Composite Superconductor," IEEE [rans. Magn. 15, 731 (1979).

11. S. Tokanura and T. Kato, "Effects of Low Temperature Irradiation and other Materials for Superconducting Magnets," J. Nuc. Mater. $103 \& 104$. 729 (1981).

12. M. W. Guinan, "Radiation Effects Limits on Copper Superconducting Magnets," Lawrence Livermore National Laboratory, Livermore, CA, UCID-19800 (1983).

13. R. R. Gitman, Jr., "Organic Insulators and the Copper Stabilizer for Fusion Reactor Magnets," in Proc. of International Conference on Neutron Irradiation Effects, Atgonne National Laboratory, Argonne, It, November $9-12,1981$. 
14. R. R. Coltman, Jr, et al., Radiation Ef fects on Organic Insulators for Superconducting Magnets, Oak Ridge National Laboratory, Oak Ridge, TN, ORNL/TM-7077 (1979).

15. T. H. Batzer et al., A Tandem Mirror Technology Demonstration Facility, Lawrence Livernore National habozatory, Livermore, CA, UCID-19328 (1983). 


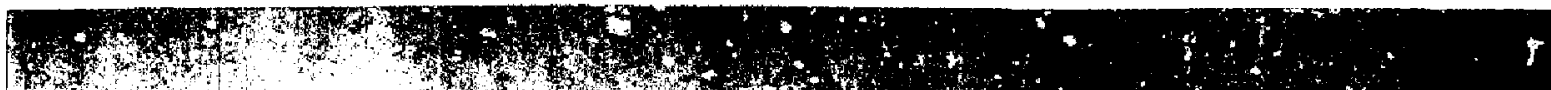
What $; \quad$, (1)

i)
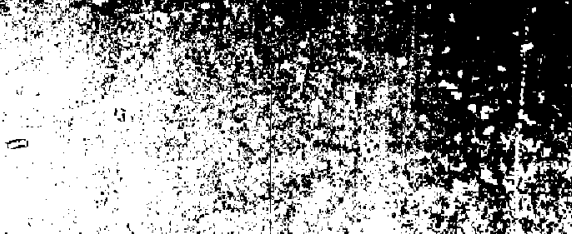

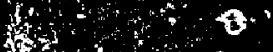
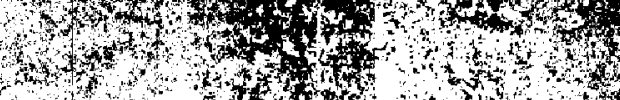

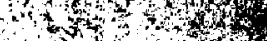

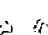

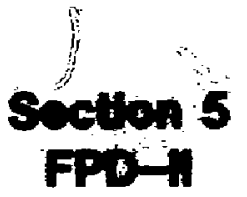

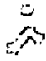

!!

$y_{3}^{3}$

FPo-1.

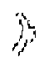

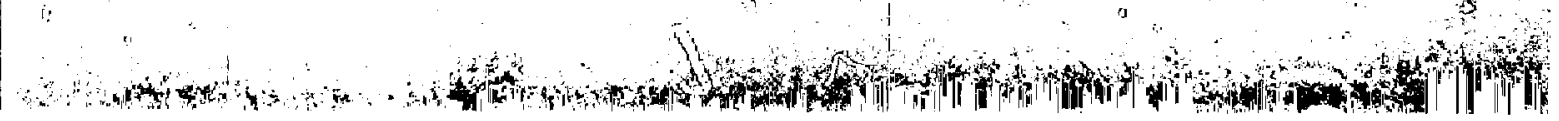


THE FPD-II CONFIGIJRATION OQVERVIEW

The second option for the Tusion Power Demonstration, FPD-II, has a central cell length of $96-\mathrm{m}$ measured from the centerline of one choke coil to the other. This increased length together with an improved end plug design increases the fusion power to $480 \mathrm{MW}$. Without a deuterium-tritium (DT) axicell for nuslear testing, this ignited plasma concept would be sapable of supplying $2,200 \mathrm{MW}$ net electric power. Like the FPD-I design, the use of tritium-breeding liquid lead-1ithium blanket modules make this reactor selfsufficient in tritiun. Thus, this device should be a true fusion power demonstration reactor.

The overall configuration to FyD-1I is presented in Fig. 5-1. The baseline design features of this design include a nuclear testing station or DT-axiceIl, central ceIl modules similat to those it FPO-I that use the semicontinuous solenoid concept, and end cells configured similar to those in FPD- 1 .

The DT-axicell arrangement, ajthough based on the Mirror Fusion Test Facility $\alpha+T$ (MFTF- $\alpha+T$ ) ${ }^{l}$ configuration, was developed for the more demanding FPD-II goal. This goal requites more test area at significantly higher wall loading. The mechanical arrangement of FPD-II features a 2-m-long nuelear-test module (vs $1-\mathrm{m}^{-}$long for FPD-I) to which $4-5 \mathrm{wW} / \mathrm{m}^{2}$ of neucron power can be applied. The beam power that is needed to reach this walt loading requires the mechanical arrangement shown in Fig. 5-2.

The axicell consists of tro superconducting background coils (CS)), two copper choke coils ( $\operatorname{ccc} 1)$, one copper field-enhancing coil (cso), nuclear shielding, test madule, vacuum vessel, and support structure. The cso coils are an integral part of the test module. The choke coils ( $\mathrm{CCC}_{1}$ ) are supported by the nuclear shield (Fig. 5-3). To remove a $\operatorname{CCC}]$ coil, the test module and magnet hatch must he removed; then the Cccl coil and surrounding shield are transported in the axial direction to clear the ruclear shiejd in the bore of the CSI coils. Finally, the CSl coil is removed vertically through the magnet hatch. 

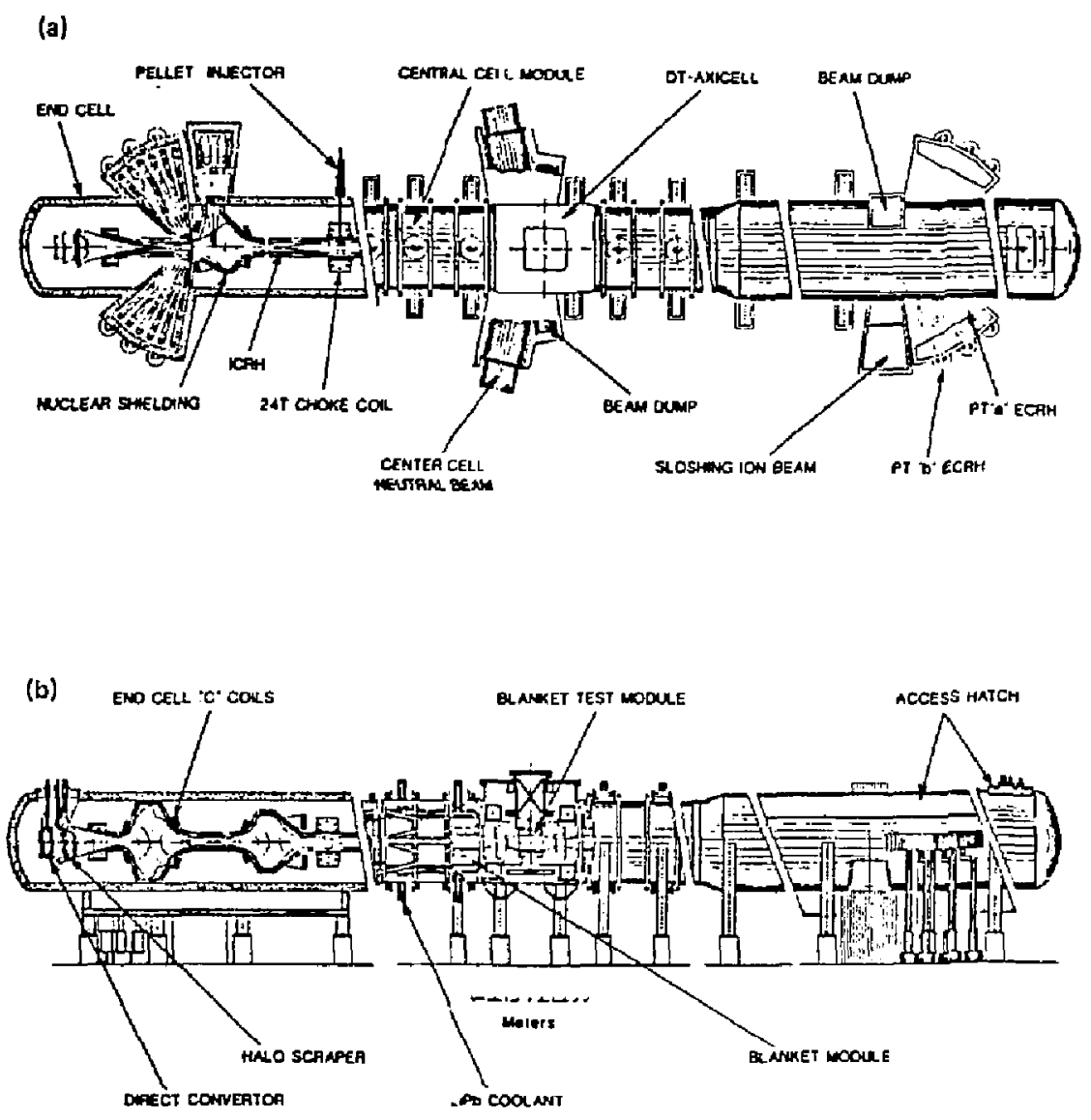

Figure 5-J. (a) FPR-II plan view; (b) fPD-II elevation vieu. 


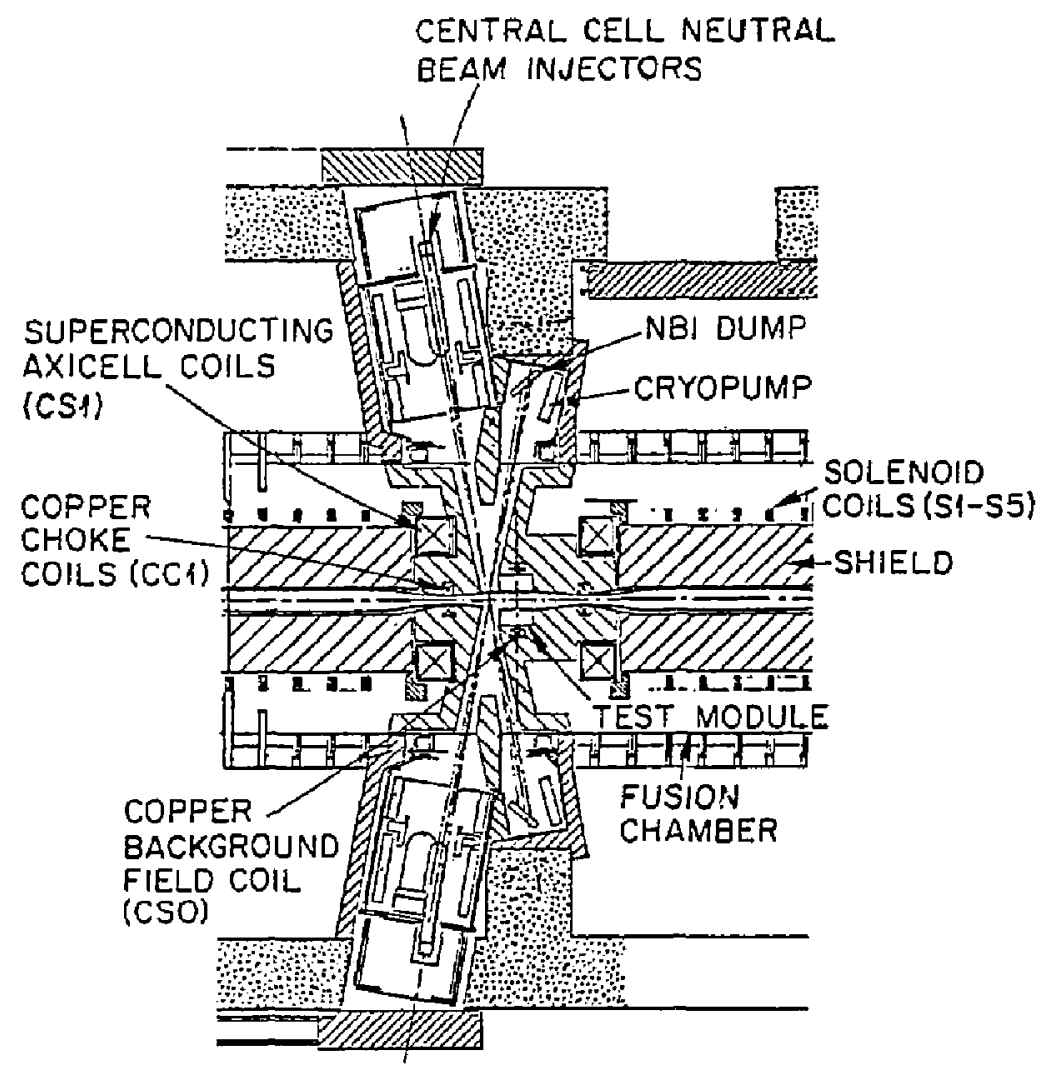

Figure 5-2. The ion-cyclotron resonant heating (ICRH) launcher design. 


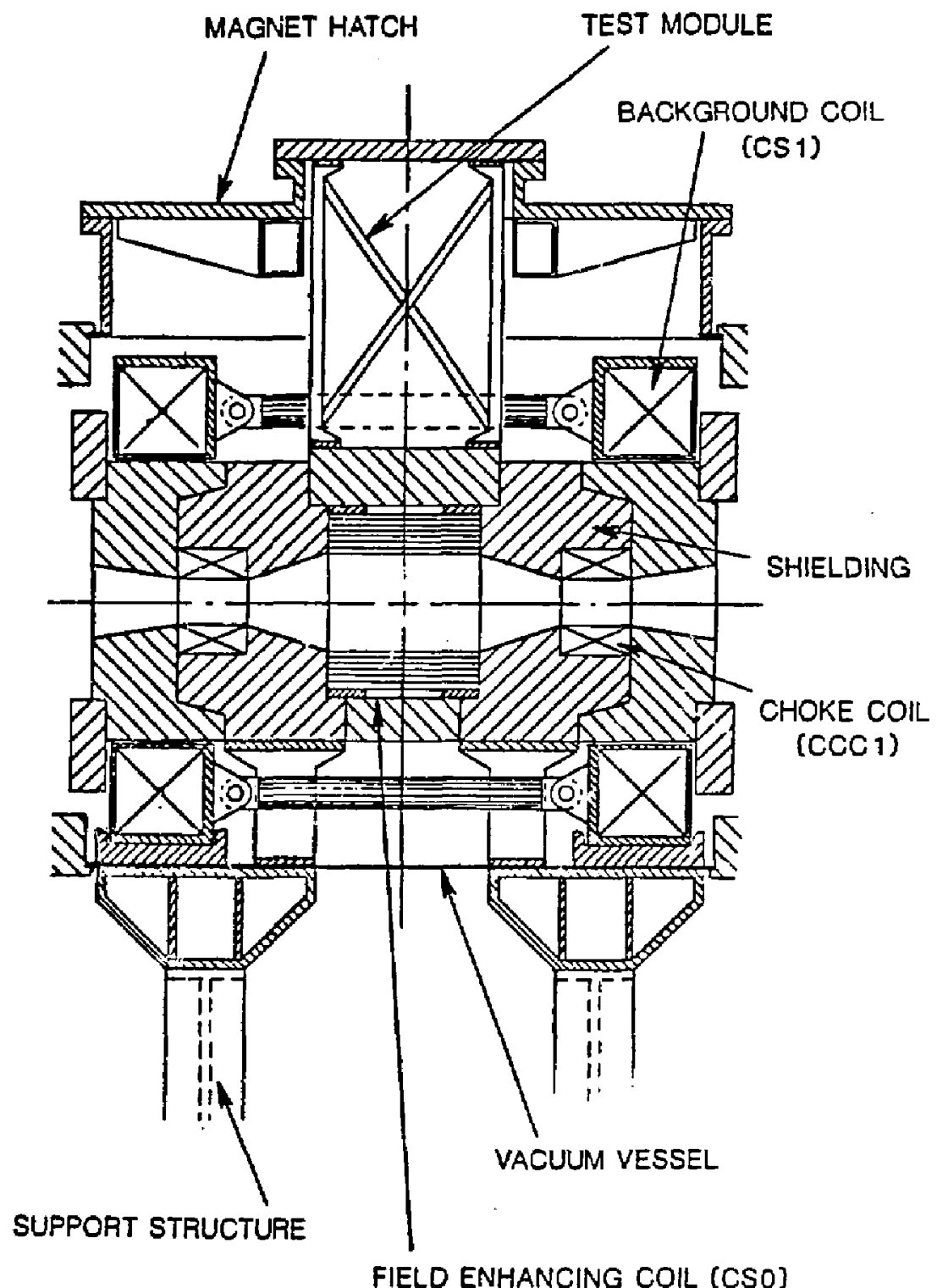

6

FIELD ENHANCING COIL (CSO)

Figure 5-3. The FPD-II DT-axicell configuration. 
The axicell vacuum vessel is a cylindrical structure with external stiffeners and two top-located access hatches (Fig. 5-4). Because the test module may be subject to frequent removal, it is furnished with a separate hatch. This large magnet hatch is also used to remove the other coils and shielding.

The axicell nuclear shield consists of a steel ball and water design that satisfies the shutdown dose-rate requirement of 0.5 mrem/hour, 24 hours after shutdown for a $5 \mathrm{MW} / \mathrm{m}^{2}$ wall loading.

For the FPD-II design, the central cell is configured (Fig. 5-4) using eiglit fu; 1-length modules and two half-length modules that are mated to the choke cails in a manner similar to the FPD-I design. Recent study shows that the portion of the central cell adjacent to the DT-axicell must be configured so that a length of the solenoid can be permanently axially connected to the DT-axicell background coils. This connection is necessary because, like the choke coil orea, large axial forces also exist between these coils as in the choke coil region. This minor modification can be easily incorporaced in the design.

The central cell module for FPD-II is similar to that for FPD-I with the exception that the portion of nuclear shielding located within the bore of the solenoid coil is sufficient to lower the shutdown dose rate to an acceptable level. Therefore, a double-walled vessel with a wacer shield is not employed; instead, a single-walled externally ring-stiffened shell is provided in a manner reminiseent of the Mirror Fusion Tast Facility-B (MFTF-B) (Fig. 5-5).

The end cell configutation is also similar to that of Fro-I with several significant improvements. First, the end cell biological shield is reduced in size significantly because of the reduced neutron source allowing the use of an end-cell double-walled vessel of only $0.6 \mathrm{~m}$ thick. Second, the reduced ICRH-subsystem power requirements allow the use of a rigid waveguide that simplifies the incegration of this subsystem; therefore, it is innecessary to incorporate a four-loop antenna. Third, the point b ECRH subsystem, while still requiring a quasi-optical approach to the transport and launcher, uses 10 active and 2 on-line spare gyrotrons (vs 12 and 2, respectively in FPD-I), This approach makes it easier to provide the clearances required for the surrounding nuclear shielding and permits the use of a less costly nuclear 


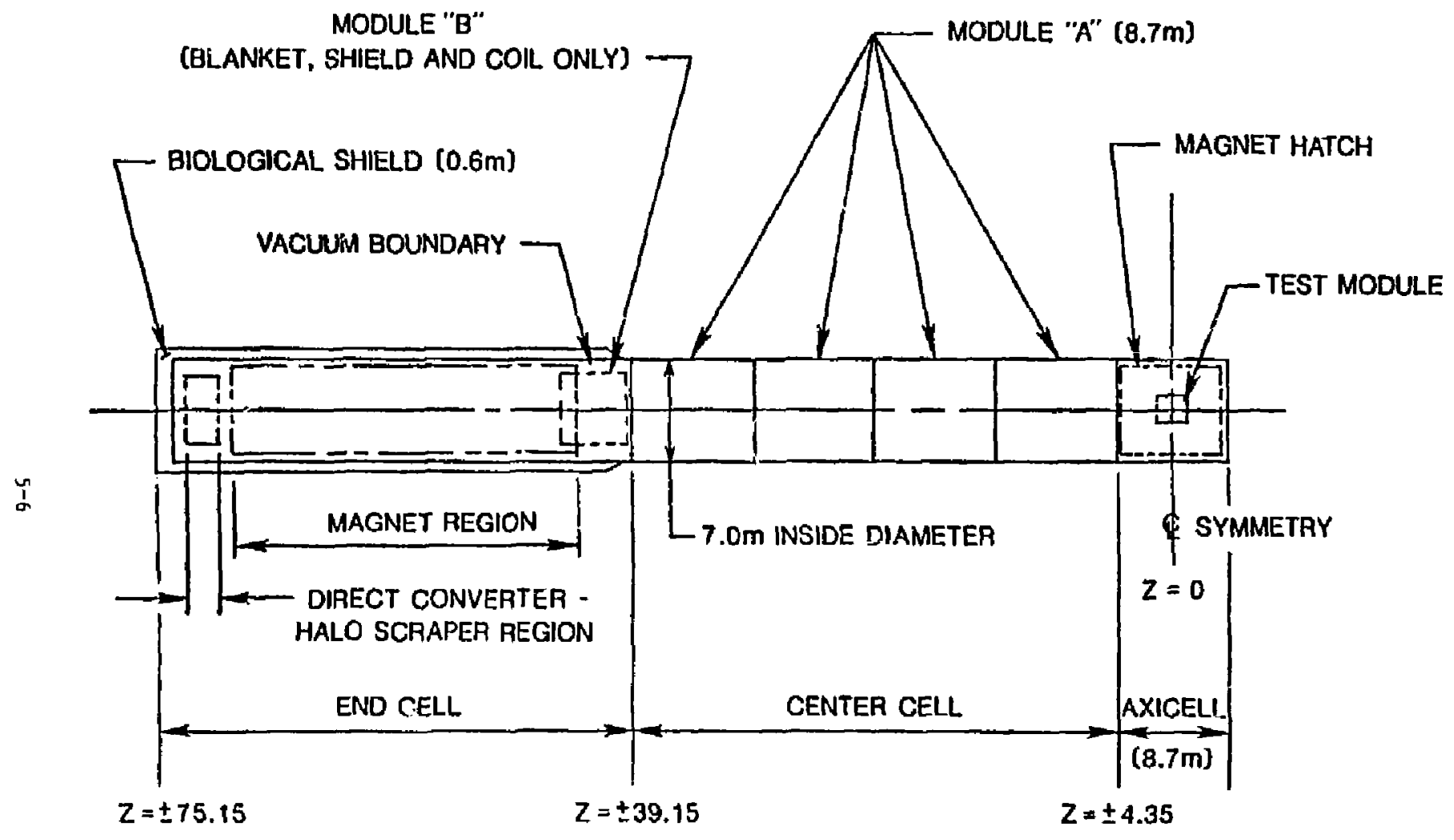

Figure 5-4. The FPD-II modular configuration. 


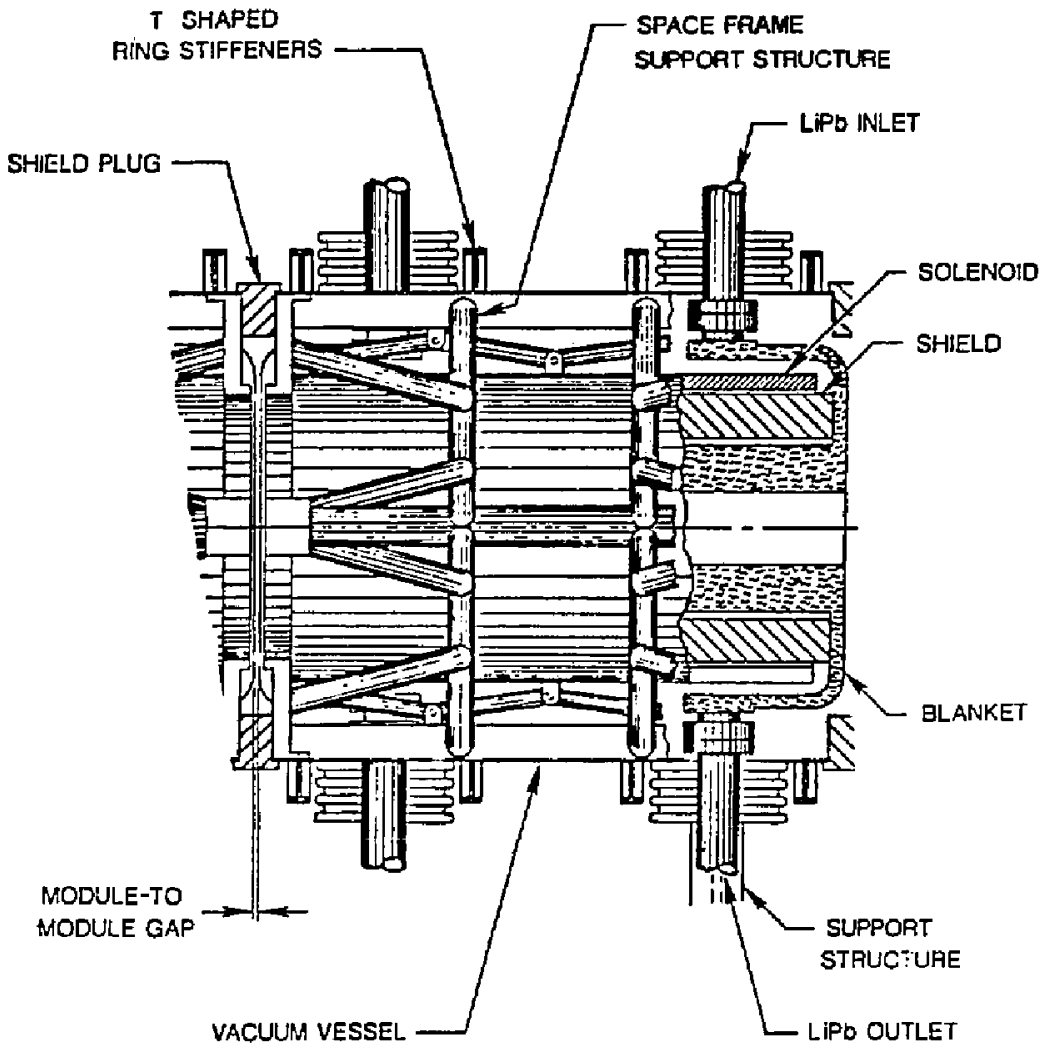

Figure 5-5. The FPD-Il central cell module. 
shield design around that portion of the access not directly in the throat of the c coils. Fourth, reduced sloshing-ion-beam power requirements tcgether with improved taxget point to coil geometry for FPD-II (the angle to ine $z$ axis being relaxed to permit $90^{\circ}$ injection) allawed us to design a much improved mechanical arrangement (Fig. 5-6). The four sources are in a fan arrangement, two in-line along the axis of the machine, such that two beams cross each other at the target point arrayed in the circumferential direction. This reduction to two beams arrayed circumferentially vs three for FPD-I, allows more space for nuclear shielding within the throat of the coils. Together with the significant reduction in neutron source strength in the end cell, this design provides improved cail protection and lowered nuclear heat load to the refrigeration syrtem.

In addition, we moved the point of pellet fueling injection so that it does not pass through the insert choke coil, but is lacated instead toward the central cell side of the choke coil.

In this section, we provide more detail for the FPD-II direct-converter and halo-scraper arrangement making significant progress in the definition of this subsystem. We have confirmed that these are lifetime components. The integration of the direct converter and halo dump into the design is accomplished in a manner similar to the FPD-I design, employing a vertical lifting approach through a dedicated hatch. This allows for ease of installation, is compatible with the overall device maintenarce/installation philasophy, shortens the reactor building, and improves our ability to replace subsystems or upgrade to a new concept, if necessary or desirable.

The FPD-II configuration is an improved design primarily becanse of a significantly better end-cell plug design that reduces the end-cell nuclearsource strength and heating-system power requirements. The central cell module design is also improved, requiring only a single-walled vacuum vessel. While the physics design of the DT-axicell was being opcimized, the mechanical configuration approach was confirmed by ou studies on the impact of a much higher $\left(4-5\right.$ vs $\left.2 \mathrm{MW} / \mathrm{m}^{2}\right)$ wall loading on the nuclear test-statian concept. 


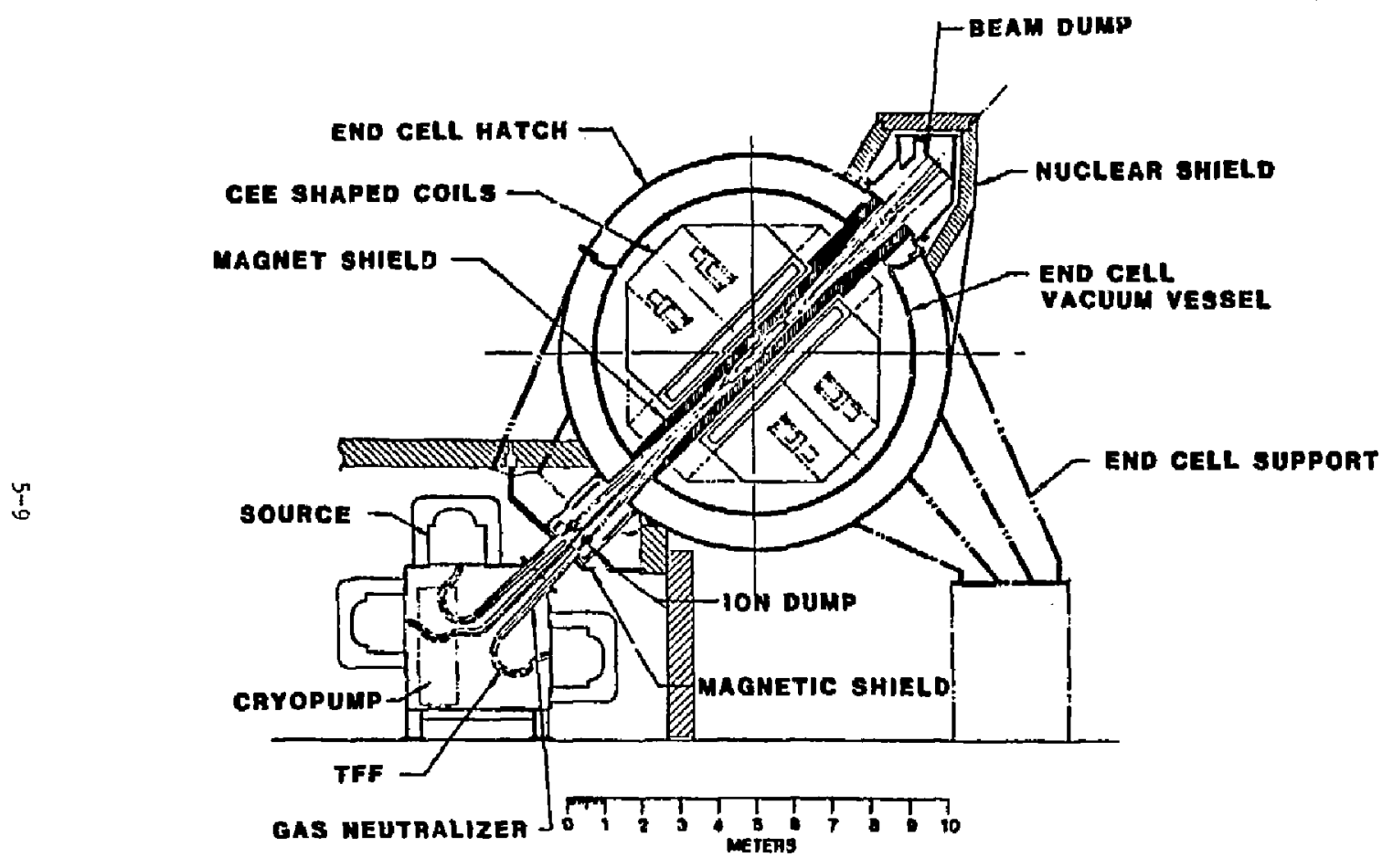

Figure 5-6. Negative-ion sloshing-beam configuration. 
AXICELL

POSITIUE-ION-BASED NEITRAL-BEAM SYSTEM

The primary purpose of the axicell neutral-beam system is to maintain the high temperature and density and hence the high wall loading needed for the blanket test module. This system also fuels the device, therefore the injected species must be of a $50 / 50 \mathrm{mix}$ of deuterium (D) and tritium (T). Nearly $25 \mathrm{MH}$ of beam power is required at at average energy of $80 \mathrm{keV}$ corresponding to $310.8 \mathrm{~A}$. The injection path is $15^{\circ}$ from the normal to the z-axis to achieve good mirror trapping, but still offset in the orthogona? rane to allow injection from both sides of the axicell with clearance from beam c'umps.

$T h_{2} D$ and $i$ beamlines differ because: (1) the neutralization efficiency has an inverse mass dependence for a given energy; (2) the heavier tritium specie has a slightly better species mix; and (3) the extracted current and accelerator grid conductance both decrease as the jnverse square root of the mass for given source dimensions. However, in most respects, the two amline configurations are similar and are based on the Technology Demon.: ration Facility (TDF) ${ }^{2}$ and MF'FF- $\alpha+T^{1}$ central-cell beamline design concepts. The average energy for these devices can be specified in two ways: (1) D and $T$ species both having an average energy of $80 \mathrm{keV}$ corresponding to a $100-\mathrm{keV}$ $\mathrm{D}$ beam and a 90-keV $\mathrm{T}$ beam; or (2) average all injected particles to derine an 80-keV D beamline and a 120-keV $\mathrm{T}$ beamline. The latter method was chosen here because the total beamline efficiency was higher and less sources were required.

Tables 5-] through 5-5 summarize the requirements, the basic beamine configuration, and the key system parameters; blowups of the axicell and the beamlines are shown in Figs. 5-7 and 5-8. Individual source currents for the $\mathrm{D}$ and $\mathrm{T}$ beamlines are $71.0 \mathrm{~A}$ and $59.3 \mathrm{~A}$, respectively. The $\mathrm{D}$ system configuration is identical to MFTF- $\alpha+T$ with, four sources in the beamline ( 3 operating/ 1 redundant) as depicted in Figs. 5-9 and 5-10. Lower extracted $T$ currents for the same source result in an extra tritium source in the D-system beamline ( 4 operating/] redundant). Consequent $1 \mathrm{y}$, the $T$-ion benting 
Table 5-1. Axicel1 beamline requixements.

\begin{tabular}{ll}
\hline \multicolumn{1}{c}{ Requirements } & VaIue \\
\hline & \\
Delivered power (Mw) & 24.86 \\
Averaged ion energy (keV) & 80 \\
Delivered current (A) & 310.8 \\
Injection angle (from $\perp$ to z-axis) (deg) & 15 \\
\hline
\end{tabular}

Table 5- 2 . Axicell beamline configuxations for TDF and MFTF- $\alpha+T$.

\begin{tabular}{|c|c|c|}
\hline & D-beamline & T-beamline \\
\hline Beam energy (keV) & 80 & 120 \\
\hline Delivered power $(M W)$ & 9.39 & 15.39 \\
\hline Full energy (MW) & 7.13 & 13.04 \\
\hline Half energy (MW) & 1.74 & 2.07 \\
\hline Third energy (MW) & 0.54 & 0.28 \\
\hline Line power (MW) & 23 & $38.25^{\circ}$ \\
\hline Injector efficiency $(\%)$ & 40.5 & 41.1 \\
\hline \multicolumn{3}{|l|}{ Diameter } \\
\hline Vacuum vesse] $(m)$ & 3.25 & 4.0 \\
\hline Beamline $(m)$ & 3.95 & 4.8 \\
\hline Length $(m)$ & 11.5 & 11.5 \\
\hline $\begin{array}{l}\text { Number of sources } \\
\text { (operating/redundant) }\end{array}$ & $3 / 1$ & $4 / 1$ \\
\hline $\begin{array}{l}\text { Beam footprint at plasma axis }\left(\mathrm{cm}^{2}\right) \\
\text { Total cryogen requirements }\end{array}$ & $8.3 \times 8.3$ & $8.3 \times 8.3$ \\
\hline $\mathrm{LH}_{3}: \mathrm{l}$ /hour) & 75 & 75 \\
\hline $\mathrm{LH}_{2}$ (l/hour) & 304 & 304 \\
\hline
\end{tabular}


Table 5-3. Axice11 beamline source fo: Oak Ridge National Laboratory (ORNL) long-pulse three-grid accelerator with fircular apertures.

\begin{tabular}{lcc}
\hline & D-beamline & T-beamline \\
\hline Source current (A) & 71.0 & 59.3 \\
Species mix & $0.82 / 0.14 / 0.04$ & $0.88 / 0.01 / 0.02$ \\
Cross section ( $\mathrm{cm}^{2}$ ) & $16 \times 40$ & $16 \times 40$ \\
Divergence (deg) & $0.5 \times 0.5$ & $0.5 \times 0.5$ \\
\hline
\end{tabular}

Table 5-4. Axicel 1 beamline mestralizer for a lor conductance, tapered, water-cooled rectangular duct.

\begin{tabular}{lc}
$\begin{array}{l}\text { Target thickness } \\
\text { neutralization })\left(95 \% \text { equi }\left(\mathrm{cm}^{2}\right)\right.\end{array}$ & $7.68 \times 10^{15}$ \\
Length $6 \mathrm{~m})$ & 1.5 \\
Cross section & $16 \times 44$ \\
$a_{1} \times b_{1}\left(\mathrm{~cm}^{2}\right)$ & $16 \times 35$ \\
$3_{2} \times \mathrm{b}_{2}\left(\mathrm{~cm}^{2}\right)$ & \\
\hline
\end{tabular}

Table 5-5. Axicell teamline drift duct (a tapered, water-cooled, rectangular duct).

\begin{tabular}{lcc}
\hline & D-beamline & T-beamline \\
\hline $\begin{array}{l}\text { Length }(\mathrm{m}) \\
\text { Cross section }\end{array}$ & 2.24 & 2.24 \\
$a_{1} \times b_{1}\left(\mathrm{~cm}^{2}\right)$ & $60 \times 35$ & $90 \times 35$ \\
$a_{2} \times b_{2}\left(\mathrm{~cm}^{2}\right)$ & $35 \times 19$ & $43 \times 19$ \\
\hline
\end{tabular}




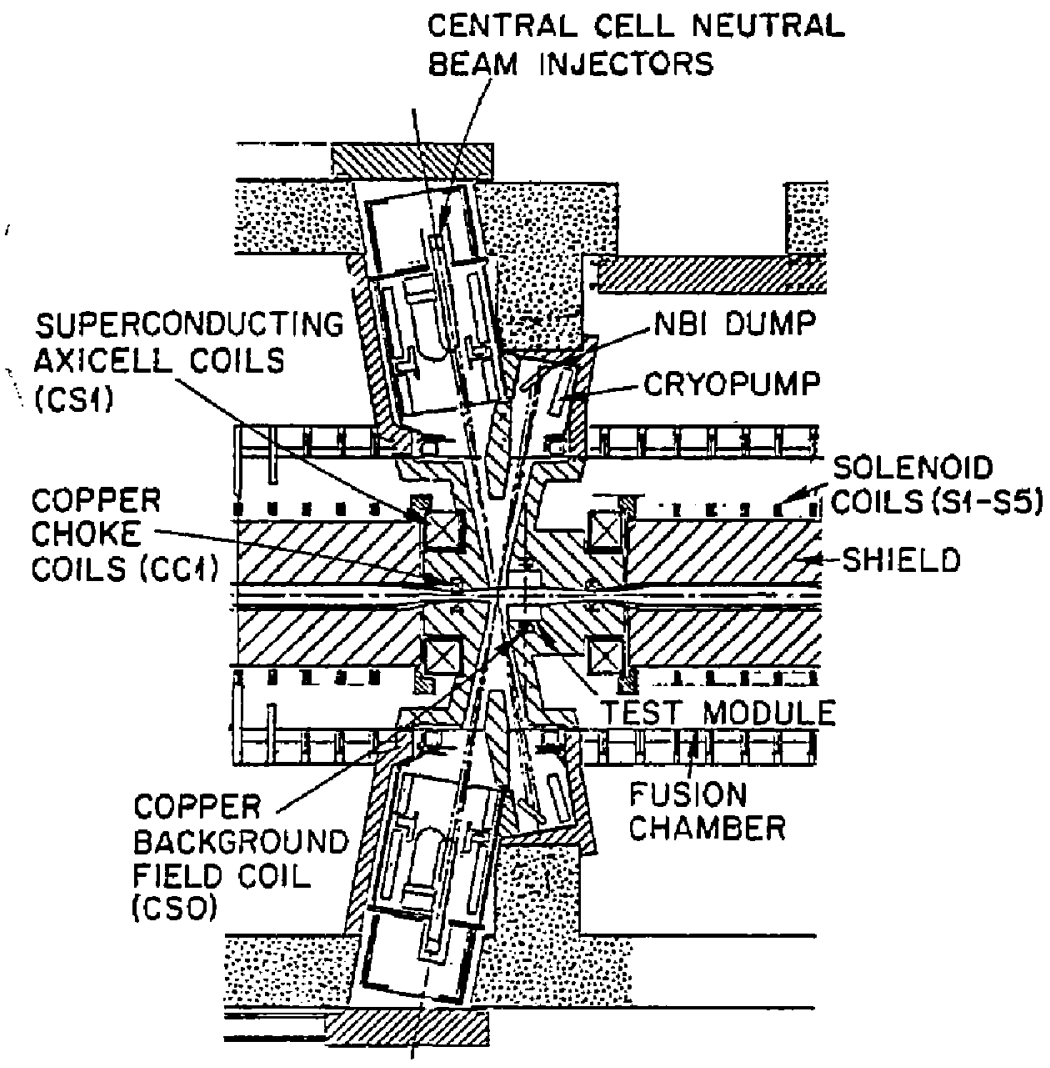

Figure 5-7. The central-cell reactor-like insert in MFTF- $2+{ }^{2}$. 


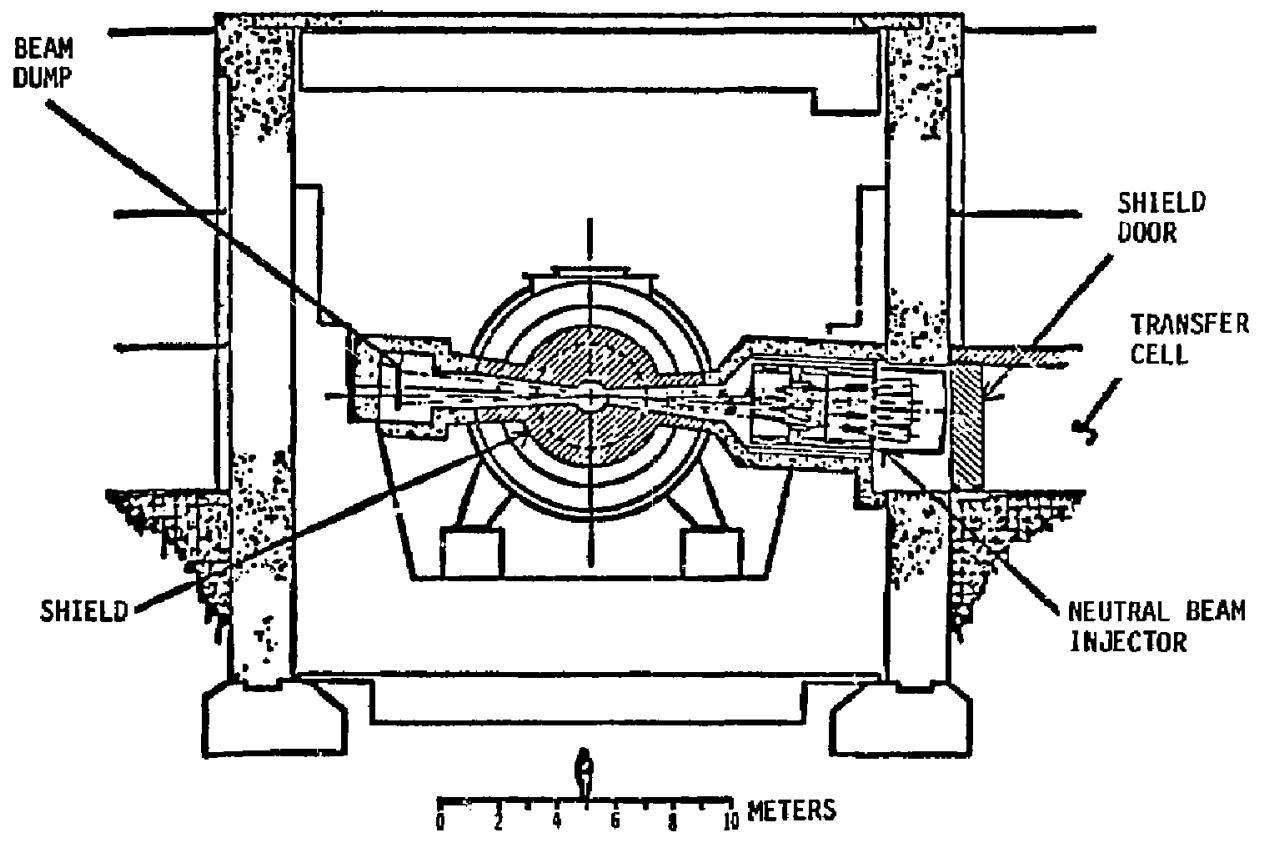

Eigure 5-8. Elevation through the central cell. 


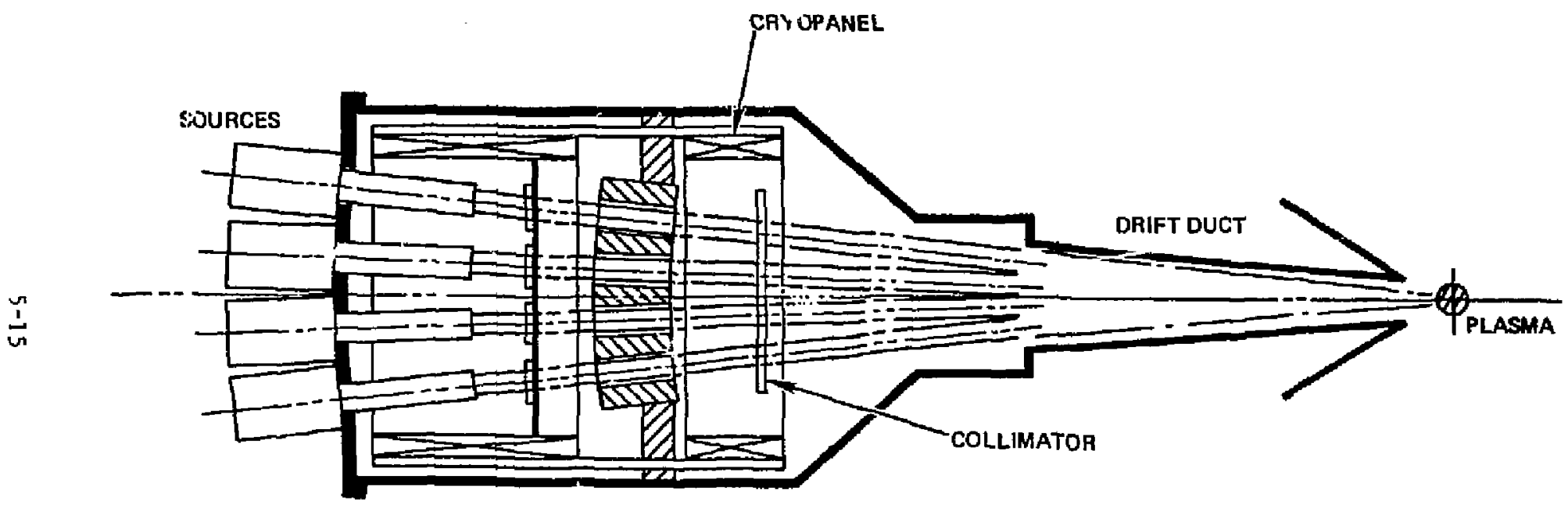

Figtre 5-9. Beamline layout. 


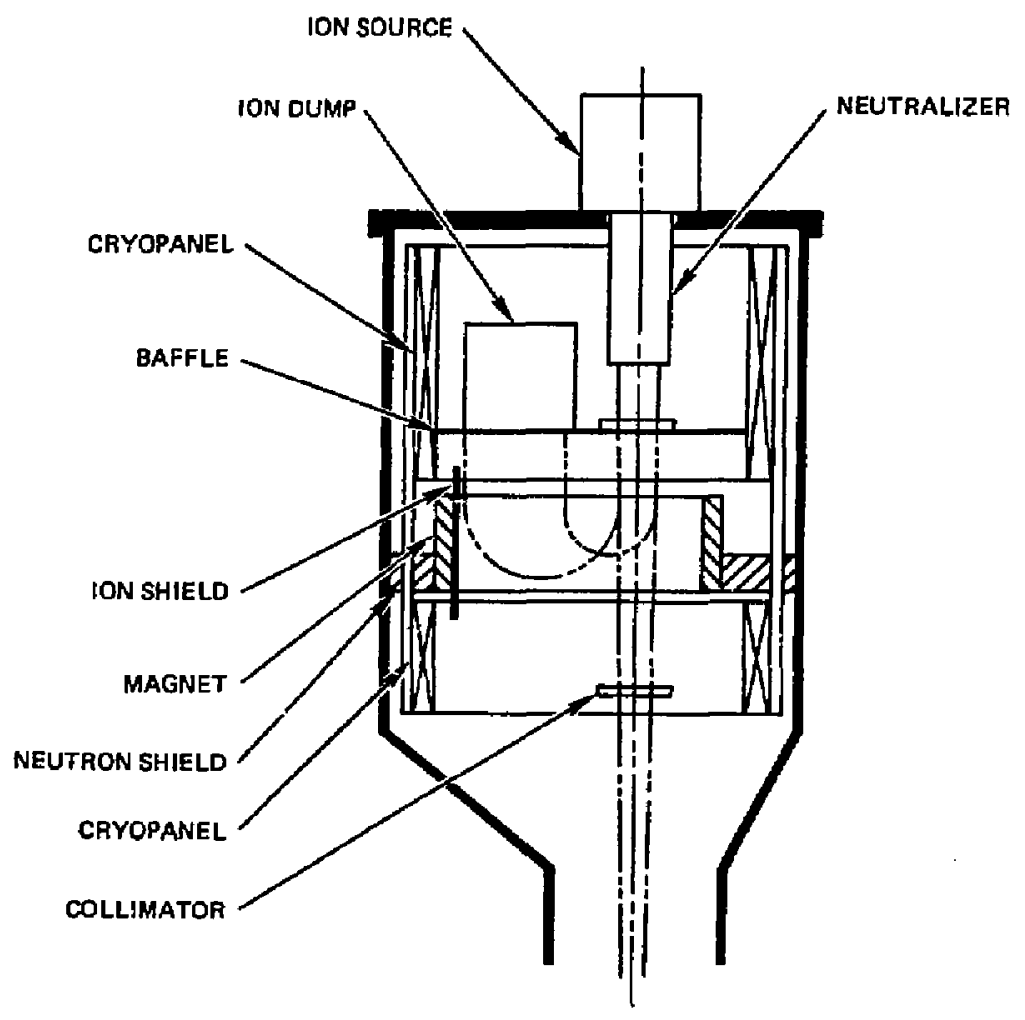

Eigure 5-10. Arrangement of beamline components.

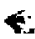


magnet requires an extra slot; plus the drift duct, the vacuum vessel, and tha shields are larger than those for the deuterium beamline.

Figures 5-11 and 5-12 summarize the power flow for the $D$ and $T$ beamilines, respectively. The beam accelerators in each beamline are powered by a single converter/transformer through protection and regulation circuitry; sources in a beamline also have a common power supply. Each ion bending magnet has its own small power unit (i.e., <50 kW). Very high powers must be dissipared in

the ion dumps; we mav need to directly convert a portion of this power to extend what may be an unacceptably short lifetime of the $i$ on dump. Finally, the efficiency for the entire axicell neutral-beam system is $40.7 \%$; the system puils 61.25 MIN of line power.

DT AXICELI MAGNETS

The axicell magnet system consists of five circular coils--three normal copfer coils and two superconducting coils. These five cails provide the axial field for this region and satisfy the other system requirements.

\section{System Function Summary}

The DT axicell is a test section that has a uniform neutron wall loading over the length of [he test module. This axicel] confines the plasma under ignition conditions with relatively high $\langle\hat{\beta}\rangle$ axicell.

\section{Requi rement Summary}

The length of the DT axics] is $5 \mathrm{~m}$, defined by $15-T$ peaks in the mirror field to satisfy the physics requirements of the I'PD machine. Key physics requirements are 5- $T$ magnetic field on axis at $z=0$ in the test space; w5-T choke field at the ends of the axicell $(z= \pm 2.5)$ for ion conf inement.

The sizes and locations of magnets must be compatible with arious ccnfigurational constraints. Tr.ese constraints include adey's access for the heating system (neutral veams); access to the test space; ard enough clear bore to accommodate the rlasma and plasma halo. 


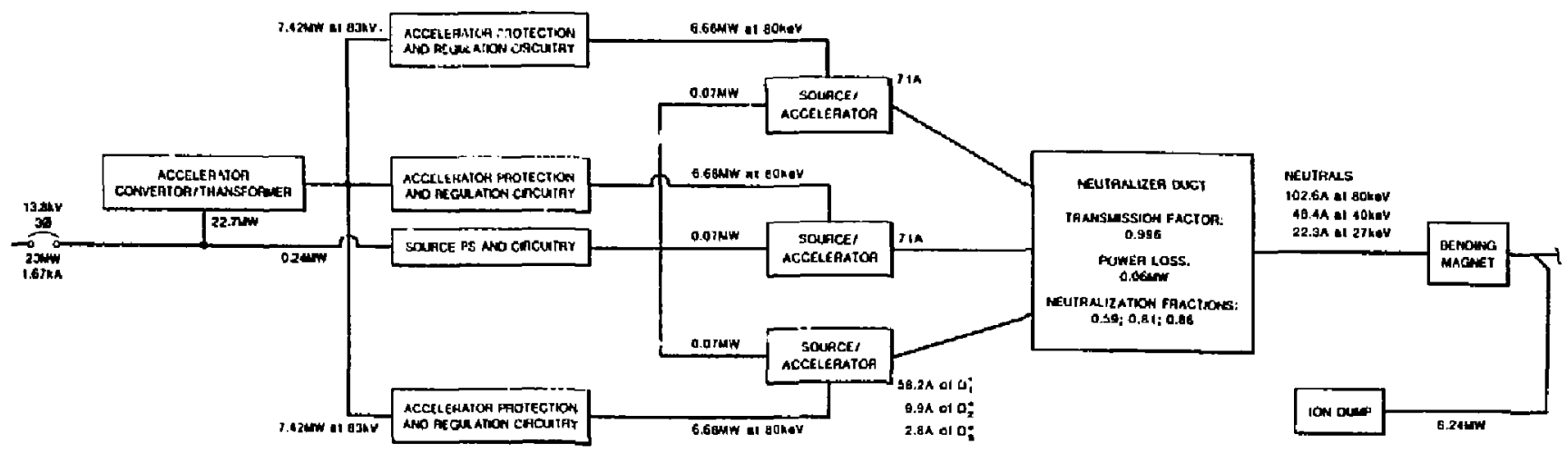

$\stackrel{i}{\infty}$

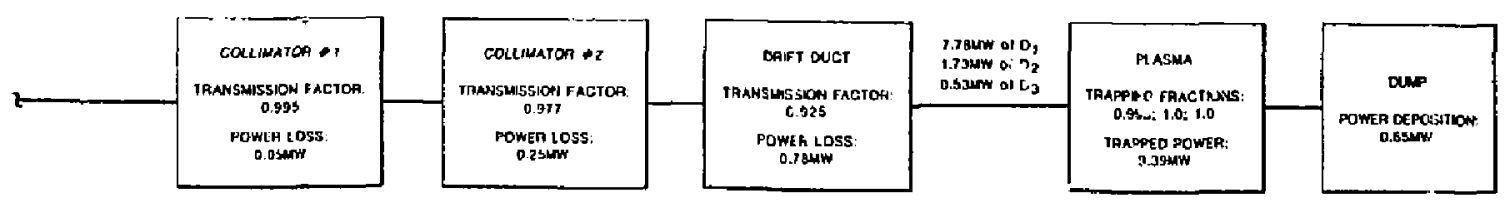

Figure 5-11. Curzent and power flow for the axicell deuterium beamline. 

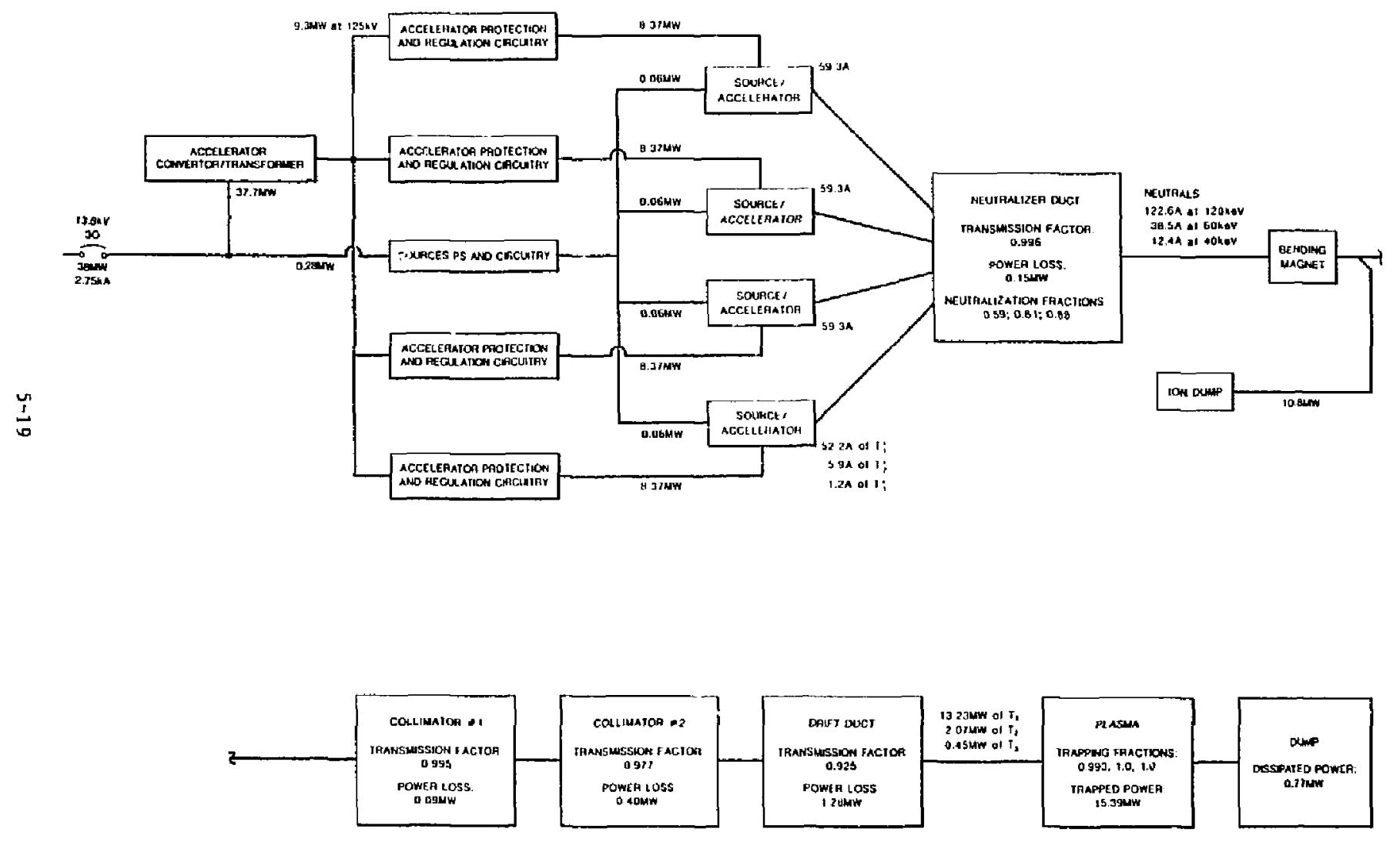

- igure 5-12. Current and power flow for the axicell tritium beamline. 


\section{Magnet Layout}

The configuration of the axicell magnets is shown in Fig. 5-13 and the key design parameters are 1 isted in Table 5-6. The superconducting coils (CS1) in conjunetion with the normal copper coil (CSO) provide 5-T background magnetic field at the midplane $(z=0)$. Under the copper choke coils (CCCI), the peak field is 15 it at $z= \pm 2.5 \mathrm{~m}$.

The peak fields at the windings of choke coils and CSO coil are 15 and $5 \mathrm{~T}$, respectively. These coils empley internally-cooled copper plates. The main design cotstraint on these coils is removal of the resistive and nuclear heat loads. These coils are designed to withstand the radial ond axial loads of normal FPD operation. The CSO coil is removed, along with the test module for access to the test space.

The cSl background field coils are superconducting. The peak field at the winding is $32 \mathrm{~T}$. The winding layout and key design parameters far these coils are given in Table 5-7. These CSl coils are similar to the coils required in the DT cell of the MFiF- $\alpha+T$. A Nb 3 Sn force-cooled conductor (shown in Fig. 5-14, similar tc the conductor used in the Westinghouse Large Coil Project (LCP) coil, is utilized in these coils. The winding is pancake wound (three to fout conductors are wound in parallel). The sp!ices, outlet LHe manifolding, and leads are located at the outer parimeter of the coil. The Lhe inlet is provided at the inner surface of the winding with no splices made at this location. With this winding concept and cooling scheme, the winding current density of $22000 \mathrm{~A} / \mathrm{cm}^{2}$ is feasible. These coils are discha god with a center-tap for keping the dump voltage at uls00 $V$ and for 1 imiting peak winding temperature rise to $200 \mathrm{k}$.

\section{Conclusion}

The design of normal copper coils and superconductirg coils needed for a DT axicell is feasible. Some development work is required for the $\mathrm{Nb}_{3} \mathrm{Sn}$ force-cooled conductor. This task has also been identified as needed in the Tokanak Jusion Core Experiment (TFCX) project. 


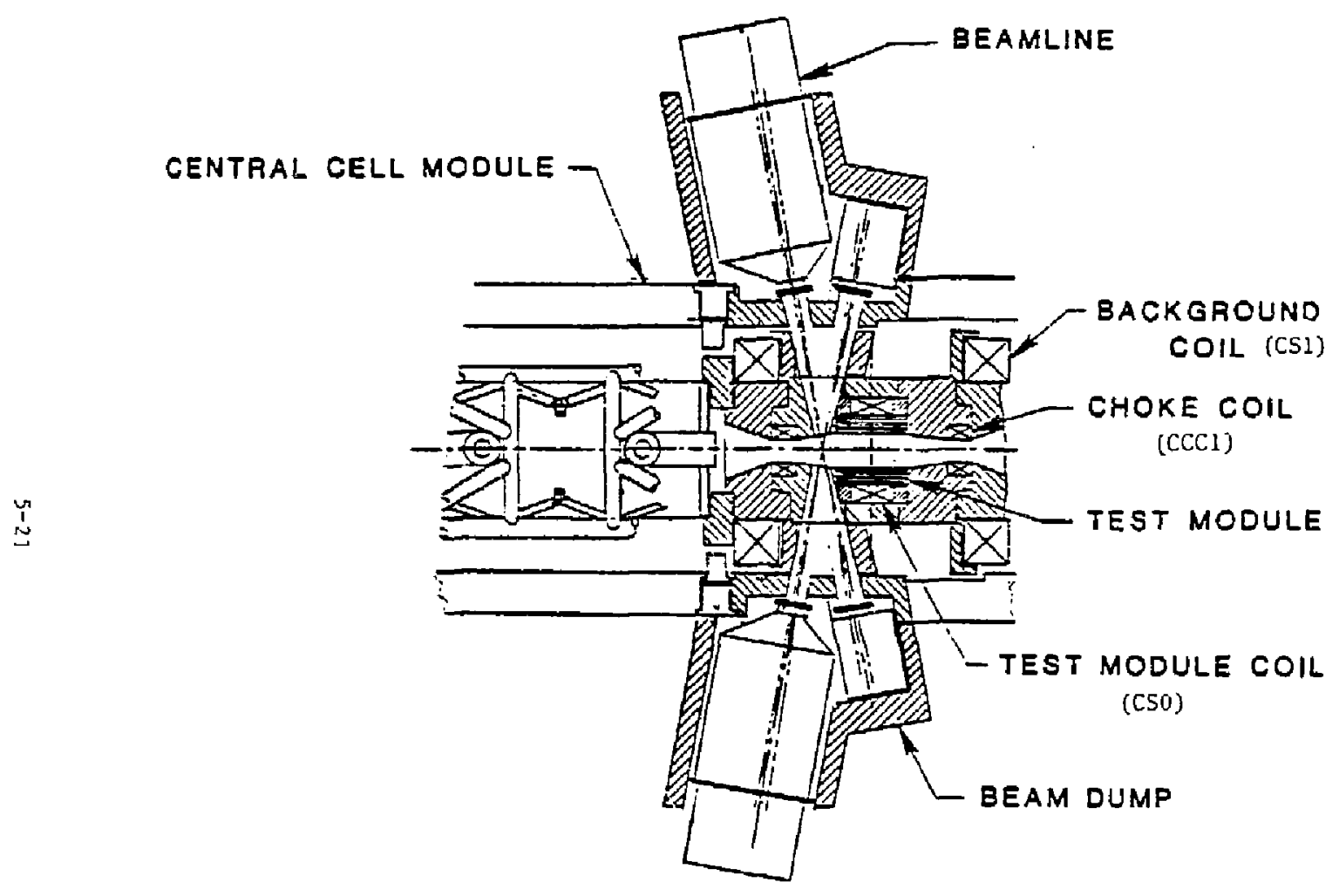

Figure 5-13. The DT axicell coil configuration. 
[able 5-6. Key design parameters for the axiceli magnets.

\begin{tabular}{lccccccc}
$\begin{array}{c}\text { Mean } \\
\text { axial } \\
\text { position } \\
(\mathrm{m})\end{array}$ & $\begin{array}{c}\text { Mean } \\
\text { radial } \\
\text { position } \\
(\mathrm{m})\end{array}$ & $\begin{array}{l}\text { Axial } \\
\text { build } \\
\Delta z(\mathrm{~m})\end{array}$ & $\begin{array}{l}\text { Radial } \\
\text { build } \\
\Delta \mathrm{R}(\mathrm{m})\end{array}$ & $\begin{array}{c}\text { Winding } \\
\text { current } \\
\text { density } \\
\left(\mathrm{A} / \mathrm{cm}^{2}\right)\end{array}$ & $\begin{array}{c}\text { HA- } \\
\text { [urms }\end{array}$ & $\begin{array}{c}\text { Peak } \\
\text { field } \\
(\mathrm{T})\end{array}$ \\
\hline $\operatorname{ccc} 1$ & \pm 2.50 & 0.50 & 0.90 & 0.38 & 2450 & 8.38 & 15 \\
$\operatorname{cs} 0$ & 0.00 & 1.20 & 1.00 & 0.09 & 2400 & 2.16 & 5 \\
$\operatorname{Csi}$ & \pm 3.15 & 2.50 & 1.15 & 1.15 & 2000 & 26.45 & 12 \\
\hline
\end{tabular}

Table 5-7. The C51 coil design parameters.

\begin{tabular}{|c|c|}
\hline Parameter & Value \\
\hline \multicolumn{2}{|l|}{ Electromagnetic } \\
\hline Operating current ( $k A$ ) & 12 \\
\hline Winding curtent density $\left(A / \mathrm{cm}^{2}\right)$ & 2000 \\
\hline \multicolumn{2}{|l|}{ Geometric } \\
\hline Tatal number of turns & 2204 \\
\hline Number of pancakes & 46 \\
\hline Number of turns/pancake & 48 \\
\hline Coil length $(\mathrm{cm})$ & 108.2 \\
\hline Soil depth $(\mathrm{cm})$ & 112.9 \\
\hline \multicolumn{2}{|l|}{ Gryogenic } \\
\hline Lhe inlet temperature $(k)$ & 4.0 \\
\hline LHe inlet pressure (atn) & 5 \\
\hline I. He outlet temperature ( $\mathrm{K}$ ) & 5.0 \\
\hline L'te outlet pressure (atm) & 3 \\
\hline Peak nuclear heating rate $\left(\mathrm{mw} / \mathrm{cm}^{3}\right)$ & $<1$ \\
\hline
\end{tabular}




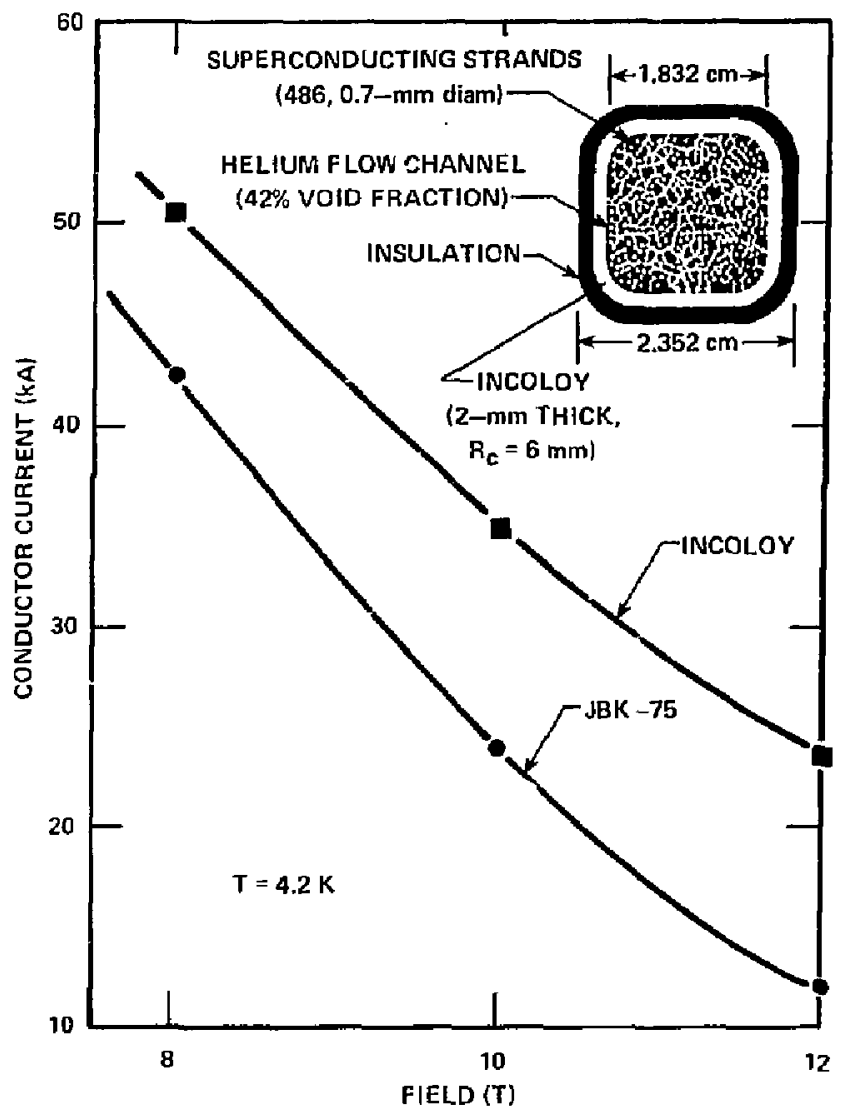

Figure 5-14. The $\mathrm{Nb}_{3} \mathrm{Sn-conductot}$ critical current as a function of magnetic field. 
SHLELING AND VACUUM CONTAINMENT

the DT axicell is located symmetricalty at about $z=0$, as shown in Fig. 5-15. The c: trical axicei] is $8.7-m$ long and has an inside diameter of $7.0 \mathrm{~m}$. The central cell A modules are the same length and can be interchanged with the axicell. The majot axicell components described in this section are the vacum vessel and the slielding.

$\underline{\text { Vacuuni }}$ Vessel

The vacuum vessel is a single-walled, erternally stiffents structure wifh two top-located hatches (Fig. 5-16). The small hatch is an integral part of the test module. The test modu?e consists of the hatch cover, test mojule, field-enhancing coil (cso), shielding, and support structure. The test module is supported fro.l the large magnet hatch (Fig. 5-17). The magnet-hatch size aljows for removal of all cilir components. The typical hatch vacuum seal is shown in Fig. 5-17.

The cest module can be removed vertically, together with the cso coil, without disturbing the other components. To remove the remainder of the coil shielding, the test module must be removed first. This sequence provides space for axial iranslation of the shielding/choke-coil (cccl) module so that the test module can be removed vertically. The ccCl coil is supported by the surrounting nuclear stiejd. To remove a background cail (CSI), all of tite adjacent shielding in the coil bore must first be remuved; then, the innercoil cold structure can be disconnected, which allows vertical removal of the coil.

\section{Nuelear Shield}

The muclear shield thickness in the axicell is an equivalent of $97 \mathrm{~cm}$, raking credit for the coils and test module where applicable. The shield thickness is based on the shutdown dose-rate requirement and a neutron wall loading of $5 \mathrm{MW} / \mathrm{m}^{2}$. The shield composition is $87-\mathrm{cm}$ steel/water $(60 \%$ steel, $40 \% \mathrm{H}_{2} \mathrm{O}$ ), 5-cm $\mathrm{B}_{4} \mathrm{C}$, followed by 5-cm lead. The steel/water shield consists of a steel container filled with a fixed-size steel ball that results in the 


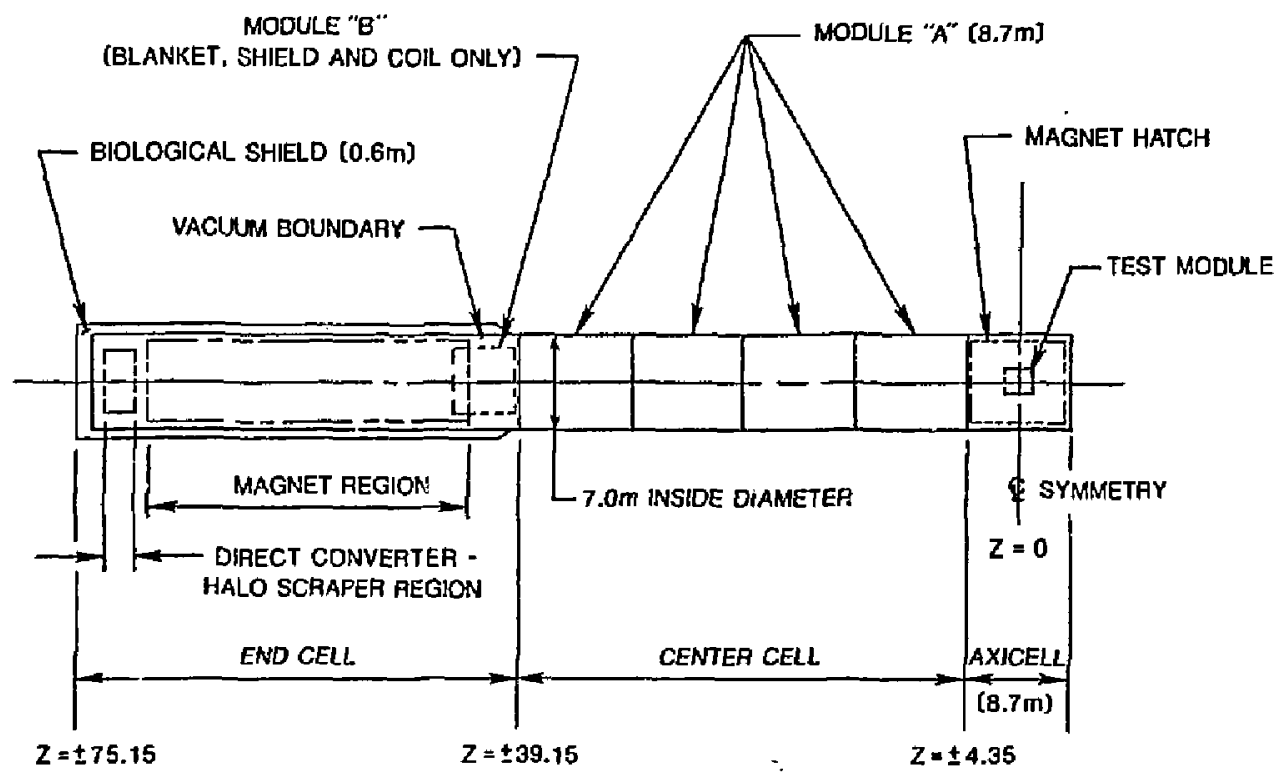

Figure 5-15. The FPD-II modular configuration. 


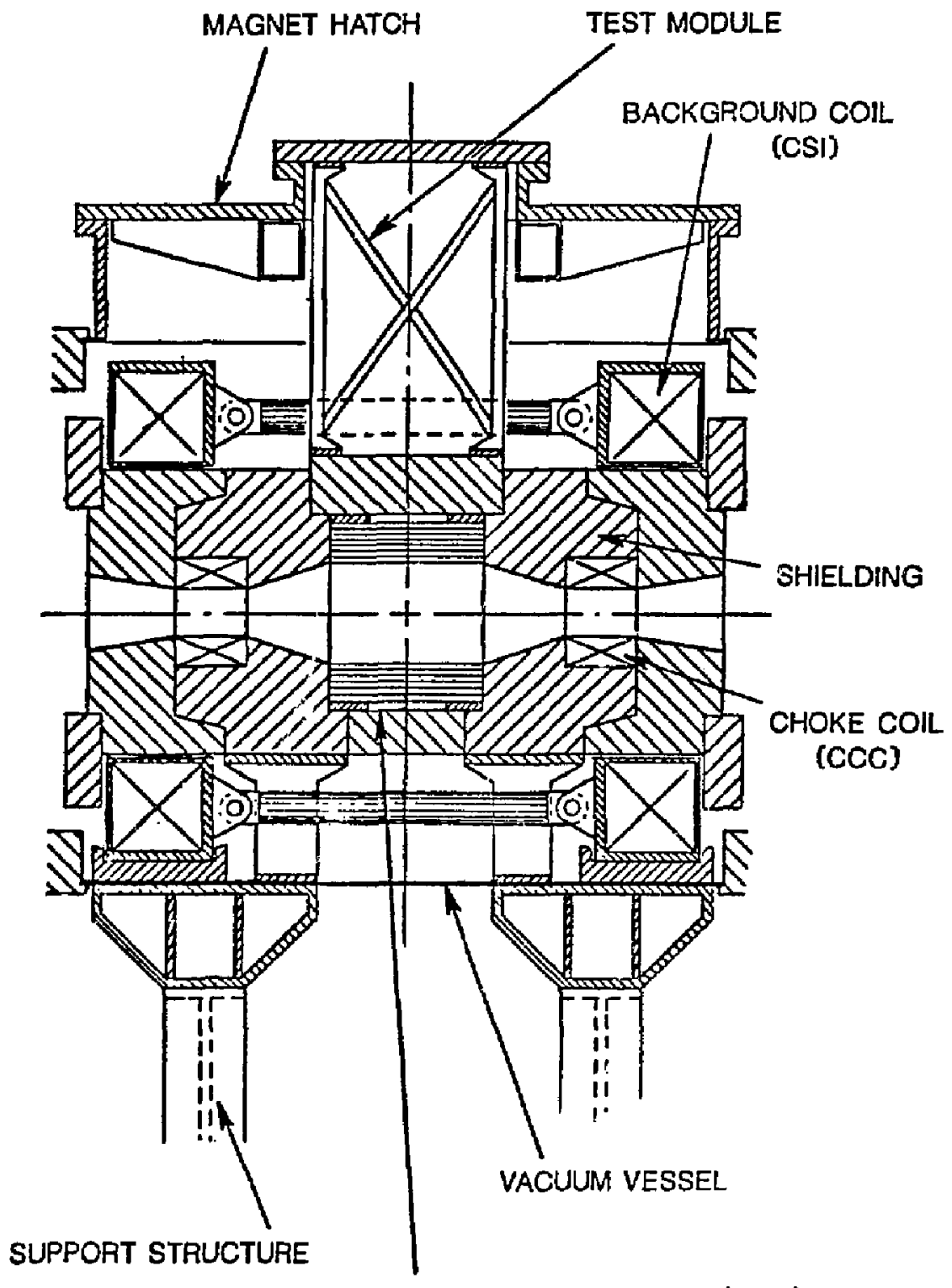

FIELD ENHANCING COIL (CSO)

Figure 5-16. The FPD-II DT axicell configuration. 


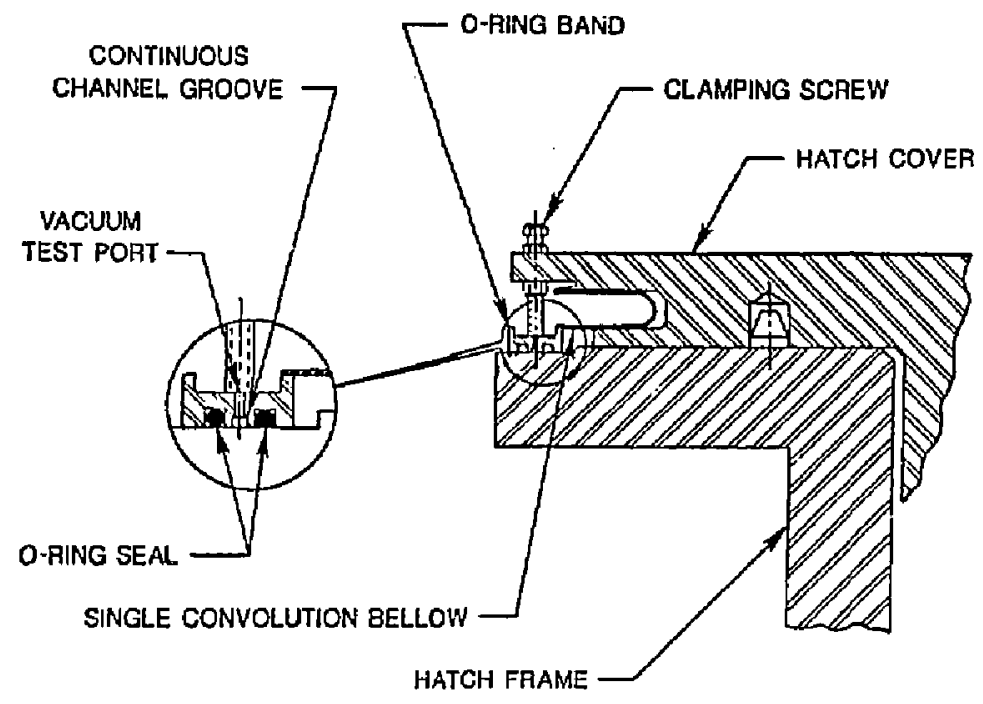

Figure 5-17. The FPD-II axicel]-hatch vacuum seal. 
$60 / 40 \%$ steel $/ \mathrm{H}_{2} \mathrm{O}$ ratio. The $5-\mathrm{cm} \mathrm{B} \mathrm{B}_{4} \mathrm{C}$ shield consists of a $20 \%$ steel container, $20 \%$ cooling $\mathrm{H}_{2} \mathrm{O}$, and $60 \% \mathrm{~B}_{4} \mathrm{C}$, with a packing density of $70 \%$ (0.7). A $5-\mathrm{cm} \mathrm{Pb}$ shield is attached to the $\mathrm{B}_{4} \mathrm{C}$.

SITPPORT STRITCTURE

Two support legs, each located under the CSl coil, are provided to transmit all loads to reinforced concrete piers.

CENTRAL CELL

CENTRAL GELL MACNETS

The central cell magnet system consists of eight full-size and two half-size solenoidal modules. Each module has correction coils integral with solenoid winding for reducing magnetic-field ripple caused by axial separation between adjacent modules. A DT axicel1 (discussed earlier in this section) is iocated at mid-point of the central cell.

The central-cell magnet modules are similar in size to those for FPD-I. Design feasibility is discussed in Sec. 4. The active length of the central cell is $92 \mathrm{~m}$. Effective lengths of the full and half-size modules are $8.7 \mathrm{~m}$ and $5.85 \mathrm{~m}$, respectively. Axial gap between adjacent modules is $1 \mathrm{~m}$.

SHIELDING AND VACUUM CONTAINMENT

The modularization of the central cell is shown in Fig. 5-15. The central cell consists of eight A modules and two $B$ modules. The A modules are self-contained assemblies, whereas the $B$ modities are without an individual vacuum vessel. The $B$-module vacuum vessel is integrated into the end cell to provide sufficient end cell length to incorporate access hatches and end transitions. Each central cell module consists of (outward from plasma) a $\mathrm{Li}_{17} \mathrm{~Pb}_{83}$ (LiPb) blanket/reflector, shie!s, solenoid coil, spacs-frame support structure, and vacuum vessel. The A modules are 8.7-m long and the $B$ modules are $6.85-m$ lorig. Each $A$ module can be independently, vertically 
removed for maintenance. Prior to a $B$ module removal, the adjacent $A$ module must be removed and the $B$ module transferred in the $z$ direction. Figure $5-18$ st.ows a typical A-module configuration.

The central-cell module design enables a huildup nssembly sequence, Fig. 5-19. The assembly equence starts with the space frame mounted in an assembly jig. The solenoid coil is installed, followed by the shield and the blanket. Alternatively, the blankets can be installed after the subassembly is installed inside the vacuum vessel. This design allows for checks and cests at each assembly step. The blankets are supported from the shield. Enough space is allowed between the components for thermal growth. Figure 5-20 shows a more detailed module-to-module seal concept.

\section{Vacuum Vessel}

A typical central-cell vacuum vessel is cylindrical $(7.0-m$ inside diameter), with external $\mathrm{T}$-shaped ring stiffeners (Fig. 5-18). The ring stiffeners are coniected by longitudinal stiffeners. The vas um vessel reacts to all loads induced by the internal components.

\section{Shielding}

The shield thickness is sized to meet the shutdown dose rate of $0.5 \mathrm{mrem} / \mathrm{hour}, 24$ hours after shutdown. The shield thickness required below the solenoid coils is $58 \mathrm{~cm}$. This shield consists of $53 \mathrm{~cm}$ of steel/water and $5 \mathrm{~cm}$ of $\mathrm{B}_{4} \mathrm{C}$. The steel/water shield is a mixture of $60 \%$; tee 1 and $40 \% \mathrm{H}_{2} \mathrm{O}$. The steel shield consists of the container that is filled with one size of steel balls (approximately 60\%). The remaining volume, $240 \%$, is filled with $\mathrm{H}_{2} \mathrm{O}$. The $5-\mathrm{cm} \mathrm{B} \mathrm{B}_{4} \mathrm{C}$ shield is mounted on the outside oE the steel/ $\mathrm{H}_{2} \mathrm{O}$ shield. The $\mathrm{B}_{4} \mathrm{C}$ shield consists of $20 \%$ steel (container), $20 \%$ cooling water, and $60 \% \mathrm{~B}_{4} \mathrm{C}$, with a density of $70 \%(0.7)$. The shield plugs (Fig. 5-18) are the equivalent of $85-\mathrm{cm}$ thick $\left(80-\mathrm{cm}\right.$ steel/water, $\left.5-\mathrm{cm} B_{4} \mathrm{C}\right)$, the same composition as the remainder of the shield. 


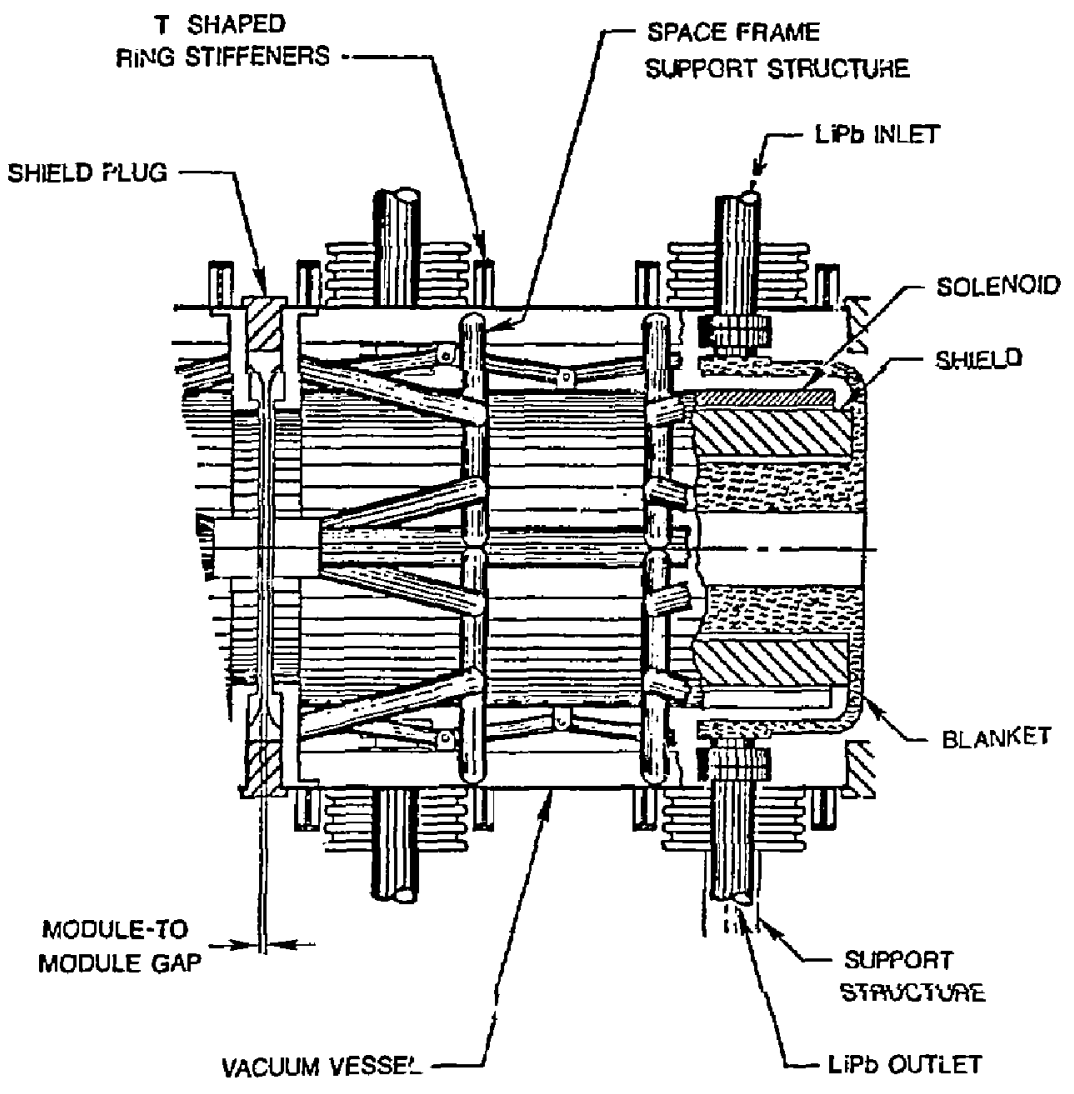

Figure 5-18. The FPD-Il central cell nodule. 


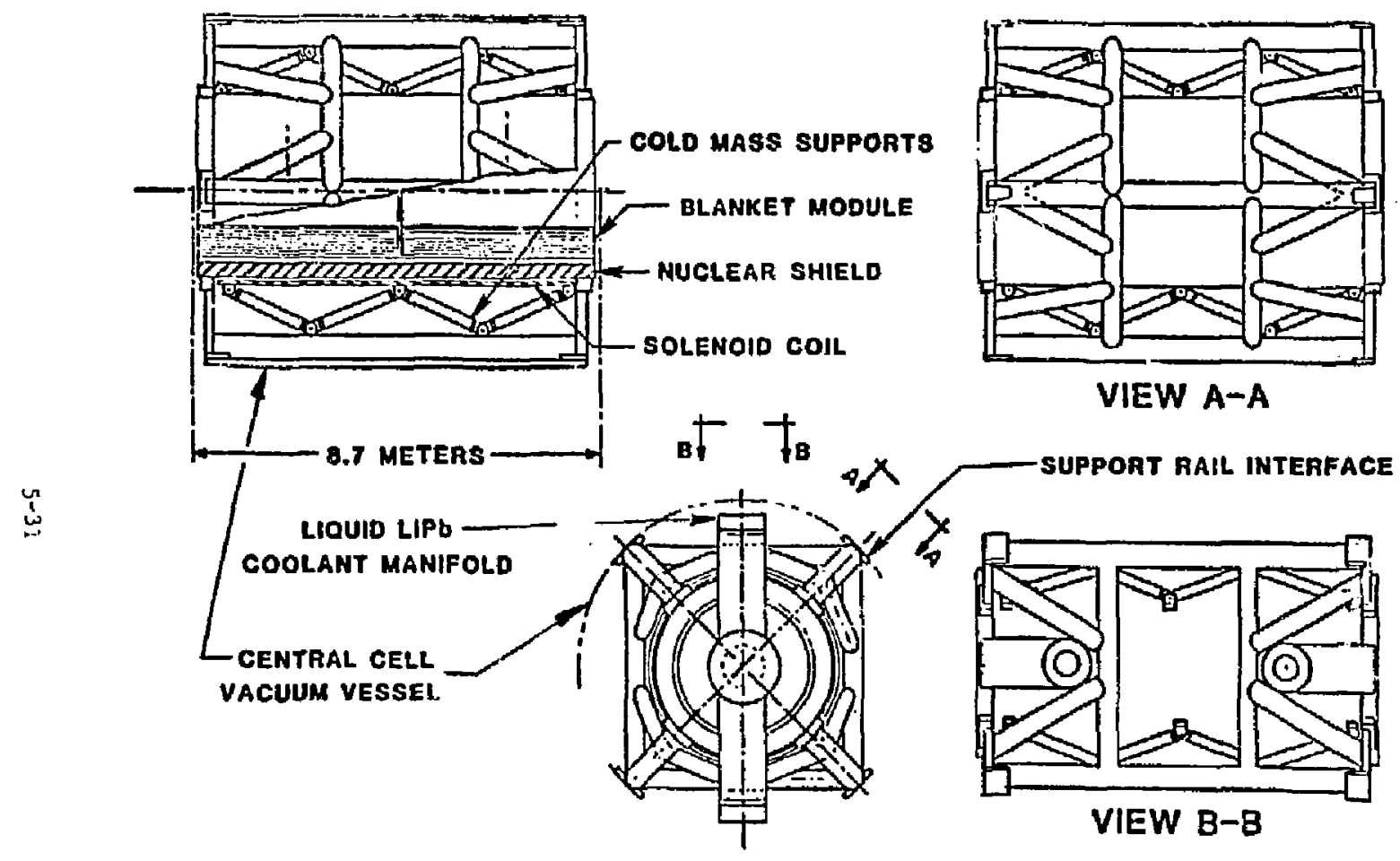

Figure 5-19. The central-cell component assembly. 


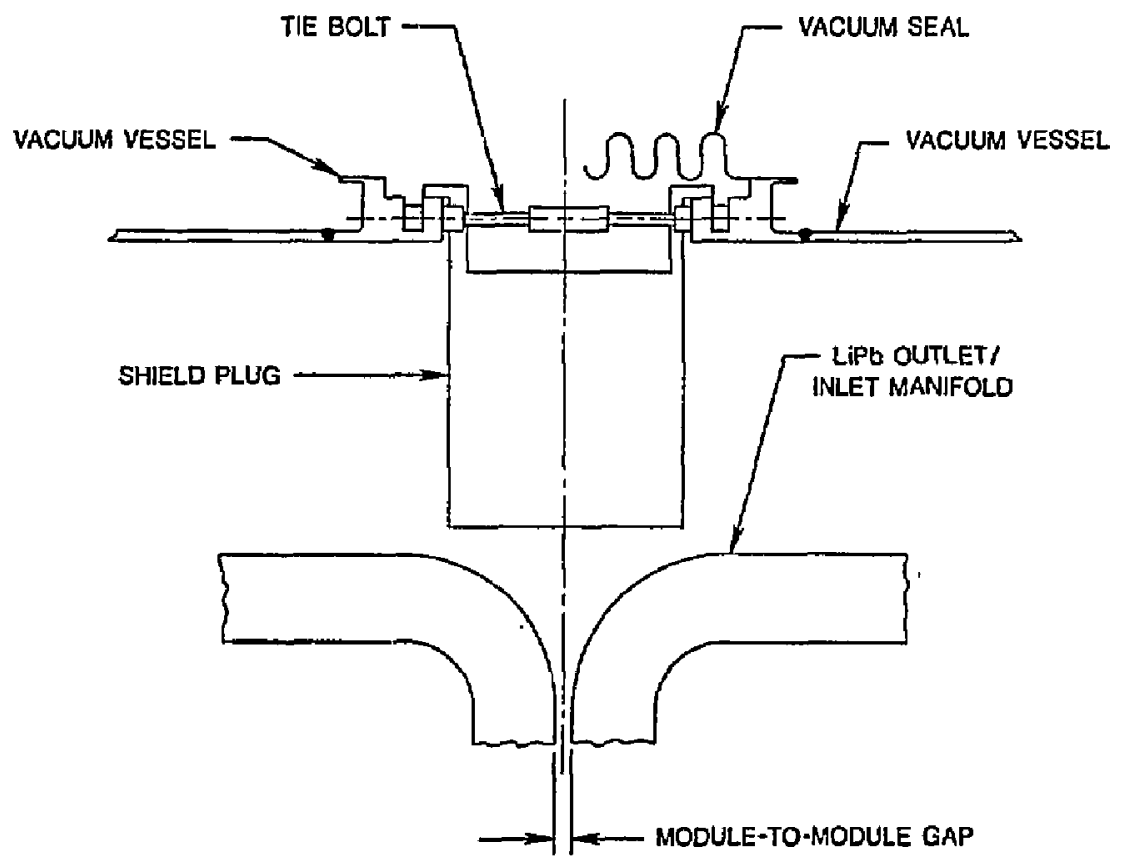

Figure 5-20. Module-to-module sea1. 
SUPPORT STRUCTURE

Each of the A modules has two sets of support legs. The support legs transmit all of the module loads to $r:$ liforced-concrete piers.

FND CELL

MAGNE'TS

The end-cell magnet system consists of two transition, two plug, two anchor-type $c$ coils, and one recitcularizing coil. All the C-type coils have essentially the same configuration, dimensions, current density, operating current, and peak fields. The $T 1$ coil has a unique separation of the winding pack into thirds in its minor radius region toward the choke coil. The recircularizing coil is the last coil in the end cels and the configuration is similar to MFTF- $\alpha+\tau$.

\section{System Finction Summary}

The magnet system is sized and arranged to provide the on-axis magnetic field required for plasma performance. In addition, the end cells provide machine plugging and magnetohydrodynamic (MHD) stability.

\section{Requirement Summàry}

On-Axis Field. The axial-field profile in the end crill region is shown in Fig. 5-21. The peak field on the c-coil conductor is $10 \mathrm{~T}$, and the maximum centerline field is $7.5 \mathrm{f}$ at $z= \pm 51$ and $56 \mathrm{~m}$. The minimum end-plug field is $2.5 \mathrm{~T}$ at $z=57 \mathrm{~m}$. In addition to these on-axis field requirements, the plasma leaving the end-plug regions must be cjicular to rccimodate a circular direct converter.

Access and Clearance Requirements. Access between and location of end cell magnets must be compatible with the plasma heating systems. These systems are: $475-\mathrm{kW}$ negative-ion neutral-beam injector at $\mathrm{z}= \pm 56.62 \mathrm{~m}, 71-\mathrm{MHz}$ ioncyclotron resonant heating (ICRH) associated with resonances at $z= \pm 59.3 \mathrm{~m}$. 


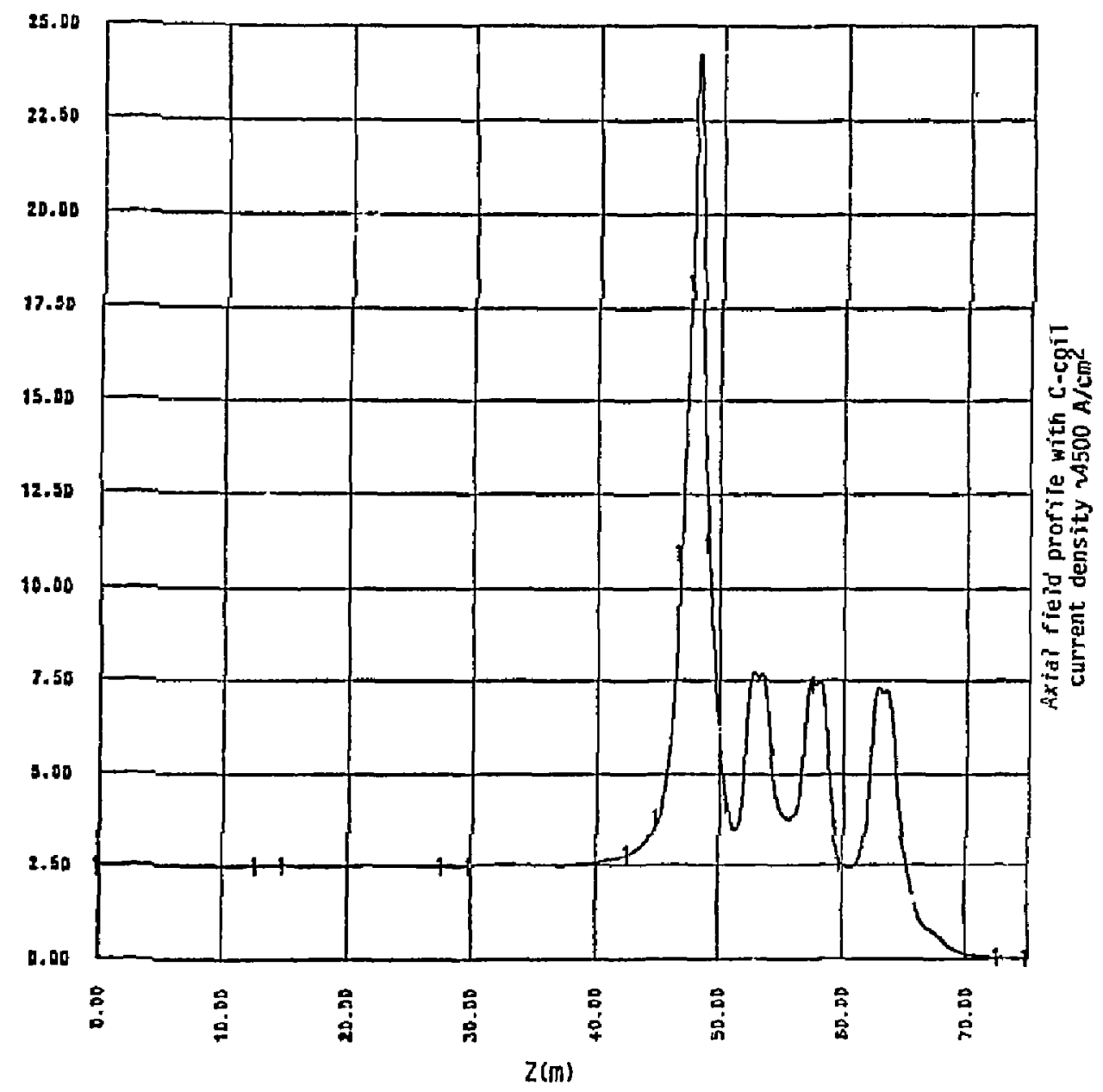

$\leftarrow$

Figure 5-21. Axial-field profile with C-coil current density at $24500 \mathrm{~A} / \mathrm{cm}^{2}$. 
Design Life and Number of Cycles. The design life and number of cycles for the end-cell magnet system are the same as for the overall system. Design life is 10 years of operation at a $10 \%$ duty factor. The superconducting magnets in the end cell are designed to withstand 120 cooldown/warmup cycles and 12,000 charging/discharging cycles at operating temperature.

Maintainability. The end cell magnets are to be designed for the life of the machine; however, realistic magnet replacement schemes must be identified during confeptual design.

End Cell Magnets

Magnet Configuration and Design. The configuration for the FPD-II end-cel1 system is shown in Fig. 5-22. locations, dimensions, currents, current densicies, and fields associated with this configuration are shom in Table 5-8. This coil-set concept meers the requirements staced earlier in this section.

The conductor selected for the $C$ coil is a modified LCP Nb 3 Sn Forcedflow conductor. The modifications assumed in this application address the need for higher current density $\left(24,500 \mathrm{~A} / \mathrm{cm}^{2}\right)$ and removal of up to $5 \mathrm{~mW} / \mathrm{cm}^{3}$ of nuclear heating. The modifications assumed to achieve these objectives are as follows:

\section{Current Density}

- Using an incoloy conduic macerial,

- Reacting at $700 \mathrm{C}$ after winding,

- After reacting, Epoxy impregnation.

\section{Nuc1ear Heating Removal}

- Using larger helium cross-sectional area,

- Having a 3-K inlet temperature for supercritical LHe.

The winding concept assumes double pancakes with three conductors in parallel. 


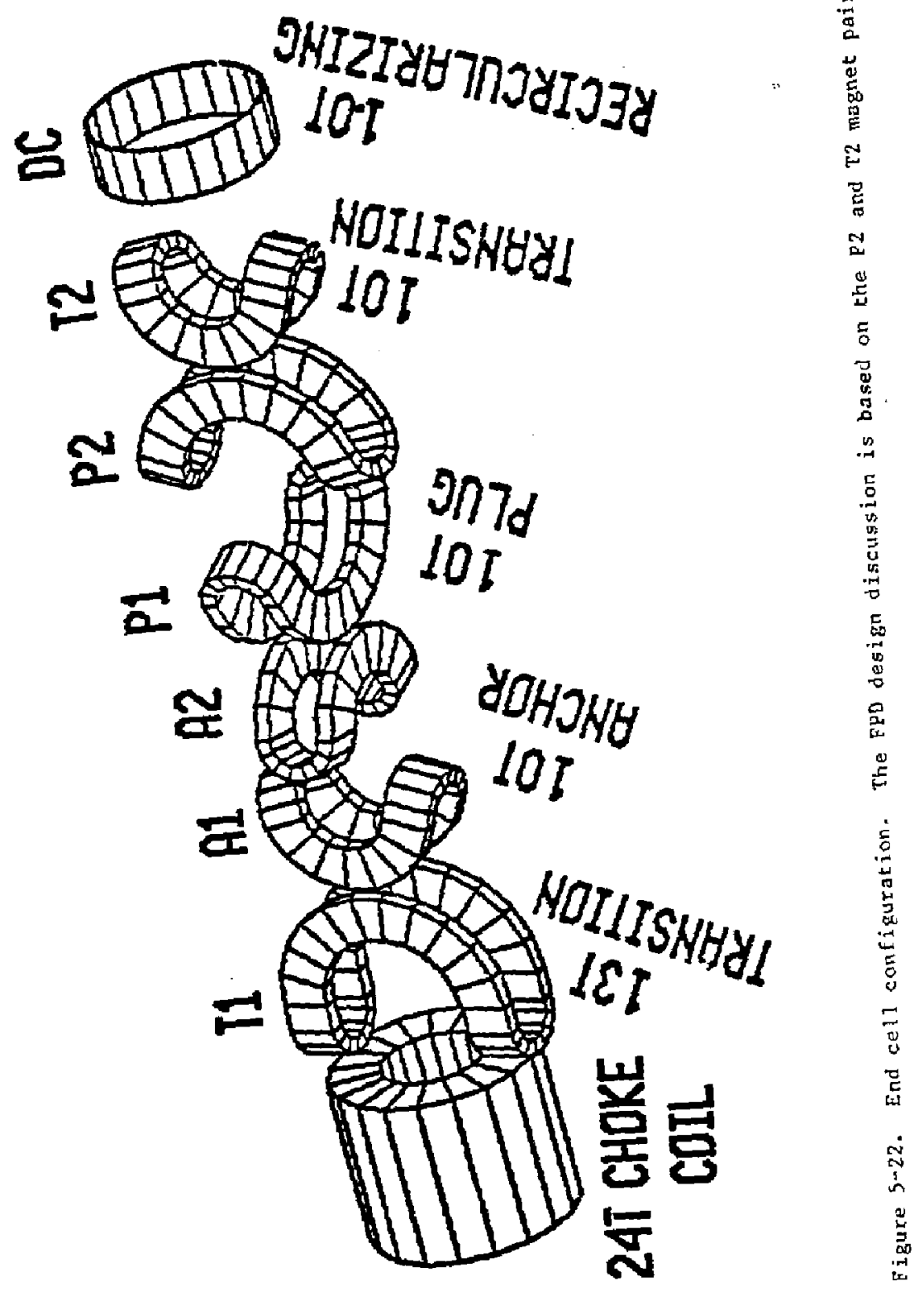


Tabie 5-8. End plug coil parameters for FPD-II (model coil ser--C83).

\begin{tabular}{|c|c|c|c|c|c|c|c|}
\hline Coils & $z_{m}$ & $\begin{array}{c}\mathrm{R}_{\text {majorl }} \\
\mathrm{R}_{\text {minor }} \\
(\mathrm{m})\end{array}$ & $\begin{array}{r}\Delta \mathrm{z} \\
(\mathrm{m})\end{array}$ & $\begin{array}{l}\Delta R \\
(m)\end{array}$ & $\underset{\left(A / \mathrm{cm}^{2}\right)}{\lambda j}$ & $\begin{array}{l}\text { Coil } \\
\text { current } \\
\text { (MA) }\end{array}$ & $\begin{array}{l}\text { Peak } \\
\text { EieId } \\
\text { (T) }\end{array}$ \\
\hline$T 2$ & 64.85 & $1.2 / 0.6$ & 0.81 & 0.27 & 4553 & 10.0 & 9.73 \\
\hline $\mathrm{P} 2$ & 60.98 & $1.7 / 0.6$ & 0.81 & $0.2 i$ & 4537 & 9.96 & 9.95 \\
\hline $\mathrm{Pl}$ & 59.96 & $1.7 / 0.6$ & 0.81 & 0.27 & 4530 & 9.96 & 10.00 \\
\hline A. 2 & 56.10 & $1.2 / 0.6$ & 0.81 & 0.27 & 4553 & 10.00 & 10.20 \\
\hline A. 1 & 54.74 & $1.2 / 0.6$ & 0.81 & 0.27 & 4553 & 10.00 & 10.40 \\
\hline $\mathrm{T} 1$ & 50.88 & $3.7 / 0.6$ & 0.81 & $=m$ & 4530 & 9.96 & 10.00 \\
\hline
\end{tabular}

Figure 5-23 shows the cross section of a typical $C$ coil in the and cell system. We selected the inner plate thickness of $5 \mathrm{~cm}$ to provide space for $30 \mathrm{~cm}$ (per side) of nuclear radiation shielding and an $\mathrm{LN}_{2}$ cold wall in the bore of the magnets. The other plate thicknesses along itit the 5.08-cm inner plate provide support for the magnetic loads from the ronductor pack. These magnetic loads produce primary membrane and both primary and secondary bending stress in the coil case. Significant reinforcing is required to resist both lobe-separating forces. Spacing within the reinforcing structural members is determired by local bending stress conditions. The use of the external stiffening avoids the use of excessively thick plate sections to carry the large loads associated with these coils. The oil material is assumed to be 304-LN stainless steel with a $4-K$ yield strength of $100 \mathrm{ksi}$.

The 1-T recircularizing coil can be designed with the forced-flow or poolboiling conductor. The final coil design will be the conduit that results in the lowest combined cryogenic, electrical, magnet system cost. A pool-boiling coil is assumed for this FPD predesign and costing effort. 


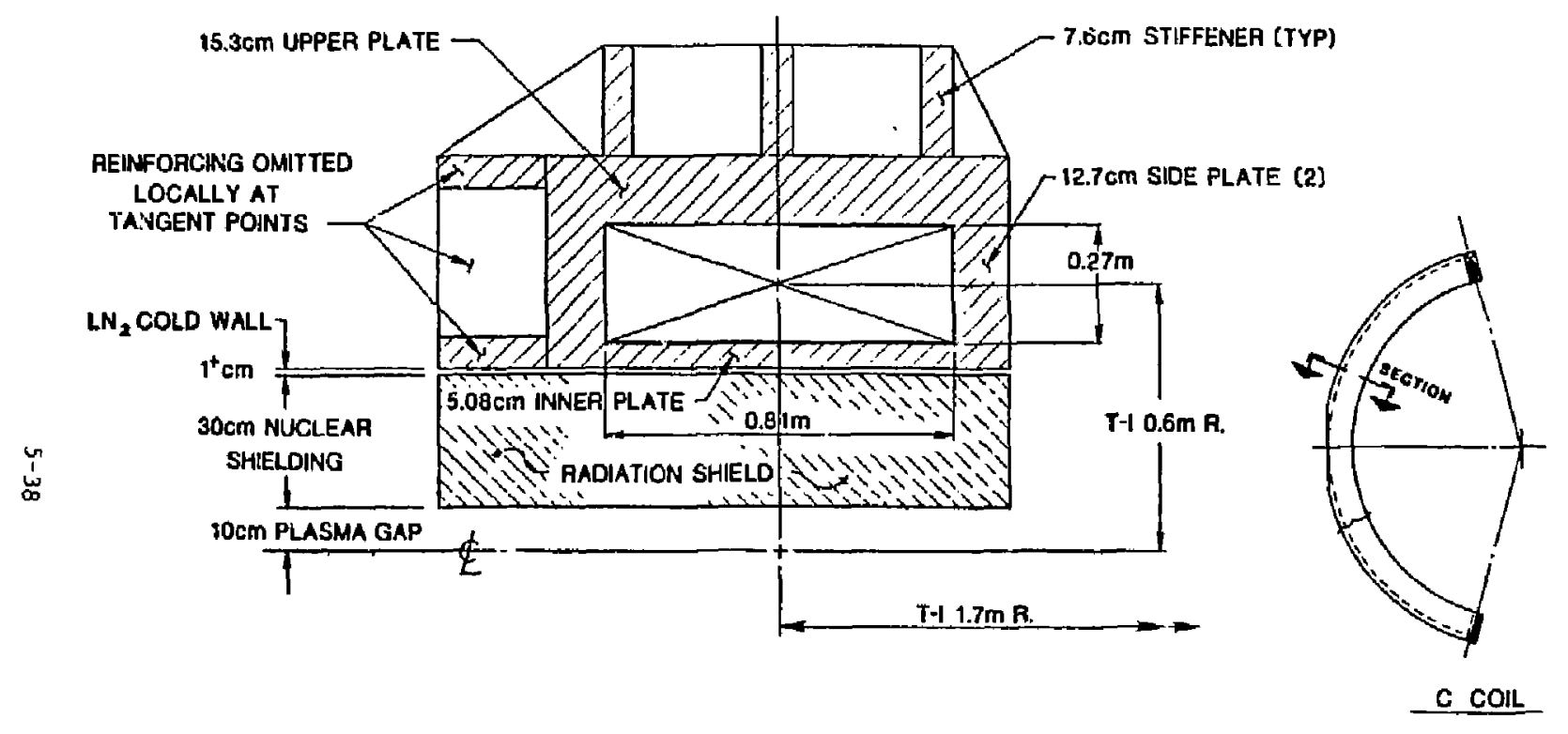

Figure 5-23. Typiral c-coil rross section. 


\section{Conclusions}

Tne end coij. system concept is achievable using the force-cooled conductor concept proposed by the Massdchusetts Institute of Technology. This Force-cooled conductor is also specified for TFCX; research and development tasks have been identified for qualifying this conductor for operating at $10 \mathrm{~T}$.

Structural/design considerations in the end-cell C coils represent a signifiaant, but believable, extrapolation from MFTF-A and MFTF-B experience. Finally, the low-field recircularizing coil is well withir the limits of current superconducting cjil technology.

END-CELL PLASMA HEATTNG SYSTEMS

Four end-cell plasma heating systems perform various functions in EPD-II: an anchor ICRH system creates high beta; a high-energy negative-ion-based neutral bear (NINB) system and two electron-cyclotron resonant heating (ECRH) systems form the thermal bartier and central-cell ion-confining potential in the plug. End-cell heating requiraments for FPD-II are listed in Table 5-9; where the table contains two sets of data, th. Fir,t set corresponds to the ronaxicell case, and the second set to the axisell case.

The key differences between the FPD-I heating requirements (see Sec, 4) and the FPn-II requirements are:

1. Lower ECRH and ICRH powers;

2. Lower becas in both the anchor and the plug;

3. Changes in all trapping fractions except for the potentiaj-peak ECRH system.

The $r f$ powers decrease in FPD-II because the new magnet set is more compact and thus the heating volume decreases. In addition, a decrease in axial .. confinement is required to limit the trapped-ion current in the transition during axicell beam operation, which further relaxes the rf power requirements. The lawir betas decrease the complexity of the $r$ systems because the frequency shift during startup cecreases. The higher heating 
Table 5-9. The end-cell heating requirements for FPD-ir. (When there are two sets of power and current requirements, the first value corresponds to the nonaxicell case and the second value, in parentinesis, to the axicell case.)

\begin{tabular}{|c|c|c|c|c|}
\hline & $\begin{array}{l}\text { Anchor } \\
\text { ICRH }\end{array}$ & $\begin{array}{c}\text { sloshing } \\
\text { NINB }\end{array}$ & $\begin{array}{c}\text { Potential- } \\
\text { peak } \\
\text { ECRH }\end{array}$ & $\begin{array}{l}\text { Therma1- } \\
\text { barrier } \\
\text { ECRH }\end{array}$ \\
\hline Heat locations - & -- & $a^{*}$ & $\mathbf{a}$ & $\mathbf{b}$ \\
\hline$-z_{\text {axis }}(m)$ & $\pm 54.25 \& \pm 56.6$ & \pm 58.78 & \pm 61.63 & \pm 60.5 \\
\hline Absorbed power (MW) & $0.26(0.21)$ & $1.37(0.47)$ & $0.35(0.19)$ & $11.09(10.57)$ \\
\hline Trapping fraction & $0.6 \times 0.5$ & 0.29 & 0.85 & 0.7 \\
\hline Delivered power (MW) & $0.87(0.7)$ & $4.71(1.62)$ & $0.41(0.23)$ & $15.85(15.0)$ \\
\hline Vacuum frequency $\left(\mathrm{H}_{z}\right)$ & $76.0 \times 10^{6}$ & -- & $84.0 \times 10^{9}$ & $70.0 \times 10^{9}$ \\
\hline Heating frequency $(\mathrm{Hz})$ & $71.0 \times 10^{6}$ & -- & $68.0 \times 10^{9}$ & $52.0 \times 10^{9}$ \\
\hline Delivered current (A) & -- & $9.91(4.99)$ & -- & -- \\
\hline Beam energy (kev) & -- & $475(325)$ & -- & -- \\
\hline Injection ang1e(deg) & $=-$ & 90 & -- & -- \\
\hline
\end{tabular}

frequencies in FPD-II also improve ECRH optics (lower-beam divergences) and offer versatility in the anchor-ICRH-launcher design (e.g., waveguides). The trapping fraction of the NINB increases because of the inclusion of multistep ionizaticn processes and alphas. On the other hand, trapping fractions for the ICRH system and the thermal barrier ECRH system are lowered in FPD-II because of uncertainty in wave physics. The ICRH change has little adverse effect because the power level is low; the ECRH trapping fraction is decreased $t=0.70$. This decrease adds $W_{4} \mathrm{MW}$ and thus one more gyrotron to each transport: system, which would not be required if a trapping fraction of 0.85 were used.

The main impact that axicell operation has on end-cell heating systems is in the sloshing-beam NINB syotem. The power to the NINB decreases fron 4.71 to $1.62 \mathrm{~kW}$; the delivered current decrease is not as Iarge because the 
injection energy for the axicell case drops from 475 to $325 \mathrm{keV}$. The ECRH and ICRli systems are defined for axicell operation, but are capable of delivering slightly greater powers when there is no axicell insert. The neutral beam systern is sized for the nonaxiceil case (4.71 MW, $475 \mathrm{keV}$ system); the operational characteristics for the axicell case are discussed later in this section.

\section{ECRH Systems}

The thermal-barrier ECRH system delivers $7.5 \mathrm{MW}$ at $52 \mathrm{GHz}$ into each plug at point $b, z= \pm 60.5 \mathrm{~m}$. As in the FPD-I device, l-MW gyrotrons are assumed tn be available and a quasi-optical transmission system is used for the thermal-barrier system at point $b$. Because of the low power requirement for the potential-peak system at goint a ( $115 \mathrm{~kW}$ per plug), a waveguide transmission system is more compact and more practical to use than a quasi-optical transport system.

The system for point $b$ is of the same configuration that was outlined in Sec. 4 in Fig. 4-3 and depicted in Figs. 4-11 and 4-12. The FPD-II ECRH configuration is shown in Fig. 5-24 and the quasi-optical transport system parameters for the 52-GHz system are listed in Table 5-10. Two transport modules are located in the pling regions, each with five operating beams and one redundant launcher. Because the magnet set is rotated at $45^{\circ}$, the beans pass between the yin-yang magnet pair through the major radius gaps with the transport modules centered about the $x-z$ plane on each side of the plug.

Also denoted in Fig. 5-24 is the potential-peak ECRH system; this low power system comprises 200-k! gyrotrons and a waveguide transmission system. A black diagram of the transmission line is shown in Fig. 5-25. To avoid potential problems associated with window failures (e.g., $\mathrm{SF}_{6}$ or windowcoolant leaks inco the plasma chamber), a vacuum wavegide was chosen for FPD-II, but power handling capabilities and arcing issues in a radiation et. fironment still need to be quantified.

The ECRH-system power flow and key system parameters are summarized in Fig. 5. 26 . The power for this pair of systems at each end cell is provided by a single converter/transformer unit rated at $25 \mathrm{MW}$ and $83 \mathrm{~kW}$, which feeds 


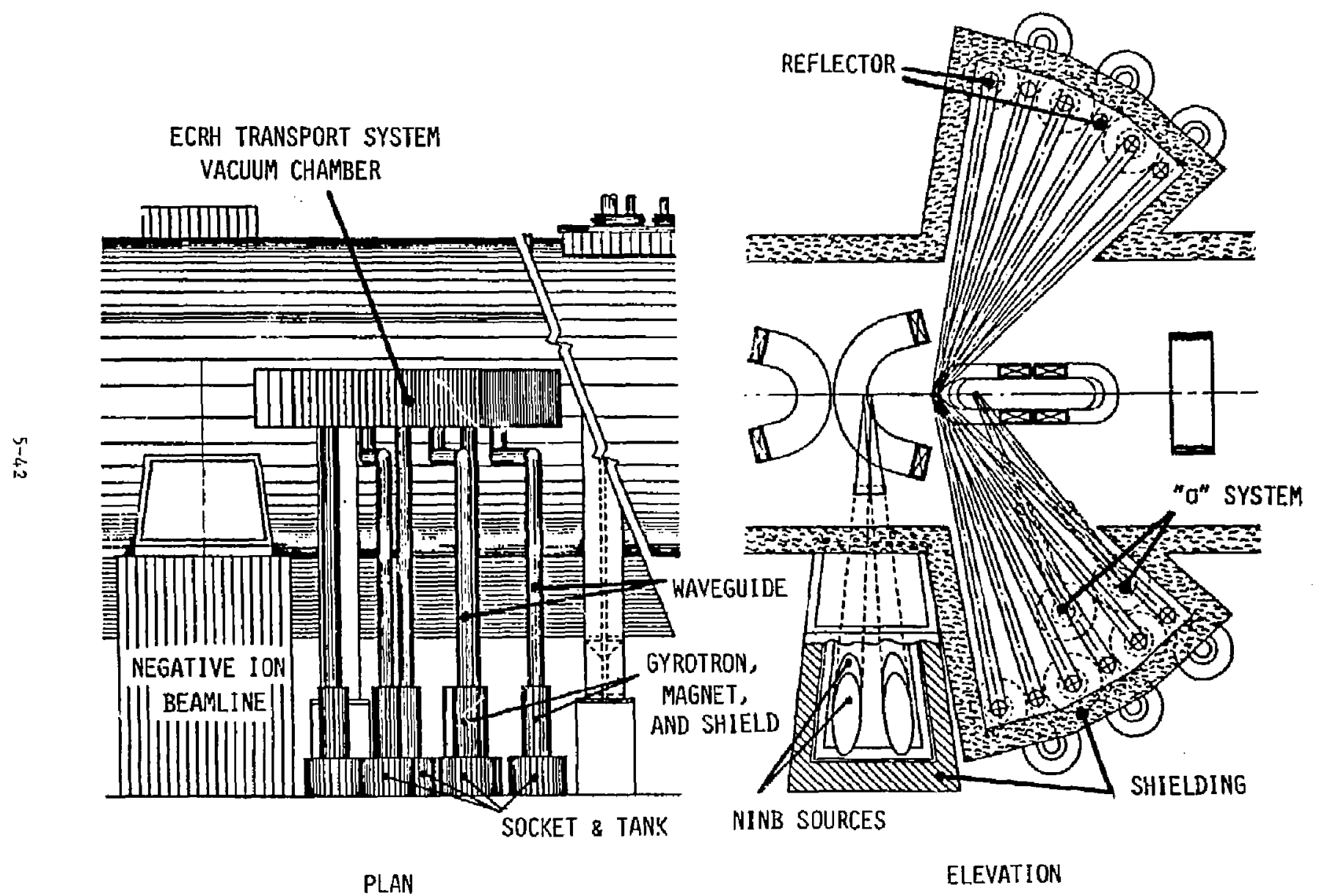

Figure 5-24. End plug and ECRH system configuration. 
Tabie 5-10. Thermal barrier quasi-optical system parameters.

\begin{tabular}{|c|c|}
\hline Type & $\begin{array}{l}\text { offset-conic }-1 \text { horn/ } \\
\text { paraboloid reflector }\end{array}$ \\
\hline Conical angle (deg) & 17 \\
\hline Cone height, $h(\mathrm{~cm})$ & 56.45 \\
\hline Paraboloid focal length, $f(\mathrm{~cm})$ & 30.19 \\
\hline Mirror diameter, $D_{m}(\mathrm{~cm})$ & 54.0 \\
\hline Initial beam diameter, $D_{0}(\mathrm{~cm})$ & 41.65 \\
\hline $\begin{array}{l}\text { Distance to point } b, x_{0}(m) \\
\text { Beam diameter at point }\end{array}$ & 8.5 \\
\hline$b, D\left(x_{0}\right)(c m)$ & 15.0 \\
\hline Distance to magnets, $x(m)$ & 7.25 \\
\hline $\begin{array}{l}\text { Maximum beam diameter in magnet } \\
\text { region, } o(x)(\mathrm{cm})\end{array}$ & 19.0 \\
\hline Number of transport systems/end & 2 \\
\hline $\begin{array}{l}\text { Number of beam launchers/ } \\
\text { erarsport system }\end{array}$ & $\begin{array}{l}6 \text { ( } 5 \text { operating/ } \\
1 \text { redundant) }\end{array}$ \\
\hline Launcher transmission & \\
\hline efficiency $(\%)$ & 96 \\
\hline
\end{tabular}




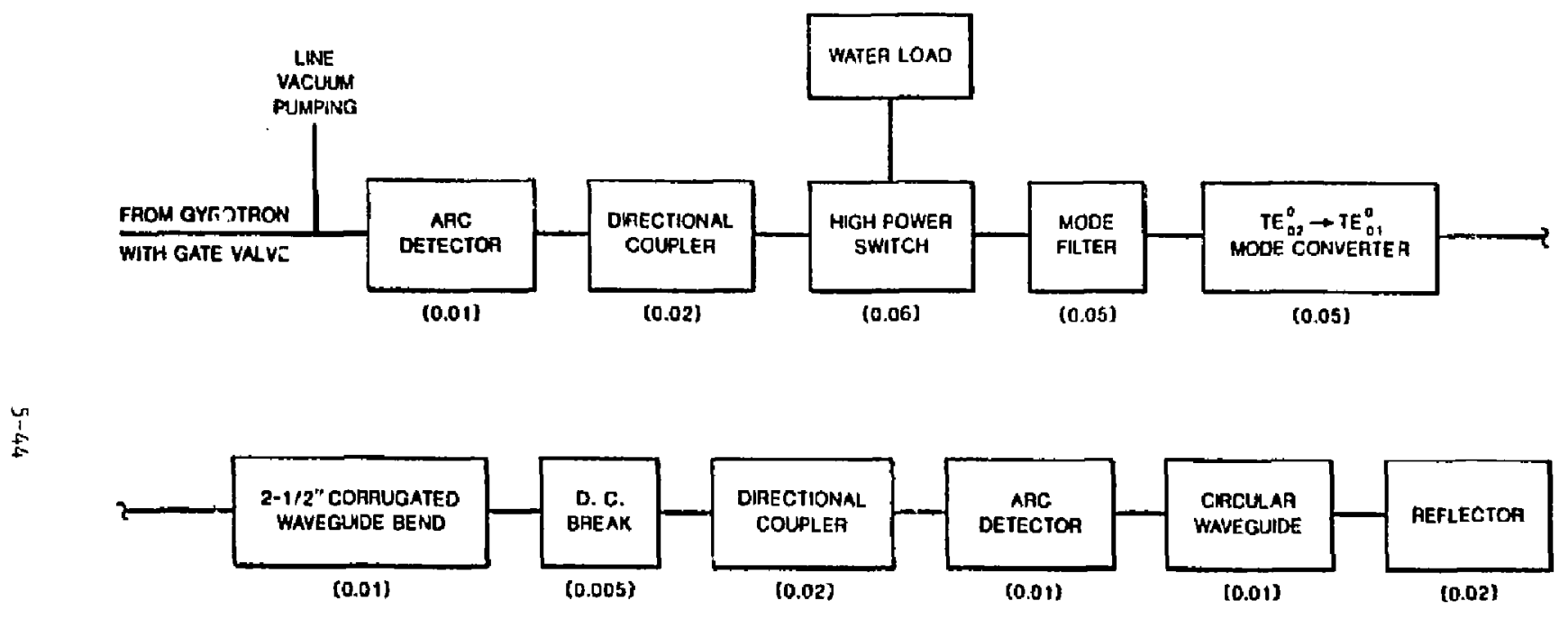

Figure 5-25. Potential-peak ECRl-waveruide transmission system. The parenthesis indicate fractional nower loss in component. Total ransmission efficiency- $-70.8 \%$. 


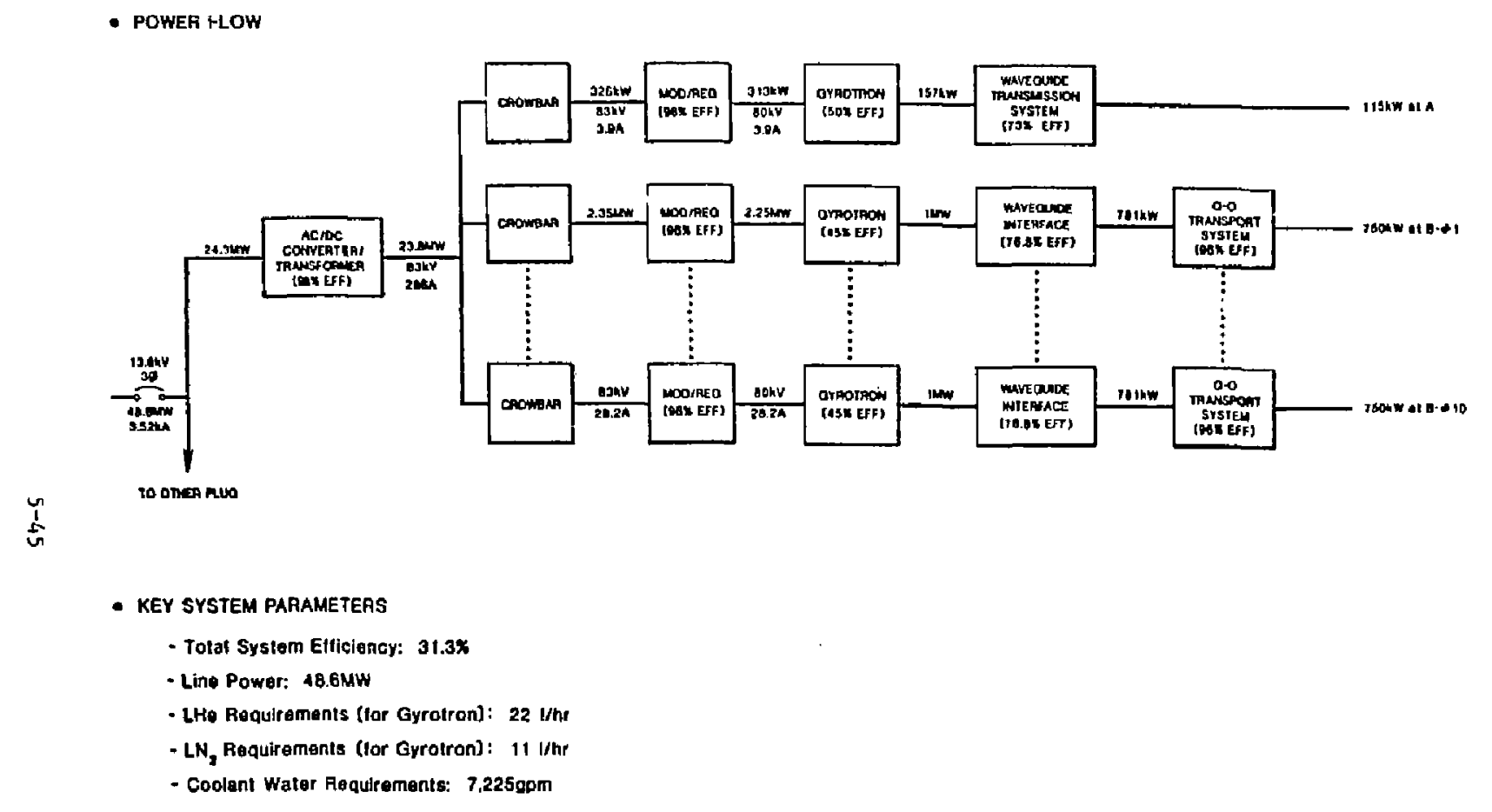

Figure 5-26. The FPD-II ECRlA power flow. 
eleven parallel protection and regulation networiss. Each network supplies a gyrotron and consists of a crowbar procection cirsuit, a modulator/regulator series tube, and a disconnect ground switch. The 1-Mw gyrotrons are assumed to operate at a lower efficiency than the $200-\mathrm{kW}$ tubes because of possible mode competition in the larger collector cavities that are expected for the bigher power. The total ECRH-1ine requirement is $48.6 \mathrm{MW}$ and the system efficiency is $31.3 \%$.

\section{Anchor ICRH System}

The anchor ICRH system must deliver $435 \mathrm{~kW}$ to each anchor when operating without the blanket test module and $350 \mathrm{~kW}$ during axicell operation. Lower beta in the FPD-II anchor results in a higher heating frequency, $71 \mathrm{MHz}_{\mathrm{z}}$, than the $54 \mathrm{MHz}$ that was required in previous studies (e.g., Mirror Advanced Reactor Stuoy (MARS), ${ }^{3} M F T F-\alpha+T,{ }^{1}$ and FPD-I); because of this higher frequency, waveguides become a viable alcernative to an ancenna launchex.

Although the coupling physics of a waveguide launcher in the ICRH frequency range is not quantified yet, its engineering benefits in fusionreactor upplications, when compared with loop antennas, have been espoused for a number of years and include:

1. Removes much of tha launcher from the harsh plasma-edge environment and thus prolongs the launche:'s 1 ifetime;

2. Is easier to maintain;

3. Has more power-handling capability.

An antenna launcher was used in the FPD-I configuration berause at $54 . \mathrm{MHz}$ the waveguides were too large without the fnurth or fifth harmonic heating. Here, the $\gtrsim 30 \%$ increase in frequency allows use of single-ridged waveguides of widths $<1.0 \mathrm{~m}$ at the second deuterium harmon: $=$ and $260 \mathrm{~cm}$ for the third harmonic. Figure 5-27 contains a schematic of a single-ridged guide and dimensions for several harmonics for a $15-\Omega$ waveguide impedance. 


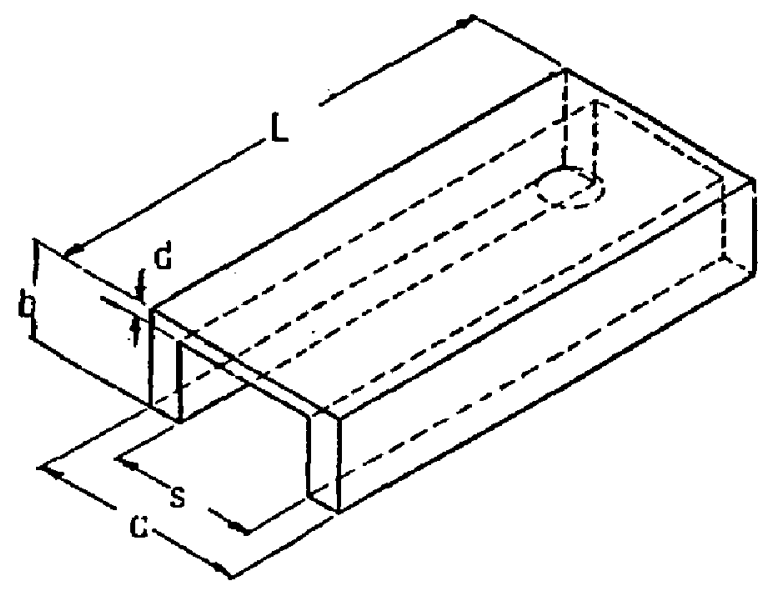

$-$

\begin{tabular}{|c|c|c|c|c|c|c|}
\hline Harmonic & $\begin{array}{r}f_{\text {heat }} \\
{[\mathrm{g} 1 \mathrm{i}]}\end{array}$ & $\begin{array}{c}\mathrm{a} \\
{[\mathrm{cm}]}\end{array}$ & $\begin{array}{c}\mathrm{h} \\
{[\mathrm{cm}]}\end{array}$ & $\begin{array}{c}\mathrm{s} \\
{[\mathrm{cm}]}\end{array}$ & $\begin{array}{c}\mathrm{d} \\
{[\mathrm{cm}]}\end{array}$ & $\begin{array}{c}\mathbf{c} \\
{[\mathrm{cm}]}\end{array}$ \\
\hline 2 & 71.1 & 95.2 & 21.4 & 71.4 & 1.61 & 4.29 \\
3 & 106.7 & 63.4 & 14.3 & 47.6 & 1.07 & 2.86 \\
4 & 142.2 & 47.6 & 10.7 & 35.7 & 0.8 & 3.10 \\
\hline
\end{tabular}

Figure 5-27. Ridged-waveguide harmonic heating alternatives. 
The remainder of the anchor ICRH system is considered of standard design and is shown in Fig. 5-28. A sumary of the entire system foilows:

- Configuration: two launchers per anchor

$$
\text { ( } 1 \text { operating/ } 1 \text { redundant) }
$$

- Launcher: single-ridged waveguide

Haveguide power: $350 \mathrm{~kW}$

Efficiency: $97 \%$

- Transmission system: mainly 6-1/8 in.

Coaxial + step transformer and two stub tuning systems

Efficiency: $82.4 \%$

Coolant 1oops

No. 1: Launcher back to stub tuner No. 2

7 BPm while operating

4 gpm while dormant

No. 2: Remainder--4 gpm while operating

- Transmitcer: multistage

Two power supplies: FPA- $675 \mathrm{~kW}, 20 \mathrm{kV}$

Driver--10 kW, $7 \mathrm{kV}$

Efficiency: $59.3 \%$

Coolant loop: $150 \mathrm{gpm}$

- Performance:

Total line power: $1.48 \mathrm{MW}$

System efficiency: $47.5 \%$

Total water coolant requirements: $330 \mathrm{gpm}$.

Power levels in this sumary are for the axicell operating scenario. Rather than the three-stub tuning system used in the FPD-I antenna system, the third scub is replaced by a $50-\Omega \rightarrow 15-\Omega$ coaxial-step-impedance transformer. The power source is a multistage amplifier chain and at $71 \mathrm{MHz}$ the 8 imac $x-2170 / 8973$ tetrode is the appropriate final power amplifier. Even though this system has a relatively low power requjrement, the waveguide anc tetrode are both capable of handling $1 \mathrm{MW}$ so that for little additional cos, the purchase of $1.5-\mathrm{MW}$ powex supply offers a margin of surplus capabilit; $\vdots_{11}$ the 


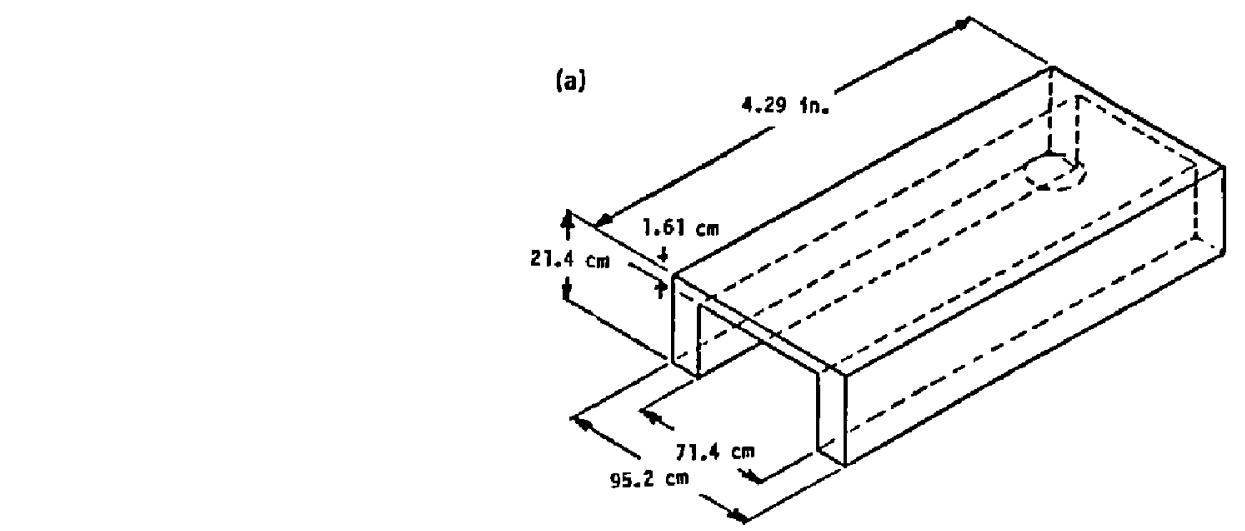

(b)

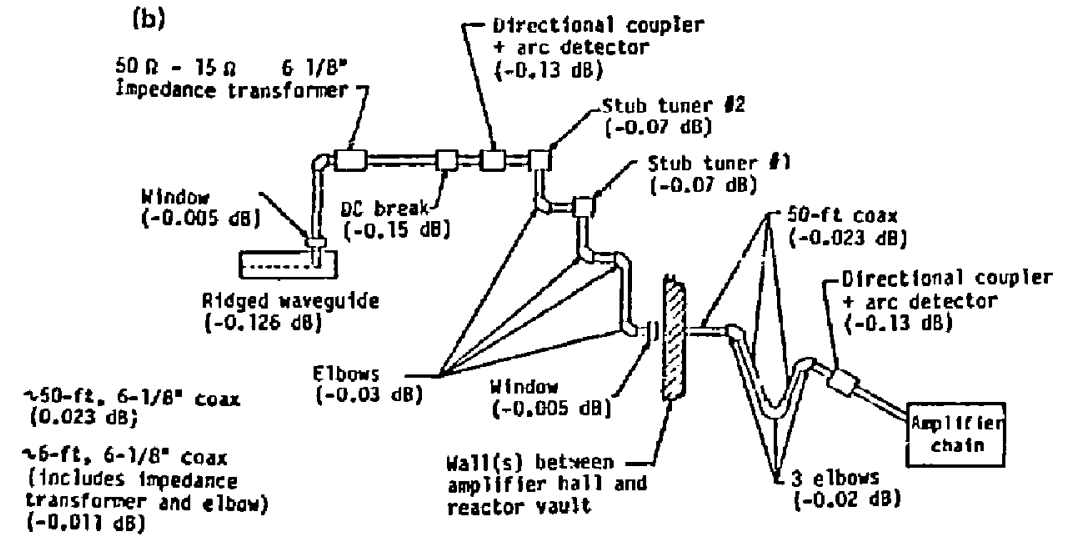

(c)

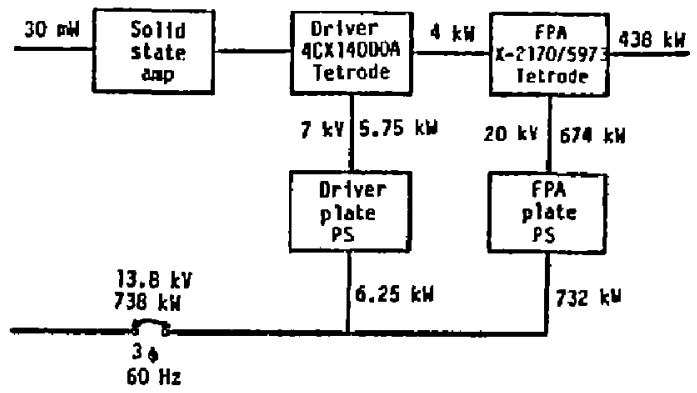

Figure 5-28. The FPD-II ICRH system description. (a) Single-ridged waveguide launcher; (b) mainly 6-1/8-in. transmission system; (c) multistage transmitter. 
event that wave-coupling and ion-trapping efficiencies are lower than assumed. The total line power for the system during axicell operation is $1.48 \mathrm{MH}$ corresponding to a $47.5 \%$ system efficiency. Without the axicell, the 1 ine power increases to $1.85 \mathrm{wW}$.

\section{Negative-Ion Neutral-Beam System}

The neutral beams that create the stoshing-ion distribution in the plugs are the heating systems most effected by whether or not there is an operating axicell. Without the axicel1, $2.35 \mathrm{MW}$ (4.95 A at $475 \mathrm{keV})$ is injected into each plug; whereas the power, current, and beam energy decrease to $800 \mathrm{~kW}$, $2.5 \mathrm{~A}$, and $325 \mathrm{keV}$, respectively, when the axicell is in operation. The system summarized below corresponds to the more demanding requirements, but we will also discuss the system implications associated with axicell operation.

- Configuration:

One beamline per plug;

Four sources per beanline ( 3 operating/1 redundant);

Sources arranged in a $2 \times 2$ array.

- 4.0-A Lawrence Berkeley Latoratory type self-extraction source at $-475 \mathrm{kV}, 2 \times 68 \mathrm{~cm}^{2}$ ribbon bean;

RF plasma generator in magnetic multipole bucket containment;

Forced cesium dirusion through converter plate;

Small transverse magnetic fields to divert electrons;

Standard 80-kV cingle-slot pre-accelerator;

Gas efficiency: $12 \%$ - total gas flow ( 3 sources): $8.8 \mathrm{~T} 2 / \mathrm{s}$.

- Transverse field focusing (TFF) transport and high-voltage accelerator :

B0-kV TFF-transport section [low energy beam transport (LEBT)] at $-395 \mathrm{kV}$ with multistage differential pumping $\rightarrow 9.0 \mathrm{~m}^{2}$ cryopump;

Four-stage TFF high-voltage accelerator $(-305 \mathrm{kV},-220 \mathrm{kV},-135 \mathrm{kV}$, $-50 \mathrm{keV}$ );

High energy beam transport (HEBT) section;

TFF focusing voltages range from +25 to $\pm 50 \mathrm{kV}$;

Divergence: $0.45^{\circ} \times 1^{\circ}$;

Pressure $1 \times 10^{-5}$ Torr. 
- Gas jet neutralizer with a Poulsen-type plug nozzle:

Optimum gas thickness: $6.5 \times 10^{15} \mathrm{~cm}^{-2}$;

Average pressure in pump chamber: $5 \times 10^{-4}$ Torr;

Approximate dimensions: $2 \times 1.75 \times 1.75 \mathrm{~m}$;

Cryopanels: $15 \mathrm{~m}^{2}$.

- Ion maginet/dump region:

Pressure $1.0 \times 10^{-5}$ Torr ;

$2.0 \mathrm{~m}^{2}$ eryopump.

The beamline configuration has much in common with the FPD-I NINB system described in Sec. 4, in particular, the source and TFF configurations shown in Sec. 4 in Figs. 4-17 and 4-18. The source current capability is more in line with the Negative-Ion Development Program's goal of $6 \mathrm{~A} / \mathrm{m}$ (Ref.4) leading to a sliginly larger source $\left(2 \times 68 \mathrm{~cm}^{2}\right)$, but a factor of $\mathrm{t} \cdot \mathrm{)}$ increase in source current $(4 \mathrm{~A})$. The gas load per source also doubles to $2.9-\mathrm{l} / \mathrm{s}$; the cryopanel area requirements in the LEBT section are $7.5 \mathrm{~m}^{2}$ with $50 \%$ LEBT grid transmissivity and $20 \%$ recycling factor.

The key departure from past designs is the use of a gas-jet neutralizer in FPD-II. This concept incorporates a Poulsen-type nozzle that was previously used to minimize flow of alkati vapor metal along negative-ion beamines. ' Although much more analysis is required on deuterium-jet neutralizers, they do not require advanced technology, should entaij only a modest development effort, and have a number of advantages when compared with conventional gas-cel] neutralizers. These advantages include:

1. A shorter magnetic shield is used, which results in a decrease in the beamline weights, and costs are less (beamlines are easier to mint $2: n$ ).

2. The gas curtain separates the ion beam from the neutral-beam region.

3. The jets he:p pump the beamline.

4. The jets prevent the gas in the pumping chamber from freely flowing back into the beamline.

5. The jets permit a reduction of ion losses by a lower beamline background gas pressure.

6. The jets do not appear to represent a significant cost increase. 
Figure 5-29 represents the jet neutralizar concept. The cryopump chamber is quite large, but can be outside the main beamline vacuum and magnetic shielding envelope. The cryopanel area in the pump chamber is $15 \mathrm{~m}^{2}$.

Figure 5-30 is the current and power flow of a beamline and

Fig. $5-31$ is the beamline in the and cell configuration. The current efficiency is $41.25 \%$, whereas the power efficiency is $45.36 \%$; the difference occurs because most the current is lost at low energies. The line power requirement for the entire system is then $10.4 \mathrm{NW}$.

To operate the beamlines during axicell operation, the following changes in the beamline are required: (1) the number of operating sources decreases from three to two; (2) the individual source current decreases almost $30 \%$ to $3.13 \mathrm{~A}$; and (3) the last two stages of the TFF high-voltage accelerator are converted to nonaccelerating TFF transport sections, and the acceleration potential in the HEBT is raised $10 \mathrm{kV}$. The system line power required during this phase is $3.5 \mathrm{MW}$.

\section{DRIET PUMPING}

\section{Requirements}

Table 5-11 summarizes the FPD-II drift pumping system requirements. Each of the parameters is described in Sec. 4. Note that the plug cell has two populations: one for the so-called "cold" ions and another for the "sloshing" ions. The combination of reduced bandwidth $(10 \%$ as compared with $66 \%)$ and fewer frequencies ( 245 compared with 110 ) makes the implementation much more attractive than that of the FPD-I.

Another parameter, which eases the design problem, is the large (>10:1) reduction in flux for the transition; this results in a reduction in coil surrent and therefore power amplifier size.

\section{Configuration}

The same besic concept is planned here as in the FPU-I and MFTF-a+T. There are 13 channels for the transition and 46 ( $22 \operatorname{cold}$ and $24 \operatorname{sioshing}$ ) 


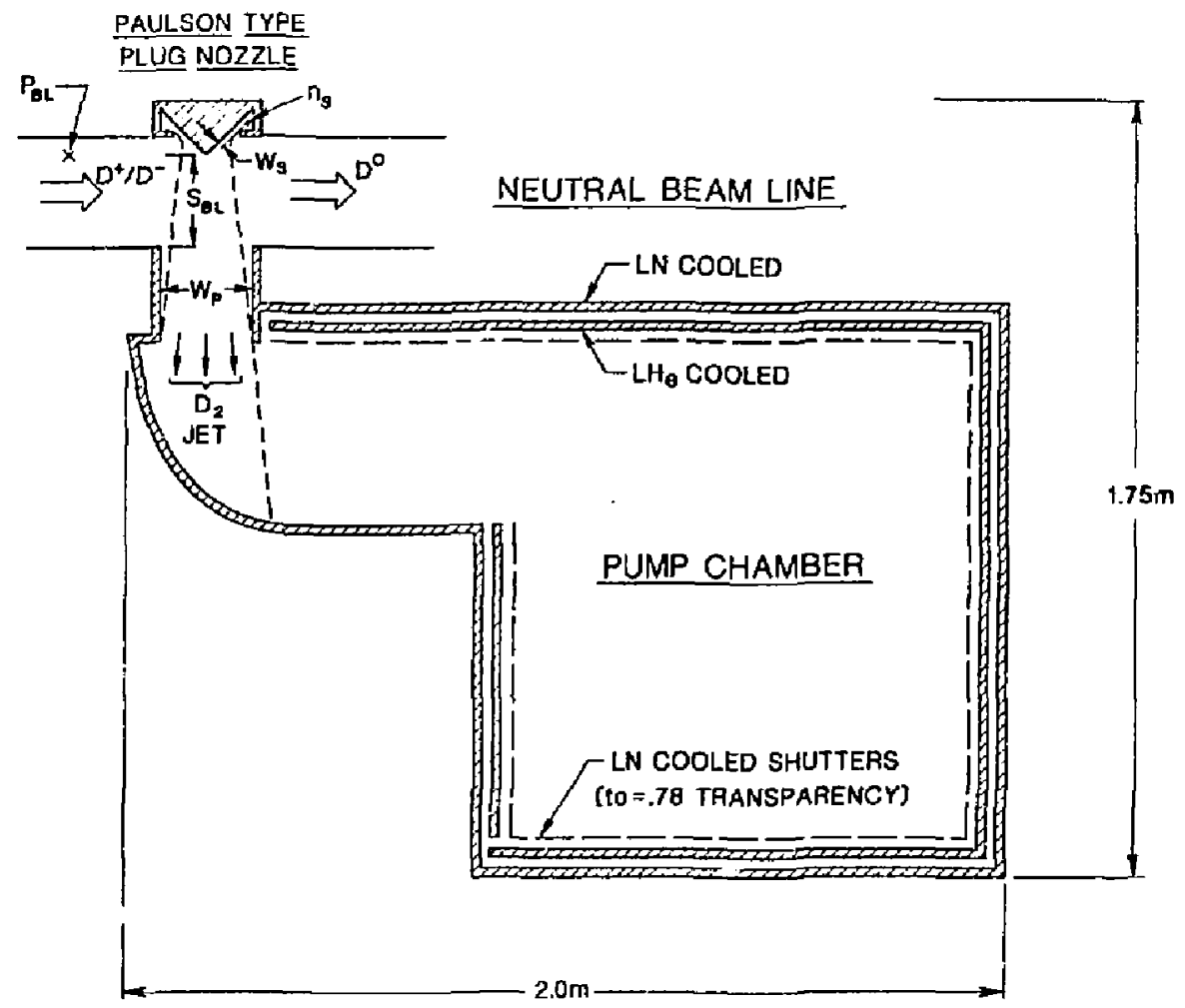

Figure 5-29. Deuterium gas jpt neutralizer concept. 


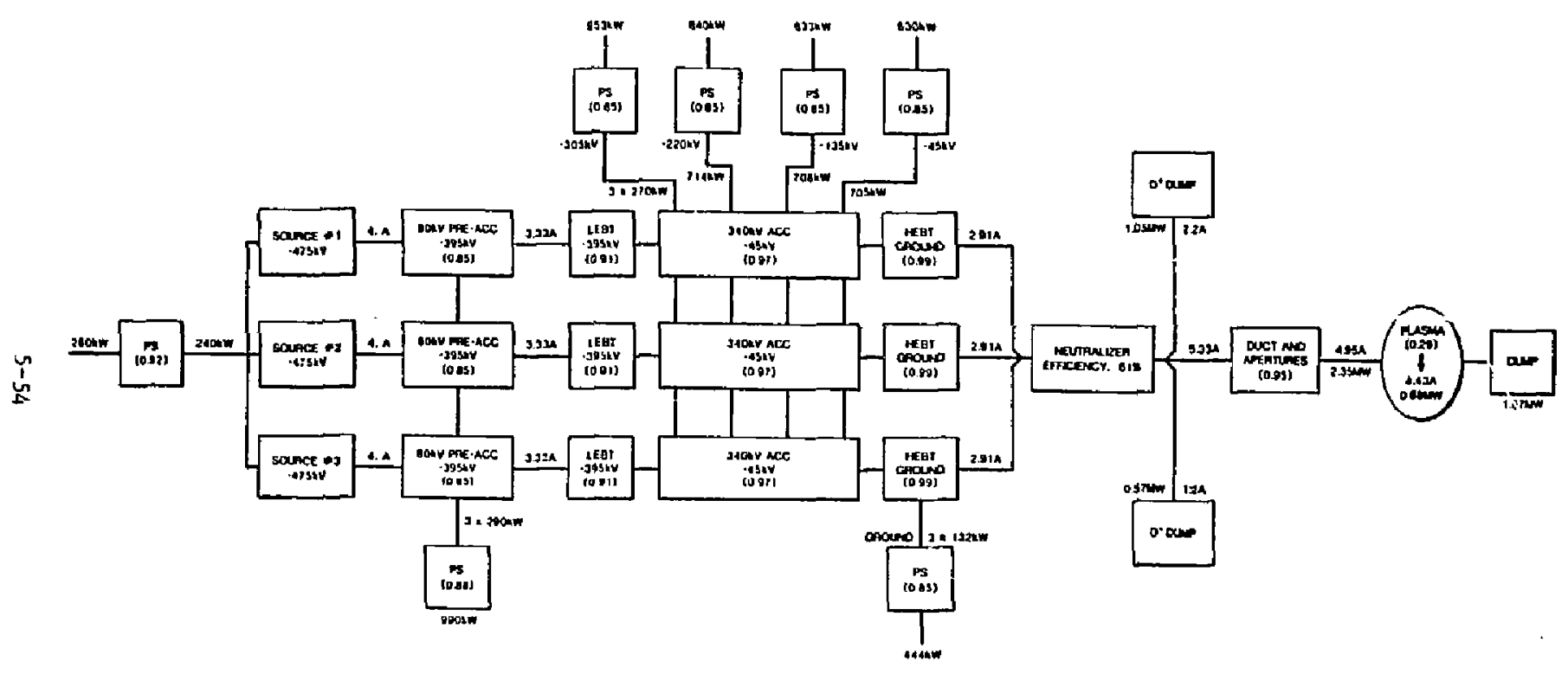

CURAENT EFFICIENCY: $11.25 \%$

POWER EFFICIENCY: $\quad$ 15.36\%

Figure 5-30. Sloshing beam current and nower flow (the Eractions in parenthesis correspond to current transmission fraction). 


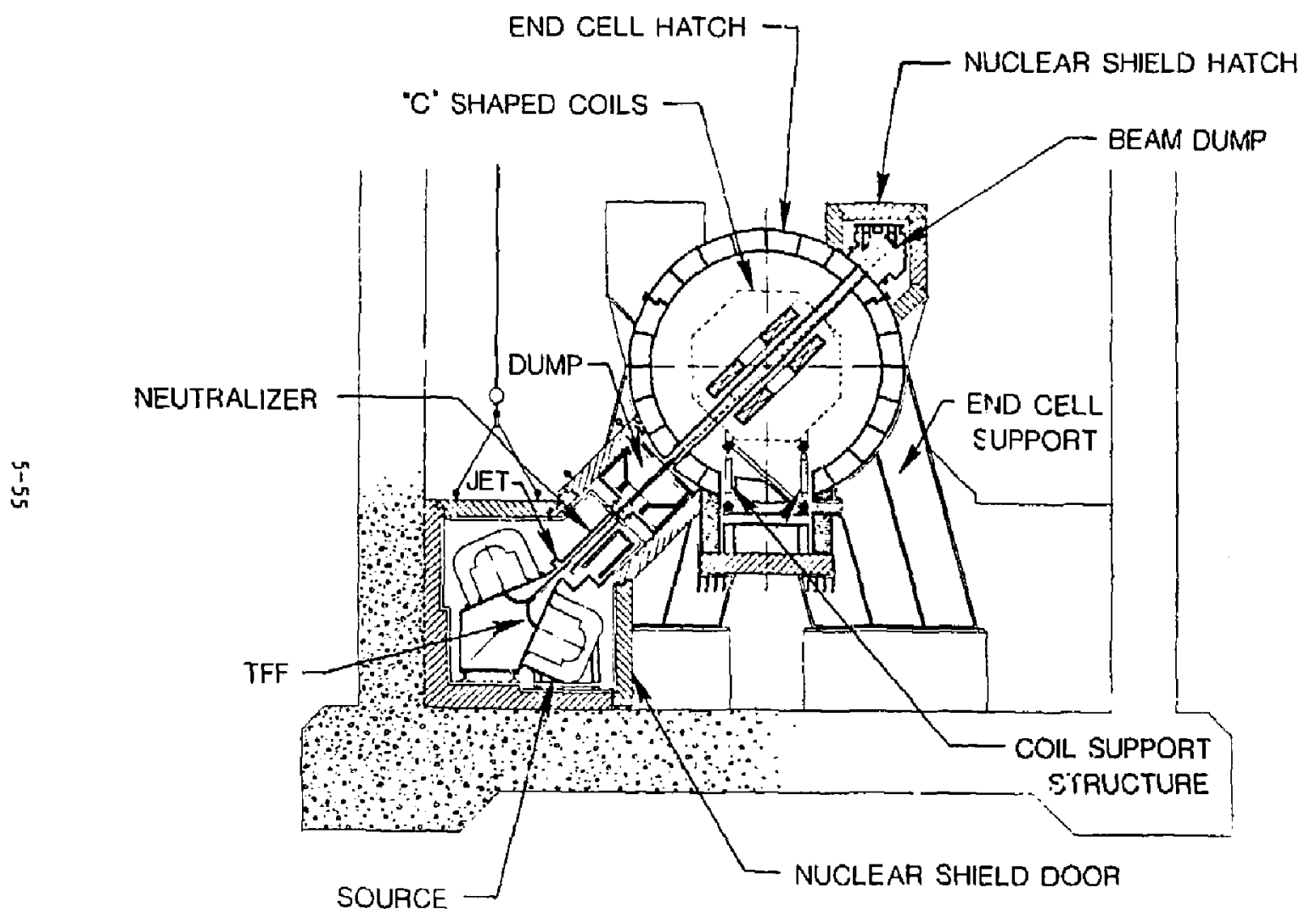

Figure 5-31. End plug and sloshing beamline configuration. 
Table 5-II. The FPD-II drift-pump requitements.a

\begin{tabular}{llll}
\hline $\begin{array}{c}\text { Transition } \\
\text { cell }\end{array}$ & Parameter & Plug cell \\
\hline & Cold & sloshing \\
106.63 & Center frequency $(\mathrm{kHz})$ & 827.6 & 1328.9 \\
37.3 & Af/f bandwidth $(\%)$ & 10 & 10 \\
39.78 & Df bandwidth (kHz) & 82.76 & 132.89 \\
13 & No. of frequencies & 41 & 48 \\
0.00538 & Perturbation flux (Wb) & 0.00349 & 0.00349 \\
\hline
\end{tabular}

Assumptions:

- MARS-1ike coil

- hairfin shape

- ccaled

- Eddy current loading

- scaled from MFTF- $\alpha+T$

channels for the plug call. He plan to have 2 tones per channel to cover the cotal af $89(41+48)$ frequencies for the piug. For further details, refer to Sec. 4 or the MFTF- $\alpha+T$ study report. ]

\section{Perfozmance}

Table 5-12 shows the results of the performance analysis. The coil currents were estimated to be:

and

$$
I_{c}=3.3 \mathrm{kA} \text { transition }
$$

$$
=0.9 \mathrm{kA} \text { plug. }
$$


Table 5-12. Performance.

\begin{tabular}{|c|c|c|c|}
\hline \multirow{2}{*}{$\begin{array}{l}\text { Transition } \\
\text { cell }\end{array}$} & \multirow[b]{2}{*}{ Parameter } & \multicolumn{2}{|c|}{ Plug cell } \\
\hline & & $\overline{\text { Cold }}$ & sloshing \\
\hline \multicolumn{4}{|c|}{ Coil: } \\
\hline 4 & Inciuctance $(\mu \mathrm{H})$ & 4 & 4 \\
\hline 8.3 & Resistance $(m \Omega)$ & 23.0 & 42.3 \\
\hline 303 & Inherent $Q$ & 901 & 789 \\
\hline 1.8 & Load resistance $(\mathrm{m} n)$ & 5.2 & 9.5 \\
\hline $24 b$ & Loaded $Q$ & $72^{\circ}$ & 645 \\
\hline 15.0 & Power ( $\mathrm{kW}$ ) & 17.6 & 32.2 \\
\hline 3.4 & Power, $I_{c}(\mathrm{kw})$ & 3.9 & 7.2 \\
\hline \multicolumn{4}{|c|}{ Transmitter: } \\
\hline 13 & No. of channels & 21 & 24 \\
\hline 10.2 & rower output $(\mathrm{kw})$ & 7.5 & 9.3 \\
\hline 0.54 & Channel bandwidth $\%$ & 0.48 & 0.42 \\
\hline 1 & Tones/channel & 2 & 2 \\
\hline \multirow[t]{2}{*}{13.7} & 'Transmission and matching & & \\
\hline & efficiency & 13.5 & $1 i .2$ \\
\hline 16.7 & Prime powet (kw) & 12.3 & 1.8 \\
\hline
\end{tabular}

Again, the analysis procedure is the same as used in the MFTF- $\alpha+T$ study. Because the flux requirement is modest, the power r quirement is small compared with FPD-I. The details of the dasign are summarizet in Table 5-1" The values are given in microfarads and microhenries for the capacit. and inductors, respectively. For this design, the plug system suppli., spectrum capable of covering the $10 \%$ handwidth. Hence any form of modulat, on (noise, cw sweep, or tone) can be used. The efficiencies, in terms of wat of prime power to amperes of circulating current, ar. 45, 65, and 86 for the transition, plug (cold), and plug (sjoshing) systems, respectively. This is goo, efficiency compared with the MFTF- $\alpha+T$, where the ratio was 170 . 
Table 5-i3. Component values.

\begin{tabular}{|c|c|c|c|}
\hline \multirow[b]{2}{*}{ Component ${ }^{a}$} & \multirow[b]{2}{*}{ Transition } & \multicolumn{2}{|c|}{ Plug } \\
\hline & & Cold & SIoshing \\
\hline$C_{1}(j, F)$ & 0.00096 & 0.0023 & 0.000907 \\
\hline$c_{2}(\mu F)$ & $0.0001 t$ & 0.00002 & 0.000010 \\
\hline $\mathrm{c}_{3}(\mu \mathrm{F})$ & 0.01150 & 0.00039 & 0.000239 \\
\hline$C_{4}(\mu F)$ & 1.00033 & 0.00160 & 0.001012 \\
\hline$I_{1}(\mu \mathrm{H})$ & 16 & 8 & 8 \\
\hline $\mathrm{L}_{2}(\mu \mathrm{H})$ & 14,060 & 2,030 & 1,400 \\
\hline$L_{3}(\mu H)$ & 228.9 & 97.1 & 60.1 \\
\hline $\mathrm{I}_{4}(\mu \mathrm{t})$ & 490.8 & 23.1 & 14.3 \\
\hline Tube & $4 C \times 5000 R$ & $4 C \times 5000 R$ & $4 C X 5000 R$ \\
\hline
\end{tabular}

\section{Future Work}

Breaking up the spectrum into bands improved the implementation of the plug system, but the system still isas 46 channeis driving a single pair of coils. Further reductions in tandwidth are desirable. lt would be wortiwhile to investigate limitations on the $Q$, f the drift pump coil because the coil 1 inits the intrinsic bandwidth. Refer to Ser. 4 for other future efforts.

\section{HALO SCRAPER/DIRECT CONYERTER}

We c'esigned a halo pump and direct convercer For FPD-II for which design parameters are mort fuliy described than cuose for FPD-I. The true crosssectional shape of the plasma detarmines the shape of the various elements in the FPD-II direct converter. We also considered the effert of the changed magnets set $(A-18$ to $C-53)$ on the design of the FPO-II direct converter. 


\section{Design Assumptions}

To minimize costs, the FPD-II direct converter produces only low-grade throw-away thermal energy. The return water-coolant temperatur ${ }^{-}$is set at $80^{\circ} \mathrm{C}$ (inlet temperature is $30^{\circ} \%$ ). We assume that the plasma crosssectional shape does not change with changes in the machine operating power level. This assumption simplifies the design process until we can determine from our studies the effects on the direct converter of plasma shape and power distribution resulting from variations in machine operating power.

\section{Design Description}

The FPD-II direct-conv: ter design is based on the $6-53$ magnet set. A recent iteration of the magnet design resulted in the $C-83$ magnet set--we have not assessed the impact of this change at this time.

The plasma cross-sectional shape obtained from the $\mathrm{C}-53$ magnet set is an irregular four-pointed star. We tried to eliminate the "lobing" of the star at the four points and to make the shape more regular. Some nudification or the shape was possible by changing the cross section, the mean radius, and the current density of the recircularizing solenoid. Because it is not possible to completely recircularize the plasma by changing only the recircularizing solenoid, the amount of recircularization necessary depends on a cost tradeof $f$ between the increasing magnet size and the fabrication complication of irregularly shaped converter elements. For the purpose of this design, we changed the recircularizing solenoid to obtain a regular shape for the leading edge of the halo scraper and the interface between the halo scraper and the halo dump. Figure 5-32 shows the plasma shape with a modified recircularizing soil.

To minimize the direct-converter cost, the elements of the converter are spread axially. The halo-scraper assembly is positioned close to the recircularizing solenoid, but allows cnough space for adequate diffusion of the neutral particles and does not exceed the peak power density of a arconium-copper halo scraper. Good spacing between the halo assembly and the coilector assembly is necessary to allow independent assembly and disassembly. 


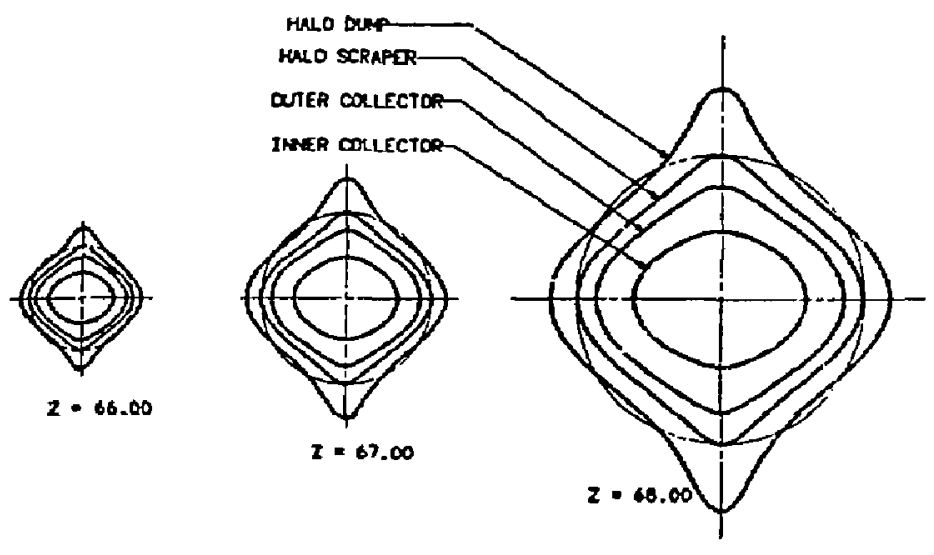

Figure 5-32. The C-53 magnet set plasma shape in the area of the FPD-II direct converter.

To simplify machining, the actively cooled elements in the halo scraper are defined as conical surfaces. These surfaces allow :onstant width sooling grooves to be milled in a straight, radial direction. Where possible, the circumferential edges have been simplified $(\mathrm{e} . \mathrm{g}$. , the inner edge of the outer collector shadows the inner collector allowing the edge of tile jner collector to be simplified).

The separate assemblies of the halo and the collector are mounted $f$ rom the vacuum vessel. The assemblies can be removed separately (Fig. 5-33). The plug for the halo scraper is sized to permit removal of the recircularizing solenoid.

The power distribution to the variaus elements of the direct converter is hown in Table 5-14. Table 5-15 lists the details of the cooled surfaces for 


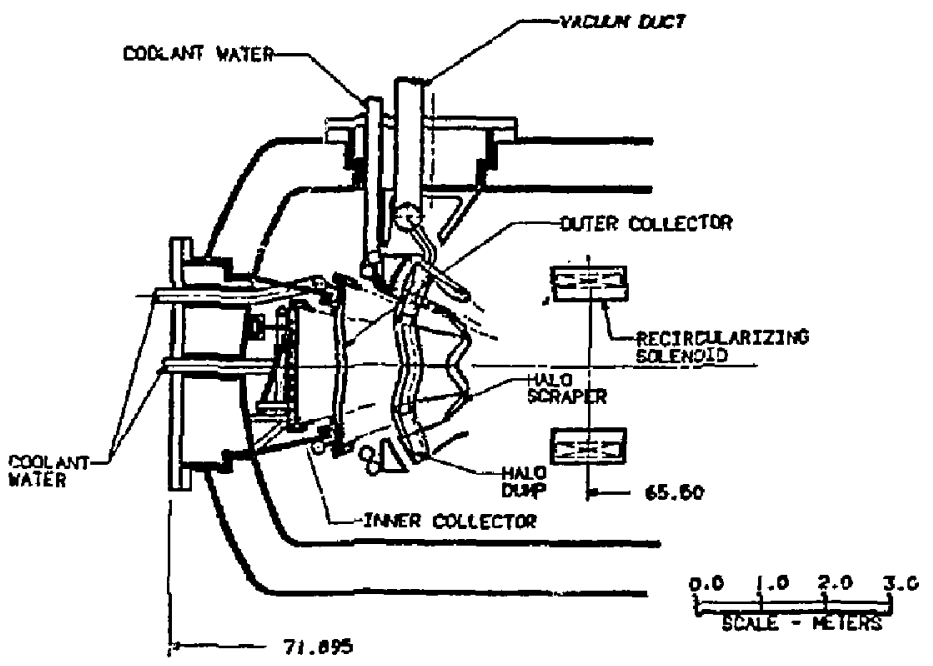

Figure 5-33, The FPD-II direct converter.

Table 5-14. Power distribution (MW both ends).

\begin{tabular}{|c|c|c|}
\hline & $\begin{array}{c}\text { Therma l } \\
\text { (MW) }\end{array}$ & $\begin{array}{l}\text { Electric } \\
\quad(M W)\end{array}$ \\
\hline Halo dump & 19.0 & 0.0 \\
\hline Halo Sctaper & 7.2 & 0.0 \\
\hline Outer collector & 4.3 & 4.2 \\
\hline Inner collector & $\underline{21.4}$ & $\underline{37.0}$ \\
\hline Total & 51.9 & 41.2 \\
\hline Total power $=93.1 \mathrm{MW}$ & & \\
\hline
\end{tabular}


Table 5-15. Direct converter thermal design.

\begin{tabular}{|c|c|c|c|c|}
\hline & $\begin{array}{c}\text { Intiar } \\
\text { collewat }\end{array}$ & $\begin{array}{l}\text { Outer } \\
\text { collector }\end{array}$ & $\begin{array}{l}\text { Halo } \\
\text { scraper }\end{array}$ & $\begin{array}{l}\text { Halo } \\
\text { dump }\end{array}$ \\
\hline Heat f1us (design) $\left(M_{m}^{\prime} m^{2}\right)$ & 1.78 & 0.62 & 1.49 & 2.07 \\
\hline Coolant flow rate (gnm) & 810 & 163 & 990 & 990 \\
\hline Coolant pressure (psi) & 620 & 620 & 620 & 620 \\
\hline Coolant pumping power ( $\mathrm{kw}$ ) & n7 & 20.5 & 76 & 76 \\
\hline Coolant yelocity $\{m\{s\}$ & 3.2 & 3.3 & 10 & 6 \\
\hline Surface temperature, $\operatorname{coppc} r\left({ }^{\circ} \mathrm{C}\right)$ & 127 & 124 & 148 & 195 \\
\hline Surface remperature, ${ }^{\circ}$ ri $\left({ }^{\circ} \mathrm{C}\right)$ & 236 & 162 & 239 & 321 \\
\hline \multicolumn{5}{|l|}{ Coolant channels } \\
\hline Width $x$ depch $(\mathrm{cm})$ & $0.7 \times 0 . \Sigma$ & $1.3 \times 0.3$ & $0.7 \times 0.4$ & $1.16 \times 0.4$ \\
\hline Number of sectors & 3 & 8 & 8 & 8 \\
\hline Channels per sector & 112 & 70 & 112 & 112 \\
\hline Channels per channel path & 1 & 3 & 4 & 4 \\
\hline
\end{tabular}

the water-sooled zirconium copper and TZM designs of the direct converter. Reduced tritium permeation is possible if the cooled surfaces are fabricated from TZM but the cost would be greater than the zirconium copper de-ign. Figure 5-34 depicts the coolant channels for the halo scraper--the coolant channels for the other elements of the direct converter are similar. Table 5-15 gives the channel dimensions.

Helium was considered as a coolant, but was not selected for three main reasons:

1. High pumping power required,

2. High capital cost of the pumping equipment,

3. Tritium extraction system required. 


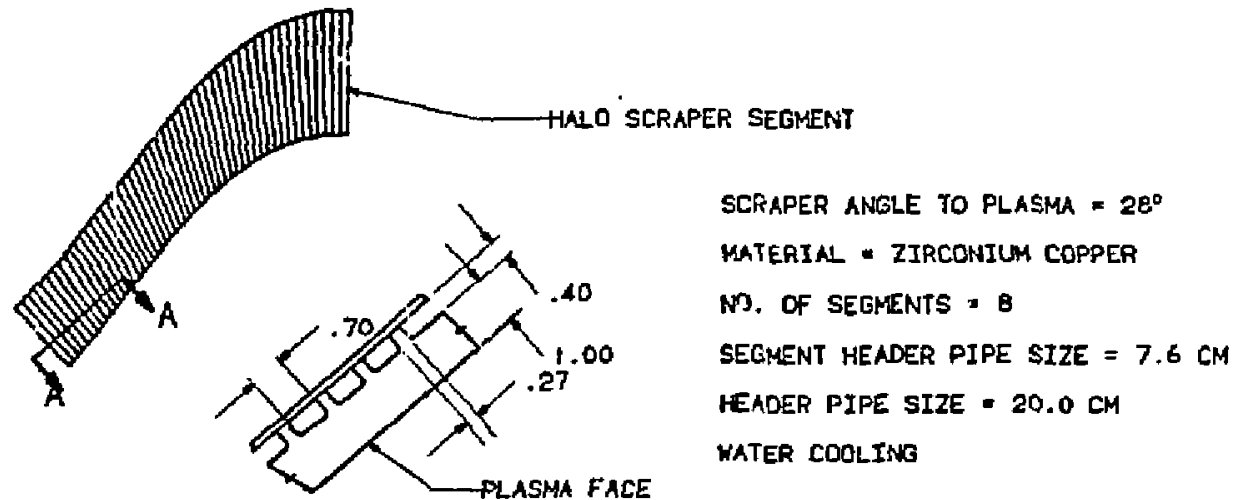

SECTION AA

Figure 5-34. The FPD-II direct converter/haln scraper coolant channels.

\section{Costs}

Table 5-16 summarizes the costs of the two direct converter optinns considered for EPD-II with a comparison to Miss.

SHIELDING AND VACUUM CONTA INMENT

The end cell region, Fig, 5-35, is a double-walled vacuum-vissel/ biological shield that contains the end cell coils, Firect converter, and halo scraper. The vesan? has an inside diameter of $7.0 \mathrm{~m}$ and a length of $40.0 \mathrm{~m}$. Each end cell has a direct-converter/halo-scraper hatch and a large magnet-access natch. The configuration in Fig. 5-35, allows for vertical removal of all the cell components. In addition, he vacuum vessel provides interface connections for the negative-ion sloshing deam, ICRH and electroncyclotion resonant heating (ECRH) rf systems, and the drift pumping coils. 
VACUUK VESSEL/BIOLOGICAL SHIELD

The end-cell vacuum vessel consists of two cuncentric, cyisadrical shells formine an annular volume for the water shielding. The inner and outer shelis are connected by radial bulkheads, as shown in Fig. 5-35. The intuer and outer shell spacing is $0.6 \mathrm{~m}$, based on biological shield requirements. Figure 5-36 shows the magnet cold-structure support box incegrated into the cylindrical vacuum vessel. The removable top hatches are framed by a beam structure. Both the magnet hatch and vacuum vessel have longitudinal stiffeners connecting the two shells and the bulkheads. The hatches are sealed with a single-convolution, welded bellows.

MACME $L$ SHIELD

In addition to the biological shield, the end cell also has a magnet shiald. The function of the magnet shield is to protect the coils from excessive heating and radiation damage. The shield consists of a 30 -cm

Table 5-16. Costs in 1984 dollacs, including materials, fabrication, and installation.

\begin{tabular}{|c|c|c|c|}
\hline & $\begin{array}{l}\text { MARS, } \\
\text { TZM } \\
\text { (M\$)a }\end{array}$ & $\begin{array}{c}\text { FPD-II, } \\
\text { TZM } \\
(\mathrm{M} \$)\end{array}$ & $\begin{array}{l}\text { FPD-II } \\
\text { Copper } \\
\text { (MS) }\end{array}$ \\
\hline Piping and supports & 1.63 & 0.52 & 0.26 \\
\hline Halo & 4.33 & 1.46 & 0.29 \\
\hline Collector & 4.0 & 1.22 & 0.24 \\
\hline Total & 9.76 & 3.20 & 0.79 \\
\hline
\end{tabular}




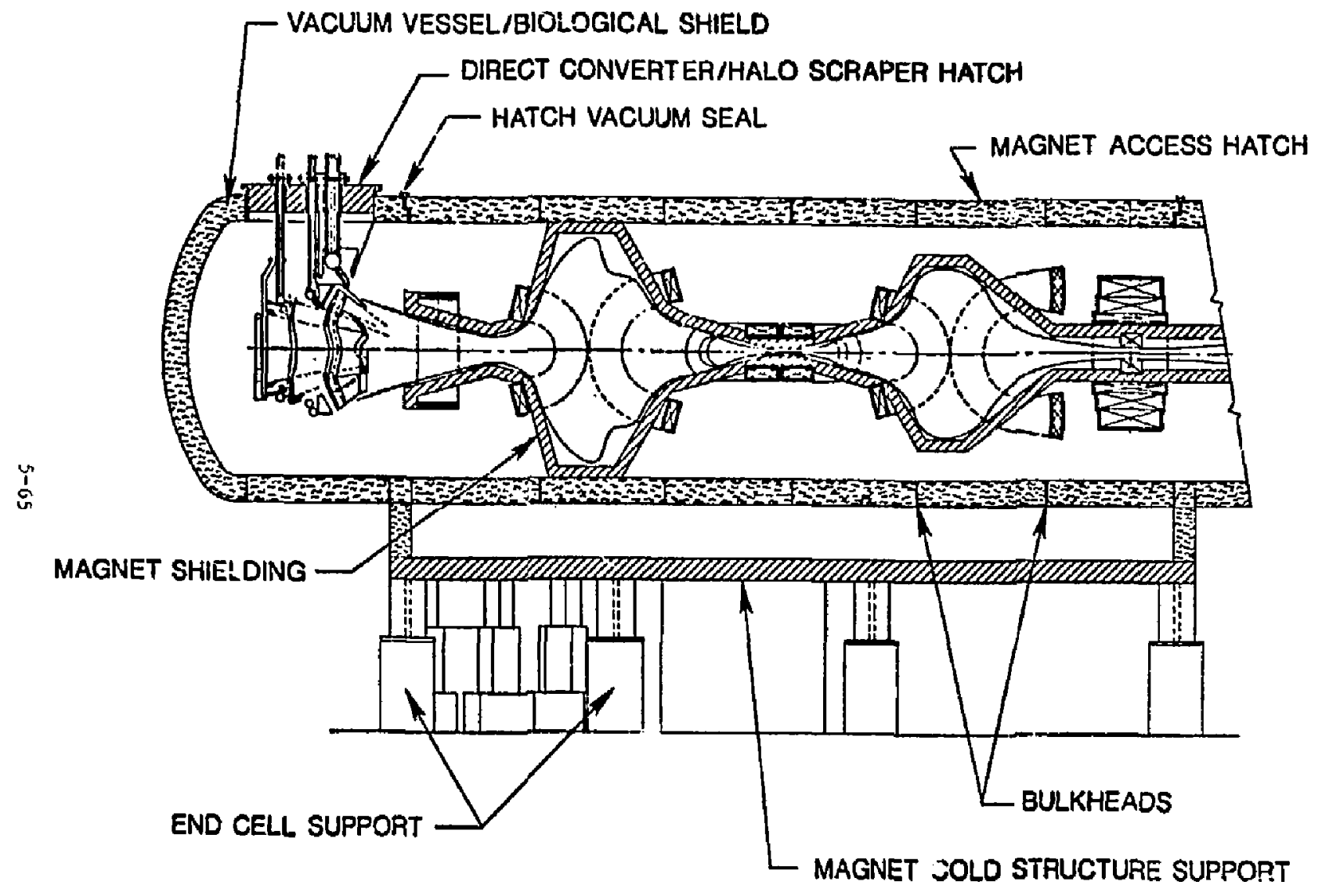

Figure S-35. The FPD-[l end-cel] configuration. 


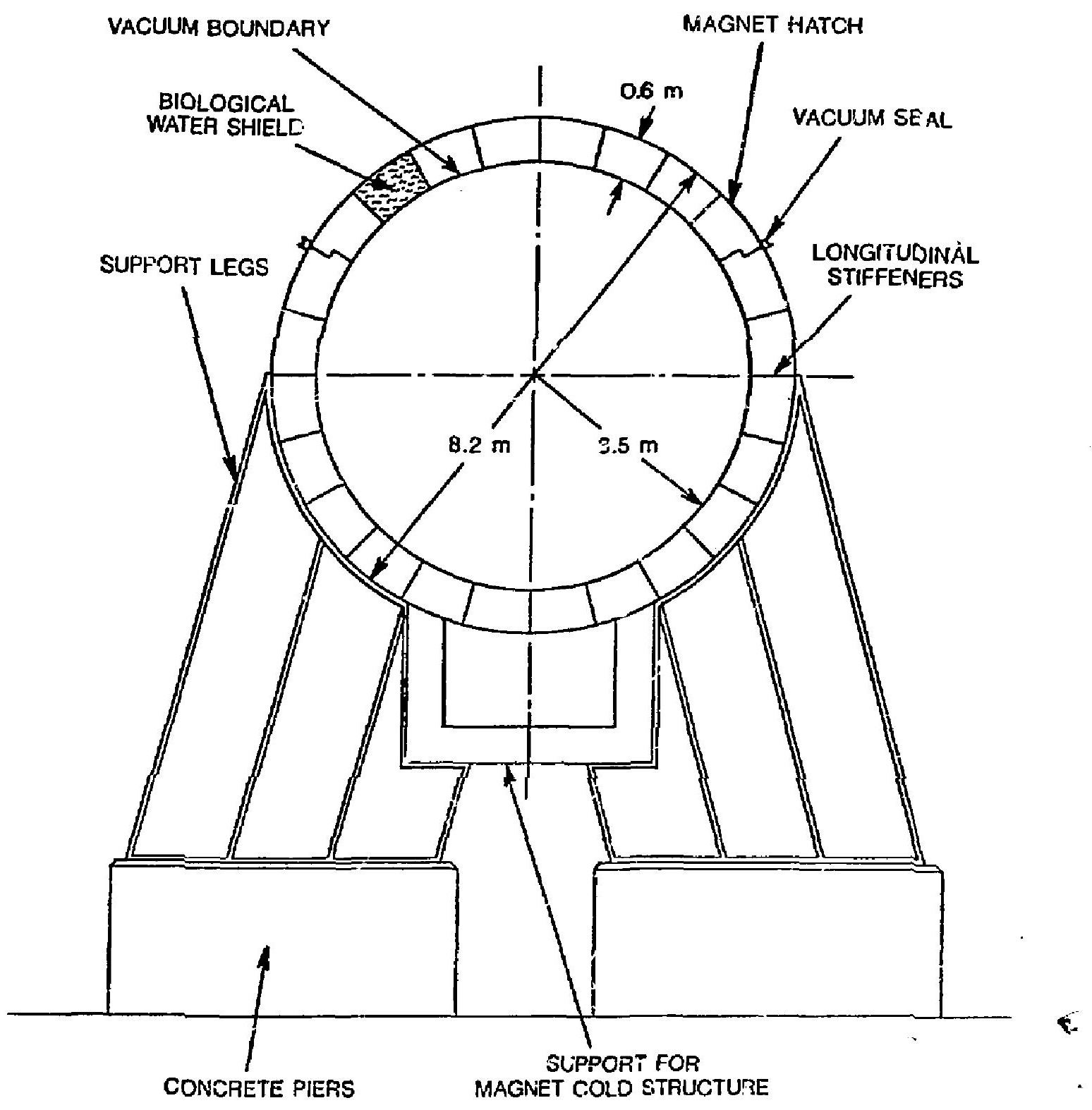

Figure 5-36. The F'D-II end-en11 vacuum vessel. 
steel/water shield ( $80 \%$ steel, $\left.20 \% \mathrm{H}_{2} \mathrm{O}\right)$ and $5-\mathrm{cm} \mathrm{B}_{4} \mathrm{C}$ shield. The steel/ $\mathrm{H}_{2} \mathrm{O}$ shield design is the layered plate concept with cooling grooves. The water maintains the shield tcmperature at a maximum of $200^{\circ} \mathrm{C}$. The steel/water shield is followed by the actively cooled $\mathrm{B}_{4} \mathrm{C}$ shield. The $\mathrm{B}_{4} \mathrm{C}$ shield composition by volume is $20 \%$ steei for the container vessel, $20 \% \mathrm{H}_{2} \mathrm{O}$ coolant, and $60 \% \mathrm{~B}_{4} \mathrm{C}$, with a density of 0.7 . The shield is located at the plasma periphery, (Fig. 5-35). In the area of the choke coil, the chickness is increased to meet local requirements.

SUPPORT STRUCTURE

Each end cell has four sets of support legs, Fig. 5-36. The support legs constrain the end cell in the vertical and lateral directions, but allows axial motion for thermal expansion.

$$
\text { C-COIL NUCLEONICS: ONE-DIMENSIONAL ESTIMATF: }
$$

\section{INTRODUCTION}

The shielding needed to limit neutron heating and damage in the c-coils to acceptable levels strongly influences end-cell size, and thus the size and cost of the entire machine. Our objective is to minimize total cost of the machine by varying the size of the end-cell C-coils in order to provide the optimum space between the coils and plasma for shielding. A procedure proposed to accomplish this objective is outlined later under this topic (see Ref. LLNL-FPD-84-018 in the Appendix).

\section{RADIATION LIMITS}

In LLNL-FPD-84-016 (see the Appendix), we originally set the maximum allowed radiation exposures in the superconducting coils at the following values: 
- $10^{11}$ xads in the insulation.

- $10^{18} \mathrm{n} / \mathrm{cm}^{2}\left(E_{n}>0.1 \mathrm{MeV}\right.$ ) in NoTi (for a $20 \% \mathrm{drop}$ in

critical current, $70 \%$ of which is annealable at room temperature).

- $4 \times 10^{18} \mathrm{n} / \mathrm{cm}^{2}\left(E_{n}>0.1 \mathrm{MeV}\right)$ in $\mathrm{Nb}_{3} \mathrm{Sn}$.

In LLNL-FPD-84-48 (see the Appendix), we revised the following fast

$(E>0.1 \mathrm{MeV})$ neutron-fluence limits to allow for mote design flexibility:

- $10^{20}$ to $10^{21} \mathrm{n} / \mathrm{cm}^{2}$ rangc for NbTi with an accompanying $25 \%$

lower critical current.

- 1 to $4 \times 10^{19} \mathrm{n} / \mathrm{cm}^{2}$ range for $\mathrm{Nb}_{3} \mathrm{Sn}$, believed achievable.

These higher limits are speculative.

Because of the time and expense involved in detailed 3-D analysis of the end cell, we developed the following $1-D$ method to essess various configurations:

1. Calculate the heating and damage rotes in the superconducting coils us the shield thickness using $1-D$ slat geometry.

2. Calculate 14-Mel neutron energy currents (wall laading) in $1-D$ slab or cylindrical geometry using coil and plasma gevmerries, and plasma source strength.

3. Combine steps 1 and 2 to obtain a $1-D$ estimate of peak heating and damage rates.

4. Integrate the plasma neutron 1 ine source as a function of $z$, in regions where source strength is significant and shield space is limited.

5. Combine steps 1 and 4 to estimate the rotal heating in the c-coils (out major assumption is that axial neutron transport is not significant.)

As a first step, the heating and damage rates ys shield thickness were calculated in $1-D$ slab geometry using both the ONEDANT code and a 30-neutron plus 12-gamra XSLIB data library based on ENDF/B-V. This code and its data 
library were developed at Los Alamos National Laboratory and used at the University of Wisconsin for the MARS project. 3

The configuration used to calculate radiation levels in the coil vs shield thickness is shown in Fig. 5-37. The shield consists of a thick zone of $\mathrm{W}(70 \mathrm{v} / \mathrm{o})+\mathrm{II}_{2} \mathrm{O}(10 \mathrm{v} / \mathrm{o})+$ boric acid $(\mathrm{lv} / \mathrm{o})+\mathrm{FE} 1422(10 \mathrm{v} / \mathrm{o})$ Eollowed by a thin zone $(\sim 4 \mathrm{~cm})$ where $\mathrm{TiH}_{2}$ replaces the $\mathrm{W}$. This shield was devisad in a preliminary optimization study (see Ref. LLNL-FPD-84-45 in the Appendix). Heating levels, neutron Elux ( $\mathrm{E}>0.1 \mathrm{MeV}$ ) and dose rates in the coil vs shield thickness at a wall laading of $1.0 \mathrm{MW} / \mathrm{m}^{2}$ are given in Figs. 5-38 and 5-39. The total heating calculation includes both the coil and its case: approximately $36 \%$ occurs in the sase and $64 \%$ in the winding pack.

The second step in the $1-D$ method is to estimate wall loading at coil locations, where source strength and geometry combine with limited shield stace to yield significant heating and/or damage rates.

To ilfustrate this process we are using the $\mathrm{C} 83$ end-cell coil set for FPD-II as an example. Figure 5-40 has both a 0 and a $90^{\circ}$ cut through 683 showing $C-c o i l$ winding packs and the hot and halo plasma boundaries (inner and outer lines, respectively) as they thread through the end-cell coils, The fusion neutron volumetric source strength along the centerline of c83 is shown in Fig. 5-41. Examining Figs. 5-40 and 5-41 together show that geometry and source arsigth combine to give four points where relatively high coileradiation levels may occur in the c-coils. Starting at the innermost $\mathrm{C}-\operatorname{coil}\left(\mathrm{T} 1^{*}\right.$ at $\mathrm{z}=50 \mathrm{~m}$ ) and working outward, the first point occurs in the second coil at $\mathrm{z}=53.3 \mathrm{~m}$. At this point a local maximum in the volumetric source strength $\left(2.6 \times 10^{11} \mathrm{n} / \mathrm{s}\right)$ and an approximately $4 \mathrm{~cm}$ half-thickness plasma fan (see Fig. 5-42 for slowup of the geometry) combine to give a 1-D wall loading on the coil of $0.023 \mathrm{MW} / \mathrm{m}^{2}$. The space between the coil and the halo pjasma is approximately $40 \mathrm{~cm}$ (Fig. 5-42). Subtractirg $15 \mathrm{~cm}$ for the coil case and insulation leaves $25 \mathrm{~cm}$ for shielding. With $25 \mathrm{~cm}$ of shielding and a wall loading of $0.023 \mathrm{MW} / \mathrm{m}^{2}$, peak local heating and other radiation leveis in the coil at this point are (Figs. 5-38 and 5-39):

tTransition coil 1. 
$0-$

N-

$\mathrm{O}^{-}$

$\stackrel{+}{0}$

9

FIRST WALL

0

( $80 \%$ STEEL, $20 \% \mathrm{H}_{2} \mathrm{O}$ )

$\stackrel{\infty}{0}$

$\ddot{0}-$

$107 \longrightarrow$

$\vec{N}-$

PLASMA

$\overrightarrow{0}$

$\vec{\sigma}$

$\begin{array}{ll}131 & \text { HALO } \\ 135 & =\end{array}$

(75\% W, TiH, PB, $10 \% \mathrm{H}_{2} \mathrm{O}$,

1\% BORIC ACID 10\%, FE 1422)

$\overrightarrow{0}-$

n

8

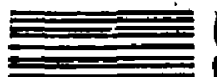

(-

s.c. coll $\quad-\frac{\sigma}{\sigma}$

$1 6 5 \longdiv { \text { SS LAYER } }$

THERMAL INSUL.

(LOW DEN. AL.)

N-

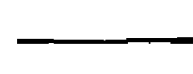

$-\overrightarrow{0}$

168.6

169.6 LN RAD SHIELD

$\stackrel{0}{0}$

品-

\section{3}

COIL CASE

(80\% STEEL, 20\% He)

$\vec{v}$

or

$-\vec{v}$

175.3 POLYIMIDE

$176.3 \frac{\text { WINDING CASE }}{\text { WIN }}$

STEEL

$178.3 \overline{\text { POLYIMIDE }}$

$-\vec{x}$

$179.3 \frac{\mathrm{cm} \mathrm{S.C.COIL}}{180.3 \mathrm{~cm}}$

Figure 5-37. The 1-D slab model. 


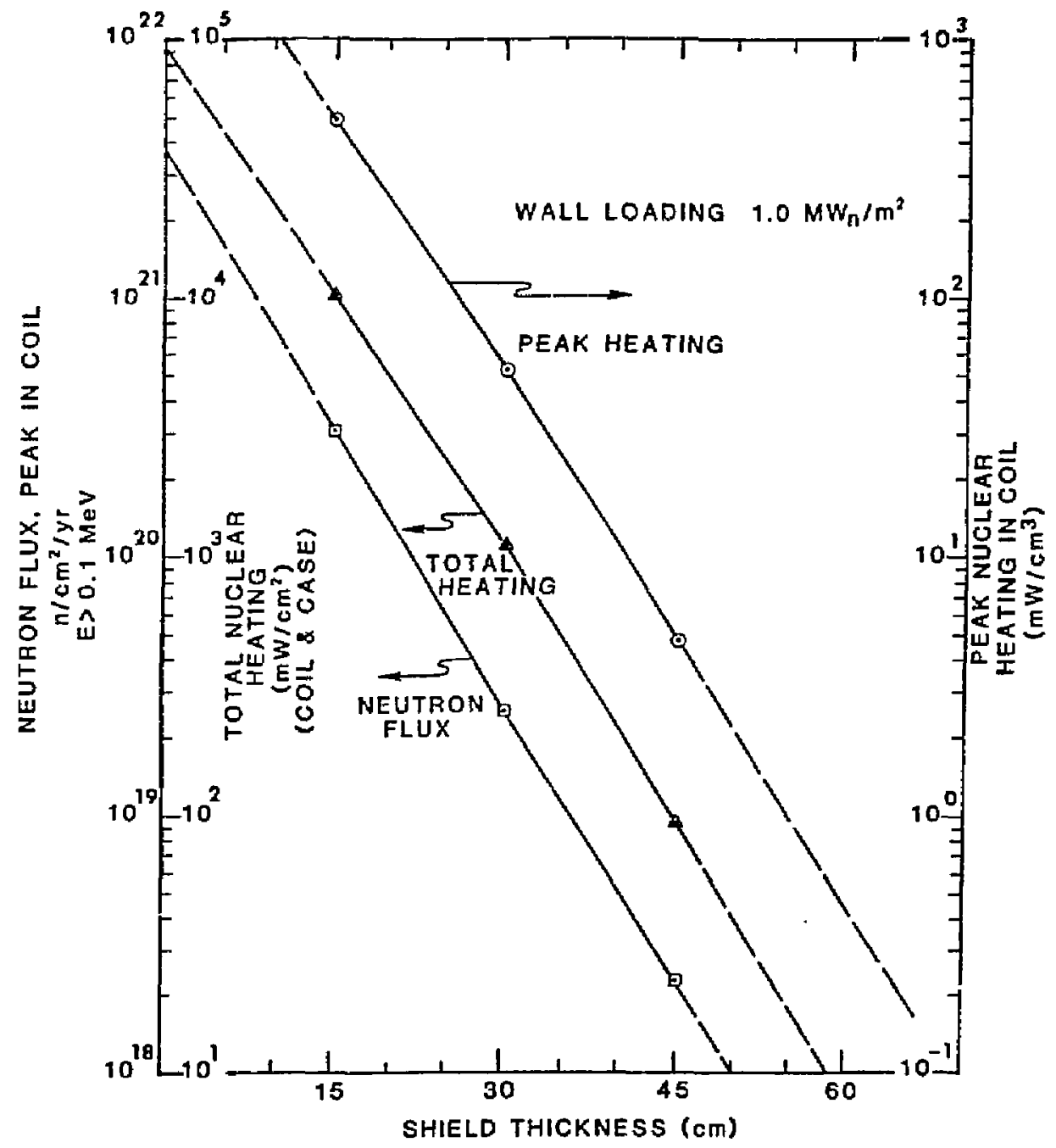

Figure 5-38. Neutron flux and heating vs shield thickness. 


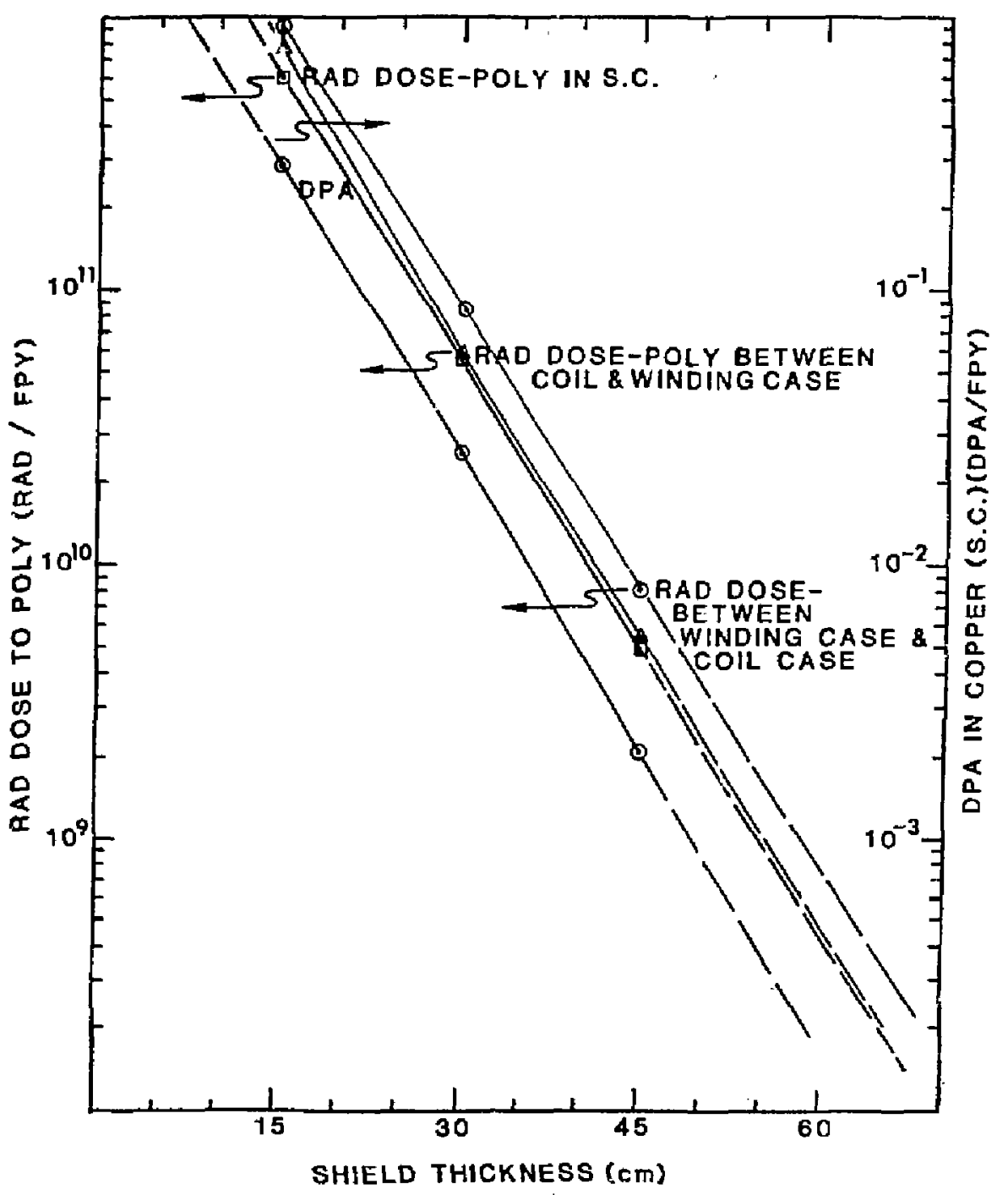

Eigure 5-39. Insulator dose rates and Cu-dpa vs shield thickness. 

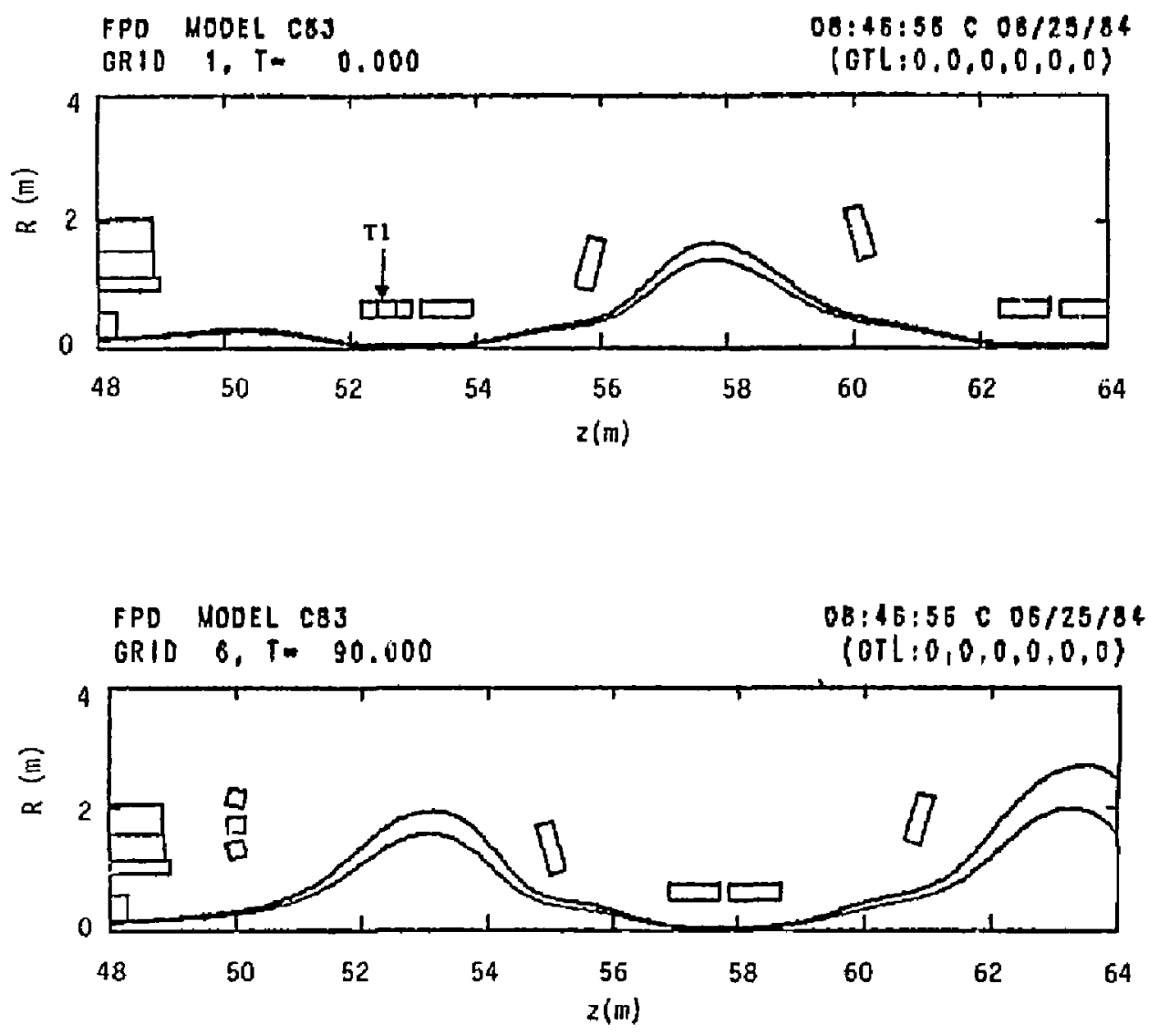

Figure 5-40. The FPD end-cel1 configuration C- 83 . 


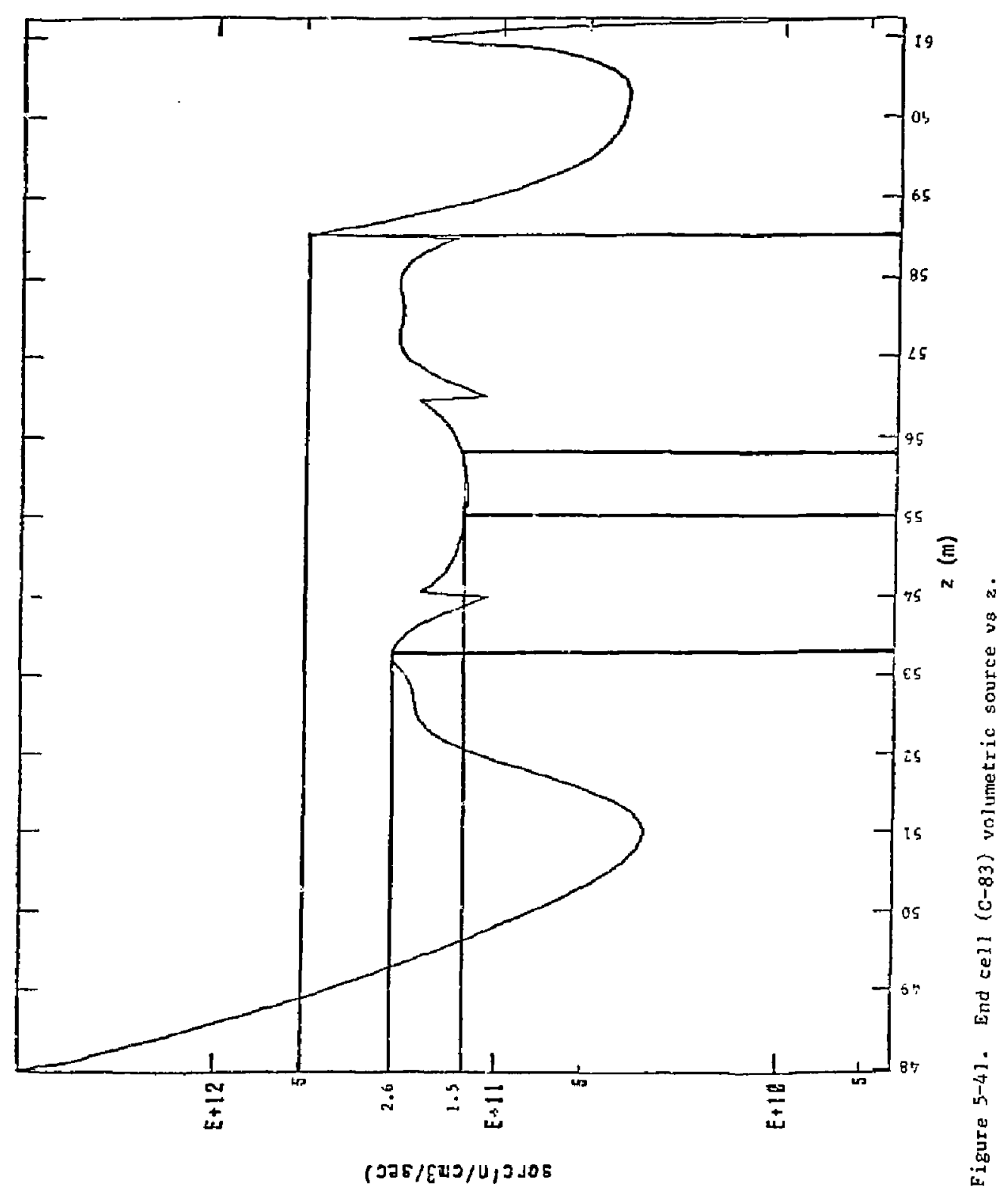




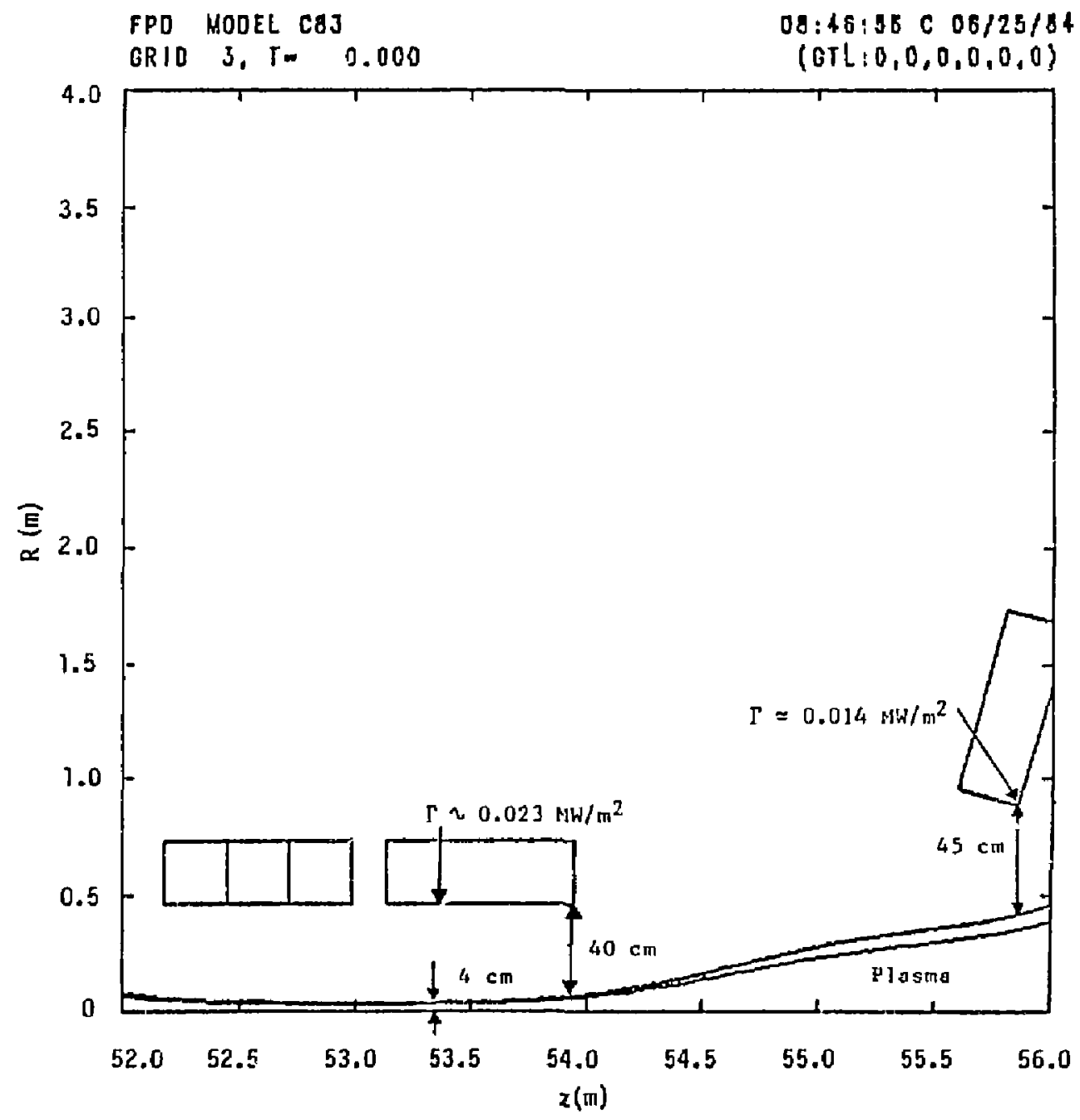

Figure 5-42. End cell (C-83) configuration $(z=52$ to $56 \mathrm{~m})$, 


$$
\begin{aligned}
& \text { - Peak heating }(P)=2.5 \mathrm{~mW} / \mathrm{cm}^{3} . \\
& \text { - Peak flux [o }(E) 0.1 \text { MeV })=1.3 \times 10^{18} \mathrm{n} / \mathrm{cm}^{2} \cdot y r \text {. } \\
& \text { - Peak rad dose to insulators }=4.6 \times 10^{9} \mathrm{rads} / \mathrm{yr} \text {. } \\
& \text { - Peak displacements per atom (dpa) in Cu }=0.0013 / \mathrm{yr} \text {. }
\end{aligned}
$$

The next two points at which local maxima in coil radiation levels may occur are at the inner sorners of the minor radia turns of the anchor coils $C_{z}=55 \mathrm{~m}$ and $55.8 \mathrm{~m}$, respectively). At these points the plasma is nearly circular, therefore, a cylindrical 1-D geometry is used to calculate wall loading. The line source strength at these two points is $3.4 \times 10^{16} \mathrm{n} / \mathrm{m} \cdot \mathrm{s}$ (Fig. 5-43); therefore, the wall loading at the coil at these two points is $0.014 \mathrm{MW} / \mathrm{m}^{2}$. The space available for shielding is $30 \mathrm{~cm}$. The lower wall loading plus $5 \mathrm{~cm}$ more shielding at these points, compared with the first point, result in heating and damage rates $70 \%$ less than at the first point.

The fourth point at which a local maximum in coil radiation levels occurs is on the centerline of the first plug $C$-coil at $z=58.6 \mathrm{~m}$. Here volumetric source strength has a sharp peak of $5 \times 10^{11} \mathrm{n} / \mathrm{cm}^{3} \cdot \mathrm{s}(\mathrm{Fig} \cdot 5-41)$ and the space for shielding is only approximately $23 \mathrm{~cm}$ (Fig. 5-44). Using a 1-D slab model, the wall loading at this point is $0.056 \mathrm{MW} / \mathrm{m}^{2}$. This wall loading coupled with space for only $23 \mathrm{~cm}$ of shielding, results in the peak $1-D$ heating and damage rates 1 isted below.

$$
\begin{aligned}
& \text { Peak heating }=8.4 \mathrm{~mW} / \mathrm{cm}^{3} . \\
& \text { - }{ }_{\pi}(E>0.1 \mathrm{MeV})=4.5 \times 10^{18} \mathrm{n}^{2} \mathrm{~cm}^{2} \cdot y r \\
& \text { Rad dose to insulator }=9.5 \times 10^{9} \mathrm{rads} / \mathrm{yr} \text {. } \\
& \text {-The dpa in } \mathrm{Cu}=.0045 / \mathrm{yr} \text {. }
\end{aligned}
$$

Because the source at this point has a sharp peak in $z$, the wall loading and resulting radiation levels are overpredicted by the $1-D$ method. Nevertheless, based on this analysis, we predict this point to have the bighest radiation levels in ". s C-coil set.

In aoultion to local peak heacing and damage rates in tie coil, total neutron-induced heating in the entire $\mathrm{C}$-coil set and the cryogenic cases is also important hecause of the cost of cryo-refrigeration. To estimate this 


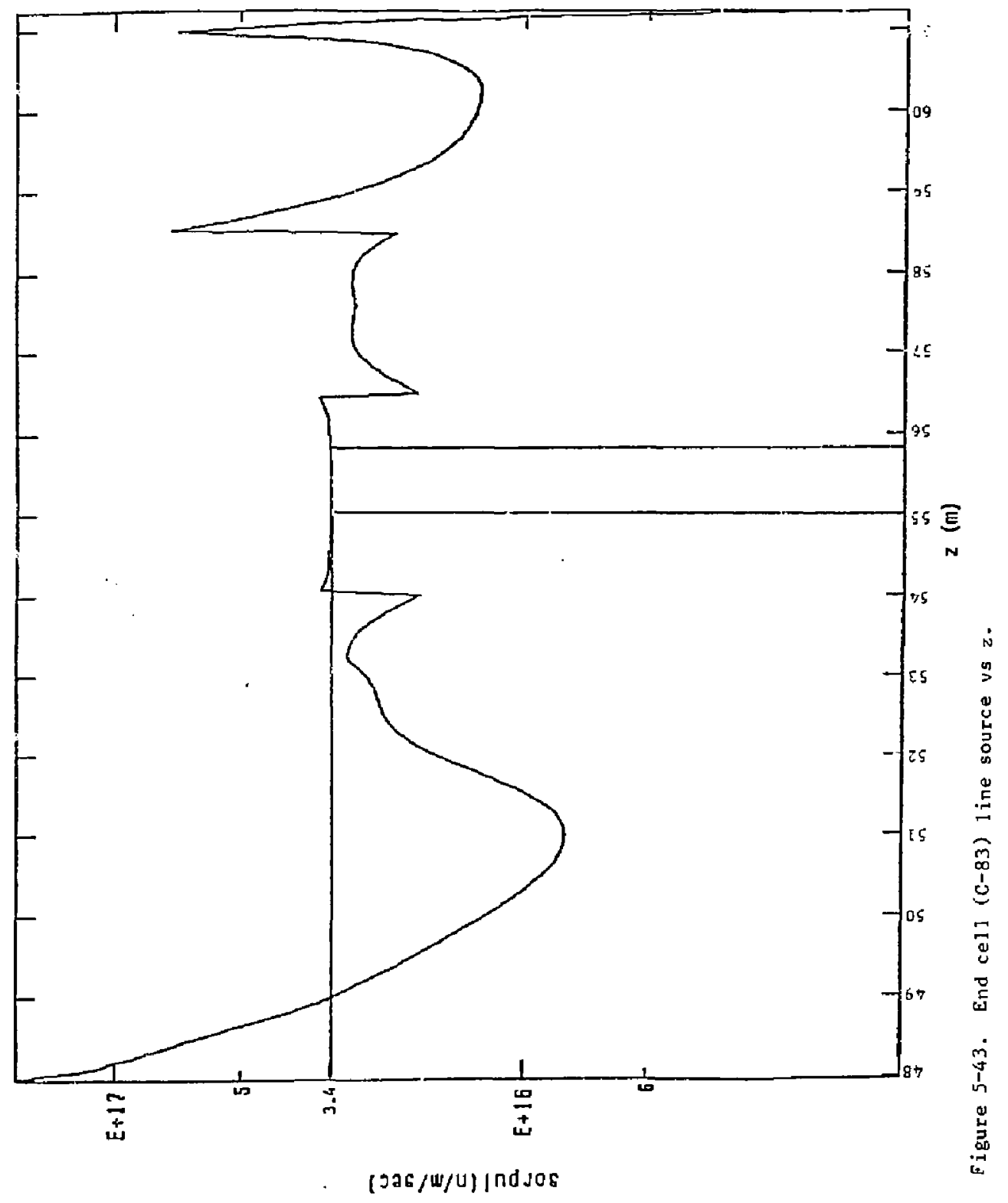




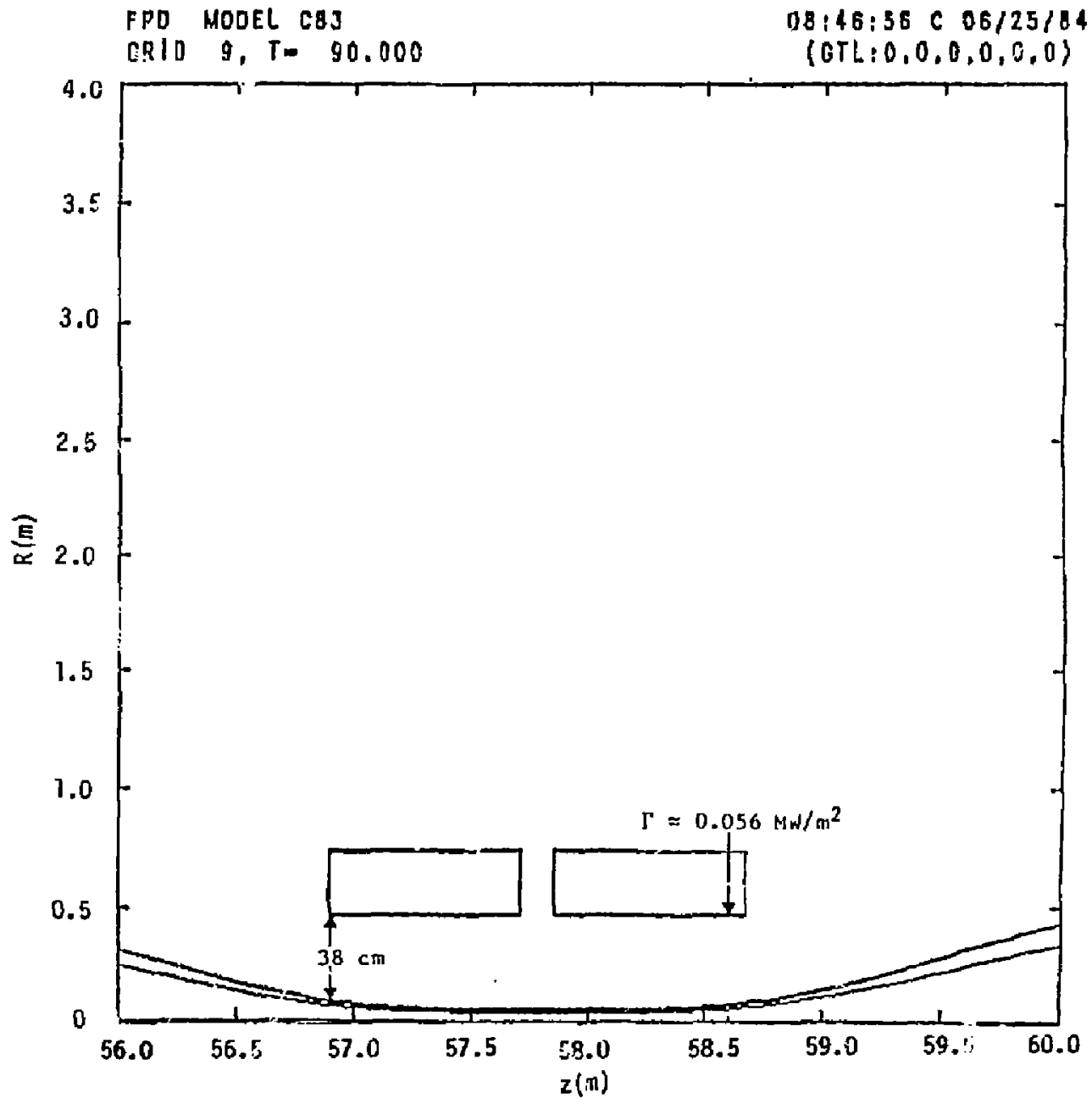

Figure 5-44. End cell (c-83) configuration $(z=56$ to $60 \mathrm{~m})$. 
total heating, the end-cell 1 ine source is integrated over $z$ in thase regions where shielding spsce is $t i m i t e d$ ( $F i g .5-45$ ). These regional sources are then attenuated by the allowable shield thicknesses in each region. For this case (CB3), the first region is taken to extend from $z=52 \mathrm{~m}$ to $z=54 \mathrm{~m}$. The source it this region is $4.1 \times 10^{16} \mathrm{n} / \mathrm{s}$ and the shielding space is $25 \mathrm{~cm}$ The attenuation factor with a $25-\mathrm{cm}$ shield is 0.023 (Fig. 5-38); therefore, total coil plus case beating is $2.2 \mathrm{~kW}$. The second region is from $z \simeq 56.7$ co $x \simeq 58.7$, and by the same methods, heating is $4.4 \mathrm{~kW}$. Thus, the total of both regions in both ends is approximately $13 \mathrm{~kW}$. Although these two regions should account for most of the $\mathrm{C}$-coil heating, there are areas outside these regions where coil heating will also occur. To accommodate this addizional heating in a crude way, total C-coil heating is assumed to be twice the two-region 2-D result. Therefore, the total heating in the C83 c-coil set is estimated to be $26 \mathrm{~kW}$. This energy is assumed to split--with approximately $36 \%$ in the windings and approximately $64 \%$ in the case--as occurred in the ONEDANT calculation.

The 1-D methodology just described was applied to a series of end C-coil magnet sats starting with Al8 (the original FPD-I configuration) and culminating with C83 (the FPD-II configuration). The results of these series of 1-D analyses are summarized in Table 5-17.

Note that both the $A 18$ and $C B 3$ peak neutron flux levels will exceed the original limits for NbTi $\left(1 \times 10^{18} \mathrm{n} / \mathrm{cm}^{2}\right)$ and $\mathrm{Nb}_{3} \mathrm{Sn}\left(4 \times 10^{18} \mathrm{n} / \mathrm{cm}^{2}\right)$ before 5 full power years of operation are reached, but that they are well below the revised, more spectlative limits of $10^{20}$ to $10^{21}$ for NbTi and within the 1 to $4 \times 10^{19}$ range for $\mathrm{wb}_{3} 5 \mathrm{n}$. The insulator dose limit of $10^{11}$ rads is not reached in either case.

We emphasize that these 1-D results are only crude estimates used to help guide end-cell optimization. The atrractive candidates must be analyzed with 3-D methods to adequately account for the complicated geometries irvolved.

PROPOSED END GELL DESIGN AND OPTIMITATION PROCEDURE

The proposed end cell design and optimization procedure follows:

1. Specify design objectives and criteria.

2. Assume (or modify) coil set parameters and check to see if feasible. 
08-5

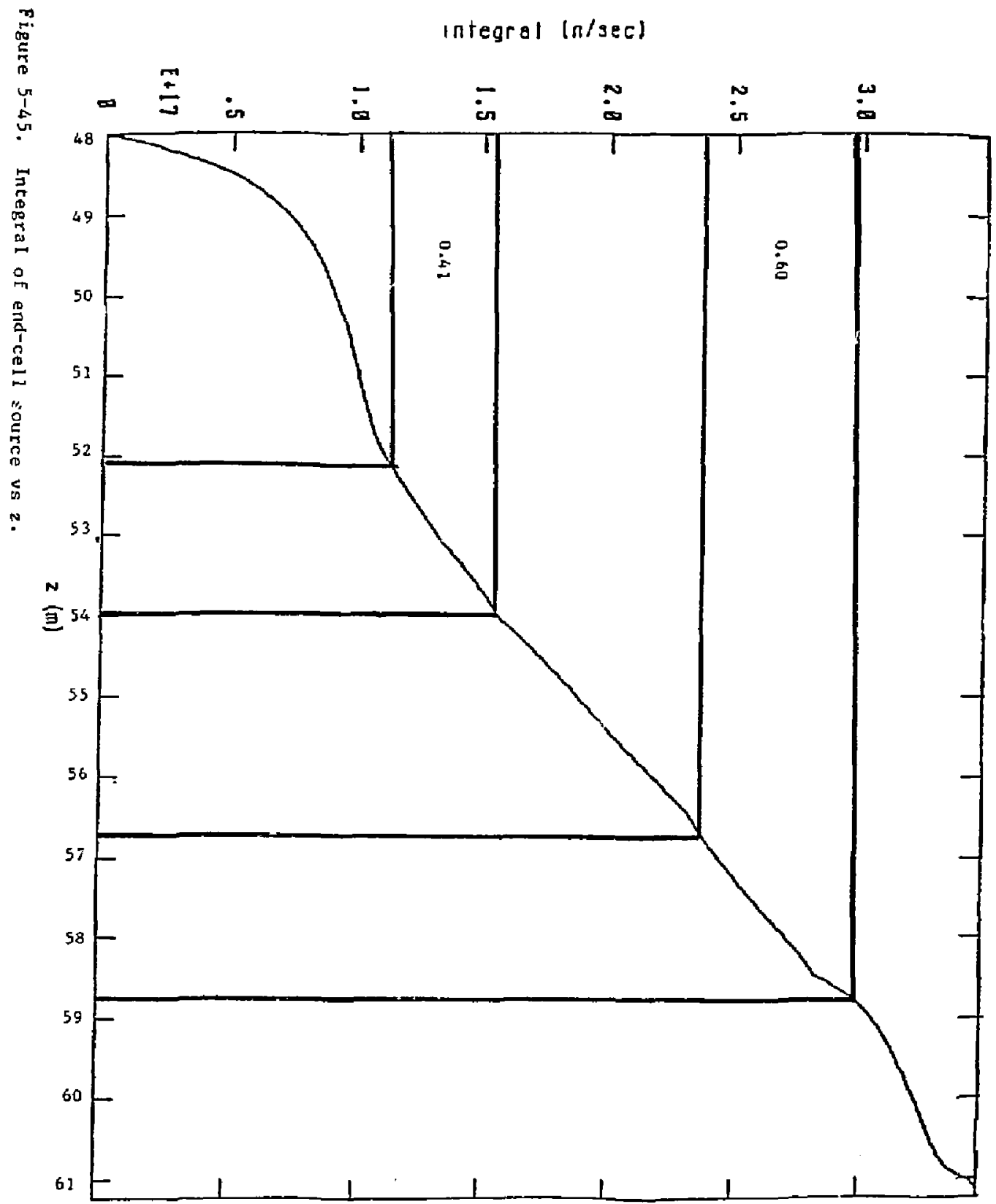


Table 5-17. Summary of 1-D analysis for five different C-coil types.

\begin{tabular}{|c|c|c|c|c|}
\hline $\begin{array}{l}\text { Coil } \\
\text { set }\end{array}$ & $\begin{array}{l}\text { Halo thickness } \\
\text { at choke coil }\end{array}$ & $\begin{array}{l}\text { Total } \\
\text { heating } \\
(\mathrm{kW})\end{array}$ & $\begin{array}{l}\text { Peak } \\
\text { heating } \\
\left(\mathrm{mW} / \mathrm{cm}^{b}\right)\end{array}$ & $\begin{array}{c}\text { Peak } \\
\text { nevtron flux } \\
\left(\mathrm{n} / \mathrm{cm}^{2} \mathrm{FPY}^{3}\right. \\
\left.\mathrm{E}_{\mathrm{n}}>0 . \mathrm{MeV}\right)\end{array}$ \\
\hline \multirow[t]{2}{*}{ A18 } & $5 \mathrm{~cm}$ & 5.2 & 2.5 & $1.2 \times 10^{18}$ \\
\hline & $2 \rho_{\alpha}$ & 6.2 & 7.5 & $3.6 \times 10^{18}$ \\
\hline C31 & $2 \rho_{\alpha}$ & 19 & 190 & $1.2 \times 10^{20}$ \\
\hline \multirow[t]{2}{*}{ C51 } & $5 \mathrm{~cm}$ & 32 & 3.2 & $1.8 \times 10^{18}$ \\
\hline & $2 \rho_{\alpha}$ & 42 & 8.1 & $4.5 \times 10^{18}$ \\
\hline \multirow[t]{2}{*}{ C61 } & $5 \mathrm{~cm}$ & 13 & 0.8 & $3.7 \times 13^{17}$ \\
\hline & $2 \rho_{x}$ & 14 & 1.7 & $7.8 \times 10^{17}$ \\
\hline $\mathrm{C} 83$ & $2 \rho_{\alpha}$ & 26 & 8.4 & $4.5 \times 10^{1 B}$ \\
\hline
\end{tabular}

${ }^{a}$ At hot spot in wirding.

b $64 \%$ winding; $236 \%$ case.

${ }^{c_{F u l l}}$ power years.

3. Calculate plasma shapes and stability and conductor fields. If okay, proceed to step 4.

4. Calculate fusian neutron scurce distribution.

5. Perform $1-D$ estimate of neutron heating and damage rates in coils with $W$ and Fe ghields.

6. Check coil radiation levels. If okay, proceed to step 7.

7. Estimate 3-D calculation of coil heating and damage.

8. Check coil radiation Jevels. If still okay, proceed to step 9.

9. Design and then estimate end cell cost, including refrigeration.

10. Modify and iterate coil set configuration or objectives, where possible, to minimize cost. 


\section{Details of Optimization Procedure}

In step 1, acceptable field configurations are specified by Lawrence Livermore National Laboratory (LLNL) along with basic superconducting coil design criteria such as $J$ vs $B$ and acceptable radiation damage rates specified by the LLNL Fusion Engineering Design Center (FEDC).

In Step 2 various coil sets are laid out (or modified) and analyzed in Step 3 to see if they produce acceptable plasma configurations and conductor fields. Steps 2 and 3 are repeated as necessary to get acceptable and consistent coil sets (LLNL).

In Step 4 fusion neutron source distribution(s) are calculated with the acceptable magnetic field configuration from Step 3 (LLNL).

In step 5 the coil set and plasma geometries and the neutron source distributions from steps 2,3 and 4 are used to perform an initial 1-D estirate for peak heating the ratiation fluxas and for damage rates in the coils with various shielding types (W vs Fe) in the available space between the coils and the halo plasma boundary (LLNL and/or FEDC).

In Step 6 the estimated coil radiation levels from Step 5 are compared to criteria (from step 1) to see if they are within acceptable leveis. If they are not acceptable, step 2 is repeated and the configuration of coil set is modified to better accommodate the shielding needs (thicker shields where fluxes are too high and thinner shields as appropriate) (LLNL and/or FEDC).

In Step $/$ cases that pass step 6 are subjected to a uuch more rigoraus (and costly) 3-D analysis of coil heating and damage rates (FEDC).

In Step 8 radiation levels from step 7 are compared to the radiation limit and other criteria to confirm whether the coil/shield configurations are still acceptable.

In Step 9 coil/shield configurations that pass step 8 are designed to the level necessary to judge whether they are technically credible. Their costs are also estimated [LLNL/FEDC/General Dynamics (CD)].

In step 10 insight gained in the earlier steps is used to modify coil set configurations to reduce cost (LINL/FEDC/GD). 
Tritium permeation through components subjected to energetic tritiun bombardment is considered a potentially sericus problem for future fusion reactors. High tritium concentrations in the region near the plasma-side surface are reached by implantation of the energetic tritium. The tritium diffuses to either the plasma-side surface, where it undergoes relatively slow recombination and release from the surface as a molecule; or to the coolantside surface, where it enters the coolant. If the permeation rate to the coolant is significant, processing of the coolant is required to maintain the tritium concentration at a tolerable level.

We investigated tritium permeation through the halo scraper and direct converter components to establish whether or not processing of the water coolant is required. We used a one-dimensional, transient, finite difference model of the copper structure to determine: the tritium permeation rate, the cotal tri"ium concentration in the water coolant, and the tritium inventory in the structure during the lifetime of FPD. We included the impact of pulsed operation in this study, however, predictions assuning continuous burn roughly agree with those using pulsed operation. We assumed that each burn pulse consisted of 300 hours of burn (the Iongest burn expected for FPD) followed by 900 hours of dwell time before the next burn.

The results of the above study are sumarized in Table 5-18. The total amount of tritium in the halo scraper and direct converter coolant system is only $52 \mathrm{kCi}$. By estimating the water volume in this coolant system at $12 \mathrm{~m}^{3}$, the end-of-life tritium concentration in the coolant, assuming no processing, is $4.3 \mathrm{kCi} / \mathrm{m}^{3}$. This is well below the $16 \mathrm{kCi} / \mathrm{m}^{3}$ present in the operating. CANDU heavy-water reactors. The inventory in the halo scraper and direct converter components is also quite low. Therefore, processing of the water coolant is unnecessary; the water could simply be barrelled and transported for disposal. 
Table 5-18. Tritium permeation rates and inventory in dixect converter/halo scraper components.

\begin{tabular}{lccc}
\hline Component & $\begin{array}{c}\text { Maximum } \\
\text { pertneation rate }\end{array}$ & $\begin{array}{c}\text { Total tritium } \\
\text { in coolant }\end{array}$ & $\begin{array}{c}\text { Tritium } \\
\text { inventory } \\
\text { in } \\
\text { structure }\end{array}$ \\
\hline Ci/day & $\mathbf{C i}$ & $\mathrm{Ci}$ \\
Halo scraper & 14 & $2.7 \times 10^{4}$ & $7.3 \times 10^{3}$ \\
Outer collector & 2.4 & $4.0 \times 10^{3}$ & $1.4 \times 10^{3}$ \\
Inner collector & 12 & $2.1 \times 10^{4}$ & $6.7 \times 10^{3}$ \\
& 28 & $5.2 \times 10^{4}$ & $1.5 \times 10^{4}$ \\
\hline Assumes no removal by processing but does account for radioactive \\
decay.
\end{tabular}

\section{MATERIALS}

A significant difference, in selecting materials for FPD-II, conpared with FPD-I, is the higher neutron wall load in the axicell. The neutron wall loading of $5 \mathrm{~mW} / \mathrm{m}^{2}$ and lifetime operation at an integrated wall load of $12.5 \mathrm{MW} \mathrm{y} / \mathrm{m}^{2}$ impose challenging requirements on the first wall and blenket struetural material of FPD-II. In steel material this exposure will produce a displacement damage level of approximately $130 \mathrm{dpa}$ and transmutation reaction product gases of 1400 to 2000 atoric ppm He and 6000 atomic ppm $\mathrm{H}$. (The exact values will depend on the detail of blanket design and steel composition.) $F$ ew data are available on the effect of this irradiation lejel on the properties of candidate structural materials, therefore, the design must allow for axicell replacement during the operating life of the reactor. However, there is some data to indicate that either a ferritic/martensitic steel or an austenitic stainless steel may be adequate for service to $12.5 \mathrm{~mW} \cdot \mathrm{y} / \mathrm{m}^{2}$ in a MARS-like blaniket module. 
Some data suggest that the ferritic/martensitic steels may be resistant to swelling up to neutron fluences producing $>100$ dpa. However, the data are for irradiations producing little helium and coverage of irradiation temperature is incomplete. Data at somewhat lower fluences suggest that tensile strength will not be degraded, but that tensile elongation will be reduced to low but usable levels. Irradiation creep rates will be known in a few years, art can be accommodated in design. The shift in the ductile-tobrittle transition temperature (DBTT) that results from irradiation of ferritic steels is a conceru. Avalable data hint that the ferritic stee] 9 Cr-1 Mo might be a better choice than HT-9 $(12 \mathrm{Cr}-1$ Mo $)$ because the lower initial DBTT can result in a DBTT after extended service that is still below the reactor shetdown temperature.

The austeritic stainless-steel type 316 would swell excessiveiy in the fluence required in the axicell. However, advanced austenitic steels have betr developed for swehling resistance and these steels may prove adequate for service to $12 \mathrm{MW} y / \mathrm{m}^{2}$. If the swelling resistance proves adequate, irradiation creep during service and reduced tensile ductility will impose 1 imitations that can be accommodated in the design.

Current activities of the Fusion Reactor Materials Program are directed at qualifying alloys for service undet conditions that are anticipated for w...e axicell. The pace of the program is such that the data -elevant to axicell conditions is now becoming avilable. As a result, the final choice of a structural alloy for the axicell should be reviewed regularly, to ensure that the best candidate material is used.

Nost other fnaterial issues in the FPD-II configuration are similar to FPD-I (see Sec. 4).

\section{ELECTRICAL SYSTEMS}

The electrical systems include the electric plant equipment of the ac power system, the power conversion for the confinement magnets, the power conversion for the microwave and neutral beam injector (NBI) systems, and the instrumentation and control systems. 
THE AC POWER SYSTEH

The ac power system includes all the switch gear, transformers, and distribution of power to the electrical loads identified in Table 5-19; the table also includes the busing and fault protection for the turbine gererator and direct converters, and the inverters of the direct conversion system. Referring to Table 5-19, the total recycle power needed for FPD-II is $128 \mathrm{MW}$ without the axicell and $243 \mathrm{MW}$ with the axicell. The total electrical power output is $40 \mathrm{MW}$ from direct converters and $205 \mathrm{MW}$ from the rurbine generator. Engineering $Q_{e}$, defined as the pcwer generated divided by the power consuned by the plant, is 1.9 without the axicell and 1.0 with the axicell.

Table 5-19. Estimate of FPD-II electrical power generation and loads.

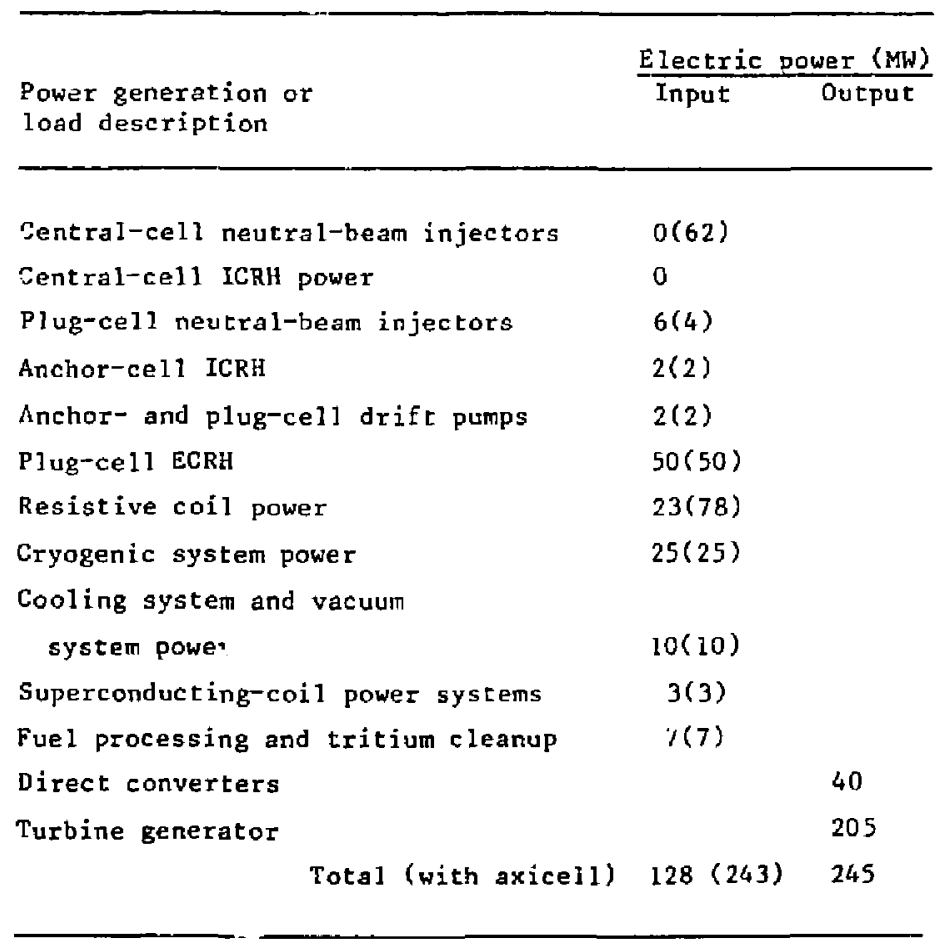


Figure 5-46 is a simplified block diagram of the power distribution system. The main $230-\mathrm{kV}$ substation provides all of the $13.8-\mathrm{kV}$ power during startup. After the plant is on line, the direct convercers and turbine generator supplies more power than that consumed without the axicell. A net powcr of 117 WW is delivered to the utility line. With the axicell, the power generated is nearly equal to the power consumed.

A small 30-HVA substation provides better reguleted power to the 4.16-kV Ioads. The 4.16-kV substaiions may selectively receive power from either the 230 - or 115-kV substations. The 4.16-kV sibstations provide power to eight 2-MW load-control centers. Two 4.16-kV diesel generators provide backup por er to silected critical loads if a power failure occurs.

Figure $5-47$ is a one-line diagram of the FPD-II power-distribution system. Mnemonics used on the diagram are defined in Table 5-20. Medium voltage power is provided by the power-distribuition system at $13.8 \mathrm{kV}$ and $4.16 \mathrm{kV}$, the preferred voltages in use taday. The substation would also be adequate for TFCX-S, the superconducting coil tokamak now being considered as a next generation machine. If TFCX-S and FPD-II were located at the same site, both machines could be operated from the same substations alternately, but not concurrently. In Fig. 5-47, note that $4.16 \mathrm{kV}$ is available from tinee sources: the 230-kV substation, the $115-\mathrm{kV}$ substation, and the diegel generator units. The turbine-generator 4500-A continuous-duty circuit breakers are custom built but comercially available. Isolation switches are provided at the 230/13.8-kV transformers, but the only main transformer circuit breakers are on the high-voltage side. Faults that may develop on the two main 13.8-kv buses will trip the high voltage circuit breakers which have more than sufficient interrupt capacity.

The 115/4.16-kV substation, not shown in Fig. 5-47, consists of a threewinding transformer that has switch gear and lightning protection on the highvoltage side. Each 4.16-kV winding provides powe: to three 2-MW load-control centers and are connected to the main system with breakers 18 and 19 shown in Fig. 5-47. 


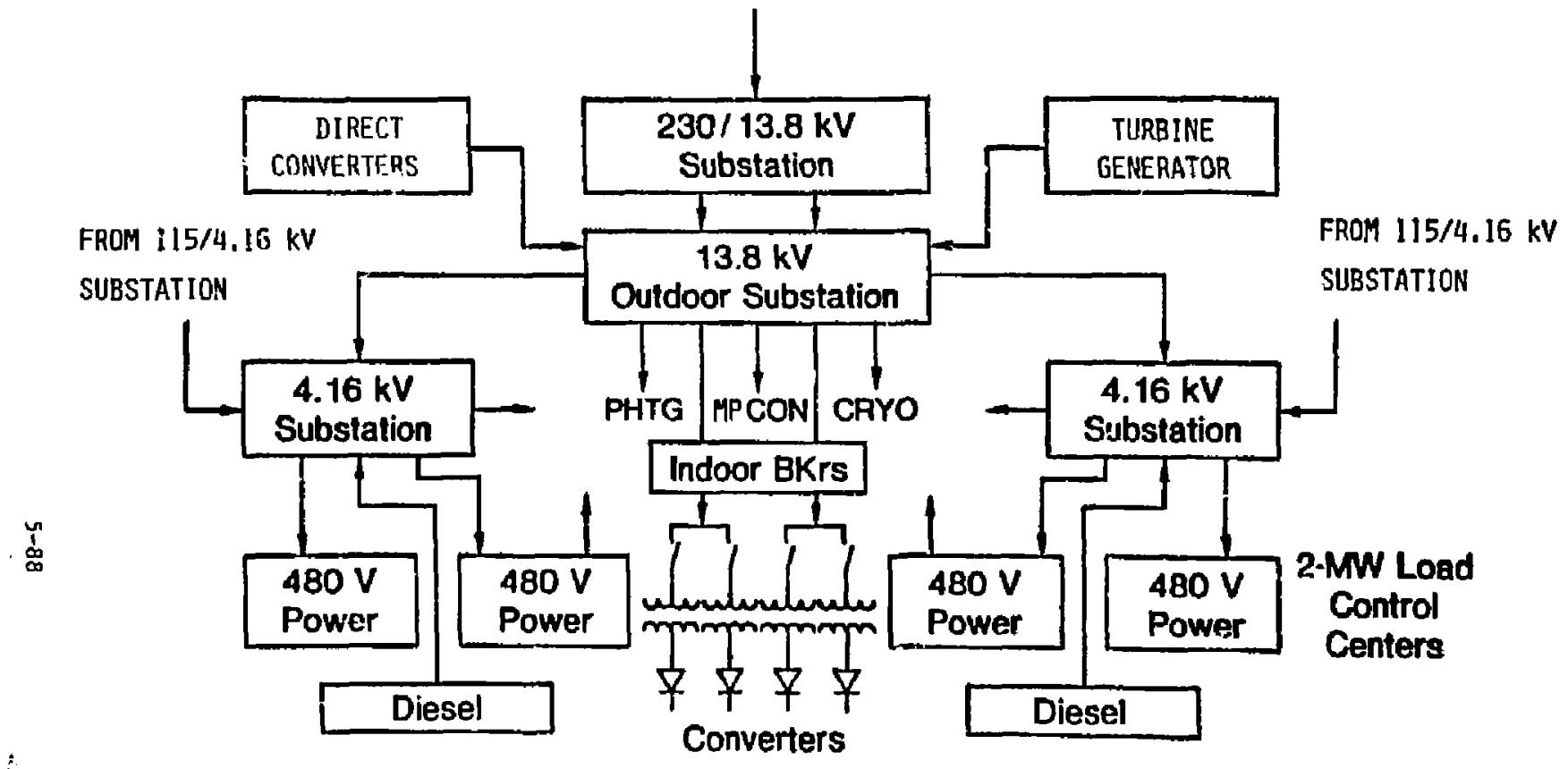

Figure 5-46. Simplified block diagram of the FPD-II power-distribution system. 


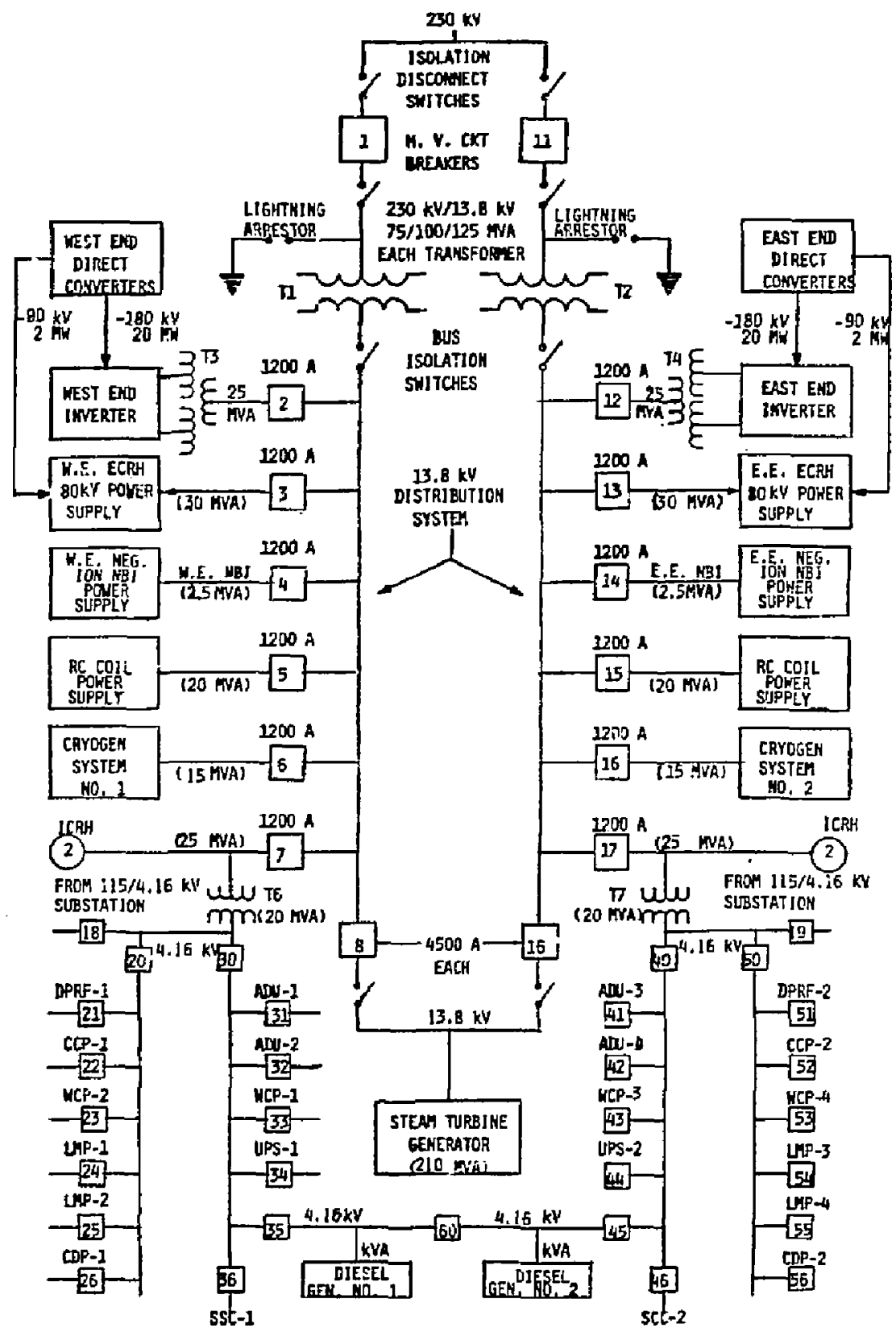

Figure 5-47. One-line diagram of the FPD-II power-distribution system. 
Table 5-20. Mnemonic definitions.

\begin{tabular}{ll}
\hline Mnemonic & \multicolumn{1}{c}{ Description } \\
\hline DRRF & Drift pump rf power \\
ADU & Atmospheric detritiation unit power \\
HCP & Water cooling pump power \\
LMP & Liquid metal pump power \\
UPS & Uninterruptible power supply \\
CFP & Condensate feed pump power \\
CCP & Condenser cooling pump power \\
SCC & Superconducting coil power \\
NPS & Number of power supplies \\
PSVOLT & Power supply voltage \\
PSKA & Power stuply current (kA) \\
BUSLM & Bus length (m) \\
NBKRS & Number of dc circuit breakers \\
NDR & Number of dump resistors \\
EDRMJ & Maximum energy dissipated in a dump resistor (MJ) \\
PDRMW & Maximum power to a dump resistor (MU) \\
& \\
\hline
\end{tabular}

ELECTRICAL POWER CONVERSION SYSTEMS

The electrical power-conversion systems include the following:

1. All the power supplies for the magnets, and power injection systems for the plasma;

2. The coil-protection equipment,

3. The cables and bussing.

Table 5-21 contains the key magnet power-conversion data for FPD-II both with and without the axicell option. Mnemonics in the column headings of the table are defined in Table 5-20. The first column of Table 5-21 refers to the characteristic configurations for the magnet power conversion for the group. These configurations are shown in Figs. 5-48 through 5-52.

$$
\text { 5-90 }
$$


Table 5-21. The FPD-II magnet power conversion data.

\begin{tabular}{|c|c|c|c|c|c|c|c|c|c|}
\hline Type & Magnet group & NPS & PSVOLT & PSKA & BUSLM & NBKRS & NDR & EORMJ & PDRMW \\
\hline$A$ & Central cel1-8 & 1 & 20 & 60 & 200 & 5 & 16 & 150 & 30 \\
\hline$B$ & Central cel1-2 & 1 & $1 \mathrm{c}$ & 60 & 120 & 2 & 4 & 55 & 15 \\
\hline$D, E$ & Choke insert-2 & I & \pm 120 & 100 & 150 & 0 & 0 & 5 & 0 \\
\hline c & Choke background-2 & 2 & 30 & 9 & 100 & 4 & 8 & 390 & 4.4 \\
\hline B & Transition-1-2 & 2 & 12 & 25 & 100 & 4 & B & 60 & 12 \\
\hline B & Anchor cel1-4 & 2 & 12 & 25 & 120 & 4 & 8 & 240 & 12 \\
\hline B & PIug cel:-4 & 2 & 12 & 25 & 140 & 4 & 8 & 240 & 12 \\
\hline$B$ & Transition $-2-2$ & 2 & 12 & 25 & 160 & 4 & 8 & 45 & 12 \\
\hline B & Recircularize-2 & 2 & 12 & 25 & 180 & 4 & 8 & 65 & 12 \\
\hline T) & Axicell choke-2 & $\vdots$ & \pm 190 & 230 & 100 & o & 0 & 0 & 0 \\
\hline c & Axicell background-2 & 2 & 30 & 12 & 100 & 4 & 8 & 500 & 12 \\
\hline E & Axicell center-1 & 1 & 165 & 80 & 100 & 0 & 0 & 0 & 0 \\
\hline
\end{tabular}




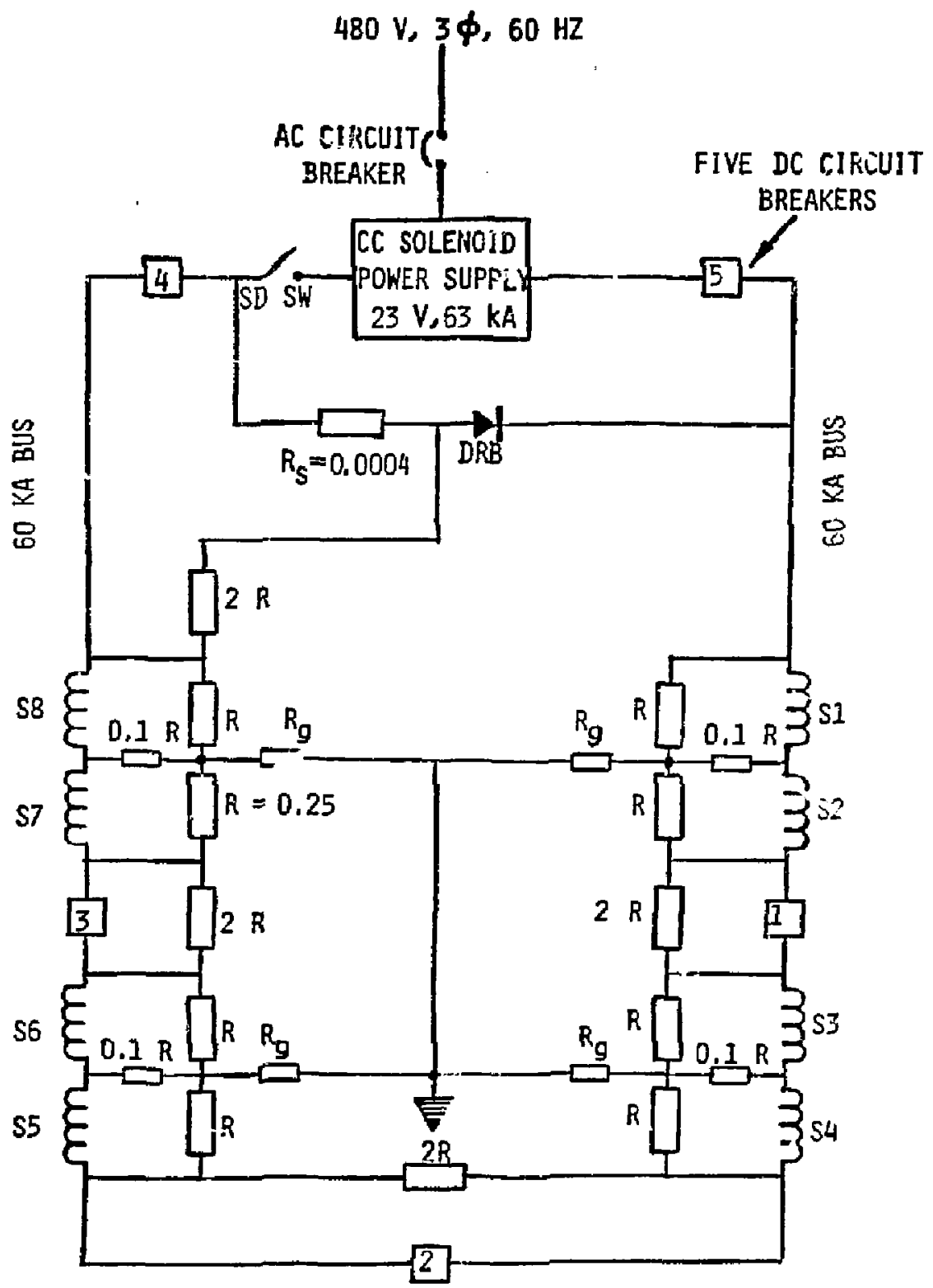

Figurf 5-48. Power-conversion system for the central cell solenoid magnets. (Type-A eircuit) 


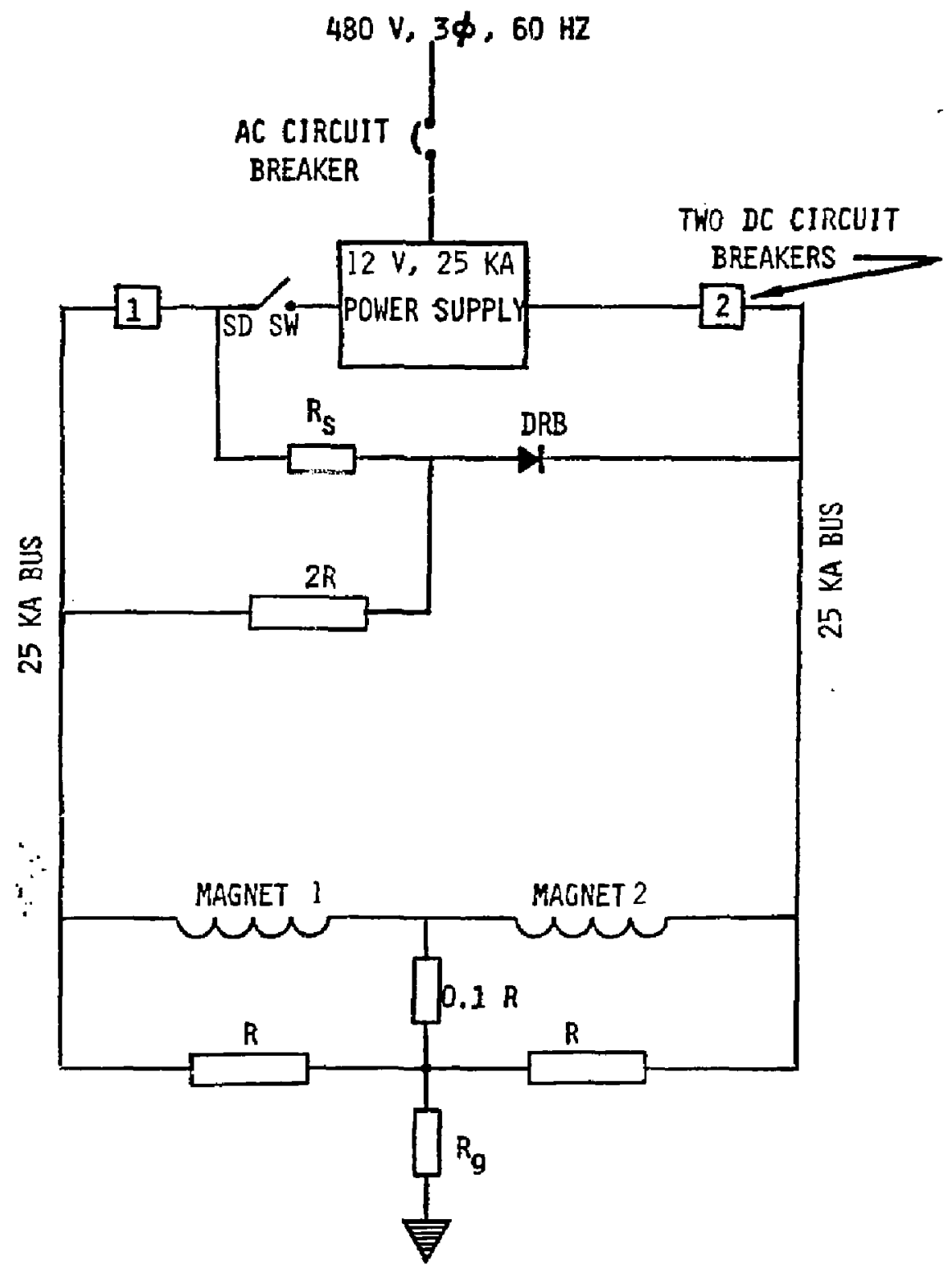

Figure 5-49. Type-B power-conversion system. 


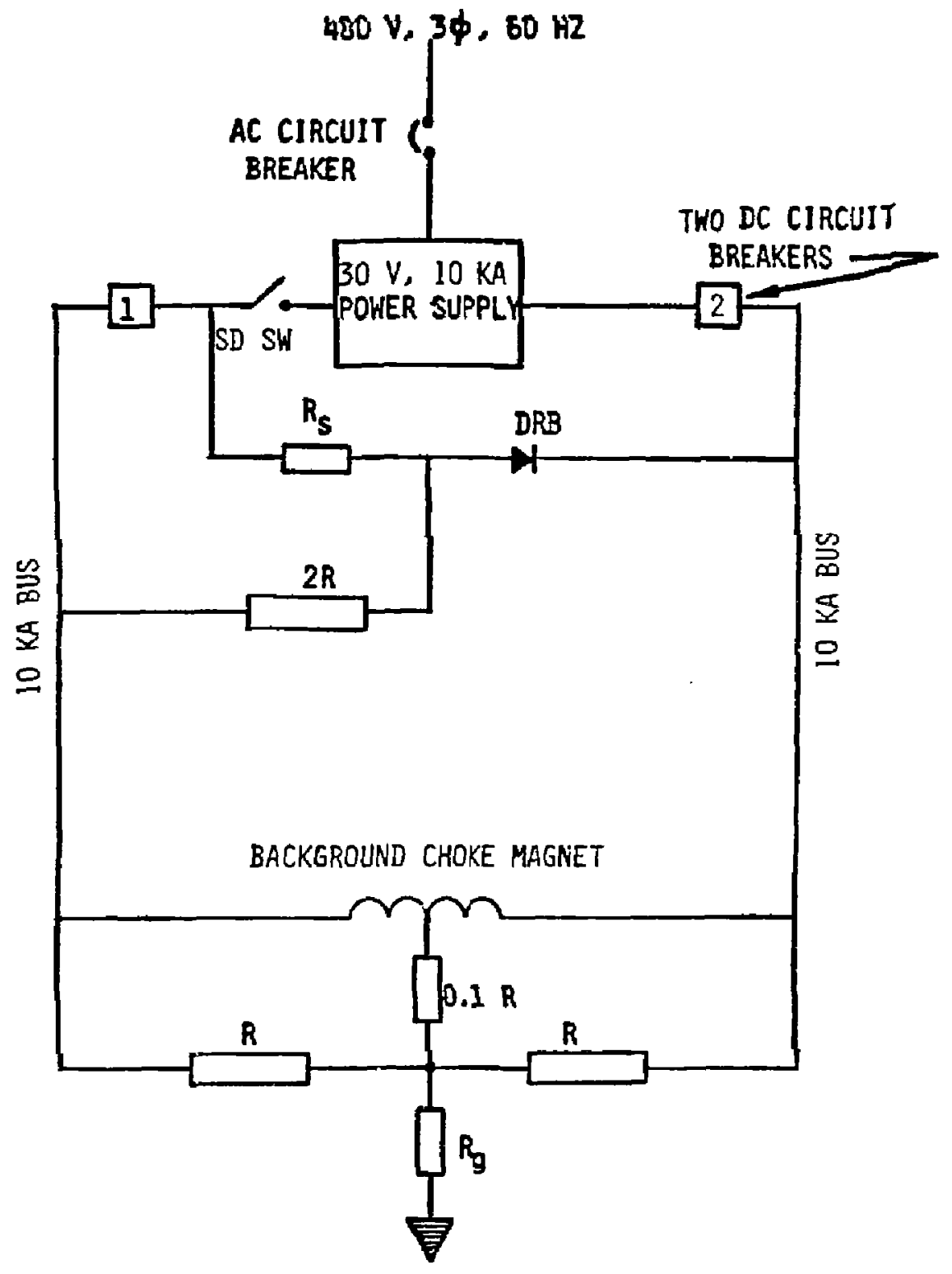

Figure 5-50. Type-c power-conversion system. 


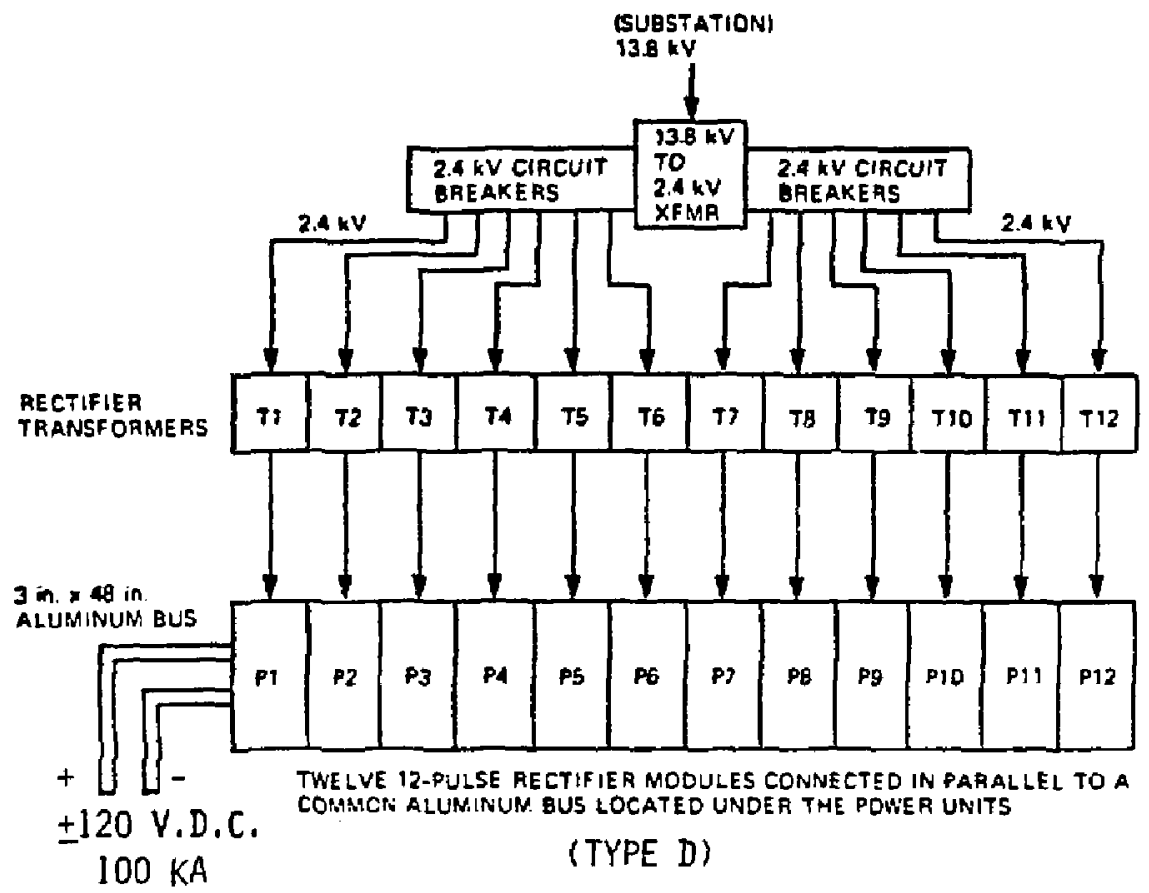

Figure 5-51. Type-D power-conversion system.

$5-4$. 


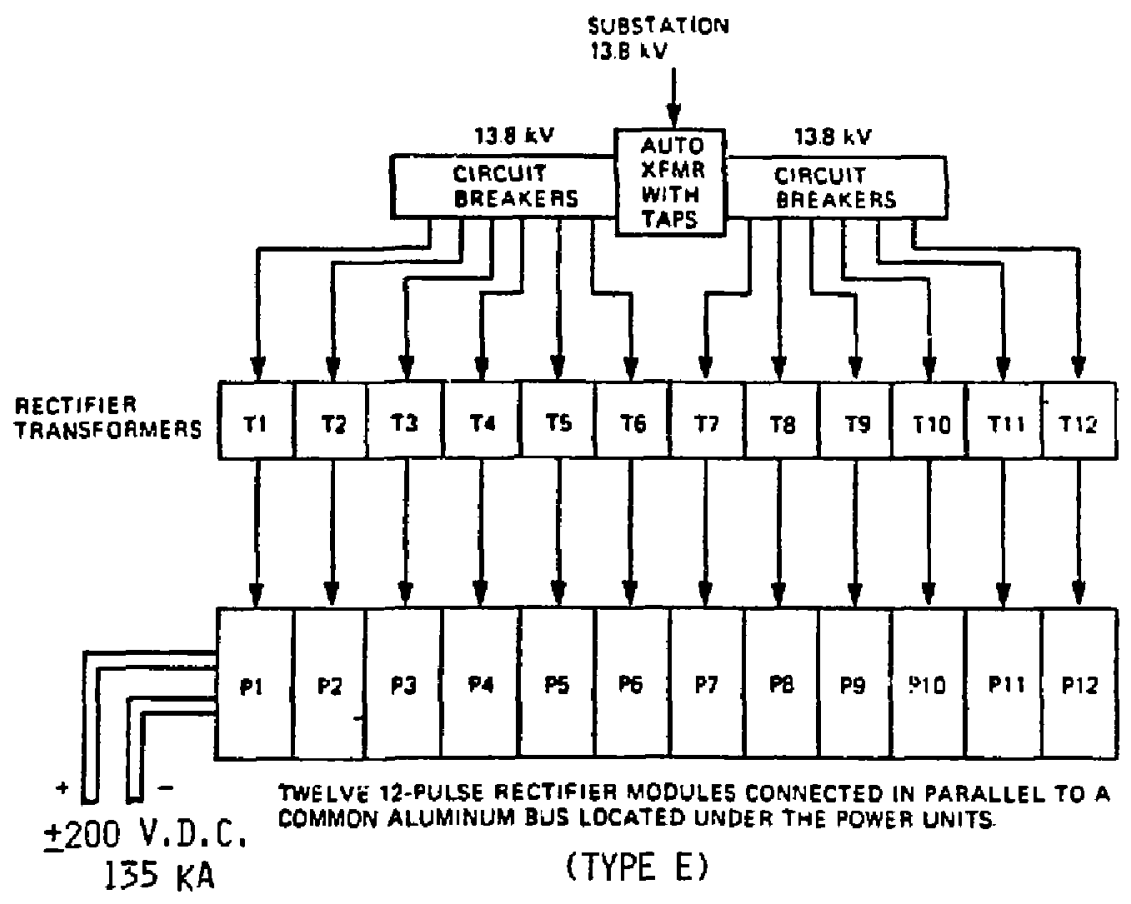

Figure 5-52. Type-E power-conversion system. 
The type-A circuit (Fig. 5-48) shows the 16 dump resistors for the $B$ main solenoid coils conneced in series. There are five large dc circuit breakers for interrupting the $60-k A$ coil currest if quench conditions are detected. The pneumatically operated slow-dump switch SD-SW has very low voltage across it because of the low-resistant-shunt slow-dump resistor $R_{s}$. The busing cross section is ten times higher than that used in the MARS study. ${ }^{3}$ Figures $5-49$ and $5-50$ slow the type $B$ and $C$ power conversion systems that apply to the two coil and single coil graupings of Table 5-2l. The only difference is that the background chcke coils are so large (higit energy) that they must have a center tap and separace dump resistors to protect them if a quench occurs.

Figures 5-51 and 5-52 depict qnwer supply construction for the resistive coils, which require substantial power at high current and moderate voltages. For the lower power coils, such as the axicell center coil and main solenoid choke coils, it may be desirable to reduce the ac line voltage to $2.4 \mathrm{kV}$ to reduce the cost of the citcuit breakers and rectifier transformers (Fig. 5-49). For the higher power axicell choke coils, the direct connection to the $13.8-\mathrm{kV}$ line via the auto transformer (shown in Fig. 5-52) may be more flexible or cost effective. In aither case, the very large currents require large crosssection busing as shown in the figares. Copper busing wil] reduce the cross section by $50 \%$, but is generally more expensive than aluminum. Joining the slabs together, however, may favor the use of copper busing.

The power conversion equipment for the plasma-heating systers consists of numerous converter/transformer units and all associated switch gear. Because the heating-system sources all require tight voltage regulation, twelve-pulse converters are used. The converters include all the surge arresters, reactors, filters, breakers, and preinsertion resistors that are required to smooth and condition the dc signal and protect sensitive elements of the unit (e.g., the thyristor valves). The larger ac-dc converter units are as follows:

- 38-MW, 126-kV, 300-A unit for the axicell tritium beamline ( 1 );

- 25-MW, 83-kV, 300-A units for the ECRH systems (2);

- 23-Mh, 83-kV, 277-A unit for the axicell deucerium beamline (1). 
The two ICRH units axe small, $1.5 \mathrm{MW}$ at $20 \mathrm{kV}$, and the multiple units for the sloshing benm system are all <1 MW with voltages ranging from 45 to $475 \mathrm{kV}$.

INSTRUMENTATION AND CONTROL

We had insufficient time to address the instrumentation and control (I\&C) issues for FPD-I and FPD-II in other than a precursory survey. The I\&C for FPD-I and -II should be about the same. The I\&C cost estimate considers four basic groups:
1. Plant process $I \& C$,
2. Safety I\&C,
3. Plasma diagnostics,
4. Supervisory-level data processing.

Each of these categories has both software and hardware aspects.

The plant process $I \& C$ includes all the data acquisition, local computers, and data transfer links to the supervisory level computers. The safety I\&C includes all sensors, data acquisition, hardware controls, and computers needed for safecy monitoring and for preventing plant startup and operation under adverse conditions. The safety isc is a highly reliable system that is independent of all other systems. Plasma diagnostics include all the plasma diagnostic systems, data acquisition, and lower level computers dedicated to the diagnostics. The supervisory level data processing includes all the large scale data processors and their support peripherals found in the control room. This system also includes the dedicared data links to other general purpose data processors located in other facilities. Ail groups have console displays.

The software and hardware I\&C cost should be comparable to that for MFTF-B or Tokamak Fusion Test Reactor (TFTR). However, more plant-process i\&C is needed for monitoring the direct-converters, shield, blanket, and halo-dump modules. The safety system must be augmented to include all tritium Eacilities and fueling systems. However, only the essential plasma diagnostics for monitoring and controlling the machine are included in the 
cost estimate. (There is very little space available for interfacing plasma diagnostics for physic experiments.) We assume that other predecessor machines will provide the plasma physics data.

The axicell addition requires add.tional loc for the high-flux blanket and shield modules as well as the additional magnets and neutral beam injectors. For cost escimating purposes, approximately $30 \%$ was added to the process ISC.

\section{TR ITIUM SYSTEMS}

In designing the tritium systems for a fusion reactor like FPD-II, we need to consider four important areas: (1) the use of neutral beams or pellet fuelers far fueling; (2) the presence of a blanket module with or wiviout a power train; and (3) fuel storage requirements; and (4) the fusion power and the fractional burn.

The tritium and deuterium mass flow rates for FPD-II are shown in Table 5-22 for two different fueling options--positive neutral beams and pellets. The efficiency of positive neutral beams ranges from 0.2 to 0.3 ; therefore, the total tritium inpat ranges from 40 to $60 \mathrm{~g} /$ hour or 4 to $6 \mathrm{~kg}$ during a burn of 100 hours (length of the longest cycle). The fueling fate for pellet fuelers may range fron 3 to 10 pellets/second with $2100 \%$ waste at each of these rates. At steady state 63 pellets/second would be fueled. This corresponds to a tritium input of 14 to $21 \mathrm{~g} / \mathrm{hour}$ or 1.4 to $2.1 \mathrm{~kg} / \mathrm{cycle}$.

The pellet fueler has two advantagas over neutral beams. First, since two heuts of tritizh fuel is stoted to ensure constant fueling during operation, a lower fueling race results in a lower inventory. Second, processing units contain lower tritium inventories at a lower rece.

The tritium inventories in the test cell and other processing areas at the throughput zates cited are sbown in Table 5-23. For beam fueling, the total inventory is 2330 to $290 \mathrm{~g}$. For pellet fueling, ic is 180 to $210 \mathrm{~g}$. With an irventory of $250 \mathrm{~g}$; both options could be handled by the same system.

The units supplied in the processing area include uranium storage beds, a fuel cleanup unit, a cryogenic distillation unit, a waste gas recovery system, a solid waste disposal system, plus all controls, monitors, analytical 
Table 5-22. Tritium and deuterium mass flow rates for FPD-II.

\begin{tabular}{|c|c|c|}
\hline Input Parameters & Value & \\
\hline $\begin{array}{l}\text { Burn time }(\mathrm{h}) \\
\text { Plant avajlability } \\
\text { Power (MW) } \\
\text { Current to central cel1 (kA) } \\
\text { Current to end cell (kA) } \\
\text { Current to test cell (kA) } \\
\text { Cycles/yr } \\
\text { Tritium fraction }\end{array}$ & $\begin{array}{l}100 \\
0.25 \\
479 \\
0.249 \\
0.009 \\
\leq 0.431 \text { a } \\
\overline{2} 1.9 \\
0.5\end{array}$ & \\
\hline $\begin{array}{l}\text { Processing variables at steady } \\
\text { state for two options }\end{array}$ & Neutral beamb & Pelletc \\
\hline $\begin{array}{l}\text { Fractional burn } \\
\text { Tritium burnup }(g / h) \\
\text { Deuterium burnup }(g / h)\end{array}$ & $\begin{array}{l}0.13 \\
3.2 \\
2.0\end{array}$ & $\begin{array}{l}0.22 \\
3.1 \\
2.0\end{array}$ \\
\hline $\begin{array}{l}\text { Tritium to plasma }(g / h) \\
\text { Deuterium to plasma }(g / h)\end{array}$ & $\begin{array}{l}12.1 \\
8.1\end{array}$ & $\begin{array}{l}7.0 \\
4.7\end{array}$ \\
\hline $\begin{aligned} \text { Tritium waste }(\mathrm{g} / \mathrm{h}) & \\
\text { Total tritium input } & (\mathrm{g} / \mathrm{h}) \\
& (\mathrm{kg} / \mathrm{d}) \\
& (\mathrm{kg} / \mathrm{cycle}) \\
& (\mathrm{kg} / \mathrm{yr})\end{aligned}$ & $\begin{array}{l}28 \rightarrow 48 \\
40 \rightarrow 60 \\
0.97+1.5 \\
4.0+6.1 \\
89 \rightarrow 133\end{array}$ & $\begin{array}{l}7+14.1 \\
14+21.0 \\
0.3+0.5 \\
1.4+2.1 \\
31+46\end{array}$ \\
\hline $\begin{array}{l}\text { Deuterium waste }(\mathrm{g} / \mathrm{h}) \\
\text { Deuterium end cell }(\mathrm{g} / \mathrm{h}) \\
\text { Total deuterium input }(\mathrm{g} / \mathrm{h}) \\
\\
\qquad \begin{aligned}(\mathrm{kg} / \mathrm{d}) \\
(\mathrm{kg} / \mathrm{cycle}) \\
\end{aligned} \\
(\mathrm{kg} / \mathrm{yr})\end{array}$ & $\begin{array}{l}19+33 \\
3.7+5.3 \\
31+46 \\
0.74+1.1 \\
3.1+4.6 \\
67+101\end{array}$ & $\begin{array}{l}4.7+9.4 \\
3.7+5.3 \\
13.1+19.4 \\
0.31+0.47 \\
1.3+1.9 \\
29+42\end{array}$ \\
\hline
\end{tabular}

aFor a test cell $23.5 \mathrm{~m}$ long.

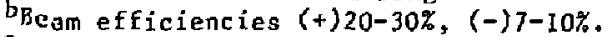

Chagte will range from $100 \%$ to $300 \%$. The beam case is 3 pellets/s. When

the reantor is started, up to 10 pellets/s may be required. 
Table 5-23. Tritium inventories (g) in FPD-Ir for two options.

\begin{tabular}{|c|c|c|}
\hline Option & Beams & Pellet \\
\hline Structure & $<30$ & $<30$ \\
\hline Beam pump & $4.5+7.8$ & -- \\
\hline Surge tank & $4.5+7.8$ & -- \\
\hline Pellet fueler & -- & $10^{c}$ \\
\hline B lariket & 3.8 & 3.8 \\
\hline Blanket recovery & 1 & 1 \\
\hline Total test ceil/heat exchanger & $43+50$ & 45 \\
\hline Storage $^{d}$ & $B O+120$ & $28+42$ \\
\hline Pellet preparation & -- & $14 \rightarrow 21$ \\
\hline Fuel cleanup & $50 \rightarrow 55$ & $43+45$ \\
\hline Cryogenic distillation & $60+65$ & $53 * 55$ \\
\hline Total processing & $190+240$ & $138+163$ \\
\hline Total & $233 \rightarrow 290$ & $183 \rightarrow 208$ \\
\hline \multicolumn{3}{|c|}{$\begin{array}{l}\text { a Dissolved tritium in a } 11 \text { components. } \\
b_{\text {Cycled } 1 / 6 \text { every } 10 \mathrm{~min} .} \\
\mathrm{c}_{\text {This inventory is a minimum. For an extruder, the }} \\
\text { inventory is at least } 20 \mathrm{~g} . \\
\mathrm{d}_{\text {Two hours of fueling. }}\end{array}$} \\
\hline
\end{tabular}

equipment, and necessary secondary confinement and processing systems needed to support the system. The units are sized based on Tritium Systems Test Assembly (TSTA) reference units. They are located in a tritium processing building separate from the test cell.

The blanket system is assumed to supply all of the tritium burnt $(26.7 \mathrm{~kg} /$ year) and also all of the tritium lost to decay, to environmental reieases or to waste in processirg. The amount lost to decay (14 g/year) depends on the plant inventory ( $250 \mathrm{~g}$ ). The amount lost to waste depends ou the efficiencies of the multiple processing systems. We assume that losses wi11 be $\leq 0.1 \%$ of the amount processed or $\leq 330 \mathrm{~g} /$ year with a required breeding ratio of 1.03 . 
The processing system used to remove tritium from the LiPb blanket includes a tritium removal system, a tritium purification system to remove gamma impurities, a tritiun control system for the power train coupled to the blanket, an impurity removal system for the LiPb, plus auxiliary equipment, dump tanks, etc. This equipment is located in the hot ceil.

Four different atmospheric tritium recovery systems (ATR) are provided for the four main tritium areas--test cell, hot cell, tritium biliding, and heat exchanger building. The units are sized for the air volumes processed and the processing time selected ( 5 days). The respective buildings have internal volumes $0=0.1 \times 10^{4} \mathrm{~m}^{3}, 22.4 \times 10^{4} \mathrm{~m}^{3}, 2.6 \times 10^{4} \mathrm{~m}^{3}$, and $24.3 \times 10^{4} \mathrm{~m}^{3}$. A throughput $\mathrm{rate}$ of 0.5 vol\%/min is needed to achieve cleanup in 5 days. This corresponds to units of $305 \mathrm{~m}^{3} / \mathrm{min}, 120 \mathrm{~m}^{3} / \mathrm{min}$. $80 \mathrm{~m}^{3} / \mathrm{min}$, and $215 \mathrm{~m}^{3} / \mathrm{min}$, respectively. The test cell and heat exchanger units are coupled to serve as backups for each other. The system for the rritium building is a separate system as is the not cell unit. The transporter unit is handled by part of the heat exchanger system. The ait in the large upper building above the test cell in which the transporter is located is cleaned by the combination of the hot cell and est celi systens.

A tritiated water recovery unit is also provided for FPD-II. It serves to remove tritium from any water system that becomes contaminated and it also is used to concentrate the tritiated wacer collected by the different ATR systems. Water systems that may become contaminated are those that serve beam dumps, halo plates, direct converter units, etc. The tritiated-water recovery unit has the potential of reducing tritium waste from the wacer systems by a factor of $10^{4}$.

The overall tritium system for FPD-II described hex is similar to that for the FPD-I design. The tritium mass flow rate for fueling FPD-II by pellet is slightly higher than FPD-I's becauge, although the fusion power increased, the fractional burn expected also increased. The fueling for FPD-II by beams is approximately twice that needed for FPD-I because greater beam power is needed in the FPD-II design. The blanket for FPD-II must produce $22 \mathrm{~kg}$ more tritium fuel each year than the blanket in FPD-I to replace the greater amount of tritium burnt. 
The maintenance requirements and operating availability for FPD-II are identical to those discussed in Sec. 4 for FPD-I, except for the addition of the DT axicell. The axicell is located at $z=0$ and consists of a test module with an integral solenoid coil (CSO), and a shield module with integral choke coils ( $\operatorname{CCC} 1$ ). These components are removable through the access port located over the test module. The present design of the axicell requires the removal of test module before the choke coils can be removed. This is a developmental concern since the test module may be a lifetime component, while the choke coils may require annual replacements. Additional configuration development is required to achieve independent replacement of the coils.

Figure 5-53 shows the disassembly of the axicell based on the design developed for MFTF- $\alpha+T$ (see Ref. 1 for a more detailed discussion of this component and its nodular subassemblies).

\section{PLANT FACILITIES}

We have used the same approach in designing the plant facilities for FPD-II as we used in FPD-I. However, the overall plant arrangement is modified to reflect the absence of a thermal-power conversion system (Fig. 5-54). In FPD-II, all of the thermal power generated is transported to an intermediate cooling-water loop and is rejected to the environment through a cooling-tower loop consisting of a mechanical-draft wet cooling cuwer (Fig. 5-55). The intermediate loop is provided to reduce migration of tritium and corrosion products to the environment. The total thermal power rejected is approximately $765 \mathrm{Mit}$. All other FPD-II facilities ate similar to the FPD-I facilities with the differences specified in the cost estimate.

rOST ANALYSIS

The total capital costs estimated for the FPD-II device are shown in summary form in Table 5-24. This estimate is in millions of mid-1984 dollars and has the following qualifications: 


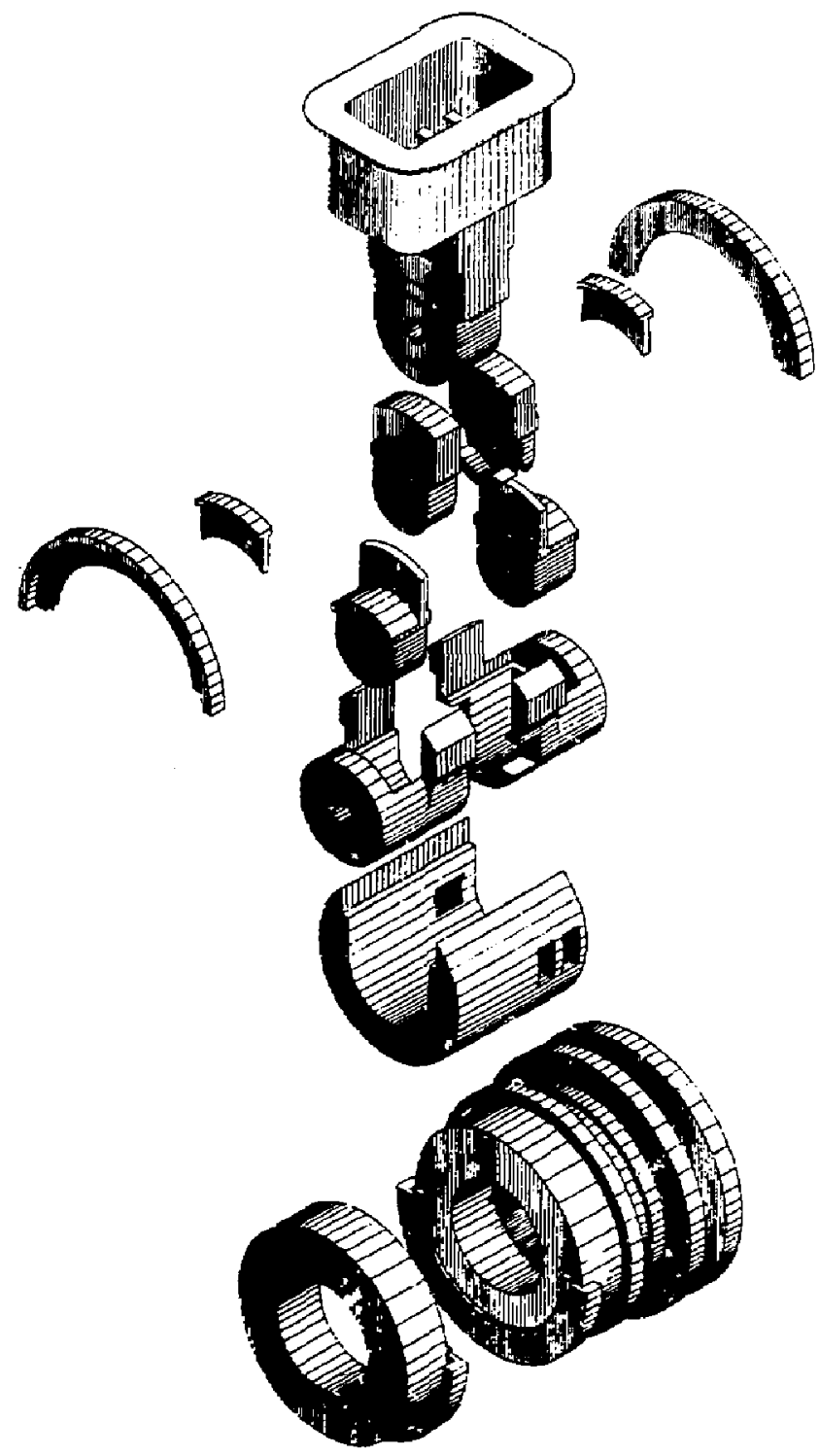

Figure 5-53. Disassembly of the DT axicall based on the MFTF- $\alpha+T$ design. 

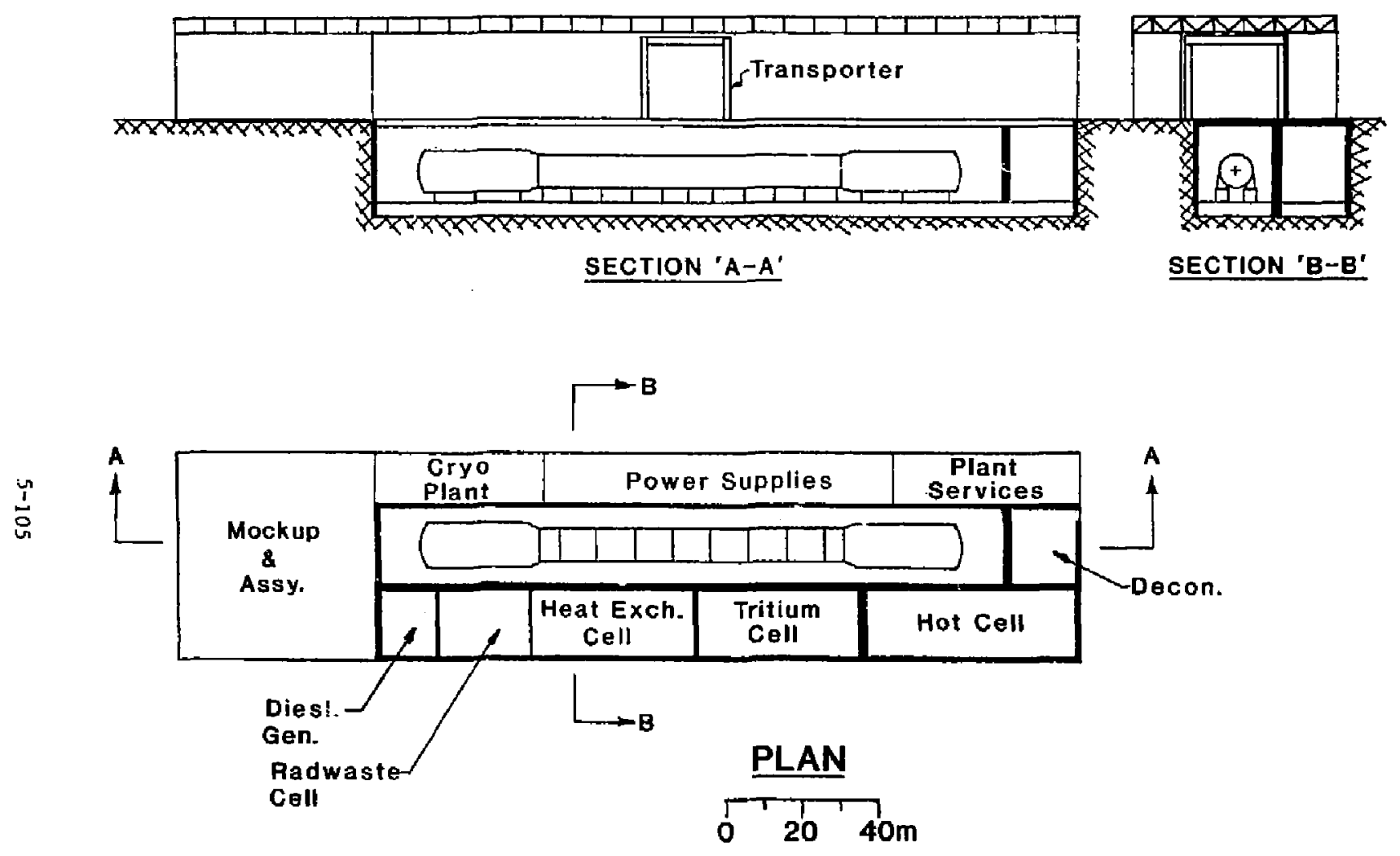

Figure 5-54. The FPO-I plant arrangement. Option 1: verticat module replacement. 


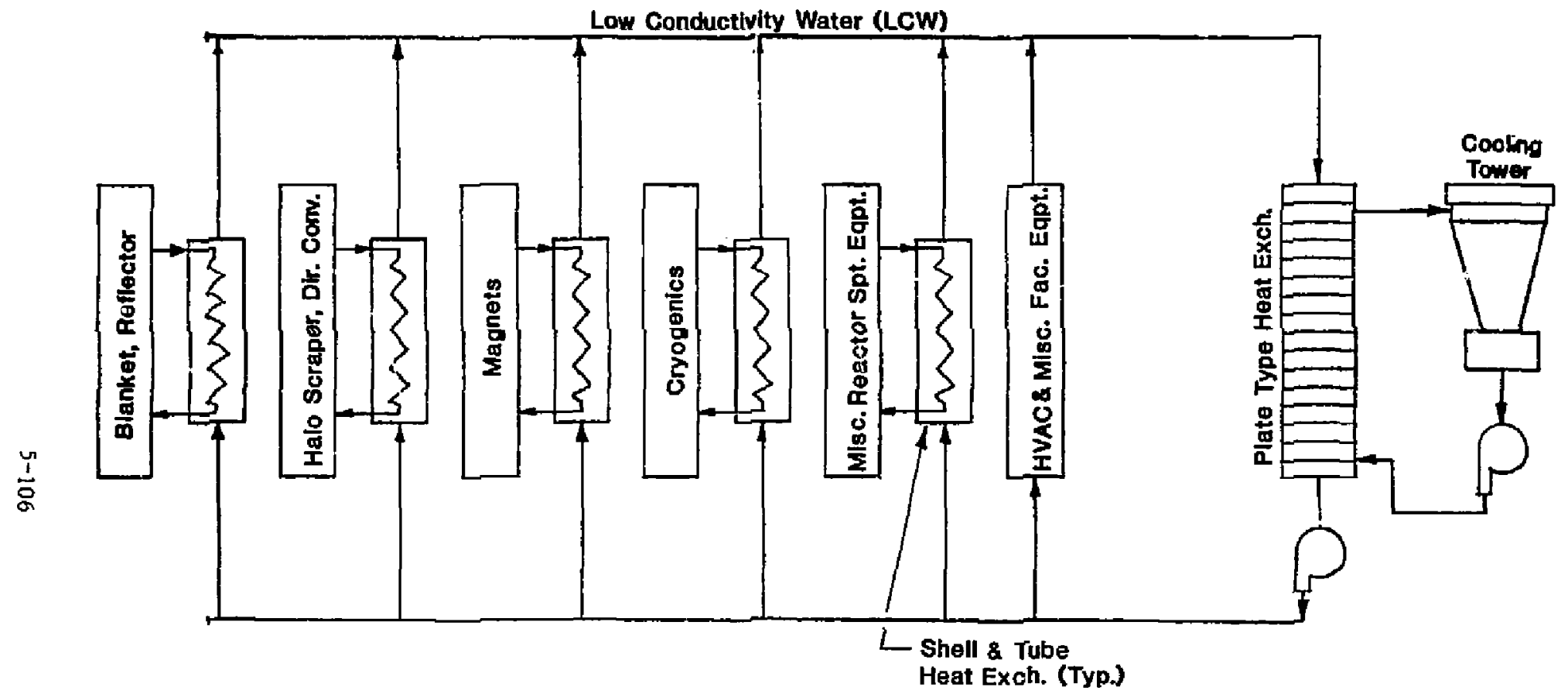

Figure 5-55. The FPD-II heat transport system. 
Table 5-24. FPD-II capital cost summary (1984 millions of dollars).

\begin{tabular}{lr}
\hline Direct cost & $1,372.3$ \\
Indirect cost & $\begin{array}{r}480.3 \\
\text { Subtotal }\end{array}$ \\
Contingency & $1,852.6$ \\
$\quad$ Toral capital cost & $2,408.4$ \\
\hline
\end{tabular}

- The device will be constructed on an undeveloped national laboratory site.

- The device will be constructed by a prime contractor who is responsible to the national laboratory for engineering, procurement, and construction.

The costs of each FPD-II component/subsystem were estinated by the engineers and organizations responsible for the design and specification of that particular component/subsystem. We developed a cost-data-collection methodology to ensure that all components and subsystems were included in the cost estimate and to ensure that all cost data had a common basis. The FPD-I work breakdown structure was initialy arranged to correspond to the standard mandatory accounts for fusion cost estimates, which is being developed at FEDC based on earlier work by Battelle. ${ }^{6}$ The engineer or organization responsible for each account developed the work breakdown below the mandatory level. Responsible engineers/organizations were provided with component cost forms that were used to transmit cost data to the FEDC Cost Engineering group. Components and subsystems were costed by using supplier quotes, by analogy with a similar component or subsystem, or by cost estimating relationships that atcempt to predict the cost based on the required performance and quantity to be purchased as correlated to historical cost data. 
The FPD-IL cost estimate differs from the FPD-I estimate because of the following factors:

- Better design definition exists for some components and subsystems;

- Design changes from FPD-I have occurred;

- Deletions and/or additions were made to the estimate.

A detailed breakdown of the FPD-II capical cost elements is presented in Table 5-25. Capital costs are composed of direct costs, indirect costs, and contingency costs. The direct costs shown in Table 5-25 include component engineering costs, equipment costs, and installation costs associated with the permanent facilities, systems, and equipment. These costs are defined as follows:

- Component Engineering Costs--Cost associated with design and verification testing of first-of-a-kind components.

- Equipment Cost--Cost associated with purchase/fabrication of equipment, which includes tooling, fabrication, Q/A, management, fabrication engineering, acceptance testing, and packaging and shipping.

- Costs--Cost of manual labor isvolved directly in exection of permanent plant facilities, systems, and equipment.

Indirect costs, shown in Table 5-25, are those costs that cannot be directly identified with specific permanent plant facilities, systems, and equipment; these costs include the following:

- Construction Services and Eauipment Cost--Temporary facilities, construction equipuent/supplies, taxes, and fees.

- Home Office Engineering and Services Cost--Plant and reactor systems engineering, procurement, cost and scheduling, $Q / A$, and consiruction management.

- Field office Engineering and services Cost-Field office operation, job supervision, $Q / A$, testing, and startup.

- Owner's Cost--Project management, engineering, Q/A, taxes, training, and inventories and spares. 
Table 5-25. The FPD-II capital costs (1984 millions of dollars).

\begin{tabular}{|c|c|c|c|}
\hline Account No. & Account title & $\operatorname{Costs} 1984$ & M\$) \\
\hline$\overline{20}$ & Land and land rights & 0 & \\
\hline 21 & Structures and site facilities & 127.0 & \\
\hline 211 & Site improvements/facilities & 5.0 & \\
\hline 212 & Reactor building & 30.0 & \\
\hline 213 & Turbine -uiluing & 0 & \\
\hline 214 & Reactor maintenance buildings & 28.0 & \\
\hline 215 & Tritium building & 12.5 & \\
\hline 216 & Electrical equipment buildings & 8.0 & \\
\hline 217 & Other buildings and structures & 43.5 & \\
\hline 22 & Reactor plant equipment & 1183.9 & \\
\hline 221 & Reactor systems & 268.0 & \\
\hline 221.1 & First walt & & 0 \\
\hline 221.2 & Blanket system & & 96.4 \\
\hline 221.3 & Shielding & & 89.5 \\
\hline 221.4 & Reactor seructure & & 77.1 \\
\hline 221.5 & $\begin{array}{l}\text { Energy and particle removal/ } \\
\text { control }\end{array}$ & & 5.0 \\
\hline 222 & Magnet systems & 339.3 & \\
\hline 222.1 & Central cell solenoids & & 76.6 \\
\hline 222.2 & Choke coils & & 30.4 \\
\hline 222.3 & Transition coils & & 58.2 \\
\hline 222.4 & Anchor cails & & 47.6 \\
\hline $22 ? .5$ & Plug coils & & 56.0 \\
\hline 222.6 & Recircularizer coils & & 5.8 \\
\hline 222.7 & Recircularizet solenoids & & D \\
\hline 222.8 & Axicell coils & & 64.2 \\
\hline 222.9 & Thermal shielding & & 0.5 \\
\hline 223 & Power injection systems & 109.9 & \\
\hline 223.1 & ECRH system & & 46.7 \\
\hline 223.2 & ICRH system & & 4.1 \\
\hline 223.3 & LHRY system & & 0 \\
\hline 223.4 & $\begin{array}{l}\text { Neutral beam injection system } \\
\qquad 5-109\end{array}$ & & 59.1 \\
\hline
\end{tabular}


Table 5-25. (Continued.)

\begin{tabular}{|c|c|c|c|}
\hline Account Na. & Account title & Costs $(1984$ & $M \$$ \\
\hline$\overline{224}$ & Vacuum systems & 0.5 & \\
\hline 224.1 & Plasma chamber & & 0.5 \\
\hline 224.2 & External vacuum vesgel & & 0 \\
\hline 224.3 & Secondary systems & & 0 \\
\hline 225 & Powet conditioning systems & 72.7 & \\
\hline 225.1 & Magnet system power conditioning & & 39.3 \\
\hline 225.2 & $\begin{array}{l}\text { Power injection system power } \\
\text { conditioning }\end{array}$ & & 27.3 \\
\hline 225.3 & $\begin{array}{l}\text { Energy and particle removelf } \\
\text { control power conditioning }\end{array}$ & & 6.1 \\
\hline 225.4 & Energy storage system & & 0 \\
\hline 226 & Heat transport system & 105.6 & \\
\hline 226.1 & Blanket heat transport system & & \\
\hline \multicolumn{4}{|l|}{38.8} \\
\hline 226.2 & Shield heat transport system & & 0.1 \\
\hline 226.3 & Czyogenic coding syster & & 35.6 \\
\hline 226.4 & Water cooling system & & 30.7 \\
\hline 226.5 & Gas cooling system & & 0.5 \\
\hline 227 & Fuel handling & $15 z .4$ & \\
\hline 227.1 & Fuel injection systems & & 7.7 \\
\hline 227.2 & Fuel processing and purification & & 19.2 \\
\hline 227.3 & Storage and receiving & & 5.2 \\
\hline 227.4 & Atmospheric recovery systems & & 26.3 \\
\hline 227.5 & Water recovery systems & & 7.7 \\
\hline 227.6 & Blanket recovery systems & & 86.3 \\
\hline 228 & Instrumentation/control (I\&C) & 71.4 & \\
\hline 228.1 & Process IGC & & 21.4 \\
\hline 228.2 & Safety instrumentation & & 3.4 \\
\hline 228.3 & Diegnostics & & 27.2 \\
\hline 228.4 & Data processing & & 20.4 \\
\hline
\end{tabular}


Table 5-25. (Continued.)

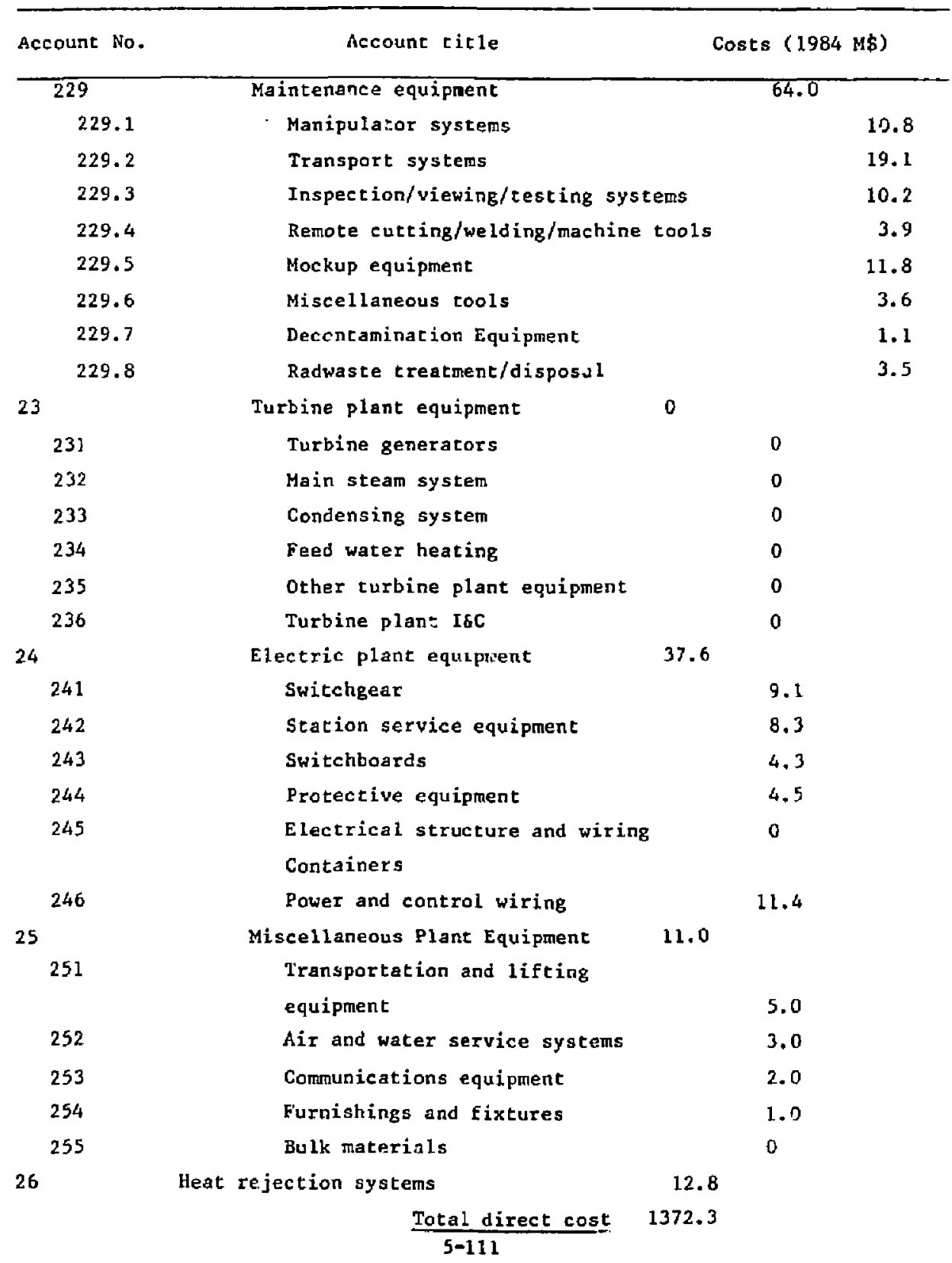


Table 5-25. (Continued,)

\begin{tabular}{|c|c|c|}
\hline Account No. & Account $t i t l e$ & Costs (1984 M\$) \\
\hline$\overline{91}$ & Construction services and equipment & 137.2 \\
\hline 92 & Home office engineering and services & 205.8 \\
\hline 93 & Field office engineering and services & 68.6 \\
\hline \multirow[t]{5}{*}{94} & Owner's cost & 68.6 \\
\hline & Total indirect cost & 480.3 \\
\hline & Subtotal & 1852.6 \\
\hline & Cont ingency & 555.8 \\
\hline & Total capital cost & 2408.4 \\
\hline
\end{tabular}

These indirect costs were included in the estimate as a percent of direct cost. Allowances used were $10 \%$ for construction services, $20 \%$ for home offica engineering, and $5 \%$ each for field office engineering and owner's cost. Contingency is an allowance for the uncertainty that exists within the conceptual design in quantity, pricing, or productivity and is under the control of the engineer/constructor and within the defined scope of the project. Contingency has been included in the estimate at $30 \%$ of the direct cost. 
1. W. D. Nelson et al., METE- $\alpha+T$ Progress Report, Oak Ridge National Laboratory, Oak Ridge, TN, ORNL/FEDC-83/9 (to be published).

2. A Tandem Mirror Technology Demonstration Facility, Lawrence Livermore National Laboratory, Livermore, GA, UCID-19328 (1983).

3. B. G. Logan et a1.; Mirror Advanced Reactor Study (MARS), Final Report, Lawrence Livermore National Laboratory, Livermore, CA, UCRL-53480 (1984).

4. W. S. Cooper and R. V. Pyle, The National Negative-Ion-Based Neutral Beam Development P1an, Lawrence Berkeley Laboratory, Berkeley, CA, PUB-464 (1983).

5. P. Poulsen and E. B. Hooper, Jr., "Large Area Negative Ion Source for Hign Voltage Neutrat Beams," in Proc. of 8th Symp. on Engineering Problems of Fusion Research, 1979, IEEE Pub. No. 79CH1441-5-NPS, p. 696.

6. S. C. Schulte, W. E. Bickford, C. E. Willingham, S. K. Ghose, and M. G. Walkex, Fusion Reactor Design Studies--Standard Unit Costs and Cost Scaling Rules, Pacific Northwest Laroratory, Richiand, Wh, PNL-2987 (1979). 


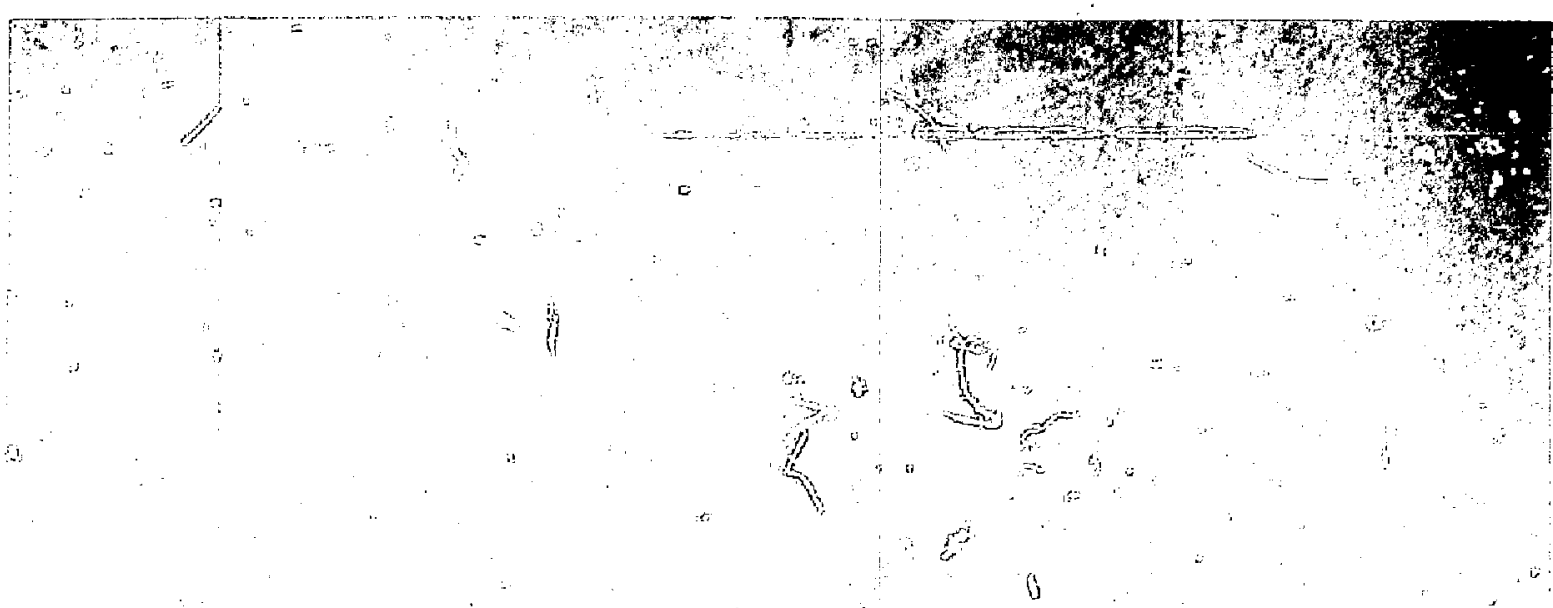

\section{Section 6 \\ STUDYING THE CRITICAL TECHNLOGY ISSUES}
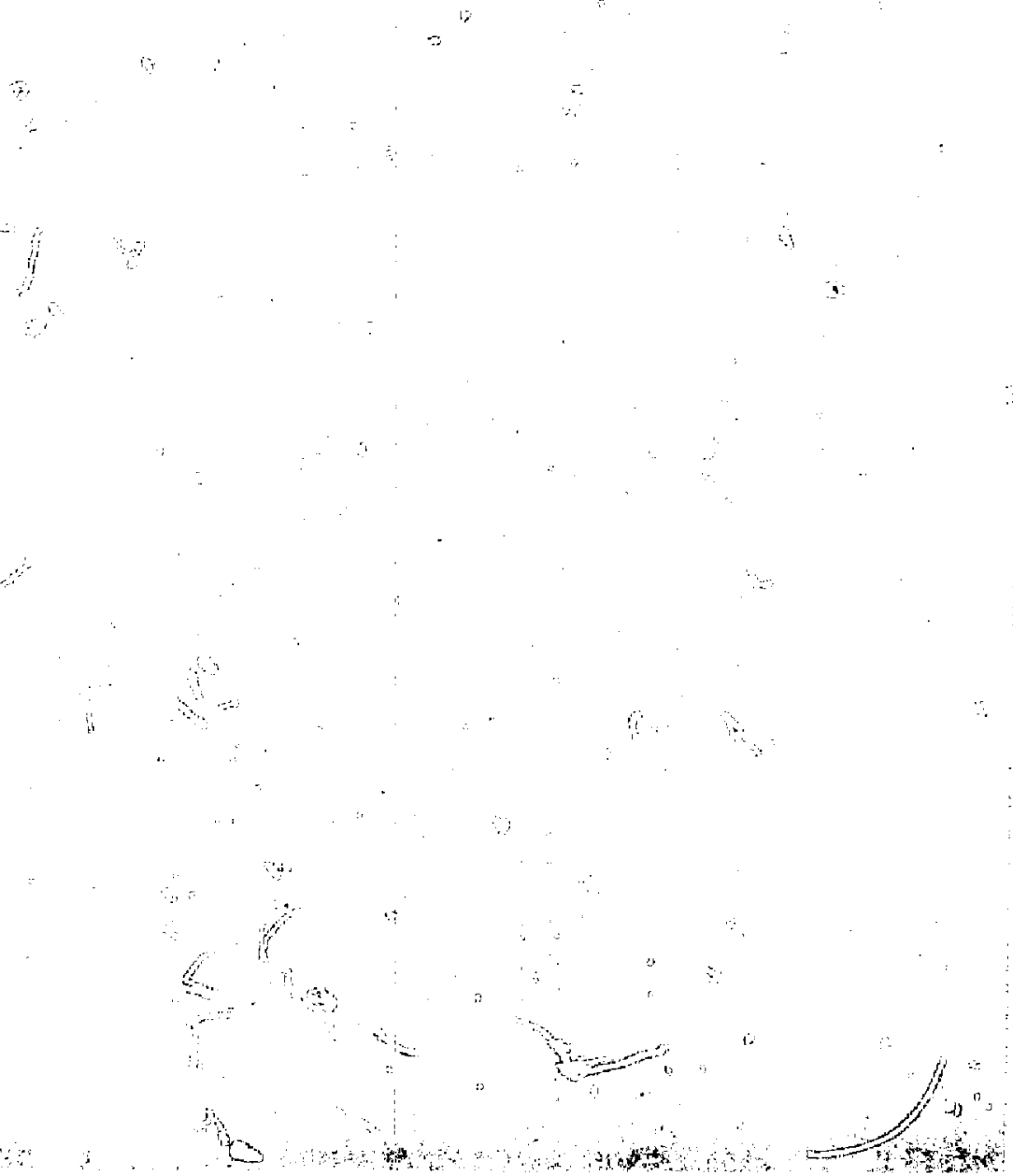


\subsection{STUDYINC THE CRIIICAL TECHNOLOGY ISSUES}

All advanced fusion reactor concepts include projections of current technology. In order that hardware performance not limit the progress of physics research, present-day experiments are based on state-of-the-art technology. Consequently, technological advances are directed by the dollars one can afford to invest in that hardware needed to reach certain physics milestones rather than by interest in developing the entire field of technology.

We recognized Exom the rutset that to operate at FPD experiment in the late 19905 , we needed to foster technological change in several key areas. Although the NARS study by LLNL and the fusion power community evaluated the techrological growth necessary for full-scale electricity production, we had to adjust the schedule of tachology development on FPD because it is a less ambitious project than Mars.

\section{CRITICAL ISSUES MEET INGS}

In 1983, we compiled a list of a:l critical issues we could anticipate for FPD (Table 6-1) and organized a seites of meetings based on the 20 issues found. (These roughly coincided with our monthly FPD design progress meetings.) Invitations were extended to members of the U.S. fusion community working on related technology. The format and proposed objectives of each workshop are shown in Table 6-2.

Only one planned workshop was not scheduled for FY84: remote maintenance. We needed a firm mechanieal configuration to bear the scrutiny of a remote-handing review, and that design was not final. However, close attention to assembly and maintenance had guided each design iteration to date. (Once our Phase III design is rasonabiy firm, we plan to hold a final meeting on this critical issue.)

After each critical issue meeting we distributed the minutes of the meting with apprepriate comments and summary. The average atcendance was about 30-- 75\% from the FPD project group and $25 \%$ consultants from other DOE laboratories and university research teams. 
Table 6-1. Critical issues for FPD.

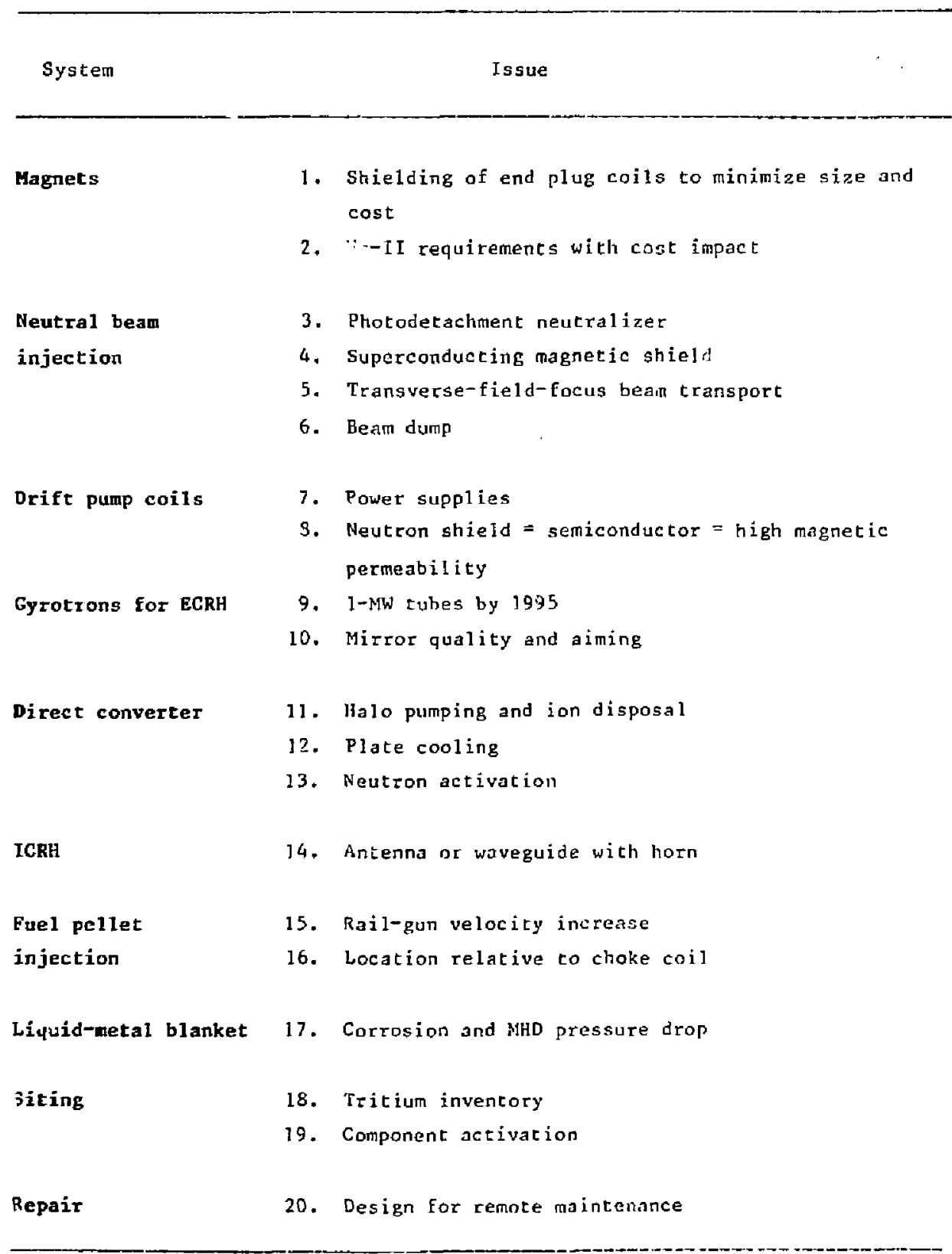


Table 6-2. Critical issue workshop format.

\section{Agend 3}

1. Present and compare design ideas.

2. Criticize and/or support.

3. Agree on design approach Eor FPD.

4. Devise test methods and schedule for FPD.

5. Assign design responsibility for FPD.

\section{Objectives}

1. Agree on basic design approach.

2. Specify design goals.

3. Define FY84 depth of study.

4. Who will pursue this study?

5. What issues will (s)he address?

6. When will the work be complete? 


\section{CuNCLUSIONS}

The critical issue meetings were all productive. Attendees concurred that the currents and voltages required for FPD seemed technically feasible. They recommended an increase in funding for beam technology to ensure attainment of timely milestones. Participants found no "black boxes" representing unknown research problems.

It was the consensus that the weakest area of current knowledge is pellet fueling. Present physics calculations indicate the need for pellet velocities. af tens of kiloneters per second. However, rail guns can deliver barely $3 \mathrm{~km} / \mathrm{s}$, and these have yet to be operated in a rapid-fire, reliable fashion. Finally, attendees noted that we must improve our ability to predict plasma-pellet heat-transfer neecis as well as fashion experiments to increase pellet velocity or add sabots to protect the pellets.

In the Appendix we include the memorandums that discuss in detail our findings concerning these critical issues. 



\section{I.0 SITING AND SAFETY}

INTRODICTION

In addition to the specifics of FPD siting and safety, we also consider two sets of general siting and safety criteria in this section. The first set consists of general site-selection criteria that seem to be universally applicable to laroe, fusion power machines, including the FPD machine. The second set comprises general reactor design criteria, which, if followed, will appreciably mitigate potential problems with siting and rafety.

GENERAL SITE-SELECTION CRITERIA

1. Telationship of the facility to population centers and density. No conflict should exist between the operation of the fusio. facility duxing its jiferime and the master plan for development in the vicinity.

2. Electrical power sources. Adequate electrical power should be available without requiring new substations and power lines.

3. Heat disposal. Heat disposal should be readily provided by using cooling towers, rivers, lakes, or oceans, and should create little or no adverse environmental effects.

4. Hot cell facility. An areo of the site should be dejicated to a hot cell facility for processing radiaactive macerials and parcs.

5. On-site disposal of radioactive waste. If possible, radioactive waste should be disposed of on site; therefore, the site must meet the NRC Class A requirements for near surface burial as outlined in the Code of Federal Regulations, 10GFr61. These waste materials include the following:

a. Operational wastes--machine parts that need regular replacement, expended material, protective clothing, rags, sludge, solvents, etc.

b. Decommissioning wastes--all of the above, plus activated machine compe: nts . 
6. Ofi-site disposal of radioactive waste. If radioactive materials cannot be disposed of an site, off-site disposal areas must be identified and be readily accessible. Material to be disposed of will be the same as in 5 above. The following transport concerns must be addressed:

a. Transportation routes must be identified.

b. Alternate rouces must be found when local ordinances restrict the transport of radicactive materials.

7. Seismic safety. The seismic safety criteria used in the design must be consistent with the local seismic requirements.

8. Tornado hazards. Tornado hazards must be considered in the design of the buildings and the facilities.

9. Flood hazards. Flood hazards must be taken into account in facilicy design,

10. Air traffic. Proximity to airports and flight paths may require additional precautions against possible effects of airplane crashes.

11. Fence-line radioactive dose rates. The projected radioactive dose rates at the fence line must conform to existing and proposed Department of Energy (DOE) and Environmenta1 Protection Agency (EPA) regulations. If property buffer zones are needed, it must be possible to acquire them.

12. Radioactive material inventories. Inventories of radioactive materials on site may be limited by special hydrology, unusual leach rates, and unusual nuclide migration rates.

GENERAL REACTOR DESIGN GRITERIA

1. Hands-on maintenance. He cannot anticipate all possible failure modes and necessary maintenance procedures; therefore, where possible, hands-on maintenance capability should be emphasized in the design. Bands-on maintenance will be possible only in selected places outside of the outer-machine shield.

2. Materials for hands-on maintenance, In regions where hands-an maintenance is highly desirable, materials that will "cool" quickly if activated should be used, making general access easier and simplifying remote handing when necessary. 
3. Remote maintenance. Mast of FPD requires remote maintenance and remote handing capability, therefore, remote maintenance should be major consideration from the start in the design studies.

4. Materials for near-surface burial. Materials must be used that, when activated, can be handled and disposed of by near-surface burial.

5. Reactor design for decomnissioning. Design the reactor for easy decomissioning (e.g., make the components modular so that highly activated parts can be easily separated from the rest of the machine).

6. Water contamination. No routine release of radioactivity should be allowed to surface or near surface water.

7. Volacile materials. In regions of high activation, use of materials that easily become volatile in accident situations should be avoided.

\section{SUMMARY OF REGILATIONS}

In addition to the above general criteria, we operate in an environment of regulations reflecting society's choices regarding the handing of hazards and hazardous materials. The following brief sumary reflects the kinds of regulations that pertain to the siting and safety of FPD.

\section{RAD IOACT IVI'TY}

The Lawrence Livermore National Laboratory (LLNL) is regulated in its handling of radioactive material by the DOE and the EPA. The current DOE regulations are concained largely in "Requirerients for Radiation Protection", DOE Order 5480.1 , Chapter $X I$. There are no current EPA regulations governing radioactive dose rates; however, the EPA has proposed regulations for the off-site dose rates ("Clean Air Act, Radiological Emissions Standards", Federal Register, April 6, 1983). These regulations apply to routine operations, not accident situations. The LLNL exposure limits for on-site personnel and routine operations, as listed in the LLNL keal th and Safety Manual Secrion 33, are based on the DOE Order 5480.1, Chapter XI. The exposure limits are the same as those stated in the NRC 10CER20 and are the recommendations of the National Council on Radiation Prorection (NCRP) and the International Protection ( $(C R P)$. The exposure limits are as follows: 
1. Whole body, head and trunk, bone marrow, gonads, and lens of the eye shall not exceed $3 \mathrm{rem} /$ quarter or $5 \mathrm{rem} /$ year.

2. Skin of whole body exposure to beta of $E$ greater than 700 keV, or $x$ or gamma of $E$ greater than $10 \mathrm{keV}$, shall not exceed 5 rem/querter or $15 \mathrm{rem} /$ year.

3. Hands, feet, or ankles shall not exceed $25 \mathrm{rem} /$ quarter or $75 \mathrm{rem} /$ year.

These dose limits are the maximum permitted during routine operations; however, the exposure policy of DOE and LLNL is to keep radiation exposures as low as reasonably achievable (ALARA). ALARA is subject to many definitions, but a draft on ALARA submitted to DOE by Kathren and Selby of Pacific Nor thwest Laboratory in April, 1980 states: ${ }^{2}$
"Both costs and dose reductions are difficult to evaluate and there may be significant variability in the perception and acceptance of risk by individuals and society. In general, dose reductions that cost less than $\$ 2000$ per person-rem of dose spared are probably always cost-beneficial, while costs in excess of $\$ 60,000$ per person- rem of dose spared are probably not cost-beneficial. In the absence of sound cost figures, an ALARA program cannot rely upon cost-benefit analysis. In such cases, the criterion must be whether or not dose reduction is reasonably achievable, given the linits of economics and practicality."

In the past, DOE has set the AR.ARA limit at $1 / 5$ of the limits presented above ( $j$.e., the design limit for DOE is shole body $0.6 \mathrm{rem} /$ quarter or 1 rem/ year). The policy at LLNL is to design to half the DOE 1 imit--300 mrem/ quarter or $500 \mathrm{mrem} /$ year. It is also LLN policy that the casual passerby (walking by the building) shall not be exposed to more than $0.25 \mathrm{mrem} /$ hour. Off-site limits are controlled by the EPA. In the "Clean Air Act, Radiological Emissions Scandards", the EPA proposes radiation dose guidelines of $10 \mathrm{mrem} /$ year whole body, and $30 \mathrm{mrem} /$ year to any organ for any member of the public residing at the site soundary. This dose limit for the general public inclujes radiation doses from all oirborne radioactivity. For fusion experiments, the limit includes any dose seceived from released tritium, from neutron activation products from the air $: n$ the experimental area, plus any 
other radiation dose sources that may be connected with the experiment. The dose 1 imit does not necessarily include the "sky shine" or radiation that escapes the shielding around the experimental facility. In our judgement all the above sources will be included in future proposals and should be allowed for in the design process. At the time of the publication of EPA's proposed regulations, the effective date was set for September 1, 1983; although the regulations were not made effective on that date, it is clear that something like these standards will be adopted in the future. The proposed EPA dose 1 imits are consistent with those imposed on the fission industry. The current NRC site boundary limits for an operating reactor are 5 mren/year for whole body and 15 inrem/year for organs.

Accident scenarios are handled ifferently from routine operations. The NRC regulation, as published in 10CFR 100 , sets the off-site dose from a maximum credible accident in a power reactor at 25 rem. The DOE draft, "Non-reactor Nuclear Facilities: Standards and Criteria Guide," dated February 1981 speaks of a type 3 accident. This is an occurrence that may occur infrequently during the lifetime $\left(10^{-3}<\mathrm{P}<10^{-1} /\right.$ year $)$. In this draft, the off-site dose Iimit for the type 3 accident is 5 rem. However, at LLNL, past practice suggests that this limit is too high. For an occurrence that might happen as often as $10^{-1} /$ year, the 1 imit should be about $500 \mathrm{mrem}$. Again, to put this into context, a release of $120 \mathrm{~g}$ of tritium from the $30 \mathrm{~m}$ stack of the LLNL tritium facility is calculated to give rise to about 3 to 4 rem to person sesiding at the fence line during passage of the clout. A ground leve1 to $10 \mathrm{~m}$ high release of $35 \mathrm{~g}$ of tritium is calculated to give about the same dose.

\section{SEISMIC REQUIREMENTS}

The following seismic criteria represent those criteria that will probably be developed for use in the FPD design.

\section{OPERABILITY}

1. Accomplish a thorough structural analysis and design or testing program to ensure that the integrity and operability of the Seismic Category I structures, systems, and components are maintained for 
the Design Basis Earthquake (DBE) condition. Seismic Category 1 structures, systems, and components shall be designed to remain functione $*$ during and after the DBF.

2. Ensure the integrity and/or operability of those Seismic Category I structures, systems, and components that are essential to assure shutdown capability, to maintain a safe shutdown condition, and to prevent or mitigate the consequences of accidents, which could result in potential off-site exposures.

3. List and categorize structures, systems, and components in the following four safety classifications: high-hazard, moderatehazard, low-hazard, no-hazard status. Guidelines for classification slall be provided by LLNL. Each safety classification has its own DBE Excitation Citeria.

4. Evaluate nonseismic Category I structures, systems, and components on a case-by-case basis. Nonseismic Category $I$ items shall be resigned using LLNL's no-hazard Standard Facility Criteria. Failure of Non-Category I items and Category I itams must not caus failure of any Category I items in successively ligher levels of the DBE requirements (i.e., an item in a lower safety classification must not cause failure of an iten in a higher safety classification).

5. Include, but do not limit, hazardous and nonhazardous structures, systems and components to building structure, piping, electrical conduit, mechanical systems, electrical systems, associated support systems, etc.

\section{SE ISMIC EXCITATION}

1. Define the DBE input ground motion for each structure, system or component configuration by specifying the maximum horizontal ground accel^ration ( $P G A$ ) and the horizontal ground response spectra. The maximum vertical ground acceleration is two-thirds of the maximum

\footnotetext{
Following the guidelines in 10CFR100, functional can be defined as performance sufficient to limit the maximum off-site dose to 25 rem. Practice at LiNL, however, has been to strive for lower exposure, even in the event of a DBE. A number that seems consistent with past practice at LLNL is to 1 imit the maximum off-site dose to 500 mrem. We suggest that FPD be designed to this performance level.
} 
horizontal ground acceleration. The response values of. the vertical ground-response spectra are equal to two-thirds of the response values for the horizontal ground-response spectra. The LLNL DBE ground-response spectra with a peak ground acceleration is normalized to $1.0 \mathrm{~g}$.

2. Assume that the DBl. horizontal ground motion occurs in any orientation within the horizontal ground-motion plane for the given structure. In addition, consider that the horizontal ground motion acts simultarecusiy with the vertical ground motion (two-directional excitations).

3. Include the following two steps in the high-hazard seismic-excitation and design requirements. LLNL requires tiat all high-hazard structures, systems, and components (Seismic bagagory I itens) go through a two-step design process. The first step consists of evaluation and design in the elastic range of response, using a ¿ynamic-response spectrum analysis with the LINL ground-response spectra and a corresponding peak ground acceleration (PGA) of $0.5 \mathrm{~g}$ (DBE) applied simultaneously with a vertical PGA of $\pm 0.33 \mathrm{~g}$. Engineering evaluations and design are accomplished by using Uniform Building Code (UBC) analysis methods in addition to UBC strength allowables. Connection evaluation and design accounts for an additional load fictor of 1.5 ; the connection design/evaluation uses forces that are 1.5 times greater than those resulting from $1.5 \mathrm{~g}$ (DBE). The second step of the design process takes the components into the inelastic range and checks the integrity of the Seismic Category I items against forces resulting from an earthquake with horizontal PGA of $0.8 \mathrm{~g}$ applied simultaneously with a vertical $P G A$ of $\pm 0.53 \mathrm{~g}$. For this design check, the item must remain functicnal during and after the earthquake.

4. Include the following two steps in the moderate-hazard seismicexcitation and design requirements. LLNL requires that all moderatehazard structures, systerms, and components (Seismic Caterory I items) go through a cwo-step desigr nrocess. The First step consists of eva:uation and design in the elastic range of respo:"- , using a dynamic response spectrum analysis with the LLNL ground-response spectra and a corresponding peak ground acceleration (PGA) of $0.25 \mathrm{~g}$ 
(DBE) applied simultaneously with a vertical PGA of $\pm 0.17 \mathrm{~g}$. Engineering evaluations ano design are accomplished by using UBC analysis mathods along with lac strength allowables. Connection evaluation and design accounts $t:=$ an additiona? load factor of 1.5; the conrection design/evaluation uses forces that are 1.5 times greater than those resulting from the $0.25 \mathrm{~g}$ (DBE). The second step of the design process takes the components into the inelastic range and checks the integrity of the Seismic Category $I$ items against forces resulting from an earthquake with horizontal PGA of $0.5 \mathrm{~g}$ applied simultaneously with a vertical PGA of $\pm 0.33 \mathrm{~g}$. For this design check, the item must remain functional during and after the arthquake.

5. Include the follewing in the low-hazard and no-hazard (conventional buildings) seismic-excitation and design requirements.

a. One- and two-story buildings and structures: current UBC requirements are upgraded for a building seismic-lateral-load coefficient of $0.25 \mathrm{~W}$ (static). If UBC seismic requirements are more stringent, UBC seismic requirements shall control. Connection evaluation and design, resulting from seismic forces, shall account for an additional load factor of 1.5 (i.e., connection design/evaluation 10 ads $=1.5 \times 0.25 \mathrm{w}$ Loads). Analysis procedures, design procedures, and material strength al lowables shall meet the requirements of the latest edition of the UBC. Lateral forces on structural and nonstructural craponents shall be designed to met the basic performance requirements of the UBC.

b. Buildings and structures greater than two stories: these buildings and structures shall meet the seismic design requirements for one- and two-story buildings and structures, and shall be evaluated and designed using the LLNL groundresponse spectra with a corresponding horizontal PGA of $0.5 \mathrm{~g}$ applied simultaneously with a vertical PGA of $\pm 0.33 \mathrm{~g}$. Engineering evaluations and design shall be accomplished by the use of inelastic analysis methods combined with inelastic stress allowables. Little regard shall be given to the condition of the building following the DBE. Primary concern is to ensure 
prevention of building collapse, thr:-eby allowing the building occupants to egress safely following an earthquake of major intensity on site, Lateral forces on structural and nonstructural components shall be designed to meet the basic performance requirements of the building structure.

c. Al1 buildings and structures with significant cross-axis coupling and/or torsional response: the design of buildings and structures placed within this category shall meet the requirements of $5 b$ above.

SPECIFIC FPD SITING AND SAFETY CONSIIERATIONS

In adcition to the above general requirements, thea are specific safe'y and siting considerations that are appropriate for FPD.

TRIT IUM USE

After surveying the special hazards of using tritium in the FPD facility, we are confident that prcper design will allow adequate containment. DOE has placed requirements on the construction of plutonium buildings (DOE 6430, Part 2), but there is no comparable document secting forth requirements for tritium buildings. However, engineers designing new tritiun facilities may need to consider a "design basis accident" in their plans. The DOE Division of Environmental Safety and Health (ES\&H) is preparing a document describing tritium building criteria. As far as legal requirements are concerned, the site boundaxy is the fence line. The NRC requirements for fission reactors state that, under normal operations, a person presumed to be residing on the fence line continuously should not receive more than $500 \mathrm{mrem} / \mathrm{year}$. DOE requires that normal operations should be designed to limit this dose to $170 \mathrm{mrem} /$ year. To give guidarce in the case of accidents, the NRC has defined an "Extraordinary Nuclear Occurrence," which covers external exposure, ingestion, inhalation, plus the food and water dose routes. This type of accident occurs when a person residing in an unxestricted off-site area receives a whole-body dose that exceeds 20 rem. This whole-bndy dose can be received ac the time of the nuclear occurrence or over a longer period of 
time. In an "Extraordinary Nuclear Occurrence", the NRC establishes the conditions for the "waivers of defense" proposed for incorporation in indemnity agreements, insurance policies, and in contracts furnished as proof of financial protection. The NRC definition of an "Extraordinary Nuclear Occurrence" carries no express or implied inference that such a dose may or may not be hazardous to the person receiving $i$ :. To put this in context, the present LLNL tritium facility has a design capability whereby release of a mega-Curie of tritiated water [HTO ( 104 grams of tritium)] in a worst-case situation will give rise to 3 rem at the fence line.

The Tritium Systems Test Assembly (TSTA) project at Los Alamos National Laboratory is wrestling with the question of accountability requirements, (set by DOE at \pm 0.0$]$ gram). For the $800-g r a n$ tritium inventory expected in FPD, $\mathrm{DOE}$ accountability requirements expect an accuracy of $12.5 \mathrm{ppm}$. This accuracy is considered unachievable because of a number of losses, (e.g., permeatior into the structure and into the water coolant). Personnel at TSTA have not found adequate equipment or methods to deal with this question.

presently, the FPD facility is projected to have about 800 grans of tritiun in the entire facility, with about 40 grams vulnerable in FPO ircelf. However, we are investigating altemative schemes for reducing the total amount of tritium. One scheme is prompt recyeling of the tritium exhausted out through the halo. This tritium, plus the included deuterium, could be purged of heavy ions and hydrogen and then recycled back to the pellet injector along with make-up tritium from the blanket breeder. Such a conceptual systen could significantly reduce the size of the tritium handing faciliry and, at the same time, it could reduce thrs total amount of tritium circulating.

MATERIAL ACTIVATION

Calculations of neutron-induced activation are proceeding, but the results obtained to date indicate that the FPD facility can be designed and constructed to aperate within existing guidelines and can be decomtissioned after its useful life. Calculations are continuing in the area of activation relevant to hands-on maintenance. Early results indicate that components, which are exposed to neutron fluxes equivalent to "first wall," will have to be handed 
remotely from the beginning of the experimental program. Cther areas may have low enough fluxes that some contact maintenance will be possible, at least early in the experimental program. Calculations of rsdionuclide inventory are underway. The important time regimes for central cell activities are as follows:

- Immediately after shutdown, when afterheat levels will be greatest;

- Twenty-four hours after shutdown, when some of the activities will contribute significantly to the radiation inside the vault;

- Months after shutdown, when major replacements might be undertaken;

- Years after shutdown, during decomissioning;

- Decades after shutdown, for waste storage considerations.

The moderate wall loading for FPD $\left(0.85 \mathrm{MW} / \mathrm{m}^{2}\right)$ in the long solenoid section, plus the high wall loading ( 4 to $5 \mathrm{MW} / \mathrm{m}^{2}$ ) in the $3-\mathrm{m}-\mathrm{long}$ central cest section, are reduced by tire rather low-load factor (30\%). Hence, for activation products with half-lives of several months or more, this scenaric, is equivalent to steady-state operation at $0.25-\mathrm{MW} / \mathrm{m}^{2}$ wall loading for the long solenoid section and $1.5 \mathrm{~kW} / \mathrm{m}^{2}$ for the central test section. Afterheat in the first wall steel immediately after shutdown will be about half that of Starfire, ${ }^{2}$ or abour $0.4 \mathrm{~W} / \mathrm{cm}^{3}$, but will decay much more rapidly than in Starfire, The copper insert coil will activate, presenting problems both in handling arre in waste disposal. The activity will be dowinted by the 5.3-year $\operatorname{co}(60)$, produced by the $(n, a)$ reaction in $C u(63)$, and will determine the shielding and handling techniques needed to replace this coil. The $\mathrm{Li}_{17} \mathrm{~Pb}_{83}$ ( $\mathrm{LiPb}$ ) used as a coolant in the blanket and first wall will activate in the neutron flux. Depending on actual residence time in the tigh-neutron-fiux regions and on the operating level and also on the availabilicy of the FPO facility, the contact-surface dose rate for cooling loops containing the Lipb could be several to many rem/hour. In addition, the LiPb will entrain corrosion products as it cirzulates. Some of these corrosion products may be already dctivaced before entrainment while others will activate as the $\mathrm{LiPb}$ circulates through the high-neutron-fiux regions of FPD. This indicates that remote maintenance should be planned for the LiPb loops from the beginning. Accident scenarios involving tipb should be investigated in the future. 
Liquid nitrogen is used in the superinsulation for several magnets (e.g., the transition and yin-yang coils). We calculated the $c(14)$ production in liquid nitrogen at the yin-yang coils (assuming a $14-\mathrm{MeV}$ neutron source strength of $1 \times 10^{13} \mathrm{n} / \mathrm{cm}^{2}$-s at this location and no additional shielding on the coils); the result was a $\mathrm{C}(14)$ production rate of 0.1 microCi/liter/year. To determine whether or not this production rate is a problem, we wi]l need to study the neutron activation of nitrogen at all points in the cooling loop and also make some assumptions about the nitrogen leak rate to the environment. The N(13) (10-min halflife) resulting from activation of the liquid nitrogen may be a hazard in the event of a massive leak under accident conditions.

\section{DECOMMISSIONING}

Long-term activation is thought to be a decommissioning rather than a waste storage problem. The total operating time of the solenoid cells (about $1.25-\mathrm{MW}$ year $/ \mathrm{m}^{2}$ ) and of the test section (5- to 7-Mw year $/ \mathrm{m}^{2}$ ) is not 1 ikely to produce large inventories of very long-lived nuclides; furthermore, we are not addressing a whole series of machines, but one isolated test bed. Decominissioning handling problems, if they occur 5 to 10 years after shutdown, axe 1 ikely to be heavily influenced by the presence of co(60) activity, just as in lightwater reactors. This $\mathrm{Co}(60)$ originates from $\mathrm{Cu}(63), \mathrm{Co}(59)$, and $\mathrm{N} i(60)$. Because $C_{0}(60)$ is a hard-gamna emitter, its presence will probably dictate the shielding needed during decommissioning. Careful choice of structural materials can result in all radioactive waste being elassified as class $C$ (suitable for near surface burial). If this is the case, a sice selection that allows on-site disposal of the waste can be extremely important because packaging and transportation problems will be minimized. Decomissioning will involve all of the techniques developed for dealing with fission reactors. In particular, it will require a custodial period for the FPD facility to allow the induced radivactivity to decay to levels that will permit disassently and disposal. This period has been estimated to be between 5 and 10 years. During this time, maintenance must be performed on the facility to protect it against deterioration and accidents. Once actual decommissioning begins, the larger radioactive components must be disassembled to allow packaging for disposa1. This may involve the use of a plasma torch, pools, and all the other techniques developed for fission aystems. If the levels are low enough, 
near-surface burial may be possible; if not, the waste must be packaged as high-level waste. In either case, decommissioning of FPO, like any other DT fusion device, will provide a major challenge.

\section{CONCLUS ION}

Siting and safety criteria for FPD are generally logical and straightforward. Careful attention to these criteria early in the design process can result in a simpler machise that satisfies the constraints listed here and results in a better overall system that is easier to operate, maintain and decommission. 
1. R. L. Kathren, J. M. Selby, E. J. Vallario, A Guide to Reducing Radiation Exposure to as Low as Reasonably Achievable (ALARA), U.S. Department oE Energy, Washington, DC (1980).

2. Starfite -- A Commercial Tokamak Fusion Power Plant Study, Argonne Nationa 1 Laboratory, Argonne, It, ANI,/FPP-8C-1 (1980). 
7 a 3

Solden $8^{r}$

TANDEN MAROR REACTOR SYSTENS CODE (TMRSC) 


\section{B.0 TANDEM MIRROR REACTOR SYSTENS COIE (TMRSC)}

\section{INTRODUCT ION}

We are developing a computer code for a tandem mirror reactor that will allow us to provide self-consistent configuration, performance, and cost analyses as a function of plasma, magnetic, and engineering parameters. With the first version of the TMRSC, we will model a configuration similar to MARS $^{1}$ and FPD, ${ }^{2}$ which incorporates the central cell auc end cell that are shown schematically in Fig. 8-1. The end cell consists of a choke coil, a c-coil transition region, an anchor C-coil set, a plug C-ccil set, and a recircularizing $\mathrm{G}$ coil. The thermal barrier in this configuration is located in the plug.

The modules comprising the TMRSC are being provided by various sources within the fusion community; the physics, magnetics, magnet, and facilicy modules are the responsibilicy of Lawrence Livermore National Laboratory (LLNi.). Neutronics, shielding, and tritium modules are being modeled by Argonne National Laboratory (ANL). Blanket thermal hydraulics, heat transport/power conversion, cryogenics, .lirect converter, and plasma heatirg systems are being provided by TRW. Magnet electrical, ac power, vacuum vessel, fueling, maintenance equipment, and instrumentation and control (Isc) modules are being modeled by Oak Ridge National Laboratory--Fusion Engineering besign Center (FEDC). The integration of the modules into the TMRSC is the responsibility of the EEDC.

\section{F:OW DIAGRAM}

The flow diagram for the TMRSC code is shown in Fig. 8-2. The code consists of separate modules, each describing a reactor component or system connected by a driver. Three feedback loops are indicated by dashed lines. These loops are necessary due to the strong coupling becween the plasma physics, the magtetics, neutronics, and magnet design parameters.

In TMRSC, we use a calculational procedure that starts at the plasma center line of the central cell and proceeds radially (Fig. 8-3). The central cell length and plasma radius are determined primarily from the desired fusion power, on-axis rlagnetic-field beta, and plasma temperature. The central cell 


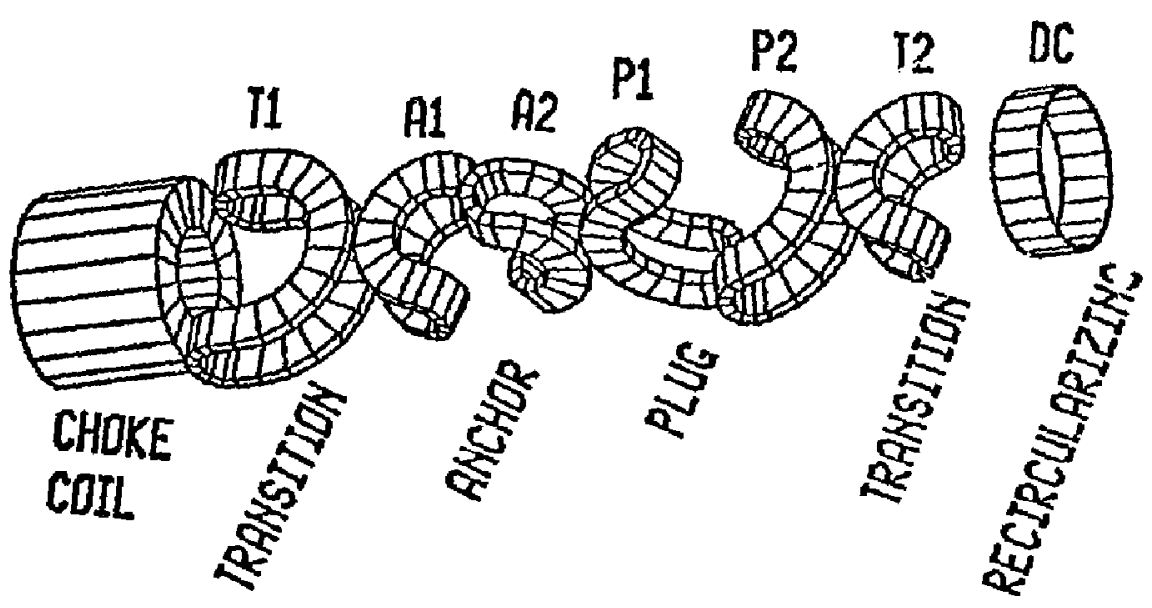

Figure 8-1. End cell configuration. 


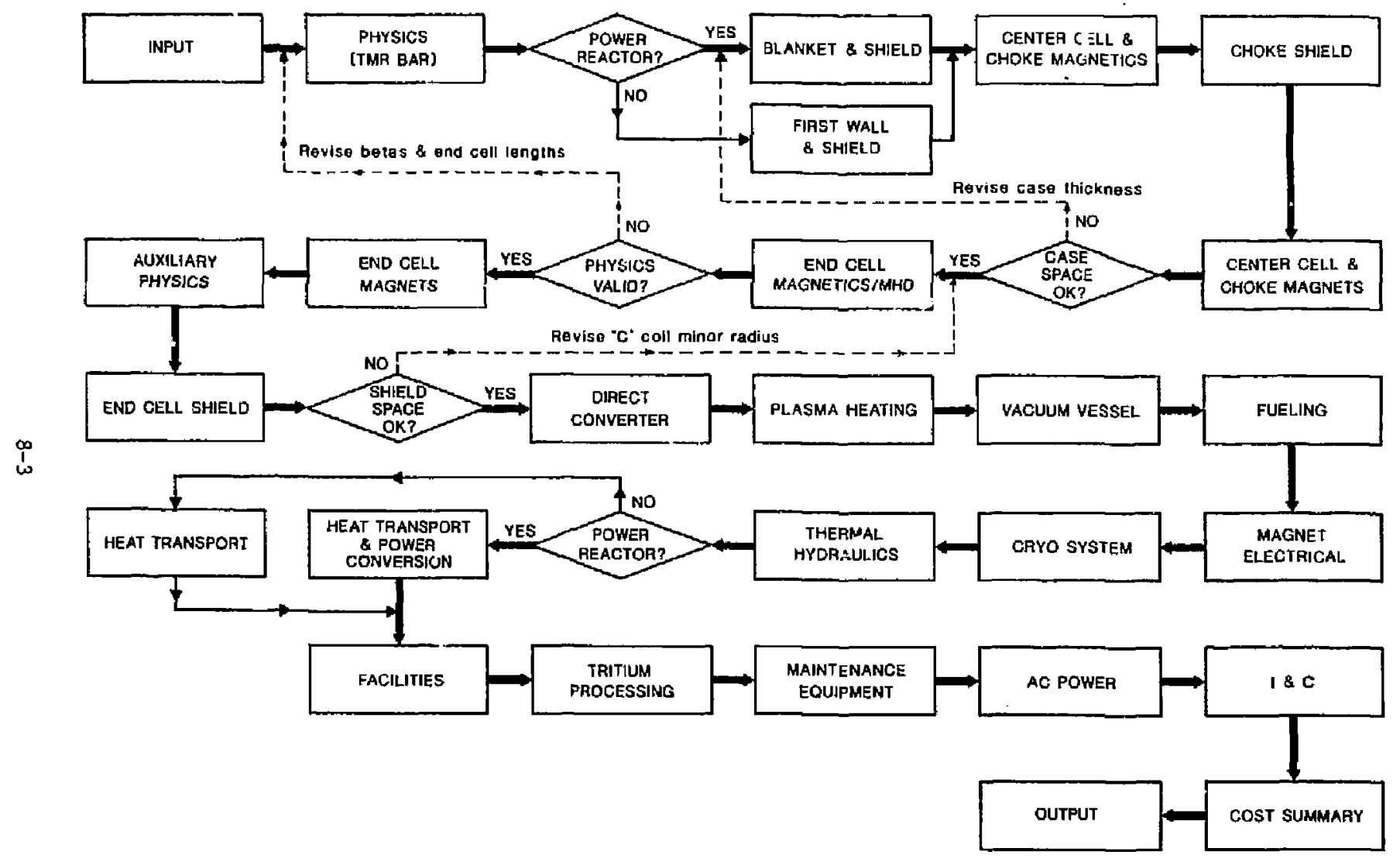

Figure 8-2. Tandem mirror reactor systems code flow diagram. 

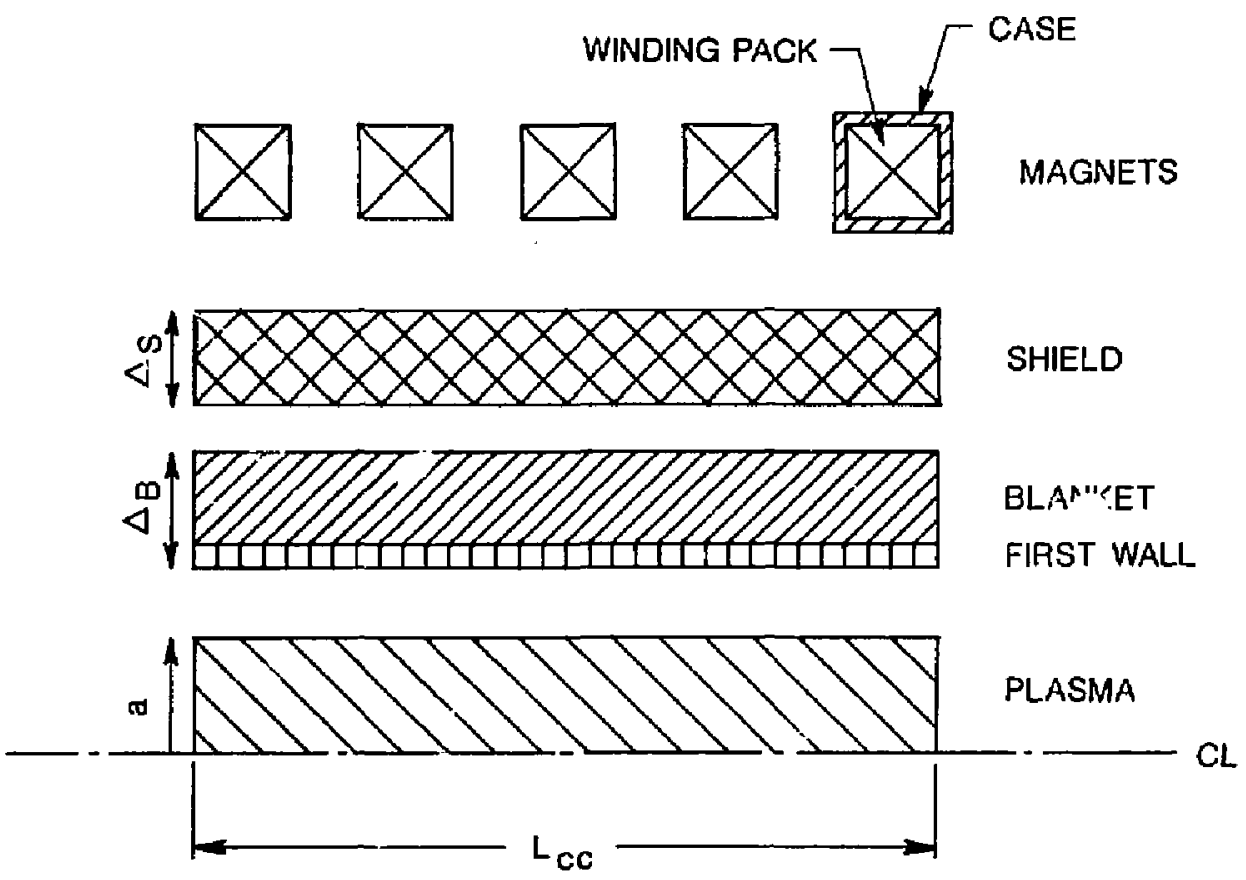

Figure 8-3. Certral ce;l configuration. 
blanket thickness is detemined consistent with the desired energy multiplication and tritium breeding ratio. The shield thickness is set consistent with nuclear response limits in the superconducting solenoidal coils. The central-cell solenoidal-coil radius is then detexmined from the summation of the plasma radius, blankec and shield thickness, and assembly gaps. The coil current and the conductor area for the solenoidal coils are determined as a function of the coil radius, desired on-axis magnetic field, and allowable coil-current density.

The code proceeds to step axially to the choke coil and end cell

regions. The plasma radius at the choke coil is a function of the desired magnetic field on the choke-coil axis and the need to pass the central cell magnetic flux. (An option exists to specify the chohe-coil plasma radius and calculate the central-cell plasma radius.) The choke coil (superconducting portion plus copper insert portion) is sized, after determining the plasua radius at the choke coil, based on the required currents and the allowable current densities. The IMRSC code also accounts for the space required for shielding of the choke coil.

The c-coil radii in the end cells are consistent with the plasma boundary, the desired on-axis magnetic field, shielding requirements, desited sweep angle, and allowable current densities. Axial positions of the coils are chosen to be consistent with recircularizing the flux in the anchor and plug wells and reducing to zero the average geodesic curvature. As previously noted, a feedback loop assures compatibility between coil geometry, neutroniçs, magnetics, and plasma stability.

Modules downstream of the iteration loops are executed in a once-through manner according to the sequence shown in Fig. 8-2.

MODULE DESCR IPTIONS

PHYSICS

The physics module of TMRSC solves multiple nonlinear linked equations to compute the steady-state plasma power and particle balance, and the plasma supplemental heating requirements for tandem mirror reactors. The code maintains quasi-neutrality at several cardinal points in the end cell region, and determines volumes, densities, potentials, and fu! :on-pover values. 
Options to find minimum length, maximum power, or maximum $Q$ are also

available. Finally, the central cell may be specified as ignited or driven.

NEUTRONICS

Five blanket options and three shield designs are available ir the neutronics module of TMRSC. Tritium breeding ratios, energy deposition, and nuclear response in the coils are determined consistent with the neutron wall loading, and material composition and thickness. End cell shielding is based on the netron source strength. Costs of the blanket and shield are also estimated with this module.

BLANKET THERMAL HYDRAULICS

The blanket thermal hydrauliss module in TMRSC is used to fetermine coolant inlet and outlet temperacure, pressure drops, pumping power, lifetime estimates, and structural temperatures for liquid-metal and gas-cooled components.

MAGNET ICS

Mrgnetics for the central cell, solenoidal coils, the choke coil, and the end-cell $\mathrm{C}$ coils are determined by the TMRSC magnetics module. Required currents are computed based on the magnetic-field profic, the coil radii, and the axial location of the coil. The central cell coils may be discrete coils or a current sheet. Conductor current density and coil-dimension or coilaspect ratio are input items. The end-cell $\mathrm{C}$ coils are sized and positioned to provide (1) the desired magnetic field profile; (2) flux tube circularity in the magnetic wells; and (3) zero average geodesic curvature. This module runs the EFFI magnetic field code and the TEBASCO (tandsm equilibrium and stability) code. Allowable value of beta in the central cell, anchor, and plug are determined consistent with magtutohydrodynamic (MHD) equilibrium and stability. These values of beta are coupled to the plasma physics through an external feedback loop. 
MAGNE'T

Central-cell and end-cell magnets are modeled by the magnet module of TMRSC. Magnet designs must be consistent with limitations of current density, maximum field, cryostability, and fluence for various conductor types. Coil-case thickness is based on allowable stress. Cost for each magnet is also estimated by this module.

NEUTRON SOURCE (AUXILIARY PHYSICS)

The neutron source module of TMRSC calculates the neutron source strength in the end cells (needed to determine shielding requirements); and frequency requirements for the plasma rf heating and drift pumping systems lelectroncyclotron resonati heating (ECRH), lower-hybrid resonant heating (LHRH), ion-cyclotron resonant heating (ICRH)]. This module also determines the magnetic flux, heat $f l u x$, magnetic-field profile, and net electrical power associated with the direct converter.

\section{LRECT CONVERTER}

The direct converter is based on a gridless design, and consists of four concentric collectors at each end. Radial drift pumping forces most of the ions in the plasma onto the halo, which is kept at ground potential by the two outer collectors. Electrons flow axially through the middle of the magnet set and are deposited on the two inner collectors, which are biased on the order of $-100 \mathrm{kV}$. Direct electrical power is produced by the electrons; heat deposited by the ions and alphas can be recovered by a thermal cycle.

The direct converter module of iMRSC calculates the collector area required for each of the four regions based on a maximum energy flux allowed (input parameter). The electrical power produced, effective radii of the collectors, length of the direct converter, and the size of the enclosing vacuem tank are aiso calculated by this module. The thermal power is determined by the heat-transport module. Costs are computed based on collector area for each region, direct electrical power for inverting equipment, and vacuum pumping requirements. 


\section{PLASMA MEATING}

The plasma-heating module of ThRSC sizes rf heating or neutral heating systems to supply the required supplemental heating to the plasma in the central cell or end cell regions. The rf systems compute required circulating power, efficiency, cost, and component sizes consistent with available space for access and required power at the launcher. The negative-ion neutral-beam module computes the circulating power, efficiency, cost, and the number of sources and associated currents to deliver the required power to the plasma. Heatingrsystem-component characteristics, such as power supplies, amplifier, waveguide, launchers, and neutralizers are also determined by this module. Positive-ion heatitig systems are not curtently included in this module but may be added later.

The fI systems for drift pumping apfication are also included in this module. The purpose of the drift-pump system is to remove ions by the profess of induced radial drifts, which hove became trapped in the end cells as they pass to the potential peaks. There are two coils in each end to pump differcht groups of ions, and each is located where the radial extent of the plasma fn the double-ellipse fan transition is maximized (one berween the transition coil and the anchor coil, the other between the anchor coil and the plug cofl). This model is based on the MARS system and produces a perturbat tion field normal to the ambient $B$ field. The physics requirements of ion pumping speed, Erequency, and geometry are used to calculate the required $r$ frequency, the required current in the coils, and the number and width of individuat ariver Erequencies. The coil inductance and voltage are computed from the specified coil geometry, and the dissipated power is determined based on the $Q$ of the circuit. Ohmic losses and total power consumption are also calculated by this module.

VACUUM VESSEL

A vacuun vessel exterior to the solenoidal coils, end-cell $C$ coils, and direct converter is sized and costed by the vacuum-vesset module of TMRSC. 
The ac-power-system-code module of TMRSC calculates characteristic design and cost data for the electrical power systems reeded to operate the reactor. This module identifies and computes the cost for major equipment such as circuit breakers, switches, transformers, lightning arresters, diesel generators, load control centers, and power feeders. This module does not include the aubine generator nor the dc direct converter in the ens cells, but it does include the switch gear and dc to ac inverters that interface with the main substation. An electrical power summary is also generated by this. module.

\section{MAGNE'T ELECTRICAL}

The magnet electrical module of THRSC computes design and cost data for the power supplies and cail protection equipment of the central cell and end cell magnets. Specifically, design and cost data for power supplies, bussing, load centers, dump resistors, dc current breakers, and associated local controls and instrumentatiou are determined by this module.

INSTRUMENTATIION AND CONTROL (I\&C)

The IEC module of TMRSC determines the costs of process I\&C, plasma diagnostic instrumentation, data transmission, data processing, and consolez located is the control building. The cost of each I\&C process and diagnoutic includes both hardware and software.

In this module, IdC are defined as the supervisory control and data system located in the main control building, plus the associated data links tc local I\&C. This module does not include the local process control and instrur mentation located in the proximity of the reactor vault.

MAINLENANGE EQUIPLENT

'he maintenance equipment module of lMRSc consists of a compiled list of reactor cell and hot cell equiptrent with unit costs. The user chooses the appropriate equipment for a particular device configuration from the 
comprehensive listing. The equipment either scales with reactor pararueters or is fixed in size and cost.

FACILITY

The facility module of TMRSC estimates the size and cost of buildings based on reactor size, thermal power from the blanket and other components, gross electrical power output, and number and capacity of each turbine generacor. Facilities considered include reactor building, hot-cell building, critium building, steam-generator building, power-supply building, cryogenics building, and central building. Also, the costs of radwaste systems equipment, miscellaneous reactor and balance of plant equipment, and special matertais are estimated in this module.

CODE STATUS

Approximately $80 \%$ of the modules have been received from the various authors within the fusion community who are contributing to this ejfort. The integration effort is approximately $20 \%$ complete. The target date for the first version of the integrated systems code is October 1, 1984. 


\section{REFERENCES}

1. B. G. Logan, Mirror Advanced Reactor Study (MARS) Final Report, Lawrence Live*mure National Laboratory, Livermore, CA, UCRL-53480 (1984).

2. C. D. Henning et al., Fusion Power Demonstration: Baseline Report, Lawrence Livermore National Laboratory, Livermore, CA, UCID-19975 (1984). 



\section{Appendix}

A MIRROR MACHINE WITH OCTUPOLE END PIUGS

$\lambda-1$ 
TO: $\quad$ Distribution

FROM: John Perkins

SUBJECT: A Mirror Ignition Machine With Octupole Erif Plugs

\section{Sumary}

For the past year or so, the Fusion Power Demonstration (FPD) project at LLNL has been developing the definition of a mirror ETR with end cells based on the MARS configuration. A major goal of the project has been to def ne the minimum iength for ignition of an optimized (i.e. lowest cost) system. However, due to the long transition lengths of the MARS-mode endcel1 configuration coupled with updated Fakker-Planck calculations of endcell trapping rates, a mirror ETR based on the MARS magnet configuration cannot achieve ignition with a central cell length less than about $90 \mathrm{~m}$.

Accordingly, during the past month, effort has been devoted to FPD with an octupole end plug. Initial results from these activities look very encouraging and optimization studies indicate that the octupole version of FPD will achieve ignition with a central cell length of $\imath 30 \mathrm{~m}$. With each end plug magnet length of only $28 \mathrm{~m}$ and $x$ total machine length of $263 \mathrm{~m}$, this suggests that a mirror ignition device operating with octupole end-plugs is potentially capable of being sited in building 431 . The principle parameters of both the MARS-mode and octupole-mode of FPD are compared in Table 1 . Note that the total machine length for the ocutpoie-mode is oniy $\sim 63 \mathrm{~m}$ compared with $2147 \mathrm{~m}$ for the MARS-mode. 
Table 1. A comparison of the FPO ignition machine with MARS and octupole end pligs. Bath are minimum length machiecs. (A more detailed parameter list for the octupole-mode is given in Tabie 2).

\begin{tabular}{|c|c|c|}
\hline & MARS-node & Octupole-mode \\
\hline Center cell lengtin ${ }^{a} L_{c}(m)$ & 90 & 30 \\
\hline End cell magnet length (m) & 19.4 & 8 \\
\hline Total machine length $(m)$ & $\approx 147$ & $\sim 63$ \\
\hline Central cell plasma radius $r_{c}(m)$ & 0.45 & 0.45 \\
\hline Fusion Power (MW) & 479 & 156 \\
\hline $\mathbf{Q}$ & 36.7 & 7.0 \\
\hline & 22.2 & $<1$ \\
\hline Neutran wall loading $\left(\mathrm{MW} / \mathrm{m}^{2}\right)$ & 1.0 & 1.0 \\
\hline Total ECRH power ${ }^{\mathrm{C}}$ & 11.4 & 21.7 \\
\hline \multicolumn{3}{|c|}{ 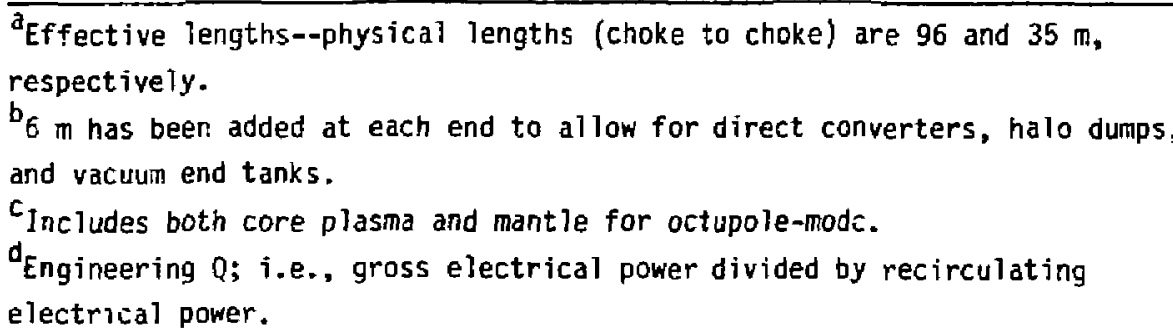 } \\
\hline
\end{tabular}

The two big advantages of the octupole version of FPD are of course cheaper end cell magnets and shorter ignition lengths. The one big disadvantage is access. Within this compact end piug system, re require the integration of seven major subsystems, namely (1) core-plasma barrier ECRH, (2) core-plasma potential peak ECRH, (3) mant le ECRH (4) sloshing ion beams, (5) drift pump coils, (6) inner recirculating octupole cails, and (7) neutron shielding. In this regard, future studies may indicate that the minimum length for ignition may not be the principle design requirement. Rather access conditions in the octupole may dictate the central cell ignition lengt, by defining a minimum volume end-cell magnet configuration. 


\section{Paraneter Scaling Studies}

Initial parametric scaling studies have been performed on the octupole version of FPO. Here we are interested in the optimum central cell plasma radius $r_{c}$ and plug beta $B_{p}$ which result in the shortest length ignition machine, while minimizing the total plug ECRH power (i.e. ECRH power for both the core plasma and the mantle). Minimizing the ECRH power is an important consideration in the octupole plug where space is at a premium.

The TMR power balance code "TMRBAR" was employed for these scaling studies. The code has been updated to model the hot electron mantle. ECRH power requirements are comrsted for both the plug core plasma and the outer mantle region.

Requirements on beta profiles across the core and mantle regions are determined oy satisfying line-averaged interchange stability requirements, thus requiring details of field curvatures through the certral cell and end cells.

The following sections present an overview of the major features of the octupole scaling studies.

\section{Effect of Central Cell Plasma Radius on Ignition Length}

Fjgure 1 snows the minimum central cell length for ignition $L_{c}$ as a function of the central cell plasma radius $r_{c}$ for the octupole version of FPD; the beta of the plug core $p l a s m a\left\langle B_{p}\right\rangle$ is shown as a parameter. A central cell field of 2.5 T was used in all these parametric trades because analysis of the previous MARS-mode FPE configuration showed that $L_{c}$ minimizes for a central cell field of $22.5 \mathrm{~T}$ and we expect this optimum field to be essentialiy independent of end cell type.

From $F_{i y} 1$ we see that, at any given $\left\langle\beta_{F}\right\rangle$, there is an optimum value of $r_{c}$ around $0.55 \mathrm{~m}$ for which the central cell ignition lengt $n$ is minimized. This can be ascribed to the fact that at larger values of $r_{c}$, end cell trapping rates drive the system to longer values of $L_{c}$, while ac smalier ${ }^{\prime} c$ a $1 r$ 'er $L_{c}$ also results due to reduced alpha particle energy deposi : on in the center cell. Now as $r_{c}$ increases at constant $B_{c}$, the cericral cell flux $\left(\pi r_{c}^{2} b_{c}\left(1-\left\langle\beta_{c}\right\rangle\right)^{1 / 2}\right)$ increases accordingly. 


$$
\begin{aligned}
& \text { Fig. 1. VARIATION OF } \\
& \text { MINIMUM LENGTH FOR } \\
& \text { IGNITION WITH CENTMLL } \\
& \text { CELL PLASMA RAONS }
\end{aligned}
$$

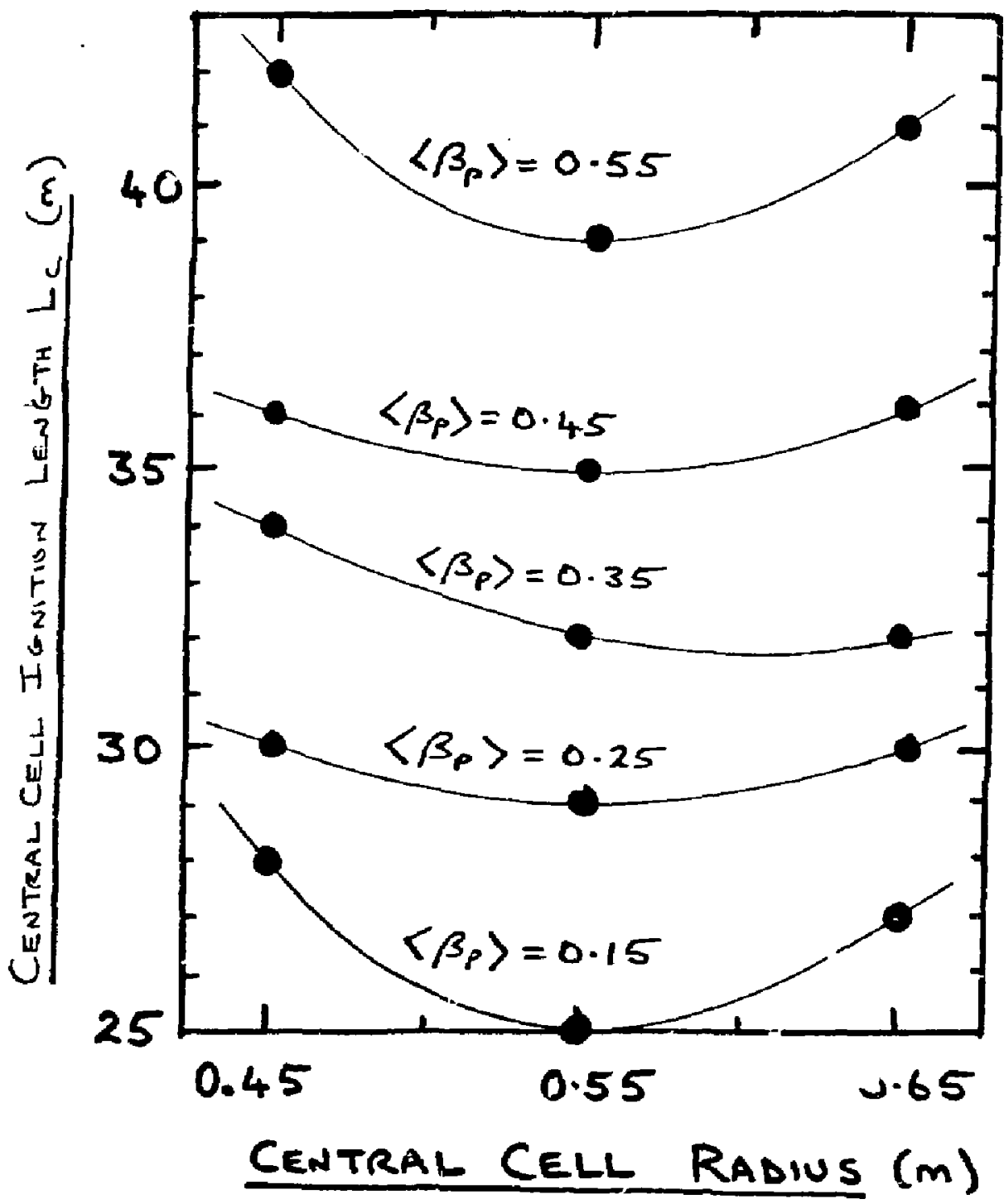


l'apping this flux through the end-cell magnets with conductor fields maintained near maximum desirable values, necessitates larger end-cell coil radii. Figure 2 illustrates the dependence of the FPD octupole magnet dimensions on the central cell plasma radius. Maintenance of a given end-cell mirror, atio with larger coil radij requires larger mirror lengths (analogous to solenoidal ripple where a constant $\triangle B / B$ is obtained for a constant ratio of solenoid radius to solenoid spacing). However, iarger end cell mirror lengths result in longer end cell trapping lengths (i.e. the length between the central cell mirror peak and the end cell potential peak). This, in turn, results in correspondingly larger end cell trapping rates. Since central cell ignition requires that alpha heating essentially supports the radial losses incurred by trapping in and pumping out of the end cell region, central cell lengths determined on $y$ by end-cell trapping would minimize for very smalt centrai cell radii.

Unfortunately, our relatively low $E_{c}$ of $2.5 T$ and high $\left\langle\beta_{c}\right\rangle$ of $60 \%$ imply large alpha particie orbits. Hence, a decreasing central cell radius results in a greater fraction of the fusion alpha energy escaping the plasm:a and being deposited in the halo. Figure 3 illustrates this effect where the fraction of the central cell alpha power deposited in the halo outside the plasma is platted as a functici of a parameter $p$ which incorporates the dependence of $r_{c}, B_{c}$ and $\left\langle B_{c}\right\rangle$ as shown. As will be shown in Sec. 4 later, the opt imum version of $F P D$-octupale has $r_{c}=0.45 \mathrm{~m}$. It is interesting to note that at this plasma radius, our ETR attains its "optimized" ignition length by discarding $220 \%$ of its centra] cell alpha heating power to the halo!

\section{ECRH Power in the Mantie}

Now from Fig. 1, with $\left\langle\beta_{p}\right\rangle=0.15$ and $r_{c}=0.55 \mathrm{~m}$, a minimum length for ignition of $25 \mathrm{~m}$ is theoretically achievalle. However, it is also necessary to assess the total ECRH requirements ( $P_{E C R H . c o r e}+P_{E C R H, m a n t l e}$ ) in the end cell. Although for a given $\beta_{p}$ and $r_{c}$, the ECRH power requirements for the core plasma are fixed from power balance considerations, we are somewhat free to select the maritle hot electron energy to minimize the mantle ECRH power. This is so since the MHD interchange criterion only defines the beta profile through the mantle allowing hot electron energy and corresponding density to be selected externally. 


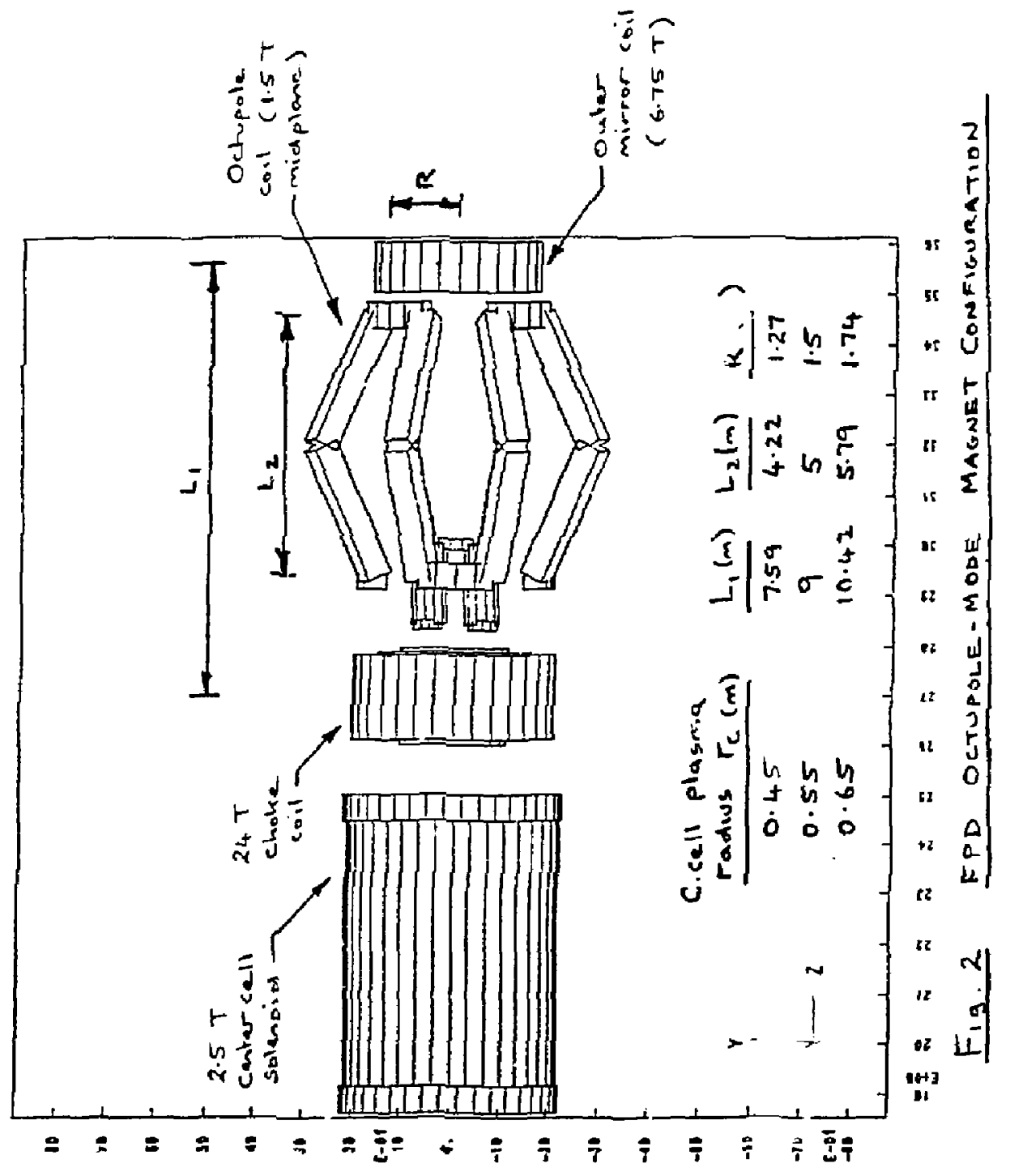




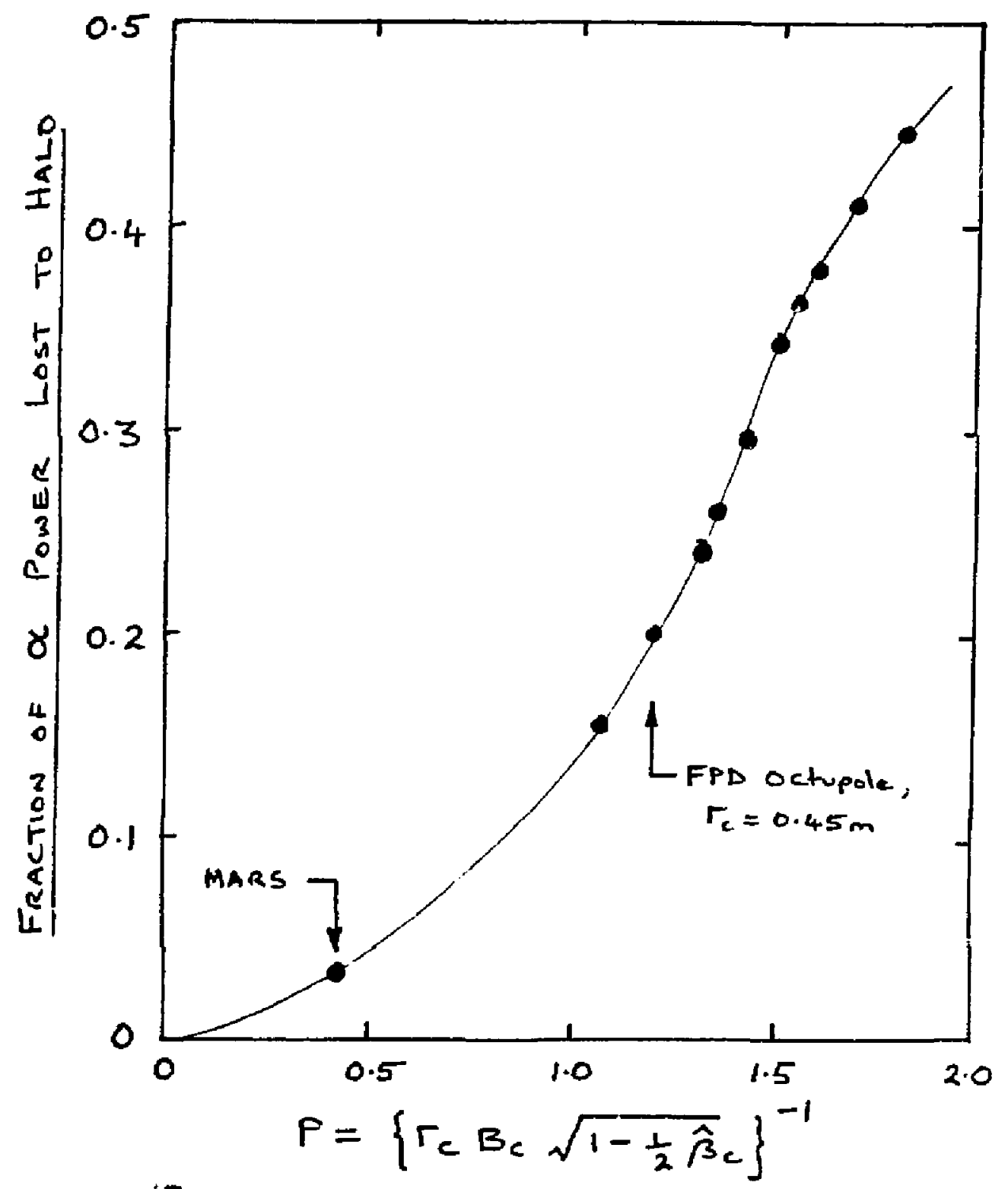

$r_{c}=$ c.cell plasma radius, $B_{c}=c$ cell l vac. field $\hat{\beta}_{c}=$ c. cell on-axis leta.

Fig. 3 EFfEct of Finite ALPHA Gyroradil ON ALPHA POWER LOSS TO HALO

A-8 
As an illustration, Fig. 4 plots the mantie ECKH power as a function of the mantle not electron energy for three values of plug Deta $\left\langle\beta_{p}\right\rangle$ in the core plasina; this figure is for the mant le oeta conditions determined by a center cell radius of $0.45 \mathrm{~m}$. As expected, a hot electron energy $E_{\text {hot }}$ can se selected to minimize $P_{E C R H}$, mantle; low values of $E_{\text {hot }}$ result in ligh $P_{E C R H, m a n t l e}$ due to scattering and drag losses while nigh values of $E_{\text {not }}$ also result in higher ECRH power due to synchrotron losses.

Therefore, for each central cell radius $r_{c}$ and each plug beta $\left\langle\xi_{p}\right\rangle$ in Fig. ?. We can now select a mantle hot electron energy to minimize the total end cell ECRH power. This minimized power is shown in Fig. 5 as a function the radius $r_{c}$ of the central cell plasma with $\left\langle b_{c}\right\rangle$ as a parafeter.

\section{FPD-octupole Baseline Selection}

Selecting the FPD-octupole baseline via Figs. 1 and 5 jllustrates tr. Catch-22 situation, i.e. a low plug oeta $\left\langle\beta_{p}\right\rangle$ resuits in a short central cell length for ignition in Fig. I but requires a high tatal ECRH power in the end cell in Fig. 5. For example, with $r_{c}=0.55 \mathrm{~m}$ ana $\left\langle b_{p}\right\rangle=0.15$, an ignition length of $25 \mathrm{~m}$ is abtained. However, this requires $268 \mathrm{Mr}$ of ECRH power with resulting low system $Q(22.7)$ and ECRH access problems in the octupole plug.

Accordingly, our current baseline employs a central cell radius of $0.4 \mathrm{sm}$ with $\left\langle\right.$ prp $\left._{p}\right\rangle=0.25$. Although this results in a larger minimum ignition length of $30 \mathrm{~m}$, the total ECRH power requirements are only $\sim 22 \mathrm{MW}$.

Table 2 provides an extended list of system parameters for the FPD ocutupole. Note that the neutron wall loading is $7 \mathrm{mH} \mathrm{m}^{-2}$ which is reasonably respectabie for blanket and technology testing. Note also that the system $Q i ;$ only 7 , an indication that the system is capable of igniting with a short central cell length and, therefore, small total fusion power.

It snould be noted that, unilike the MARS-mode of FPD, the octupole version with these parameters is unlikely to geilerate net electrical power, having an engineering $Q$ (gross electrical power divided by recirculating electric power) of less than unity. By contrast, because of the long minimum ignition length requirement in the MARS mode of FPD, it was impossible to obtain a baseline design with $q_{\text {eng }}$ less inan two! 


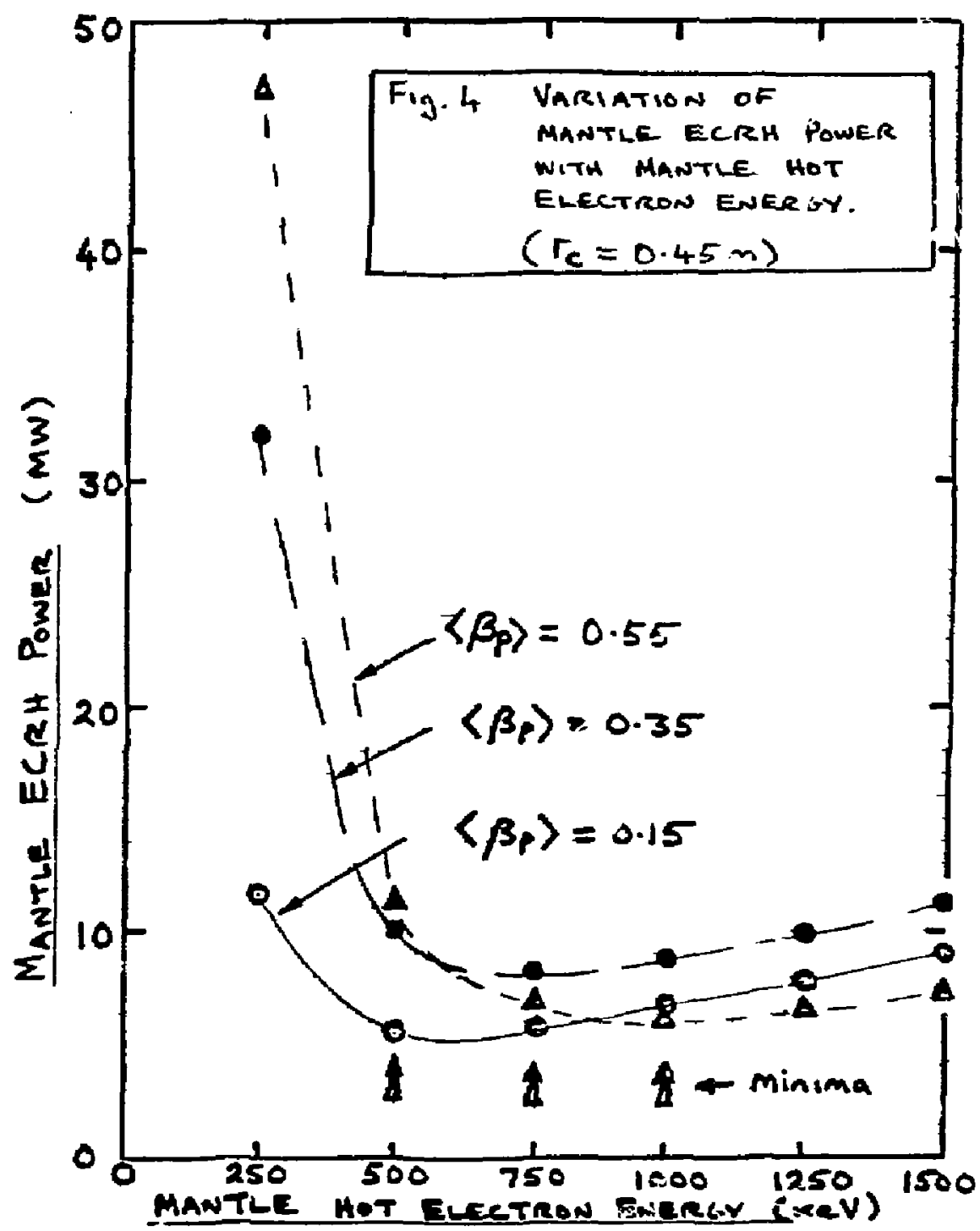

$A-10$ 


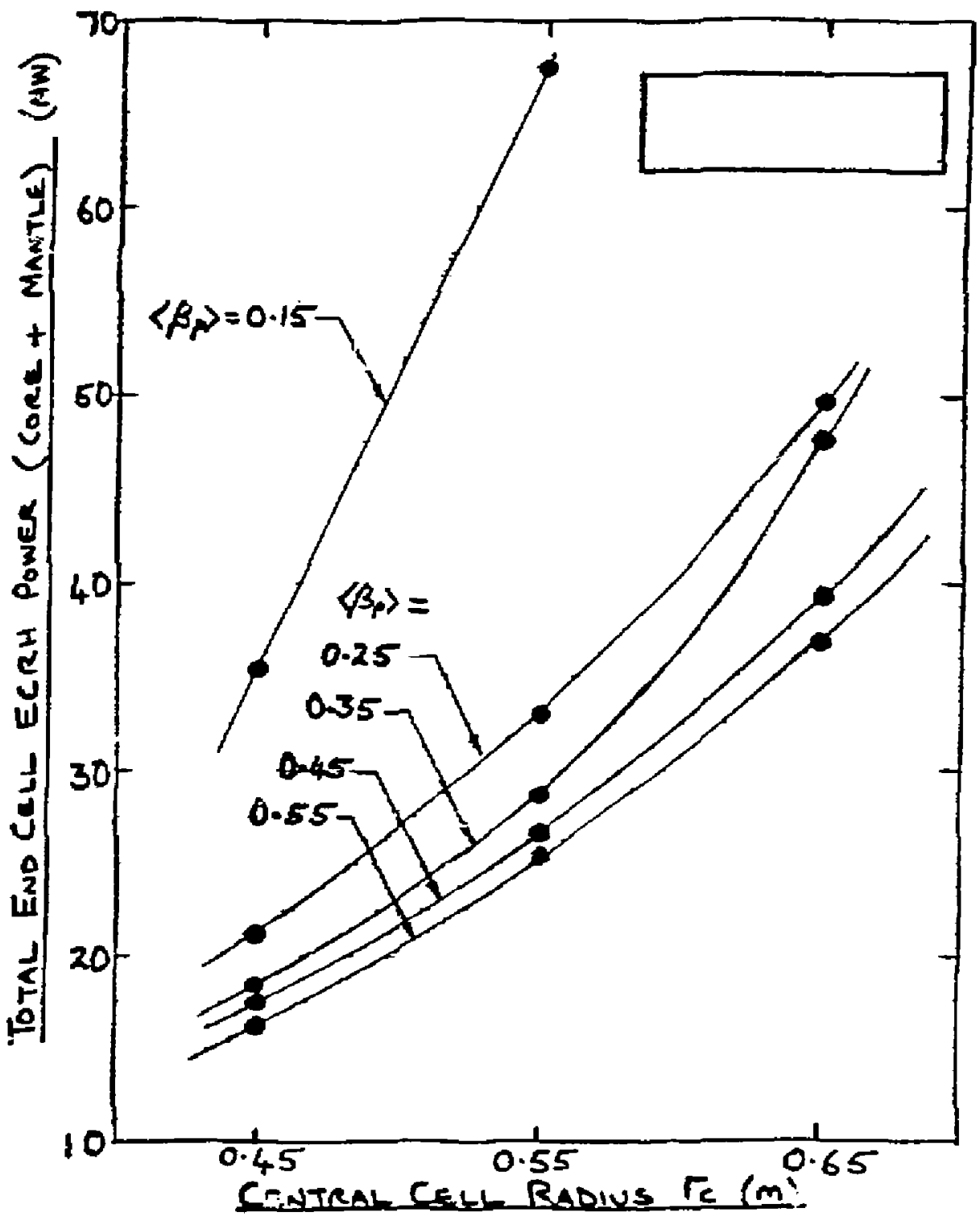

Fig. 5 VARIATION OF TOTAL
END CELL ECRH POWER WITH CENTRAL CELL plasma radius.

A- II 
Table 2. Pre.iminary paraneters for FPD-octupole.

General

Fusion power (Mw)

lieutron wa]l ijading $\left(\mathrm{MW} / \mathrm{m}^{2}\right)$

Q (overall)

Q (core piasina only)

Qeng

Required cold fuelling curreit (A)

Uverali macnine ?ength (m)

1.0

7.0

10.5

$<\mathrm{T}$

102

$\imath 63$

\section{Central Cell}

Effective lerizth (m)

30

Physical length (m)

$\mathrm{B}_{\mathrm{C}}(\mathrm{T})$

PYasma radius (m)

35

First wali radius $(m)$

12.5

$\left\langle\mathrm{H}_{\mathrm{C}}\right\rangle$

0.45

0.67

0.6

Choke coil

Bchoke ( $T$ )
Coif inner radius (m)
plasma radius (m)

End cell

Tota end cel] magnet length ${ }^{b}$ (m)

28

Core ECRH power, barrier (MW)

13.8

Core ECRH power, potential peak (Mis)

0.46

Mant le ECKH power (Mir)

7.4

Sloshing ion beam energy (keV)

475

Slosning ion beam power (Mir)

0.67

Total heating power (MH)

22.3

<bp

0.25

$\left.<s_{\operatorname{mant}}\right] \mathrm{e}^{>}$

0.45

Mantle not electron energy (keV)

750

End cell trapping current (A)

79.2

achoke to choke.

Choke cail to outer mirror. 
Clearly, a net power producing ETR based on the octupole could be obtained by simply increasing the central cell length in the current design above $30 \mathrm{~m}$ until the fusion powter is large enough to give $Q_{\text {eng }}=1$. However tnis is not the most desirable method of achieving this result. In fact, racher than allowing the fusion power, wall loading and $Q$ to float (downwards) to achieve an absoiute minimum length, minimum cost, ignition machine as we nave cone above, we would fix the fusion power at some reasonably high level where we would be confident of obtaining Qeng 21 ano solve for the corresponding length. In this latter case, the optimum central cell field and plasma radius would differ from the $2.5 T$ and 0 ij values above, and the res. ${ }^{\top} t i n g$ macnine would be considerably more expensive than the present minimum lengtr ignition baseline. Such considerations are being ipplied to the scaling scudies for MINIMARS now in progress where we require $Q_{\text {eng }}>4$.

hiork is continuing on the FP[1-octupole design in tnre. main areas, namely (1) improvf plasma engineering and magnetics moaeling, (2) integration of plasma heating systems in the octupoie plug and (3) evaluation of systen costs. 
YIN-YANG SHIELDING

$\leftarrow$

$A-14$ 
MEMORANDIJM

LLNL-FPD-84-45

T0: FPO Distribution 2

SUEJECT: Yin/Yang Shielding for the FPD

A series of calculations have been done on shielding for the Yin/Yaris caits in the FPD. The actual configuration for a typical calculation is detailed in Figure 1. The calculations were done on the LASL code ONEDANT in $7-D$ slah geometry with the data file from Lajla El-u..ebaly at the University of Wisconsin.

This set of calculations differs from previous ones we have done in that, within a given thickness of snield, performance was optimized as a function of thickness of $\mathrm{TiH}_{2}$ substituted for part of the in shield at the back. Table l shows the numerical results of these calculations. Fiyures 2-4 show the results of this optimization, in graphical form, for shiels thicknesss of $15 \mathrm{~cm}, 30 \mathrm{~cm}$ and $45 \mathrm{~cm}$. Coupled with the $14.3 \mathrm{~cm}$ thickness of case and insulation to the super conducting windings, these shields qive total distance to the plasma chamber of $29.3 \mathrm{~cm}, 44.3 \mathrm{~cm}$ and $59.3 \mathrm{~cm}$ for the three. The caiculations were done assuming a first wall neutron loading of $7 \mathrm{Mk} / \mathrm{m}^{2}$.

Broad optima were found at the following splits between $W$ and $\mathrm{TiH}_{2}$ :

$\begin{array}{ccc}\text { Shield Thickmess } & \text { W Thickness } & \mathrm{TiH}_{2} \text { Thickness } \\ 15 \mathrm{~cm} & 11 \mathrm{~cm} & 4 \mathrm{~cm} \\ 30 \mathrm{~cm} & 24 \mathrm{~cm} & 6 \mathrm{c} \\ 45 \mathrm{~cm} & 41 \mathrm{~cm} & 4 \mathrm{~cm}\end{array}$


Performance indicators $f_{c} ;$ these three cases are tabulated in Tables 2 ar. 3 and are plotted in Figures 5 and 6 .

While in this particular configuration, substitution of the $\mathrm{W}$ by $\mathrm{TiH}_{2}$ clearly reduces the neutron fluence for energies over $0.1 \mathrm{Mev}$, it does 1 ittle to mitigate the nuclear heating. In order io investigate the possibility of helping in this area, another several calculations were run in which some of the $t$ lingsten was removed and a comparable thickness of pb was added at the back $0:$ the shield. Table 4 lists the results. While the total nuclear heating can be reduced in this why, other important parameters rise. He will need to consider the entire system performance to detemine the optimum shield.

Finaliy, Table 5 shows the distribution ai nuclear heating in the $5 c$ case, winding pack, and magnet itse?f for a typicil shield $(30 \mathrm{~cm}$ shield made up of $24 \mathrm{~cm} W$ anú $5 \mathrm{~cm} \mathrm{TiH_{2 }}$ ). It may be that Hel can be used for cooling in the case while HeII can be used in the winding pack and SC magnet itself. This should apprec iably affect the economics of the helium refrigeration system and r.ay shift the optimum to a higher nuclear heating level. 
Table 1. Performance Indicators

For Shield of $\mathrm{W} / \mathrm{TiH}_{2}$

\begin{tabular}{|c|c|c|c|c|c|c|c|c|}
\hline Shield & $\mathbf{W} / \mathrm{TiH}$ & ht $r_{i}$ & ht 9 & ht $t$ & HT $n$ & HT $g$ & HT T & $n$ fluence \\
\hline $15 \mathrm{~cm}$ & W & $7.6 \mathrm{el}$ & $4.4 \mathrm{e} 2$ & $5.2 e 2$ & $2.2 \mathrm{e} 3$ & $7.4 \in 3$ & $9.6 \mathrm{e3}$ & $5.4 \mathrm{e} 20$ \\
\hline $15 \mathrm{~cm}$ & $13 / 2$ & $5.9 \mathrm{el}$ & $4.2 \mathrm{e} 2$ & $4.8 \mathrm{e} 2$ & $1.8 \mathrm{e} 3$ & $7.9 e^{3}$ & $9.7 \mathrm{e} 3$ & $3.6 \mathrm{e} 20$ \\
\hline $15 \mathrm{~cm}$ & $11 / 4$ & $5.2 \mathrm{el}$ & 4. $3 \mathrm{e} 2$ & $4.8 e 2$ & $1.5 \mathrm{e} 3$ & $8.4 \mathrm{e} 3$ & 1.004 & $3.0 \mathrm{e} 20$ \\
\hline $15 \mathrm{~cm}$ & $\mathrm{TiH}_{2}$ & $6.2 \mathrm{e} 7$ & $5+9 e 2$ & $6.5 e 2$ & $1.7 e 3$ & $1.1 e^{4}$ & $1.3 \mathrm{e} 4$ & $3.5 \mathrm{e} 20$ \\
\hline $30 \mathrm{~cm}$ & $W$ & $7.6 \mathrm{e} 0$ & $4.7 \mathrm{el}$ & $5.4 \mathrm{el}$ & $2.2 \mathrm{e} 2$ & $7.8 e 2$ & $1.0 \mathrm{e} 3$ & $5.2 \mathrm{e} 19$ \\
\hline $30 \mathrm{~cm}$ & $27 / 3$ & $4.9 \mathrm{e} 0$ & $4.5 \mathrm{el}$ & $5.0 \mathrm{el}$ & $1.5 \mathrm{e} 2$ & $8.7 \mathrm{e} 2$ & $1.0 \mathrm{e} 3$ & $2.8 \mathrm{e} 19$ \\
\hline $30 \mathrm{~cm}$ & $26 / 6$ & $4.2 \mathrm{e} 0$ & $4.8 \mathrm{e}]$ & $5.2 \mathrm{el}$ & $1.2 \mathrm{e} 2$ & $9.4 \mathrm{e} 2$ & $1.1 \mathrm{e} 3$ & $2.4 e] 9$ \\
\hline $30 \mathrm{~cm}$ & $21 / 9$ & $4.2 \mathrm{e} 0$ & $5.2 \mathrm{el}$ & $5.6 \mathrm{e} 1$ & $1.7 e 2$ & $1.0 \mathrm{e} 3$ & 1. Je3 & $2.3 \mathrm{e} 19$ \\
\hline $30 \mathrm{~cm}$ & $\mathrm{JiH}_{2}$ & $7.9 \mathrm{e} 0$ & $1.0 \mathrm{e} 2$ & 1.lez & $2.0 \mathrm{e} 2$ & $1.9 \mathrm{e} 3$ & $2.1 e 3$ & $4.4 \mathrm{e} 19$ \\
\hline $45 \mathrm{~cm}$ & $W$ & $6.9 e-1$ & $4.4 \mathrm{e} 0$ & $5.1 \mathrm{e} 0$ & $2.0 \mathrm{el}$ & $7.2 e\}$ & $9.3 \mathrm{e} l$ & $4.6 e 18$ \\
\hline $45 \mathrm{~cm}$ & $41 / 4$ & $3.9 \mathrm{e}-1$ & $4.3 \mathrm{e} 0$ & $4.7 \mathrm{e} 0$ & $1.2 \mathrm{e} 1$ & $8.5 \mathrm{el}$ & $9.7 \mathrm{el}$ & $2.3 \mathrm{e} 18$ \\
\hline $45 \mathrm{~cm}$ & $36 / 9$ & $3.5 e-1$ & $5.0 \mathrm{e} 0$ & $5.4 \mathrm{e} 0$ & $9.7 \mathrm{eo}$ & $9.7 \mathrm{el}$ & $1.1 e 2$ & $2.0 \mathrm{e} 18$ \\
\hline $45 \mathrm{~cm}$ & $31 / 14$ & $4.0 \mathrm{e}-1$ & $6.0 \mathrm{e} 0$ & $6.4 \mathrm{e} 0$ & $1.1 \mathrm{el}$ & $1.1 \mathrm{e} 2$ & $1.2 \mathrm{e} 2$ & $2.2 \mathrm{e} 18$ \\
\hline $45 \mathrm{~cm}$ & $\mathrm{TiH}_{2}$ & $1.1 \mathrm{e} 0$ & $1.8 \mathrm{el}$ & $1.9 \mathrm{el}$ & $2.7 \mathrm{el}$ & $3.2 \mathrm{e} 2$ & $3.5 e 2$ & $5.9 e i 8$ \\
\hline
\end{tabular}

where: $h t n$ is peak SC heating due to neutrons ( $\mathrm{nwh} / \mathrm{cm}^{3}$ )

ht $g$ is peak $5 C$ heating due to gammas $\left(\mathrm{mw}^{2} / \mathrm{cm}^{3}\right)$

ht $t$ is sum of ht $n$ and ht $g$

HT $n$ is total SC coil \& case heating due to neutrons $\left(\mathrm{mw} / \mathrm{cm}^{2}\right)$

HT $g$ is total SC cail \& case heating due to gamas ( $\mathrm{mk} / \mathrm{cm}^{2}$ )

$H T T$ is sum of HT $n$ and HT $g$

$n$ fluence is the neutron fluence in the first $c m$ of $S C\left(n / \mathrm{cm}^{2}-F P Y\right.$ ) 
Table 2. - Performance Indicators

For Optimal Shields

\begin{tabular}{|c|c|c|c|c|c|c|c|c|}
\hline Shield & $\mathrm{W} / \mathrm{TiH}$, & ht $n$ & nt $g$ & ht $t$ & HT $\mathrm{n}$ & $\mathrm{HT} g$ & HT T & $n$ fluence \\
\hline $15 \mathrm{~cm}$ & $11 / 4$ & $5.2 e]$ & $4.3 \mathrm{e} 2$ & $4.8 \mathrm{e} 2$ & $1.5 \mathrm{e} 3$ & $8.4 \mathrm{e} 3$ & 1.0 e4 & $3.0 \mathrm{e} 20$ \\
\hline $30 \mathrm{~cm}$ & $26 / 6$ & $4.2 \mathrm{e} 0$ & $4.8 \mathrm{el}$ & $5.2 e 1$ & $1.2 \mathrm{e} 2$ & $9.4 \mathrm{e} 2$ & $1.1 e 3$ & $2.4 E] 9$ \\
\hline $45 \mathrm{~cm}$ & $41 / 4$ & $3.9 e-1$ & $4.3 \mathrm{e} 0$ & $4.7 e 0$ & $1.2 \mathrm{el}$ & $8.5 \mathrm{el}$ & $9.7 \mathrm{el}$ & $2.3 e 18$ \\
\hline
\end{tabular}

where: ht $n$ is peak SC neating due to neutrons $\left(\mathrm{m}^{\prime} / \mathrm{cm}^{3}\right)$

ht $g$ is peak SC heating due to gammas ( $m k^{\prime} / \mathrm{Cm}^{3}{ }^{3}$ )

$h t \quad t$ is sum of ht $n$ and $h t g$

HT $n$ is total SC coit \& case heating oue to neutrons (mk/ $/ \mathrm{cm}^{2}$ )

HT $g$ is total SC coil \& case heating due to gammas $\left(\mathrm{mh} / \mathrm{cm}^{2}\right)$

HT $T$ is sum of HT $n$ and HT $g$

$n$ fluence is the neutron fluence in the first $\mathrm{cm}$ of SC ( $\left.\mathrm{n} / \mathrm{cm}^{2}-F P Y\right)$

Table 3. - Performance Indicators

Radiation Dose to Polyimide (rads/FPY) and $O P A$ in $C U$

\begin{tabular}{|c|c|c|c|c|c|}
\hline Shield & $\mathrm{W} / \mathrm{TiH}_{2}$ & case & pack & Sicoil & DFA in $\mathrm{Cu}$ \\
\hline $15 \mathrm{~cm}$ & $11 / 4$ & $9.5 e] 1$ & $7.9 \mathrm{e})$ & $6.2 \mathrm{e} 11$ & $2.9 \mathrm{e}-1$ \\
\hline $30 \mathrm{~cm}$ & $24 / 6$ & $8.9 E 10$ & $6.0 \mathrm{e} 70$ & $5.5 \mathrm{e} 10$ & $2.4 e-2$ \\
\hline $45 \mathrm{~cm}$ & $41 / 4$ & $8.0 e 9$ & $5.4 \mathrm{es}$ & $4.9 \mathrm{eg}$ & $2.1 e-3$ \\
\hline
\end{tabular}

where: case is the dose in the poly between case ard winding pack

pack is the dose in the paly between winding pack and $5 C$

$S C$ coil is the dose in the poly in the SC coil

$D P A$ is the displacements per atom per FPY in Cu in SC coll 
Table 4. - Performance Indicators (Pb)

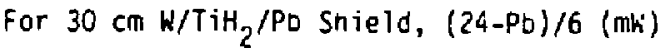

\begin{tabular}{lllllllll} 
Shield & $\mathrm{Pb}$ & $\mathrm{ht} n$ & $\mathrm{ht} \mathrm{g}$ & ht $\mathrm{t}$ & HT $\mathrm{n}$ & HT g & HT T & n fluence \\
\hline $30 \mathrm{~cm}$ & $0 \mathrm{~cm}$ & $4.2 \mathrm{e} 0$ & $4.8 \mathrm{el}$ & $5.2 \mathrm{el}$ & $1.2 \mathrm{e} 2$ & $9.4 \mathrm{e} 2$ & $1.1 \mathrm{e} 3$ & $2.4 \mathrm{e} 19$ \\
$30 \mathrm{~cm}$ & $2 \mathrm{~cm}$ & $4.9 \mathrm{e} 0$ & $3.9 \mathrm{el}$ & $4.4 \mathrm{e} 1$ & $1.4 \mathrm{e} 2$ & $7.2 \mathrm{e} 2$ & $8.7 \mathrm{e} 2$ & $2.9 \mathrm{e} 19$ \\
$30 \mathrm{~cm}$ & $4 \mathrm{~cm}$ & $5.8 \mathrm{e} 0$ & $3.8 \mathrm{el}$ & $4.4 \mathrm{el}$ & $1.7 \mathrm{e} 2$ & $6.9 \mathrm{e} 2$ & $8.6 \mathrm{e} 2$ & $3.6 \mathrm{e} 19$ \\
$30 \mathrm{~cm}$ & $6 \mathrm{~cm}$ & $6.9 \mathrm{e} 0$ & $4.1 \mathrm{el}$ & $4.8 \mathrm{e} 1$ & $2.0 \mathrm{e} 2$ & $7.5 \mathrm{e} 2$ & $9.5 \mathrm{e} 2$ & $4.5 \mathrm{e} 19$
\end{tabular}

where: ht $n$ is peak SC heating due to neutrons ( $\mathrm{mW} / \mathrm{cm}^{3}$ )

$h \dot{L} g$ is peak SC neating due to gammas ( $\mathrm{min} / \mathrm{cm}^{3}$ )

hit $t$ is sum of $h t h$ and $h t g$

HT $n$ is tota) SC coil \& case neating due to neutrons ( $\mathrm{mh} / \mathrm{cm}^{2}$ )

HT $g$ is total SC coil \& case heating due to gammas $\left(\mathrm{mb} / \mathrm{cm}^{2}\right.$ )

HT $T$ is sum of HT $n$ and HT $g$

$n$ fluence is the neutron fluence in the first $c m$ of $5 C\left(n / \mathrm{cm}^{2}-F P Y\right)$

Table 5. - Heating Distribution for $30 \mathrm{~cm}$ Shie1d, 24/6 Total heating in SC coil Assembly $\left(\mathrm{mh} / \mathrm{cm}^{2}\right.$ of coil)

\begin{tabular}{llll} 
Component & HT n & HT g & hT T \\
\hline Coil Case & $1.6 \mathrm{el}$ & $3.9 \mathrm{e} 2$ & $4.1 \mathrm{e} 2$ \\
Poly & $3.5 \mathrm{el}$ & $2.3 \mathrm{e} 1$ & $5.8 \mathrm{e} 1$ \\
Winding Case & $8.0 \mathrm{e} 0$ & $1.6 \mathrm{e} 2$ & $1.7 \mathrm{e} 2$ \\
Poly & $2.2 \mathrm{e} 1$ & $1.3 \mathrm{e} 1$ & $3.5 \mathrm{e} 1$ \\
SC coil (1 cm) & $4.0 \mathrm{e} 0$ & $4.8 \mathrm{el}$ & $5.2 \mathrm{e} 1$ \\
Rest of SC & $3.5 \mathrm{el}$ & $3.1 \mathrm{e} 2$ & $3.5 \mathrm{e} 2$ \\
TOTAL & $1.2 \mathrm{e} 2$ & $9.4 \mathrm{e} 2$ & $1.1 \mathrm{e} 3$
\end{tabular}

where: HT $n$ is nuclear heating due to neutrons $\left(\mathrm{mh} / \mathrm{cm}^{2}\right)$

HT $g$ is nuclear heating due to gammas $\left(\mathrm{mk} / \mathrm{cm}^{2}\right)$

HT $T$ is sum of HT $n$ and HT $g$ 


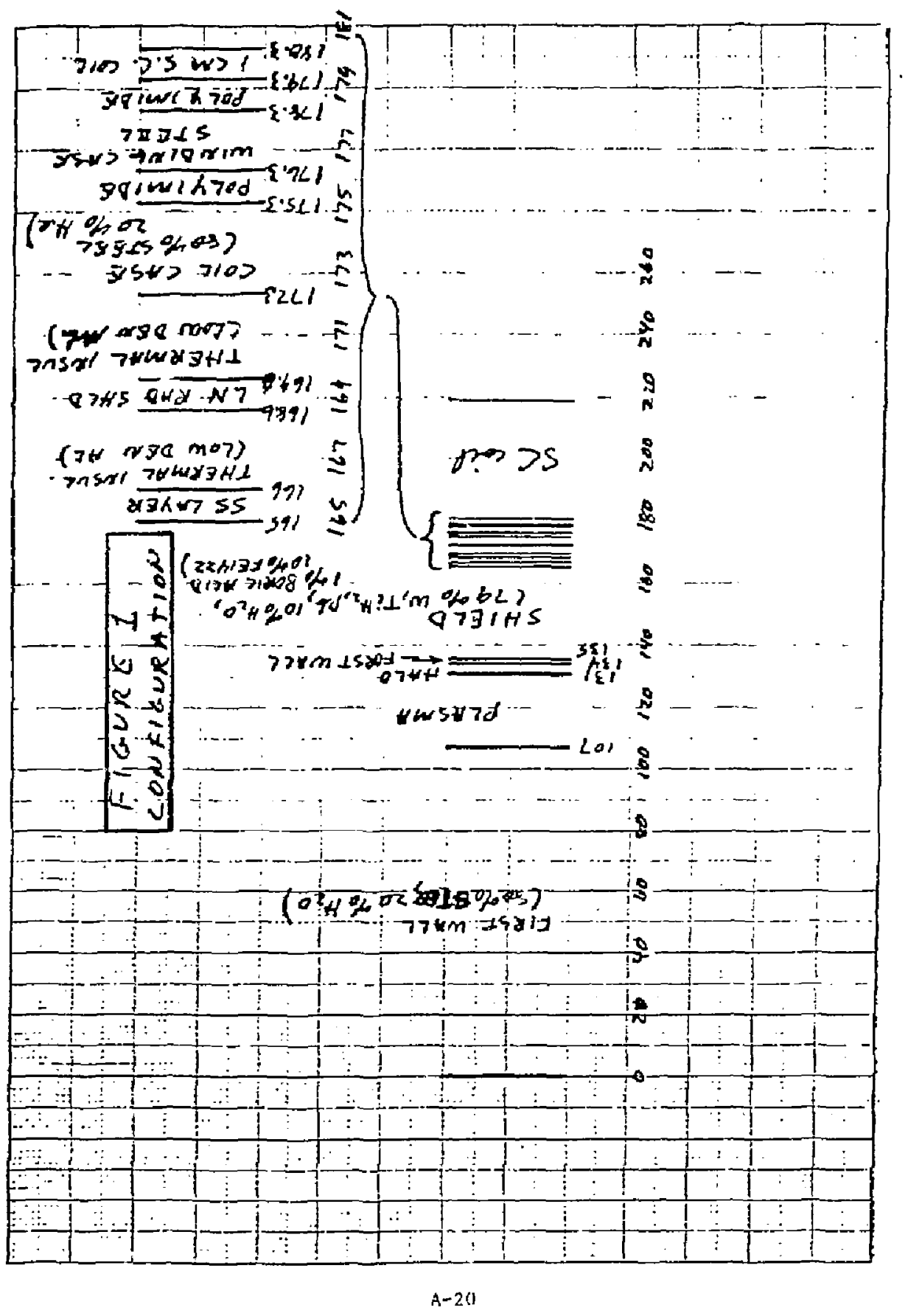

6 


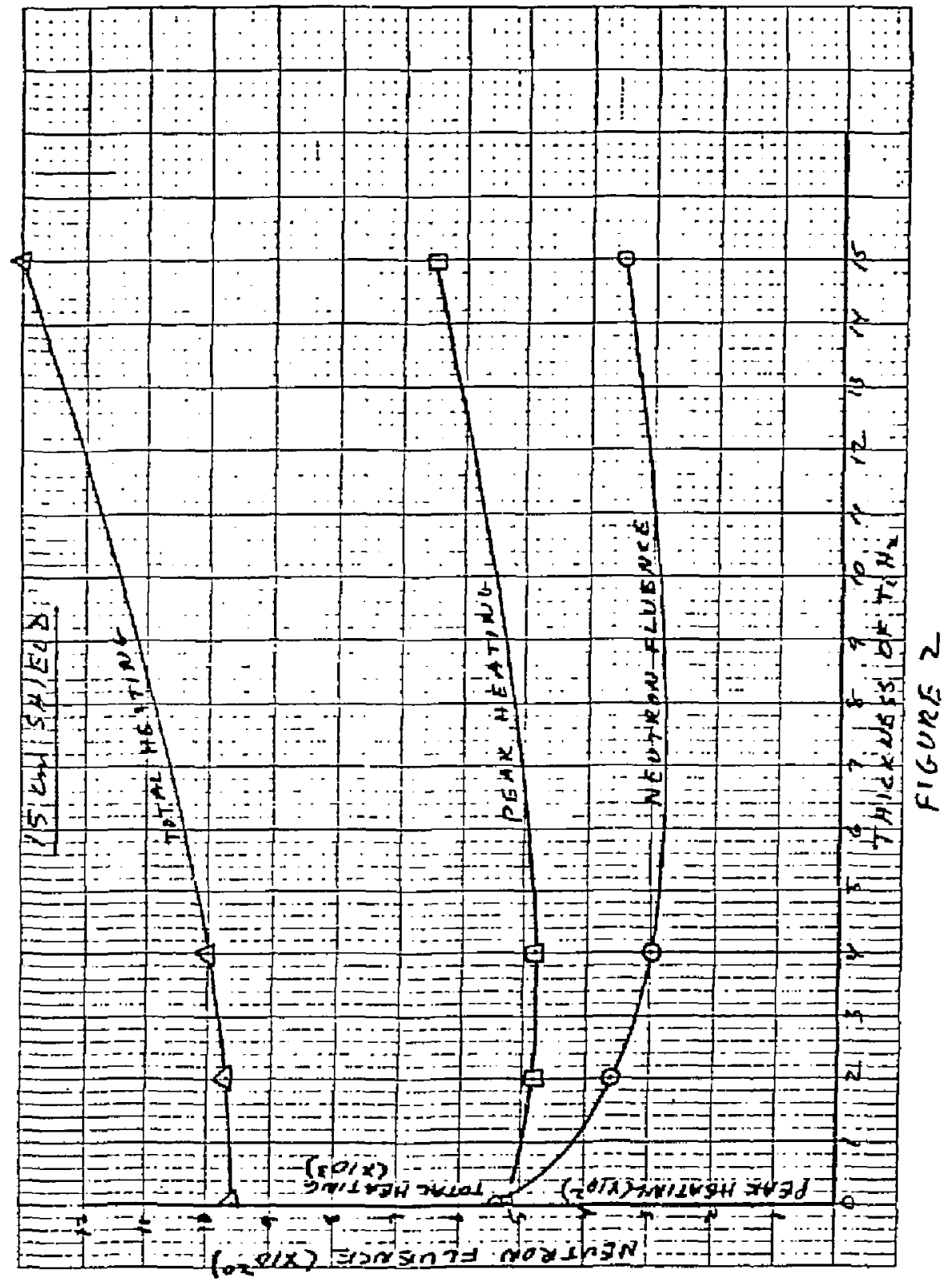




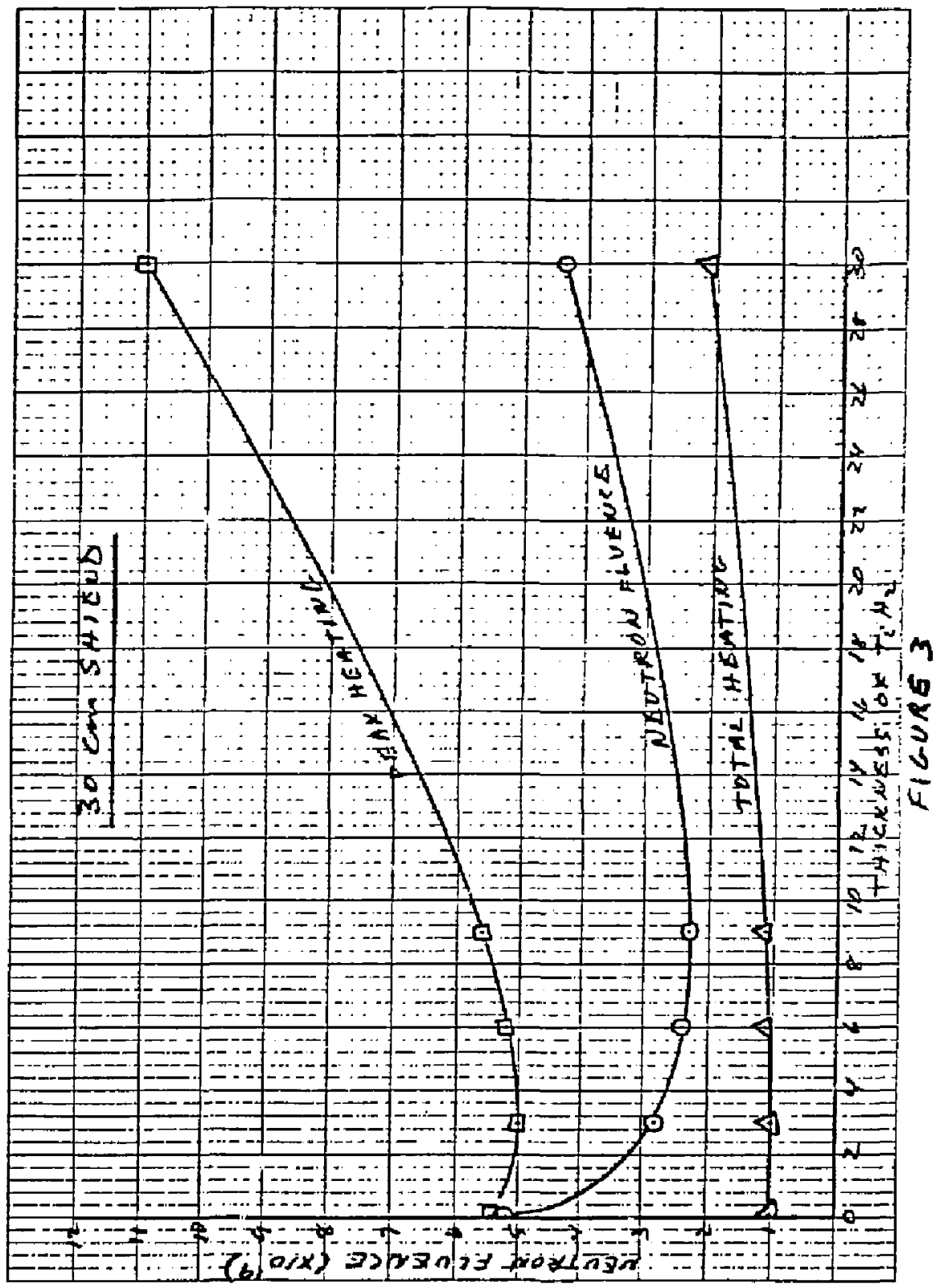




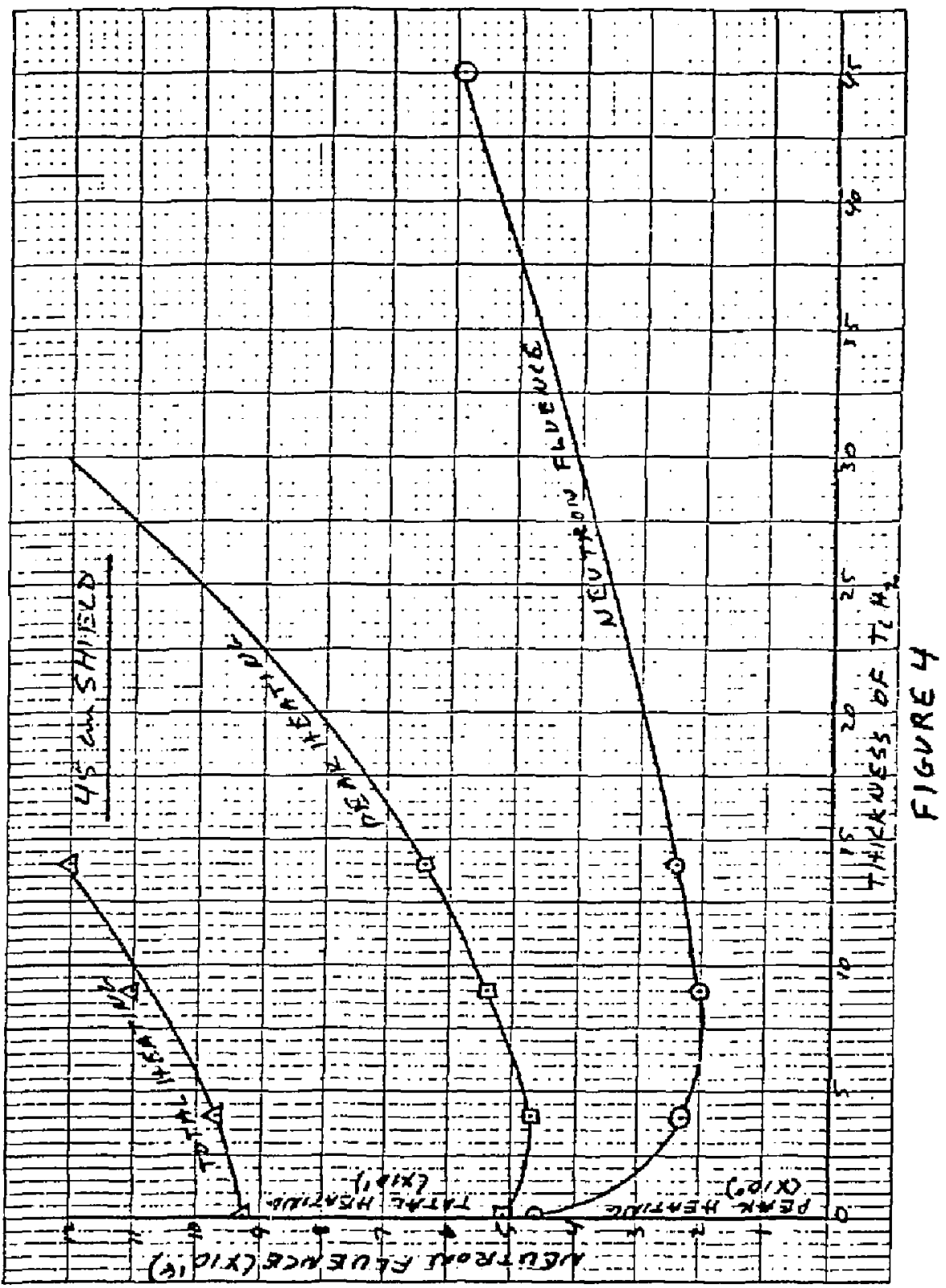




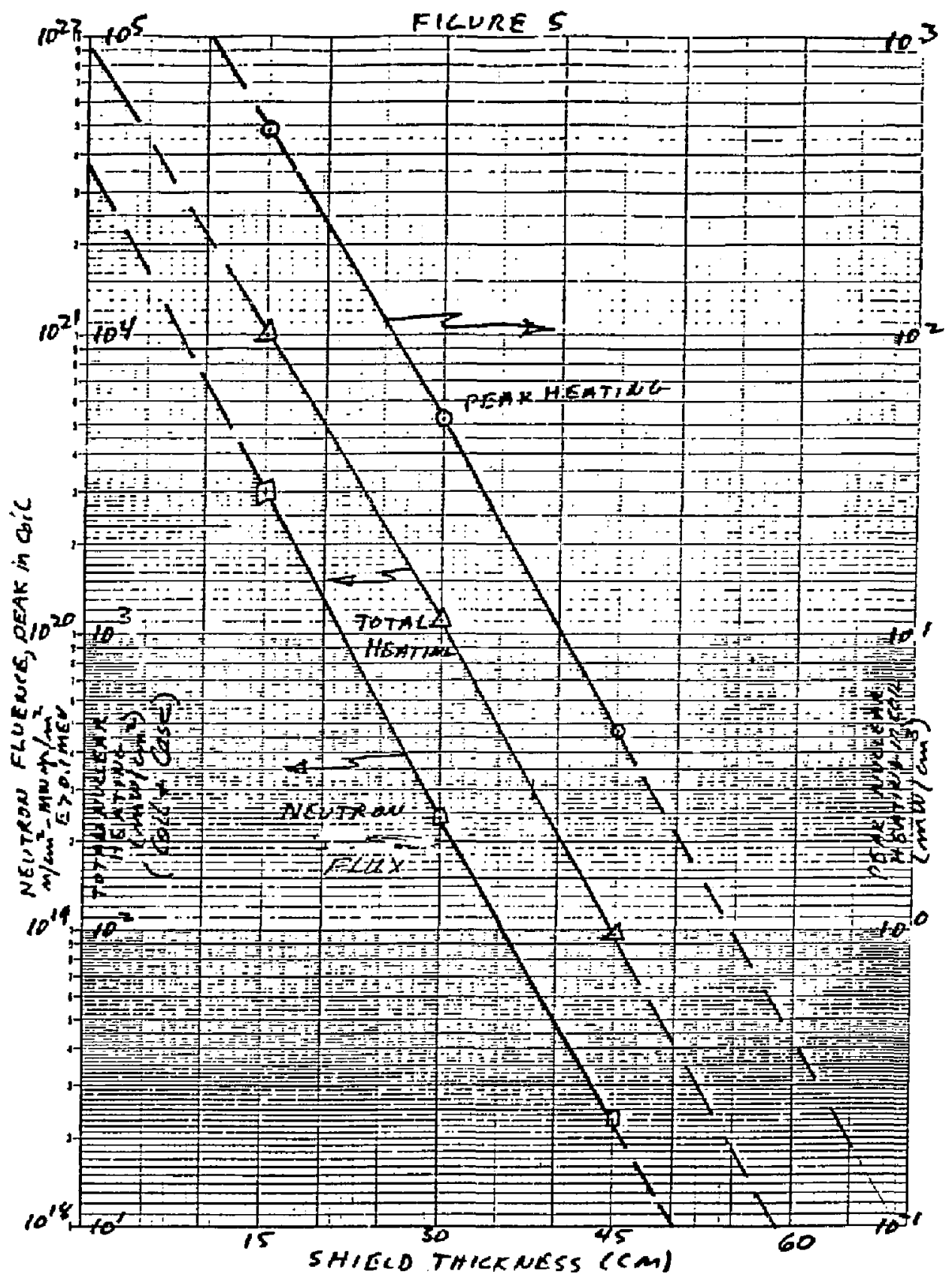

A-24 
FICURE 6

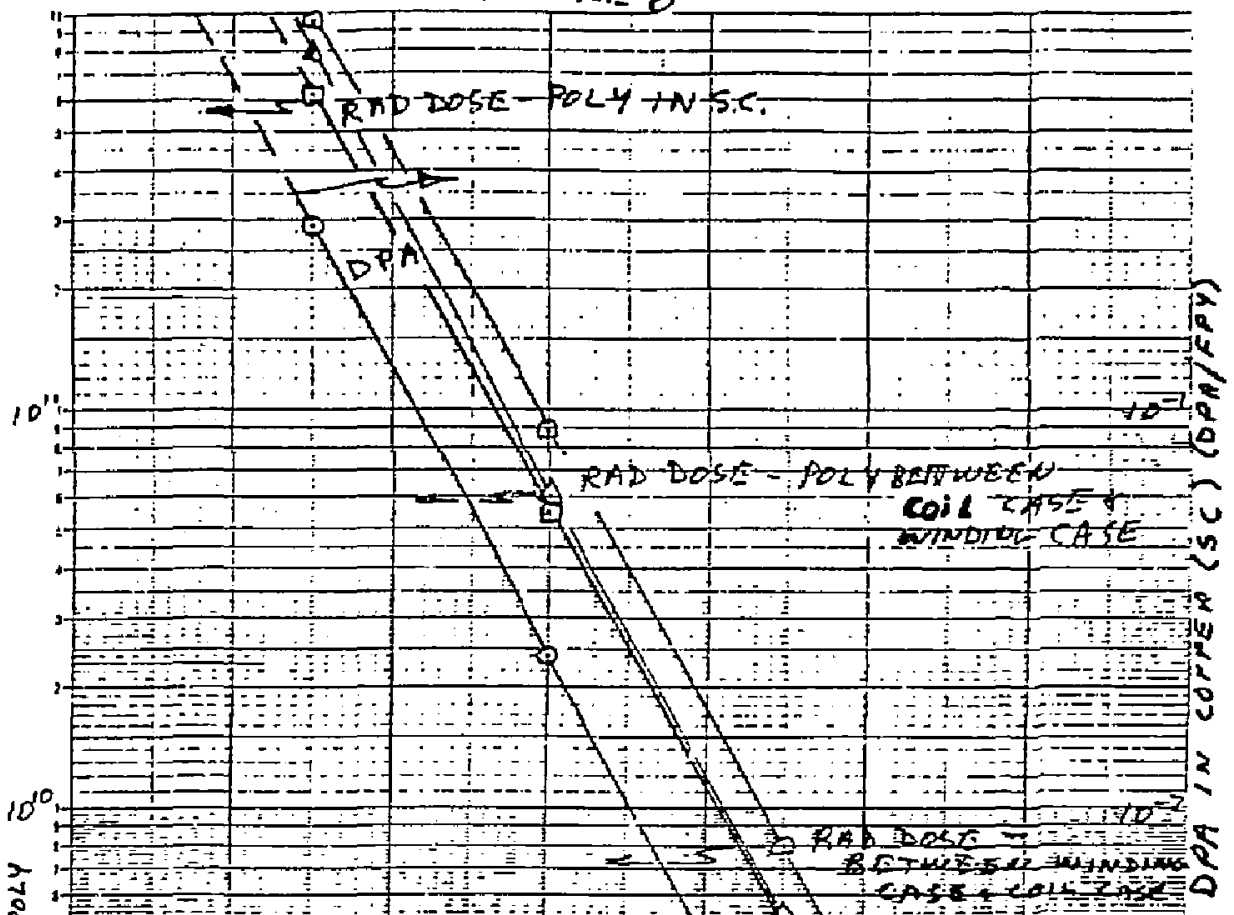

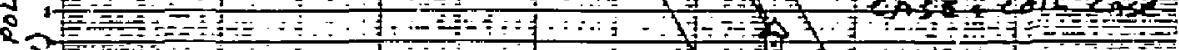

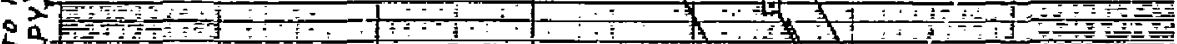

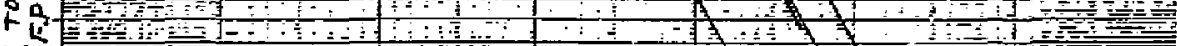

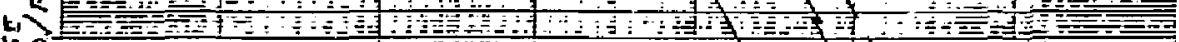

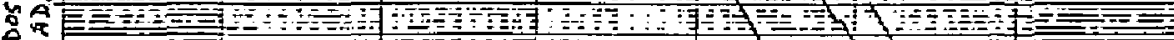

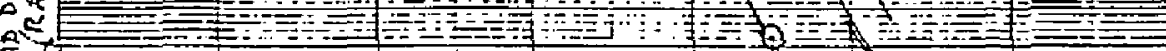

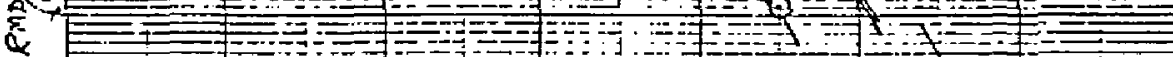

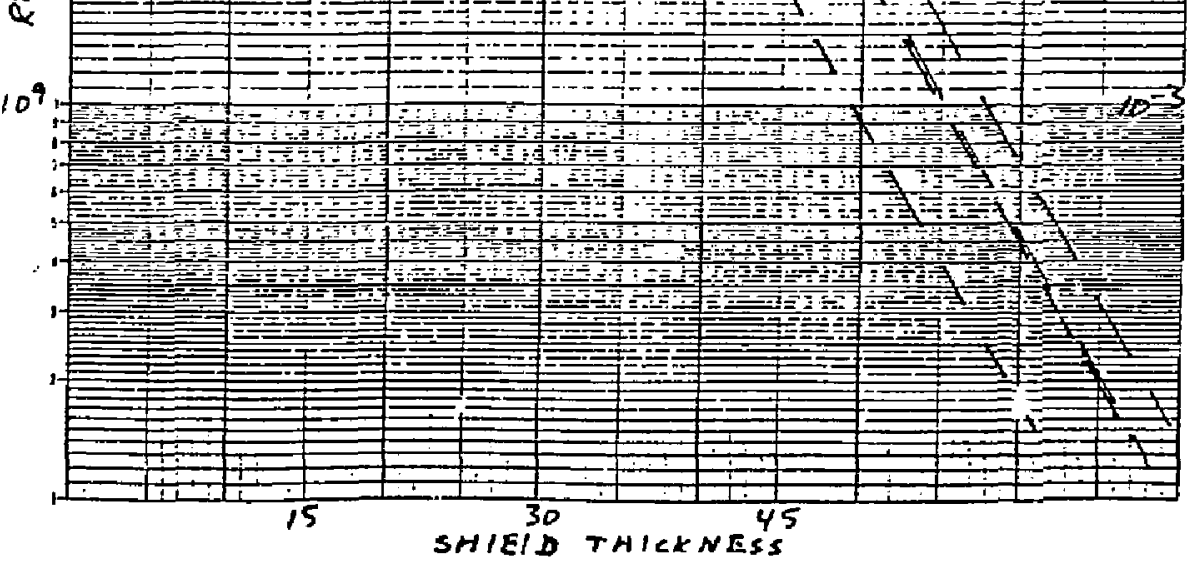

A- 25 
NEUTRON FLUENCE DESTGN LIMIT FOR SUPERCONDUCTING MAGNĘTS

-

$$
\text { A }-26
$$


T0: Distribution

LLNL -FPD-84-48

rROM: J. D. Lee

March 20, 1984

SUBJEC]: Neutron Fluence Design Limit for SC Magnets

This subject was reconsidered at an informal meeling held at til: FEDC on February 22, 1984.

For reference, this subject was formaliy considered at the Magnet Critical Issues meeting held December 5tl in Philadelphia and reported by Neef in LLNL-FPO-84-016. Recommendations made included:

- Radiation limit to electrical insulation - IC" rads maximum lat a max. compressive stress of 30,000 psi).

o Radiation limit to superconductor

- for NhTi - $10^{18}$ fast (E>0.1 MeV) neutrons $/ \mathrm{cm}^{2}$ will result in a $20 \%$ decrease in critical current. Annealing at room temperature will regain $70 \%$ of that $20 \%$.

- for Nb3Sn - $4 \times 10^{18}$ fast neltrons $/ \mathrm{cm}^{2}$ witl result in a $20 \%$ increase in critical current. A greater fluence then causes a fairly rapid decrease in critical current, so use $4 \times 10^{18}$ neutrons $/ \mathrm{cm}^{2}$ as an upper limit.

$A^{+}$the February 22nd meeting we discussed adopting a more genera] criteria that trades off fluence and magnet design parameters.

NbTi - Based on discussians with Mike Guinan, there appears to be evidence the degradation of the critical current in Nbij saturates at $\approx 25 \%$ of its initial value in the 6 to $10 \times 10^{18} \mathrm{n} / \mathrm{cm}$ fluence range (see Fig. 1). Likewise, the resistivity increase in Cu miy saturate at $\approx 330 \mathrm{racm}$ at a fluence of $\approx 10^{19} \mathrm{n} / \mathrm{cm}$. Mike thinks that the conductor fluence limit may result from low cycle fatigue $i$ il tha $r_{u}$, occurring at a fluence in the $10^{20}-10^{21}$ range.

$\mathrm{Nb}_{3} \mathrm{Sn}$ - UnTike NbTi the drop in $\mathrm{J}_{\mathrm{c}}$ in $\mathrm{Nb}_{3} \mathrm{Sn}$ is nat expected to saturate. But there is hope the fluence limit can be increased into the $1-4 \times 10^{19}$ range before $J_{C}$ drops to an unacceptable low value (see

Fig. 2). Data must be developed to support this hope. 
LLNL-FPD-84-48

March 20, 1984

In summary we should consider increasing the fluence limit in NbTi and NbjSn while decreasing their cumrent densities accordingiy. There may be an c?'imum in the fluence vs current density tradeoff. This opt inium (lowest cost system) could be searched for oy examining a number of coil sets in which the minimum available space between the helo plasma and the coil pack varies between 30 and $60 \mathrm{~cm}$. Peak condurtor and total coil heating should also be included in such a trade study.

1 have collected a number of references on this subject but we need more input from the SC materials community on radiation effects, especially on $\mathrm{Nb}_{3} \mathrm{Sn}$.

JDL: 1 ?

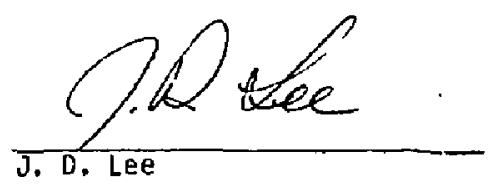

Att 3 chments

20842

References:

1. c. L. Snead, Jr. and T. Luhman, "Radiation Damage and Stress Effects in Superconductors: Materials for High-Field Applications, "Brookhaven National Laboratory, BNL-33230.

2. P. Hahn, B. S. Brown, H. W. Weber and M. W. Guinan, "Spallation and 14 MeV Nelatron Irradiation of Stabilized NbTi Superconductors," Argonne National Laboratory, IP-II-7 (1983).

3. M. W. Guinan and ?. A. Van Konynenburg, "Fusion Neutron Effects on Magnetoresistivity of Copper Stabilizer laterials," Lawrence Liverr re National Lésoratory, UCRL-90134 (1983).

4, C. D. Henning, E. N. C. Q.alder, J. R. Miller and L. J. Perkins, "Supercunciucting (Radiation Hardened) Magnets for Mirror Fusion Devices," Lawrence Livermore Nationa] Laboratony, liCRL-90092 (1983).

5. F. Narda i, H. W. Weber and R. K. Maix, "Neutron Irradiation of a Broad Spectruri of NbTi Superconductors," Cryogenics (Aprii 1981).

6. H. Attaya, et. al., "Blanket and Shielding Consideraiions for Advanced Tokamak Reactor Concepts," University of Wisconsin, UWFDM-562 (1983). 


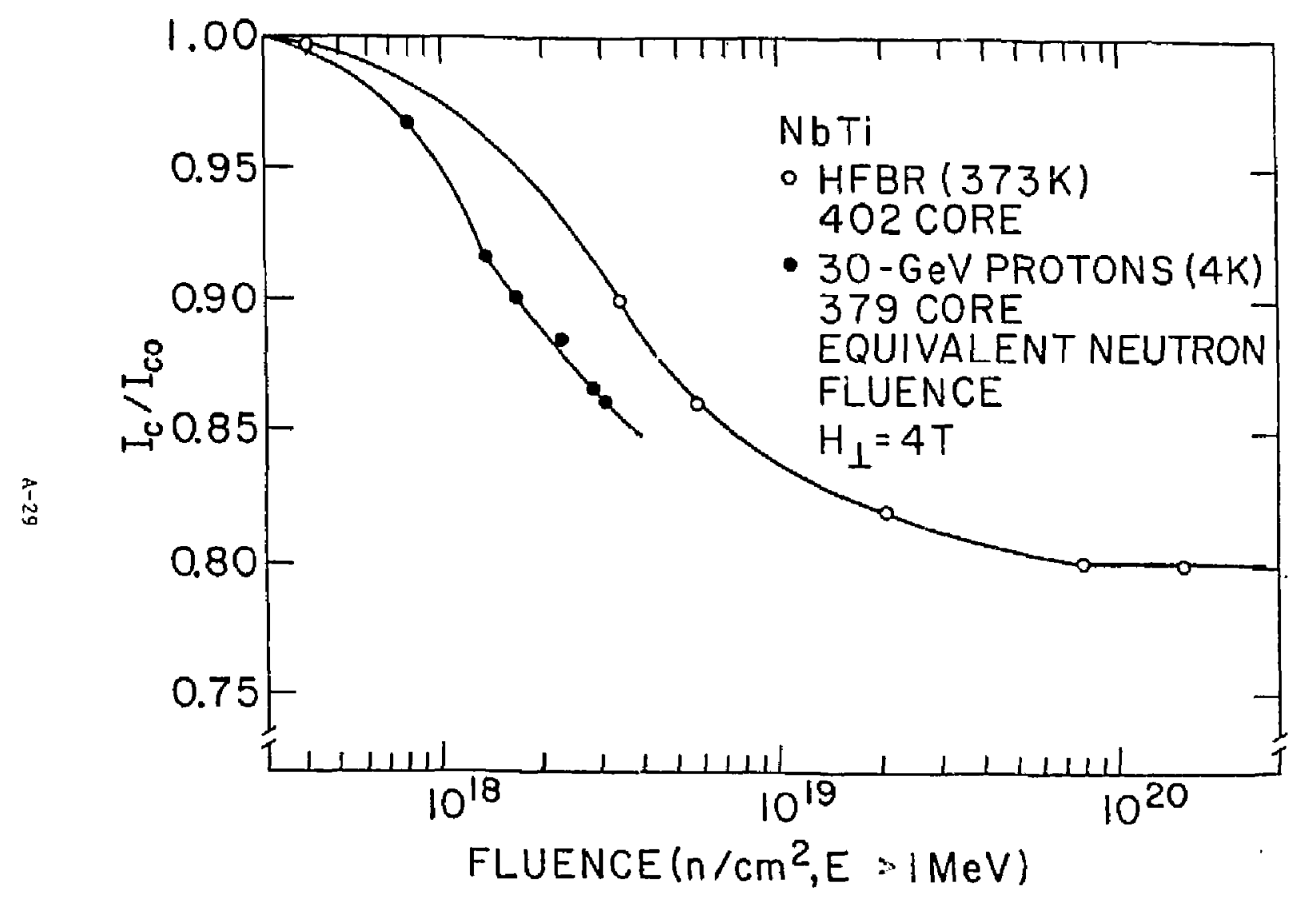

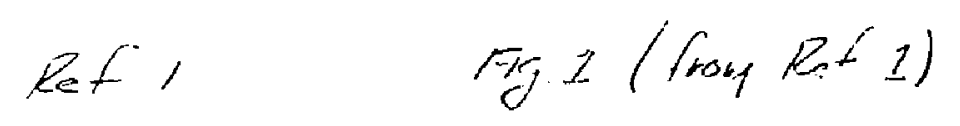




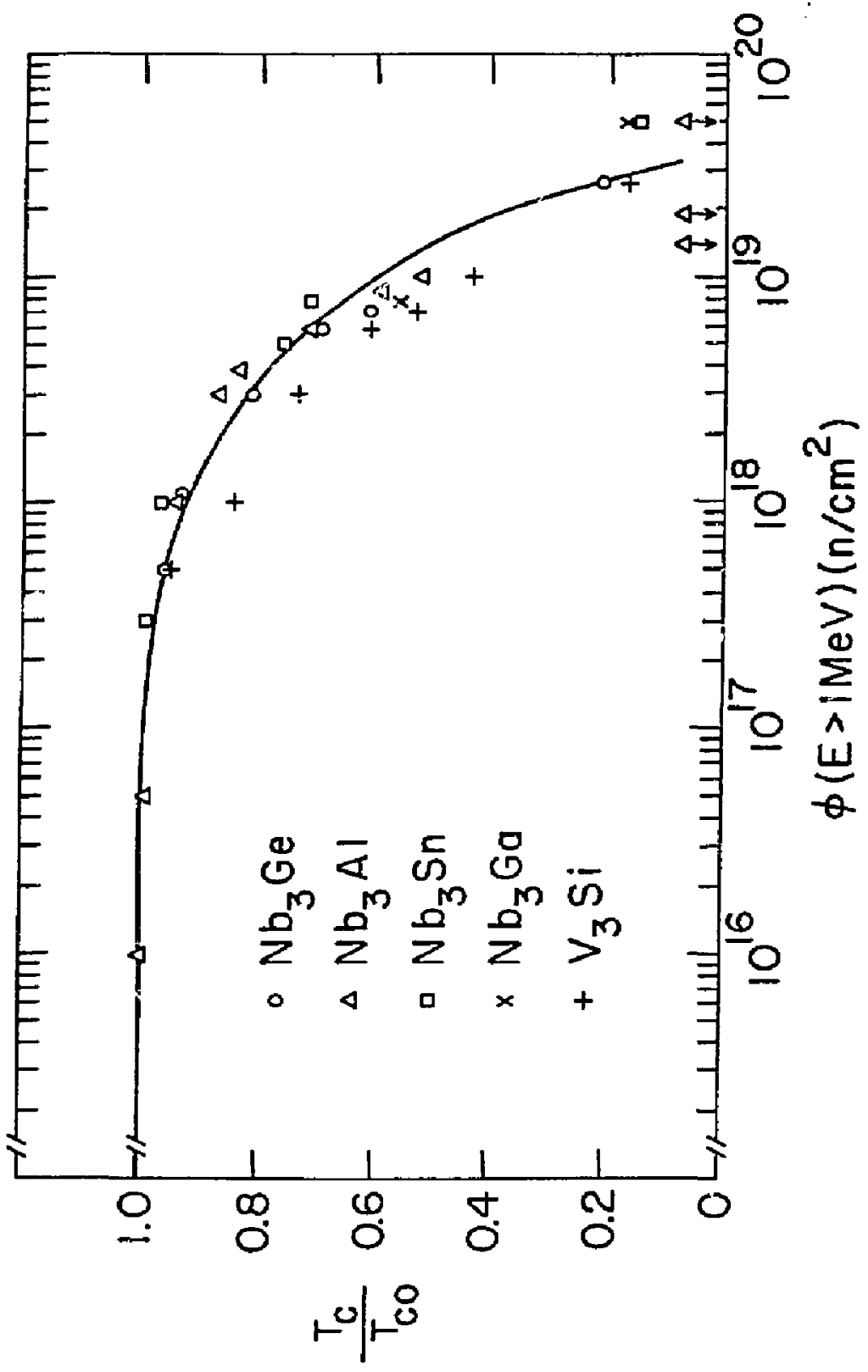

6

$A-30$ 
CRITICAL ISSUES

A-31 
JuJ y 9,1984

TO:

Distribution

FROM: William s, Neef, Jr*, L-644

SUBJECT: Report on the Critical Issue Meeting on the Direct Converter held at the Fusion Engineering Design Center on June 14, 1984

The monthly FPD progress meeting was helJ at Oak Ridge, Tennessee in. June. The Direct Converter discussion was held the second day and occupied the full morning. Presentations were made by $B$. Barr of LLNL, M. Petravic of PPPL, and T, LuzzI and I. Clarkson of GAC.

B. Barr reported on theoretical work that he and M. Gilmore at LLNE are pursuing concerning radial potential profile. The plug voltage is assumed "flat" and one gyroradius has been assumed as the radial distanoe for voltage reduction in the halo. The current design has 18 MW of Ion power in the halo - hence being dissipated on the halo scraper at the halo pump inlet. Barr's viewgraphs are included with this report.

Dr. Petravic from Princeton is a member of the physics group designing divertors and limiters for their tokamaks. In their case $10 \mathrm{eV}$ plasme may hit the first wall of a liniter. At that energy erosion of a tungsten surface is not a problem. In their designs inciden: jower can be less than 500 watts $/ \mathrm{cm}^{2}$ so cooling can be accomplished in a straightforward manner. They do observe hot spots and note that they are stationary (ie, they do not "dance around" on the limiter).

For diverters he distingulshed between high recycling regions and low recycling regions and said they would probably be separated on future designs by some physical barrier.

Gruman's presentation emphasized three main issues; 1) the geometry of the exit flux is neither circular or elliptical and may require unusual plate configurations to achieve radial voltage control, and 2) the water cooling of said plates requires complex header configurations. The voltage stand-off of separate segments has not been designed as yet, and 3) water velocity of 10 meters per second is required for plate cooling and may lead to an erosion problem if any cavitation is present.

One 1ssue not yet addressed is the ond-of-life disposal of the central plate which sees a considerabie neutron flux. These neutrons "beam" from the central cell. Our neutronfes analysis has not given integrated values for this flux. It will be available soon. The material choice to control tritium permeation will be strongly influenced by the activation and disposal problem. tuzi-and Glarkson's-viewgereincluded with this popont. 
Repor on the Critical Issue Meeting on the Direct Converter held at the Fusion Engineering Design Center on June 14, 1984

July 9, 1984

Page 2

The concensus was that very good progress has been wade in direct converter design. Problem areas are well understood if not completely solved. We will have a credible deslgn ready for FPD and subsequent. Tandem Mirror Reactors.

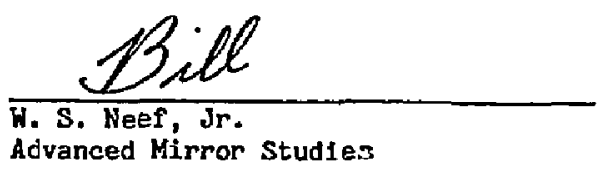

$1741 v$

WSN: $\tan$

cc: U/G Package - Barr
V/G Package - Grumman 


\title{
MEMORANOUM
}

\author{
T0: Distribution \\ LI.NL-FPD-84-017 \\ FROM: $\quad$ W. S. Neef, Jr. \\ December 15,1983 \\ SUBJECT: Report on the FPD Critical Issue Meeting on Orift. Pump Coils, \\ December 13, 1983
}

We thank you for your participation in the Drift Pump Workshop. It was requested that we send out the names and addresses for all attendees and you will find that attached to this memo.

Copies of all the vowgraphs-presented during-the-meeting are-also tactuded for-your-

The following list of critical issues related to $\mathrm{drift} p$ :mping is the one generated during the afternoon portion of the meeting. Responsible organizations and/or individuals are listed as we agreed during the meeting.

\section{Design for FPD Drift Pumps}

1. $B_{\perp}$ vs $B_{\|}$physics study.

LLNL, Byers

2. Modeling the geometry for eddy current

(Turner at ANL)

calculation.

Metzler at FEOC

3. Side-by-side coil arrangement $(2 \pm \Delta z)$

each with fewer driving frequencies -

study coil current and efficiency.

Metzler at FEOC

4. Use of ferrites for neutron shielding near

Neef at LLNL

DP cail (possible to improve antenna Q).

5. Circuit efficiency and cost for the $B_{1}$ method - as a function of current. Use MARS parameters and vary coil curreni from 2000 to $20,000 \mathrm{~A}$.

6. Antenna fatigue damping of mechanical vibration (for drift $\omega$ as well as bounce $\omega$ ).

Neef at LLNL

7. Neutron shielding of nearby superconductor.

LLNL Neef \& Lee

FEDC Gohar

8. Physics Q effects - ability to heat cold LLNL Perkins particles. 
9. Charge-exchange particle bombardment heating if coil is exposed.

LLNL Perkins

10. Choice of shielding material PbO, WC, $\mathrm{WO}_{3}$, $W$ in transformer core form, etc.

(ORNL Wiffin)

FEDC Metzler

LLNL Neef

11. It was suggested by Jon Smith that we

look into "kicker" magnets in synchrotrons

FEDC Metzler since they use iron cores and are

LLNL Neef geometrically similar.

A scheduled date for completion of this drift-pump design is mid-March 1984.

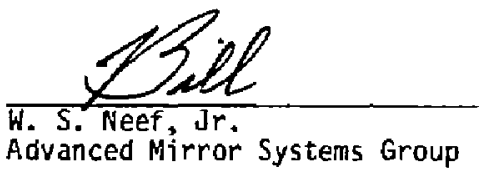

WSN: ic

19152 
MEMORANDUM

TO:

Distribution

LLNL-FPD-84-016

FROM: W. S. Neef, Jr.

December 15, 1983

SUBJECT: Results from FPD Critical Issues Meeting on Magnets in Philadelphia

The Advanced Mirror Studies Group at Livermore thanks you for your participation in the workshop on superconducting coils for the Fusion Power Demonstrator. We believe the meeting was productive and very educational. The viewpoints of those less directly concerned with the FPO design were of special value. A more critical, less biased viewpoint is vital to prevent any tendency to "preach to the choir." We believe viewpoints differing from ours were well represented.

You recall that we attempted a final summary of all design criteria. The following is a reproduction of that list to assist us in beginning the design of the FPD magnet set.

1. Fraction of the critical current to be used in design:

- for NbTi use $\approx 70 \%$

- for $\mathrm{Nb}_{3} 5 \mathrm{n}$ monolith use $\approx 50 \%$

2. The miñmum energy margin was set at $200 \mathrm{millijoules} \mathrm{per} c c$.

3. The maximum allowable terminat voltage during a dump:

- 1000 yolts for a magnet cooled by pool boiling

- 3000 volts for a magnet cooled by forced convection

4. Maximum internal temperaure during a quench should be $300 \mathrm{~K}$ for all coils, regardless of whether cooled by pool boiling or forced convection.

5. Stress limits

a. Steel structure at $4.2 \mathrm{~K}$ or lower; use 100,000 psi design stress (assumes 150,000 psi minimum yield point) and fracture toughness of $200 \mathrm{ksi} \sqrt{\mathrm{in}}$ minimum.

b. Conduit for conductor; use 100,000 psi design stress and fracture toughriess of 80 psi $\sqrt{\text { in. }}$. 
c. High purity copper; 28,000 psi design stress.

d. Insulator (polyimide); 30,000 psi compression.

6. Allowable conductor surface heat $f_{1} \times x$ for recovery:

a. Pool boiling - Helium I - 0.3 watts $/ \mathrm{cm}^{2}$

b. Pool boiling - Heirum II -

$$
\text { NbTi } \quad 1.0 \text { watts } / \mathrm{cm}^{2}
$$

$\mathrm{Nb}_{3} \mathrm{Sn} \quad 2.0$ watts $/ \mathrm{cm}^{2}$

\section{c. Forced convection 0.2 watts $/ \mathrm{cml}^{2}$}

7. Conductor strain shal1 be $0.33 \%$ maximum for all designs.

8. The question of instability resulting from coolant vapor lock was felt to be entirely design specific so no attempt was made to specify any parameters.

9. Radiation limit to electrical insulation - 10 " rads maximum.

10. Radiation limit to superconductor

- for NbTi - $10^{18}$ fast neutrons/cm² will result in a $20 \%$ decrease in critical current. Annealing at room temperature will regain $70 \%$ of that $20 \%$.

- for $\mathrm{Nb}_{3} \mathrm{Sn}-4 \times 10^{18}$ fast neutrons $/ \mathrm{cm}^{2}$ will result in a $20 \%$ increase in critical current. A greater fiuence then causes a fairly rapid decrease in critical current, so use $4 \times 10^{18}$ neutrons $/ \mathrm{cm}^{2}$ as an upper limit.

The next three items on the list requirs immediate action by LLNL, assisted by the FEDC.

11. Establish a few ( 3 or 4) baseline magnet configurations that satisfy stability criteria and cover a range of radii (we suggest $r_{\min }=0.7$, $0.8,0.9,1.0)$. 
LLNL -FPD-B4-016

December 15, 1983

12. For each configuration above calculate a profile of nuclear heating rs depth into magnet.

13. Establish an experiment schedule.

- number of shots

- number of thermal cycles

- duration of and time between thermal cycles.

If you believe this summary requires correction, please contact me at $415-422-6747$ or FTS $532-6747$.

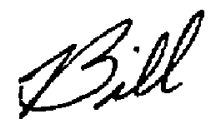

W. S. Neef, Jr. Advanced Mirror Studies Group

WSN : 1c

$1914 z$ 
MEMORANDUM

LLNL-FPD-84-024

TO: $\quad$ FPD Distribution

FROA: L. John Perkins JP.

SUBJECT: FPO Plasma Engineering: Critical Issues

A meeting was held at LLNL on December 21, 1983 to discuss criticál plasma engineering issues for FPD. This had the abjective of defining tasks to be undertaken in the next few months. These tasks are documented below; suggested participants are listed at the end of each item. Those items marked with an asterisk denote near-term tasks to be completed for the February FPD meting at the FEDC.

1. FPD baseline parameters. ${ }^{\star}$ A (reasonably) consistent physics parameter set is required for general distribution especially to FPO engineering personnel. Further consideration of end cell trapping rates (both $H_{D T}$ and $H_{\alpha}$ ) are required before this set can be finalized (see also item 10 below). (RBC/MEF/RSD/LJP)

2. Effect of coil geometry on $c$. cell ripple, field taper, beta and cost. ${ }^{\star}$ Trade study between sheet type magnets and discrete (MARS-like) magnets. Control of ripple from discrete magnets by means of $\mathrm{Fe}$ inserts. (RHB/LJP/GHH/BMJ) 
3. Effect of end cell coil geometry on off-axis field distortion. (RHB/BMJ)

4. Benchmarking of TEBASCO with the new 30 MHD equilibrium code to examine spurious flux tube distortions. (RHE)

5. Continuing effort on the radial transport code TMT with applications to:

(a) Halo physics (see also 7 below).

(b) Wall potential control.

(c) Pellet fueling.

(JMG/GWH)

6. Nesutron source in end cel1,* Generate neutron source distributions for various end cell magnet configurations for use in shielding studies. $(\mathrm{RBC} / \mathrm{JOL})$

7. Halo and direct convertor analysis. Generation of particle and power flows to direct converter, halo scraper and halc dump including peaking factors where applicable. Evaluation of pumping geometry at end dumps. Initiation of halo fluid-flow model for accurate quantification of halo parameters jncluding required power input. Couple with TMT results when available. (WLB/WNK/GWH/JMG)

8. Startup (time to get serious about this!). Employment of TREQ code to address startup issues for FPD. (MER)

9. Anchor ICRH analysis. * Evaluation of:

(a) Sufficiency of passing ion fueling of anchor for MHD stability.

(b) Inclusion of anchor ICRH power in power baIance.

(c) TEBASCO runs with off-midplane density distribution (sloshing-iontype distribution) rather than present model of midplane-peaked distribution. (RBC/MEF/RHB) 
10. Differential trapping rates of $D$ ard $T$ in transition region. I ormal corisideration of $D$ and $T$ transition irapping rates, over and above $a$ simple $\sqrt{m}$ dependence. This may, for example, lead to the requirement for other than a 50/50 D/T mix in the central cell with implications for c. cell power baiance. (RSD/RBC/MEF)

11. Alpha (central cell) and sloshing ion (end-cell) adiabaticity. Effect of field profiles, etc. on adiabaticity limits and resulting consequences for beta. (LJP/RSD/RBC)

12. ECRH physics. Inclusion of new (strong ECRH) physics madels. Eviluation of updated modeis for synchrotron radiation, reflection, and reabsorption. (GWH/RBC)

13. Replacement of existing DT cross sections with new LANL evaluations." Examination of effects on system parameters. (LJi')

14. Hork will also continue in the following ancillary areas:
(a) TMRBAR upgrade -- modular version with flexible $I / 0$.
(MEF)
(b) TMRBAR-TMG coupling requirements. (RHB/MEF/RBC/LJP)
(c) Evaluation of smaller TMRs based on novel end-ceil concep-s. (RSD) 
To: Distribution LLNL-FPO-84-42

FROM: W. S. Neef, Jr.

SUBJECT: Report on the Critical Issues Meeting on Pellet Injection into FPD, February 28, 1984

Gordon Hamilton presented a review of the MARS fueling requirements and capped it off with a summary of similar calculations for FPD using the parameter set considered valid on February 23, 1984. It is attached to this memo. About 1.5(10)21 atoms per second will be required. This cou?d be provided by 2.8-m outside aiameter pellets introduced at a rate of 2.1 per second.

Calculations by Campbell and Gilinore on pellet peretration give disturbingly high velocity requirements for MARS. Their most ontimistic calculations show the need for about $30 \mathrm{~km} / \mathrm{sec}$ pellet velocity and some of their work shows that $100 \mathrm{~km} / \mathrm{sec}$ may be marginally sufficient for MARS. This compares to current accomplishments for railguns at Liverinore of $3 \mathrm{~km} / \mathrm{sec}$. (The maximum velocity ever achieved by any raijrun is $12 \mathrm{~km} / \mathrm{sec}$ !)

The biggest unknown in physics understanding appears to be the correct radial diffusion laws that would reval how far we really must penetrate the plasma to uniformly fuel it across its dianeter. The laws guver ing pellet evaporation in hot plasma seem to be well understood and have been conf irmed by experimentat resutts (with no is pwer present).

stan Milora of ORNL surveyed their experimental efforts. Both centrifuga? and pneumatic injectors can be used as pre-accelerators to a railgun. Their injector on Doublet III (GA Technologies) can fire 20-40 pellets per second at a velocity of $0.8 \mathrm{~km}$ per second. They are developing a pneumatic injector for use on TFTR in 1986 or 1987 . It will shoot $3.5-$ mmdiameter pellets at $1.5 \mathrm{~km}$ per second.

The injector that ORP!L used on the PDX experiment has a "magazine" of only four peliets, each $1.5 \mathrm{~mm}$ diameter, and has velocity capability of ouly $1 \mathrm{~km}$ per second. The four pellets can be adjusted as to time interva?. The gun barrel length is one meter.

Current gas injectors use hydrogen at $i 300 \mathrm{psi}$ and $250^{\circ} \mathrm{C}$ released through a modified solenoid valve. ihe pressure rise behind the pellet occurs in about 2 microseconds. The pellets remain cylindricai but appear to have "eroded" in diameter about 0.5 min when they emerge from the barrel and also appear to be about 0.5 mm longer than when they were cut off the extrusion. 
LLNL-FPD-84-42

March 5, 1984

Page 2

Any slight misalignment or tube curvature causes pellets to break in half and fly as two shorter cylinders. Milora estimates that to avoid this breakage tube curvatures must have at least a 30-40-meter radius. (This eliminates any possibility of avaiding coils or shielding by employing curved tubes.)

Experiments at the University of Illinois were reviewed by Prof. Kevin kim. They have accelerated plastic pellets to date with a density 15 times that of a D-T pellet. A gas injector pre-accelerator followed by a $20-\mathrm{cm}$ railgun achieves plastic pellet velocities of $0.15 \mathrm{~km}$ per second. Their initial tests have been with circular pellets in a square bore. They intend to convert to a circular bore to solve the blow-by problem which results in an undesired spark in front of the pellet :-s well as the desired one behind the pellet.

Ron Hawke of Livermore discussed his railgun results. He mentioned several key lessons learned experimentally:

0. .0005 inches run-out is necessary to avoid pellet breakage of 1.5- to 5-m-long railguns.

- Sealing the gas at low velocity in the pre-accelerator is difficult. Once at speed the problem is not severe.

- Any gun capable of $50 \mathrm{~km}$ per second is going to have to be 50 to $100-m$ long.

- A sabot is probably going to be necessary to reach $50 \mathrm{~km}$ per second.

Ron believes any experimental program to achieve $50-\mathrm{km}-\mathrm{per}-\mathrm{second}$ railgurs will cost over $\$ 10$ million (but not as much as $\$ 100 \mathrm{million.)}$

General conclusions that can be drawn from the meeting:

- Radial transport scaling is certainly different than in tokamaks. Some experiments in TMX-U or MFTF- $B$ would be most helpful in testing the validity of theory. Since MFTF- 8 will have $2-3(10)^{13}$ deuterium particles per cc and ion temperature of about $15 \mathrm{keV}$, the most reactor-relevant data would be obtained there. Of course no hot alphas would be present.

- The use of sabots to help achieve high pellet velocities should be more thoroughly evaluated. We should try separation of sabot and pellet, probably magnetically if a metal sabot is employed. 
LLNL-FPD-84-42

March 5, 1984

Page 3

WSN: $1 c$

- Another interesting idea was use of a sabot of low 2 material which permits deeper penetration of the hot plasma. This sabot continues on through the plasma, dumping its D-T load as it traverses the plasma diameter. It then enters a "get lost" hole in the wall on the far side of the plasma. Some of the sabot will ablate from the plasma but if the atomic weight is very low that may be tolerable.

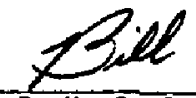

W. S. Neef, Jr.

Advanced Mirror Studies

$2035 z$ 
T0: Distribution

LLNL $-F P D-84-47$

FROM: W. S, Neef, Jr.

March 19, 1984

SUBJECT: Correction to the Report on the Critical Issues Meeting on Pellet Injection into FPD

Professor Kevin Kim of the University of Illinois called my attention to an error in the previously distributed meeting report (LLNL-FPD-84-42 dated Murch 5, 1984). On page 2 the information in the second paragraph is incorrect.

He has achieved plastic pellet velocities of 500 meters per second without a gas pre-accelerator. Considering the density ratio of $15: 1$ between plastic and a frozen hydrogen pellet, this is equivalent to achieving a hydrogen pellet velocity of 7.5 kilameters per second.

I apologize for the misinformation. Please attach this "erratum memo" to your document dated March 5, 1984.

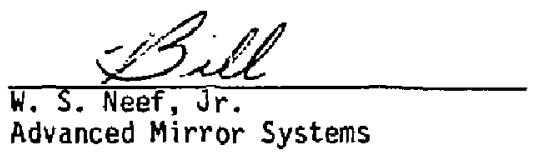

WSN: Ic 
MEMORANDUM

TO: Distribution

LLNL-FPD-84-50

FROM: $\quad$ H. S. Neef, Jr.

Apri] 10, 1984

SUBJECT: Report on the RF Critical Issues Workshop at TRW, Inc. on March 21, 1984

On Wednesday, March 21, we held an RF Workshop related to the Fusion Power Demonstration. Attendees were:

$\underline{\text { LLNL }}$
R. Bulmer
W. Cummins
J. Doggett
]. Lee
H. Neef
J. Yugo

FEDC

S. Freije (TRW)

D. Neison

A competing meeting in Rome on RF issues related to tokamaks (especially INTOR) restricted our attendance. Neither MIT nor the Universizy of Wisconsin were able to send a representative to this FPD discussion. Those able to attend were treated to excellent reviews of plasma heating on TMX-U (now in progress) and MFTF-B (in design).

We are sending along with this letter three sets of viewgraphs:

Set $\# 1$ - from FEDC on a $+T$, FPD, MARS (presented by Freije)

Set \#2 - ECRH on MFTF-B (presented by Yugo)

Set \#3 - ICRH on MFTF-B (presented by Romesser)

Set \#4 - ICRH on TMX-U (presented by Cummins)

In addition the following comments and/or suggestions were extracted from notes taken by me during the meeting. 
1. Relativistic electron ray tracing code development is oeing done at Livermore in their Electronics Engineering Department (contact 3. Yugo for details). Don Batchejor at ORNL is also working on ray tracing at high voltage. Since the discriminaiury powers of the plug plasma are being questioned relative to RF power aimed at points "a" and "b" (refer to MARS Interim Report), it would be appropriate to follow progress closely in this ray tracing area.

2. One-megawatt gyrotrons should be available by 1993 or 1994 on the way to $2.5 \mathrm{Mh}$ tubes targeted for early in the next century. For FPD one megawatt seems reasonable. Both larger and small

converter-transformers have been buit and successfulity operated.

3. Bill Cummins gave his view that vacuum waveguides (no windows) are probably okay if pumped at both ends. High voltage gradients will give more problems than poor vacuum.

4. Any vacuum cavity for mirrors of a quasi-optical system needs isolation valves on both sides, $\dot{\dagger} . \mathrm{e}$. , to gyrotrons (allows gyr. removal and replacement) and to plasma (allows adjustments on mirror positions without losing main vacuuri).

5. On MARS the angle at which ECRH entered the plasma proved to be "risky business." Plasma trapping and reflection were profoundly affected. The gyrotron produces a gaussian beam but what "mode" arrives at the turning/focusing mirror?

6. During plasma startup a wide range of frequencies are expected to be needed. The gyrotron cavity "changes shape" at different

frequencies so electron beam energy recovery may be inefficient under some conditions. If we desire (need?) $80 \%$ recovery it may require a many-stage converter covering a wide voltage range.

7. In MFTF-B waveguides $w i l l$ be at vacuum (windows are regarded as risky hardware and are being eliminated). Reflectors are to be used to aim the beam as it emerges from the waveguide. Steering of these reflectors will be accomplished by air motors. Three or four degrees steering allows for support position change due to magnet cooling to $4 \mathrm{~K}$. A iming accuracy required is \pm 1 degree or within a few inches (measured on the magnetic axis).

8. MFJF $-B$ gyrotrons must have very good mode control to fit various plasma sperating conditions.

a) Ordinary wave is poorly absorbed at low electron temperature.

b) Fortunately resonant plasma surface shifts help bridge the gaps between frequencies and modes.

c) Absorption sometimes suffers due to angle of approach (a ray tracing calculation will show this). 
9. OSHA is requiring many RF detectors at the TFTR facility. Analys is of stray microwave signals showed that painted liquid nitrogen panels reflect only $30 \%$ of incident power, hence they are a good "sink" for stray RF power.

10. Steve Freije reports that the LIS program is driving big gyrotron development now. Present accoliplishments are $100 \mathrm{~kW}$ (CW) at $14 \mathrm{C} \mathrm{gHz}$ for LIS.

The $60 \mathrm{gHz}$ development program is nearly complete - but with poor mode output for our use - because no particular mode had been specificed.

The $120 \mathrm{gHz}$ development program at Varian is seven years from completion. They may achieve their target of $2.5 \mathrm{MW}$ by 1996 . (This makes our prediction of $1.0 \mathrm{MH}$ for FPD look sound.)

Varian's present research is on closed-cavity (one frequency) gyrotrons. He need more variable frequency research. $D O D$ is funding the Free Electron Maser (FEM) development - not fusion!

Steve feels we have been optimistic in our efficiency estimates for all aspects of big gyrotron operation. One example is in electron direct conversion. Our $81 \%$ estimate (MARS) perhaps should be $60 \%$.

11. Mode conversion was discussed. Very long waveguide mode convertors are one of the reasons we chose a quasi-optical system. Milled reflectors do mode conversion in "zero" length, replacing space-consuming waveguide convertors.

12. ICRH future requirements are not expected to be greatly different than current operating procedures. We now inject 1.5-2.0 MW for short pulses with system efficiency of 54\%. Present use of Faraday shields is a debatable issue. Japanese and German researchers report better results with the shields. But the shield has to be so clase to the plasma that it acts as a sort of limiter, so it may have very 1 imited life.

13. Cummins reports that TMX-U will use two $170^{\circ}$ loop antennas to surround a circular plasma cross section. The Faraday shield consumes about $70 \%$ of the power broadcast. A new "slot" antenna conforming to the plasina shape is being butit also. The slot length is about one meter in the plasma axis direction. It has (1) high plasma coupling coefficient, (2) two frequercy exitation ranges, (3) low impedence, (4) is a low loss coupler, has good vacuum characteristics.

Bjll says to watch out for voltage holding problems - sharp corners - insulator flashover (the same oid stuff, which seems to have been forgotten by present mechanical designers). 
LLNL -FPD-B4-50

April 10, 1984

14. Tom Romesser, during his viewgram presentation, mentioned overali ICfl efficiency (wail plug to at ; )rbed power) around 80\%. The Faraday shield is one of the prithe consumers of "wasted" power. He says wall plug to ion efficiency is about $50 \%$.

Shield heat load is a serious concern primarily because radiation fron halo plasma and convection from halo plasma are not well understood. Tom thinks it may be posstble to back off a few centimeters from the plasma edge - with some sacrifice in efficiency.

New gyrotrons wi\}l have higher efficiency than conventional ICRH driver amplifiers. We badiy need tunable systems because we don't have room for two or three separate systems at frequencies chosen to fit specià piasma conditions (startip, etc.).

One message came through clearly. Use a "plywood dryer" instead of communication system components which are too easily demaged. A sudden load change was likened to being struck with a hammer - and the antenra, shield, and amplifiers should be able to recover from such rude treatment. Another clear message from Tom, "Try not to have to be close to hot plasma!" Also, "Get rid of RF windows!"

15. Often a semiconductor is a better "insulator" than $\mathrm{Al}_{2} \mathrm{O}_{3}$. It allows a little bleed-off current. No charge islands build up on the surface resulting in high $d E / d x$ and electrical breakdown. In a]l cases avoid hydrogenous materials.

16. The weak link in the reliability chain is both ICRH and ECRH power tubes.

17. Instrumentation and control on RF power seems reasonably reliable at the present and little improvement should be required to meet expected needs.

Thanks for your interest in furthering our FPD design. We believe this workshop brought out many interesting lessons learned and will serve as an effective guide to our applications of RF power to reactor designs.

WSN: 1c

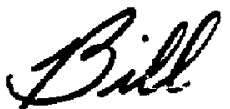

W. S. Neef, Jr.

Advanced Mirror Systems Group

21092 
T0: Distribution

LLNL -FPD-84-56

FROM: W. S. Neef, Jr.

Apri1 23, 1984

SUBJECT: Report on the Critical Issue Meeting on Negative Ion Neutral Beam Injection into the Fusion Power Demonstrator

On April 5, 1984, the Lawrence Berkeley Laboratory hosted a meeting on negative ion neutral beams. This meeting was instigated by the LLNL Advanced Mirror Reactor Group. We plan to use negative ions for the "sloshing" beams in the FPD end plugs. So it is necessary to know the performance level to be expected from high energy ion injection by the year 1995 .

Grant Logan gave a brief review of sloshing ion production by RF vs negative ion beams. About $300 \mathrm{keV}$ ion energy will be required with $n_{\text {peak }} / n_{\text {midplane }}=1.4-2.0$. The density difference is difficult to achieve with pre heating. He showed that it is aiso difficult to limit the density of hot electrons and also have a high Q for reactor performance if RF heating is used. It is essential that high efficiency 300 kel neutral beans be available for optimum plug performance because they put the ions right where you want them.

The Berkeley team of Cooper, Ehlers and Andersun gave exceilent status reports on the source, accelerator, and transverse field beam transport. Attiched to this memo are copies of alt viewgraphs presented.

Joel Fink, Negion, Inc, is a consultant to both LLNL and LBL on neutral beam studies. He reviewed the three promising methods of converting accelerated ions to neutrals. They are 1) gas neutralizer, 2) plasma neutralizer, and 3) photodetachment neutralizer. His viewgraphs are al so attached to this memo. One conclusion reached was that photodetachment can be very efficient but also very costly. In addition it has an impressive i ist of technical problems headed by the laser development. Its technical advantages are important but the price appears today to be too high. Joel concludes that all three approaches should be deveToped. There is clearly no best or cheapest way at this time.

The design of beam dumps was discussed by Alan Paterson, LaL mechanica 7 engineer. I sumarize his coments here.

1. Inclined copper plates can be used for about one second with a flux of $2000 \mathrm{w} / \mathrm{cm}^{2}$ normal to the copper surface.

2. McDonne]1-Douglas zirconium-Copper panels have coolant pressure arop of ino psi. A $120 \mathrm{keV}$ at 60 ampere beam will be the maximum capability of that design. 
LLNL-FPD-84-56

Apri1 23, 1984

3. In Europe two unusual designs are operating and bear watching: a) rotating targets (Germany), and b) hyper-evapotron (JET at Culham).

In reviewing my notes taken during our discussions, I find some disconnected but pertinent comments made during the afternoon discussions. I list them here in no particular order as food for thought.

1. It may be necessary for LBL to increase their present neutralizer clearance around the beam. It was made quite tight to restrict conductance, thus minimizing pumping requirements both upstream and downstream. The beam "edge" is not sharp so we may be restricting bean delivery to the target by the present close clearance.

2. Filaments have about a 40 -minute life in positive ion source chambers. This points to a reliability problem. Perhaps some sort of RF plasma generator might be a more reliable method--but this must be demonstrated by cperational experience.

3. The amperes per meter already achieved by the negative ion sources at $L B L$ is only a factor of two below the FPD requirement. They feel 6 amperes per meter should be achieved without great difficulty.

4. Neutron effects on sumarium-cobalt permanent magnets should be investigated.

5. It may be difficult to supply coolant to high voltage cryopumps. Some pumps may be at 200 to $300 \mathrm{kilovolts}$ from ground potential in an FPD design.

6. Will laser windows tolerate neutrons? Even well shielded beam lines will have many scattered neutrons in and near a photodetachment neutralizer and its laser optics.

As a final note, it has come to our attention that during the week of April 9-13 the positive ion source selection cormittee met at DOE and selected the LBL design over the ORNL competition. The final deliberations and reasons for selection have not yet been made public. The importance of this to the FPo design team is in the planning of a $5 \mathrm{mH} / \mathrm{m}^{2}$ test section in the central cell. Such an engineering test regime would be positive-ion driven. To date the blanket test section proposed employs ORNL beams. No major changes in concept should result from that switch.

WSN: 1C

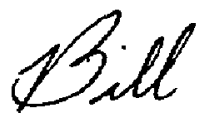

H. S. Ncef, Jr.

Advanced Pirror Systems Group

21552 
SITING AND SAFETY CRITERIA

\&:

$A-52$ 
MEMORANDUM

LLNL -FPD-84-032

T0: $\quad$ FPO Team

FROM: Grant Logan and Dave Dorn

SUBJECT: FPD Siting and Safety Criteria

At this stage in the FPD design phase, it seems useful to document our criteria on siting and safety considerations. These considerations are distilled from our djscussions at INEL on January 19, 1984. As such, they are subject to change as outside influences change and as our perceptions change. However, for now we are asking that they be adopted by the entire FPO comunity as working criteria. If any of you have problems with these criteria, please surface them early so that we can all work toward the same goals. Call or write either of us before the next FPo meeting (February 22-23, 1984 at FEDC) or present your suggestions at that meeting.

\section{INTRODUCTION}

The FPD/ETR Safety Critical Issues meeting was heid at the Idaho Nacional Engineering Laboratory (INEL) on January 19, 1984. Appendix A lists the attendees. Steve Pjet reported on recent experimental data from the Hanford Engineering Development Laboratory (HEDL) on combustion tests of LiPb. There were no temperature increases, $n$ s visible flames, and no aerosois were detected, Questions as to the level of detection of aerosols were raised and further experiments were suggested. He further reported that potential first wall materials were investigated. Among these were vanadium, $P C A$, and HT-9. The HT-9 looked best from the viewpoint of safety considerations and is suggested as the material of choice. 
Dave Dorn also presented a "straw man" set of siting and safety criteria for the FPD. There was general agreement with the proposed criteria and some suggestions for augmentation. Further consultation and thought have resulted in the following set.

\section{GENERAL CRITERIA}

\section{Site Selection Criteria}

1. Relationship to population centers and density. There should be no conflict between the operation of the fusion facility during its lifetime and the master plan for development in the vicinity.

2. It is desirable that adequate electrical power be available without requiring new substations and power lines.

3. Heat disposal (cooling towers, rivers, lakes, oceans) should be readily accomplished with little or no adverse environmental effects.

4. There should be an area of the site that can be dedicated to a hot cell facility for processing radioactive material and parts.

5. It is highly desirable that it be possible to dispose of radioactive waste onsite. To do this will require that the site meet the NRC requirements for near surface burial as outlined in 10 CFR 61 .
a) Operational wastes - machine parts that need regular replacement, expended material, protective clothing, rags, sludge, solvents, etc.
b) Decomissioning wastes -

6. In the event that radioactive material cannot be disposeo ii onsite, it will be necessary to identify offsite disposal areas, readily available. Material to be handled will be the same as in 5 above.
a) Transportation routes must be identified.
b) If there are local ordinances restricting radioactivity transport, alternate routes must be found.

7. The seismic safety criteria followed in the design must be consistent with the local seismic requirements .

8. If there are tornado hazards, they must be considered in the design of the buildings and the facilities. 
9. If there are flood hazards, they too must be taken into account.

i9. Proximity to airports and airplane flight paths may require additional precautions against possible effects of airplane crashes.

11. The projected radioactive dose rates at the fence-line need to conform to existing and proposed DOE and EPA regulations. If biffer zones will be needed, it must be possible to acquire them.

12. Limits on inventories of radioactive materials for a site may be forced by special hydrology, unusual leach rates, and unusual nuclide migration rates.

\section{Reactor Design Criteria}

1. Since we cannot anticipate all failure modes and the necessary maintenance procedures, hands-on maintenance capability should be emphasized in those parts of the design where possible. We recagnize that hands-on maintenance will be possible only in selected places outs ide of the outer machine shield.

2. In regions witere hands-on maintenance is highly desirable, use materials which will "cool" quickly if activated. This will make general access easier and will sirplify remote hand?ing when needed.

3. Recognizing that most of the FPD will require remote maintenance, remote handling capability and design for remote maintenance should be major considerations of design studies right from the start.

4. Use materials which when activated can be handled and disposed of by near surface burial.

5. There should be no routine release of radioactivity to surface or near surface water.

6. In regions of high activation, avoid use of materials that can be volatilized easity in an accident situation. 


\section{SPECIFIC CRITERIA APPLICABLE IF FPO CONSTRUCTEO AT LLNL}

The seismic criteria we intend to follow in coristructing the FPD are:

- No loss of life at $0.5 \mathrm{~g}$ horizontal acceleraticn.

- No collapse of building or major internal structures at $0.5 \mathrm{~g}$.

- No major economic loss at $0.5 \mathrm{~g}$.

- No loss of function of safety systems (for instance - emergency tritium clean-up system, atmospheric confinement) at $0.5 \mathrm{~g}$.

The seisinic response spectrum assumed for the LLNL site is shown in Fig. 1.

As far as regulations on radioactivity, the Lawrence Livermore National Labu.'नtory, as a Department of Energy research facility does not come under the NRC. We Operate under the DOE and the EPA reguiations. The current DOE regulations are contajned largely in "Requirements for Radiation Protection", DOE Order 5480.1, Chapter XI. There are no current EPA regulations governing radioactive dose rates; however, EPA has proposed regulations for the offsite dose rates ("Clean Air Act, Radiological Emissions Standards", Federal Register, April 6, 1983) which were to have been adopted September 1, 1983. These regulations are to apply to routine operations, nut accident situations.

Accident scenarios are handled differently. The NRC regulation as pubiished in 10 CFR 100 sets the offsite dose from a maximum credible accident in a power reactor at 25 rem. Such an accident should have a probability of no more than $10^{-4} / y^{\mu}$. DOE Order 5480 speaks about a type 3 accident, periaps occurring three times in the plant lifetime. The offsite dose limit for the t.ype 3 accident is 5 rem. Again, to put this into context, a release of $120 \mathrm{~g}$ of tritium from the LLNL tritium facility is calculated to give rise to about 3-4 rem to a person residing at the fence line during passage of the cloud.

LLNL exposure limits for onsite personnel and routine operations, as listed in the LLNL Health and Safety Manual Section 33, are based on the DOE order 5480.1, Chapter XI. The exposure i imits are the same as those stated in the NRC 10 CFR 20 and are the recorinendations of the National Council on Radiation Protection (NCRP) and the International Council on Radiatior. Protection (ICRP). These are: 
1. Whole body, head and trulak, bone marrow, gonads and lens of the eye $3 \mathrm{rem} /$ quarter or $5 \mathrm{rem} /$ year.

2. Skin of whole body exposure to beta of $E<700$ kev or $x$ or ganrna of $E<10 \mathrm{kev}$ shall not exceed $5 \mathrm{rem} /$ quarter or $15 \mathrm{rem} /$ year.

3. Hands, feet or ankles shall not exceed 25 rem/quarter or 75 rem/year. These dose limits are the maximum permitted from routine operations; however, the exposure policy of DOE and LLNL is to keep radiation exposures as low as reasonably achievable (ALARA). ALARA is subject to many definitions, but a draft on ALARA submitted to DOE by Kathren and Selby of Pacific Northwest Laboratory in April, 1980 states:

"Both costs and Jose reductions are difficult to evaluate and there may be significant variability in the peception and acceptance of risk by individuals and society. In general, dose reductions that cost less than $\$ 2000$ per person-rem of dose spared are probably always cost-beneficial, while costs in excess of $\$ 60,000$ per person-rem of dose spared are probably not cost-beneficial. In the absence of sound cost figures, an ALARA progran cannot rely upon cost-benefit analysis. In such cases, the criterion must be whether or not dose reduction is reasonably achievable, given the limits of economics and practicality." In the past, UOE has set the ALARA limit at $1 / 5$ of the Iimits presented above; j.e., the design limit for $D O E$ is: whole bady 0.6 rem/quarter or $1 \mathrm{rem} /$ year. The policy at LLNL has been to design to half of this - $300 \mathrm{mrem} /$ quarter or 500 mrem/year. It is also LLNL policy that the casual passer-by (walking by the building) not be exposed to more than 0.25 mren/hour.

Uffsite limits are controlied by the EPA. In the "Clean Air Act, Radiological Emissions Standards", the EPA proposes radiation dose guidelines of 10 mrem/year whole body and 30 mrem/year to any organ for any member of the public assumed to reside at the site boundary. This dose limit for the general public includes radiation dose from all radioactivity which is air-born. For fusion experiments, $; i$ includes dose from any tritium released, dose from neutron activation products from the air in the experimental area, plus any other radiation dose sources that may be connected with the experiment. It also includes 
any "sky shine" and radiation which escapes the shielding around the experimental facility. At the time of the publication of the proposed regulations, the effective date was set for September 1, 1983. It was not made effective at that date; however, it is clear that something like these standards will be adopted. This limit is consistent with that imposed on the fission industry. The current NRC site boundary limits for an operating reactor are $5 \mathrm{mrem} / \mathrm{year}$ - whole body and 15 inrem/year - organ.

LLWL presently has an operating tritium facility which releases about 2000 Ci/year (200 mg/year) during the course of normal operation. The effects of this at the site boundary have been measured at about $0.13 \mathrm{mrem} / \mathrm{year}$. The present tritium facility is up-grading their equipment and procedures and expects to drop their releases to less than $500 \mathrm{Ci} /$ year $(50 \mathrm{mg} /$ year). However, other programs at LLNL also have tritium operations and routine releases. Among those identified are the Linear Accelerator, the RTNS, the Laser target facility. Others may aiso exist. 


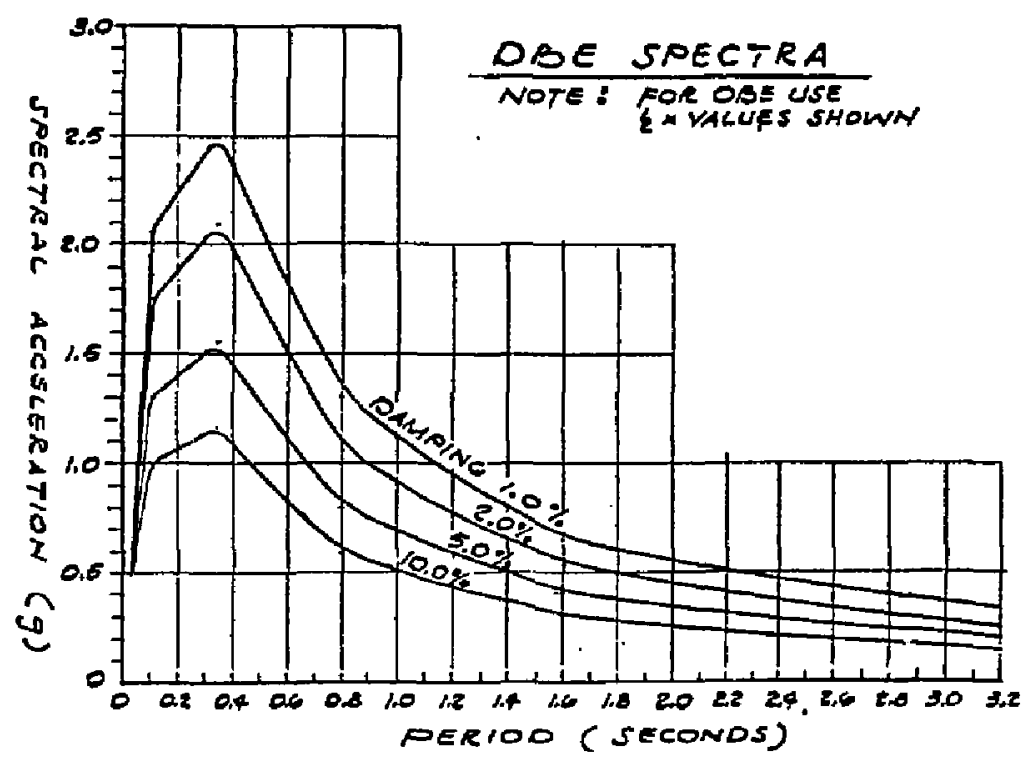

FIGURE 1 .

The Seismic Response Spectrum Assumed for the LLNL Site. 